Thaís Santos Contenças

\title{
Orientação Espacial da Atenção Automática e Voluntária com Ressonância Magnética Funcional Relacionada à Eventos
}

Tese apresentada ao Programa de PósGraduação em Fisiologia Humana do Instituto de Ciências Biomédicas da Universidade de São Paulo, para obtenção do Título de Doutor em Ciências. 
Thaís Santos Contenças

\section{Orientação Espacial da Atenção Automática e Voluntária com Ressonância Magnética Funcional Relacionada à Eventos}

Tese apresentada ao Programa de PósGraduação em Fisiologia Humana do Instituto de Ciências Biomédicas da Universidade de São Paulo, para obtenção do Título de Doutor em Ciências.

Área de concentração: Fisiologia Humana

Orientador: Prof. Dr. Edson Amaro Júnior

Co-orientador: Prof. Dr. Luiz Eduardo Ribeiro do Valle

Versão original 


\section{DADOS DE CATALOGAÇÃO NA PUBLICAÇÃO (CIP)}

Serviço de Biblioteca e Informação Biomédica do

Instituto de Ciências Biomédicas da Universidade de São Paulo

reprodução não autorizada pelo autor

Contenças, Thaís Santos.

Orientação espacial da atenção automática e voluntária com ressonância magnética Funcional / Thaís Santos Contenças. -- São Paulo, 2014.

Orientador: Prof. Dr. Edson Amaro Júnior.

Tese (Doutorado) - Universidade de São Paulo. Instituto de Ciências Biomédicas. Departamento de Fisiologia e Biofísica. Área de concentração: Fisiologia Humana. Linha de pesquisa: Atenção espacial.

Versão do título para o inglês: Automatic and voluntary spatial attention orientation studied by event-related functional magnetic resonance imaging.

1. Atenção espacial 2 . Atenção automática 3 . Atenção voluntária 4. ressonância magnética funcional 5 . Movimentos oculares

I. Amaro Junior, Prof. Dr. Edson II. Universidade de São Paulo. Instituto de Ciências Biomédicas. Programa de Pós-Graduação em Fisiologia Humana III. Título. 
Candidato(a):

Título da Tese:

Thaís Santos Contenças.

Orientador(a):

Prof. Dr. Edson Amaro Júnior.

A Comissão Julgadora dos trabalhos de Defesa da Tese de Doutorado, em sessão pública realizada a .................., considerou

( ) Aprovado(a)

( ) Reprovado(a)

Examinador(a): Assinatura:

Nome:

Instituição:

Examinador(a): Assinatura:

Nome:

Instituição:

Examinador(a): Assinatura:

Nome:

Instituição:

Examinador(a): Assinatura:

Nome:

Instituição:

Presidente: Assinatura:

Nome:

Instituição: 


\section{PARECER 982/CEP}

A Comissão de Ética em Pesquisas com Seres Humanos do ICB, na sessão de 14.12.2010, APROvou o projeto intitulado: “Evolução Temporal e Espacial da Atenção Automática e Voluntária com Ressonância Magnética Funcional" sob responsabilidade de execução dos autores Prof. Dr. Edson Amaro Júnior, Prof. Dr. Luiz EduARDo Ribeiro DO Valle e a aluna Thaís Santos CONTENÇAS.

Cabe a pesquisadora executante elaborar e apresentar a este Comitê, relatórios anuais ( parciais ou final), de acordo com a resolução 196/06 do Conselho Nacional da Saúde, item IX. 2 letra c.

O primeiro relatório deverá ser encaminhado à Secretaria deste CEP em

14.12.2011

Atenciosamente

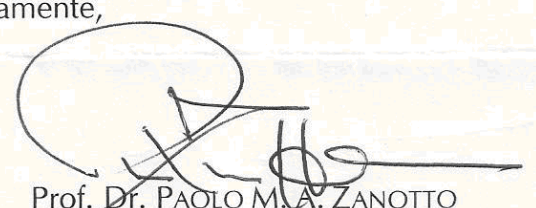

Prof. Dr. PAdlo M. Aa. ZanOTTO

Coordenador da Comissão de Ética em

Pesquisas com Seres Humanos - ICB/USP

Comissão de Ética em Pesquisa com Seres Humanos do Instituto de Ciências Biomédicas / USP Aprovada pela Comissão Nacional de Ética em Pesquisa - CONEP, em 10 de fevereiro de 1998. 
Dedico este trabalho aos meus pais, Ricardo e Flora que com muito apoio, incentivo e compreensão, não mediram esforços para que eu chegasse até esta etapa de minha vida. 


\section{AGRADECIMENTOS}

À minha família querida, que, com muito apoio e carinho, sempre acredita no meu potencial, incentivando conquistas como esta. Obrigada pai, mãe, irmã, Gabi e bolinha.

Em especial, agradeço ao meu marido Rafael por compreender minha ausência em muitos momentos para a elaboração desta pesquisa e também pelo apoio que dedicou a minha tese, já que contei com sua presença como voluntário dos experimentos deste trabalho.

Ao meu orientador, professor Edson Amaro Júnior, pela confiança, paciência e pelos seus ensinamentos durante esta trajetória, notadamente, pelas inúmeras vezes que acompanhou a pesquisa independentemente do horário.

Ao meu co-orientador, professor Luiz Eduardo Ribeiro do Valle, pela importante contribuição e incentivo que dedicou a este trabalho. Serei eternamente grata.

Aos colaboradores, Mariana Nucci e Raymundo Azevedo Neto, que participaram diretamente na realização desta pesquisa.

Aos colegas de laboratório do Inrad (Katerina Lukasova, Joana Balardin, Gilson Vieira, Khallil, Paulo Bazán, Ana Paula Valadares) e do ICB (Viviane Bueno e Luanna Righ) que também auxiliaram no desenvolvimento deste trabalho.

Ao Antônio Cesário pelo auxílio e desenvolvimento dos equipamentos utilizados na RMf.

Aos biomédicos e enfermeiros pelo suporte durante as coletas de dados.

Aos voluntários que contribuíram para a realização deste trabalho, em especial meus queridos alunos universitários, aos quais nutro grande carinho.

Aos secretários do ICB, José Maria e Paloma, que sempre dispensam incansável atenção aos alunos. 
Aos membros da banca de qualificação, prof. Ronauld Ranvaud, prof. Gilberto Xavier e prof. João Sato, que contribuíram para a finalização desta pesquisa. Aqui, também registro especial agradecimento ao prof. João Sato por me apresentar ao prof. Edson Amaro Júnior, o que facilitou o rumo tomado por esta pesquisa.

Enfim, a todos que contribuíram direta ou indiretamente na conclusão da minha tese, seja com uma palavra de incentivo, seja com a participação ativa, enfim, todos foram muito importantes. 


\section{RESUMO}

Contenças TS. Orientação espacial da atenção automática e voluntária com ressonância magnética funcional relacionada à eventos. [tese (Doutorado em Fisiologia Humana)]. São Paulo: Instituto de Ciências Biomédicas, Universidade de São Paulo; 2014.

A atenção visuoespacial pode ser considerada como a atividade neural que seleciona certas regiões do espaço em detrimento das demais. Existem dois tipos de orientação da atenção: atenção automática e atenção voluntária. Há evidências de que as áreas cerebrais associadas à estes dois tipos se sobrepõem, porém alguns autores observaram que há áreas distintas de ativação cerebral para atenção automática e voluntária. Estas diferenças resultaram em visões distintas a respeito de modelos cerebrais envolvendo a atenção visuoespacial. $O$ objetivo de nosso trabalho foi identificar quais são as principais redes de ativação neuronal durante a mobilização da atenção automática e voluntária com Ressonância Magnética Funcional (RMf) relacionada à eventos, utilizando a tarefa de Posner modificada (1980). Participaram deste estudo vinte adultos jovens e saudáveis (17 mulheres). A tarefa foi programada no ambiente Eprime (Psylab, EUA) e os participantes treinaram antes de realizar o experimento de RMf. As condições foram pseudorandomizadas com otimização por algoritmos genéticos. Cada tentativa começava com um Ponto de Fixação na tela e dois anéis demarcados, um em cada lado. Após o aparecimento do Estímulo Precedente (E1), um Estímulo Alvo (E2) aparecia dentro de um dos anéis. Nestes experimentos foram consideradas as condições válida, neutra e inválida. Os dados foram adquiridos em 3 runs para cada Experimento. A aquisição das imagens foi realizada em um sistema de 3 tesla (Philips Achieva), acoplado à um sistema de detecção de movimentação ocular (eye tracker) compatível com ambiente de RM (Magconcept, USA). As imagens de RMf foram adquiridas com sequências BOLD, GRE-EPI com TR=2s, TE $=30$ s, voxels isotrópicos de $3 \mathrm{~mm}$. O tempo e a resposta ao estímulo foram registrados (Zurc\&Zurc, São Paulo, Brasil). A análise das imagens de RMf foi realizada com o programa FSL 4.1 (Oxford University, Inglaterra) e incluiu a correção de movimento, filtro espacial, remoção de artefatos e transformação da imagem para o espaço comum. O mapas cerebrais representando o efeito de grupo (usando o modelo de regressão linear) foram produzidos com limiar de $Z>2,3$ e nível de significância de $p<0,05$ (corrigido para comparações múltiplas). O tempo de reação foi menor quando o E2 apareceu na condição válida em comparação com a condição inválida. Houve superposição dos mapas de ativação na condição de atenção automática e voluntária em extensa rede, envolvendo áreas: frontais (giros pré-centrais, frontais médios, frontais mediais e giro frontal inferior direito), parietais (bordas dos sulcos intraparietais, giros pós-centrais, angulares, supramarginais e pré-cuneo), temporais (giros temporais médios e no giro temporal superior esquerdo) e occipitais (giros fusiformes e no giro lingual direito. Observamos outras áreas: giros do cíngulo anteriores e posteriores, parahipocampais, ínsulas, colículos superiores e inferiores, e cerebelo). Concluímos que as redes frontoparietais foram detectadas tanto na mobilização da atenção visuoespacial automática quanto voluntária. No entanto, o giro frontal superior esteve presente apenas na mobilização da atenção voluntária. 
Estes resultados mostram que a distinção parece estar em áreas cerebrais envolvidas em subsistemas que incluem a orientação e reorientação da atenção automática e voluntária.

Palavras-chave: Atenção Espacial. Atenção Automática. Atenção Voluntária. Ressonância Magnética Funcional. Movimentos Oculares. 


\begin{abstract}
Contenças TS. Automatic and voluntary spatial attention orientation studied by eventrelated functional magnetic resonance imaging [Ph. D. thesis (Human Physiology]. São Paulo: Instituto de Ciências Biomédicas, Universidade de São Paulo; 2014.
\end{abstract}

Visuospatial attention can be considered as the neural activity that selects certain regions of space at the expense of others. There are two types of orientation of attention: automatic attention and voluntary attention. There is evidence that the brain networks associated with these two types overlap, but some authors have observed that there are distinct areas of brain activation for automatic and voluntary attention. These differences resulted in different views about brains models involving visuospatial attention. The aim of our study was to identify brain networks associated with automatic and voluntary attention using Event-Related Functional Magnetic Resonance Imaging (fMRI) and a new modification of the Posner task (1980). The study included twenty young healthy adults (17 women and 3 men). The task was programmed in Eprime environment (Psylab, USA) and all participants trained before performing the experiment in the MRI machine. The conditions were pseudorandomized with the optimization method of genetic algorithms. Each trial began with a fixation point on the screen and two demarcated rings, one on each side. After the onset of the Prime Stimulus (S1), a Target Stimulus (S2) appeared inside one of the rings. In these experiments the valid, neutral and invalid conditions were considered. Data were acquired in three runs for each experiment. Image acquisition of this project was performed on a 3 Tesla system (Philips Achieva), coupled to an MR compatibel eye tracker system (Magconcept, USA). All fMRI images were acquired using BOLD sequences, GRE-EPI with $T R=2 s$, $T E=30$ s, with $3 \mathrm{~mm}$ isotropic voxels. Response time and choice during fMRI experiment were recorded (Zurc\&Zurc, Brazil). Image analysis of fMRI was performed using FSL 4.1 software package (Oxford University, England) including: motion correction, spatial filter, removal of artifacts and image transformation for the common space. Brain maps representing group effect (using the linear regression model) where threshold using a $Z>2.3$ at cluster level and $p<0.05$ (corrected for multiple comparisons). Reaction times were shorter when the $S 2$ appeared in the valid condition compared with the invalid condition. Automatic and voluntary attention brain activation maps overlaped in frontal areas: precentral, middle frontal, medial frontal gyrus and right inferior frontal gyri; parietal areas: edges of intraparietal sulcus, postcentral, angular, supramarginal gyrus and pre-cuneus; temporal areas: middle temporal gyrus and left superior temporal gyrus; and occipital areas: fusiform gyrus and right lingual gyrus. Other areas was observed in anterior and posterior cingulate, parahippocampal gyrus, insulas, superior and inferior colliculus, and cerebellum. Superior frontal gyrus showed increased response in the voluntary attention when compared with automatic attention. We conclude that the frontoparietal networks were detected in both the mobilization of automatic and voluntary visuospatial attention. However the superior frontal gyrus showed response only in the voluntary attention. The distinction between these two subsystems involved in orientation and reorientation of automatic and voluntary attention.

Keywords: Spatial Attention. Automatic Attention. Voluntary Attention. Functional Magnetic Resonance. Eye Movements. 


\section{LISTA DE ILUSTRAÇÕES}

Figura 1. Representa o desenho de diferentes formas de apresentação dos estímulos

Figura 2. Áreas corticais envolvendo as três redes atencionais .......................... 26

Figura 3. Modelo Neuroanatômico do controle atencional ................................. 28

Figura 4. Fluxograma do desenho experimental ............................................ 33

Figura 5. Condições estimulatórias do experimento de Atenção Automática ....... 39

Figura 6. Condições estimulatórias do experimento de Atenção Voluntária ......... 40

Figura 7. Posicionamento do Eye tracker na Ressonância Magnética ................ 41

Figura 8. Imagem da delimitação da pupila "dark pupila" .................................... 42

Figura 9. Janelas do programa ViewPoint ..................................................... 43

Figura 10. Grade de calibração do eye tracker ............................................... 44

Figura 11. Variáveis consideradas na análise de dados do Experimento de Atenção Automática e do Experimento de Atenção Voluntária

Figura 12. Distribuição dos voluntários por classificação socioeconômica............ 52

Figura 13. Média ( \pm e.p.m.) da pontuação da Escala Visual Analógica de Humor (VAMS) antes de depois do exame de ressonância magnética funcional.

Figura 14. Média ( \pm e.p.m.) dos tempos de reação ao estímulo alvo na condição válida, neutra e inválida.

Figura 15. Média ( \pm e.p.m.) dos tempos de reação nos experimentos de atenção automática e de atenção voluntária, nas condições válida, neutra e inválida.

Figura 16. Média ( \pm e.p.m.) do efeito atencional no experimento de atenção automática e no experimento de atenção voluntária.

Figura 17. Média ( \pm e.p.m.) dos tempos de reação ao estímulo alvo na condição válida, neutra e inválida.

Figura 18. Média ( \pm e.p.m.) dos tempos de reação nos experimentos de atenção automática e de atenção voluntária, nas condições válida, neutra e inválida

Figura 19. Média ( \pm e.p.m.) do efeito atencional no experimento de atenção automática e no experimento de atenção voluntária. 
Figura 20. Média ( \pm e.p.m.) dos tempos de reação na Sessão Treino e na Sessão Prova

Figura 21. Mapa probabilístico de ativação de grupo do experimento de atenção automática $(\mathrm{N}=20)$ no contraste das tentativas válida versus neutra $(\mathrm{V}>\mathrm{N})$..

Figura 22. Mapa probabilístico de ativação de grupo do experimento de atenção automática $(\mathrm{N}=20)$ no contraste das tentativas inválida versus neutra $(\mathrm{I}>\mathrm{N}) \ldots \ldots \ldots .$.

Figura 23. Mapa probabilístico de ativação de grupo do experimento de atenção automática $(\mathrm{N}=20)$ no contraste das tentativas válida versus inválida $(\mathrm{V}>\mathrm{l})$.

Figura 24. Mapa probabilístico de ativação de grupo do experimento de atenção automática $(\mathrm{N}=20)$ no contraste das tentativas inválida versus válida $(\mathrm{I}>\mathrm{V})$.

Figura 25. Mapa probabilístico de ativação de grupo do experimento de atenção voluntária $(\mathrm{N}=20)$ no contraste das tentativas válida versus neutra $(\mathrm{V}>\mathrm{N})$.

Figura 26. Mapa probabilístico de ativação de grupo do experimento de atenção voluntária $(\mathrm{N}=20)$ no contraste das tentativas inválida versus neutra $(\mathrm{I}>\mathrm{N})$.....

Figura 27. Mapa probabilístico de ativação de grupo do experimento de atenção voluntária $(\mathrm{N}=20)$ no contraste das tentativas inválida versus válida $(\mathrm{I}>\mathrm{V})$.....

Figura 28. Mapa probabilístico de ativação de grupo dos experimentos de atenção $(\mathrm{N}=20)$ no contraste dos experimentos de atenção automática versus atenção voluntária $(A>V)$.

Figura 29. Mapa probabilístico de ativação de grupo dos experimentos de atenção $(\mathrm{N}=20)$ no contraste dos experimentos de atenção voluntária versus atenção automática $(\mathrm{V}>\mathrm{A})$

Figura 30. Mapa probabilístico de ativação de grupo dos experimentos de atenção automática e voluntária $(\mathrm{N}=20)$.

Figura 31. Mapa probabilístico de ativação de grupo dos experimentos de atenção automática $(\mathrm{N}=20)$, através da análise de conjunção.

Figura 32. Mapa probabilístico de ativação de grupo dos experimentos de atenção voluntária $(\mathrm{N}=20)$, através da análise de conjunção.

Figura 33. Mapa probabilístico de ativação de grupo dos experimentos de atenção automática e atenção voluntária $(\mathrm{N}=20)$ - análise de conjunção

Figura 34. Mapa probabilístico de ativação de grupo dos experimentos de atenção automática e atenção voluntária $(\mathrm{N}=20)$ com sobreposição dos mapas .. 79 


\section{LISTA DE ILUSTRAÇÕES}

Quadro 1. Representação das áreas neurais envolvidas com a Atenção Automática, nas condições Válida $>$ Neutra $(V>N)$, Inválida $>$ Neutra $(I>N)$, Válida>Inválida $(V>I)$ e Inválida>Válida $(I>V)$

Quadro 2. Representação das áreas neurais envolvidas com a Atenção Voluntária, nas condições Válida $>$ Neutra $(V>N)$, Inválida $>$ Neutra $(I>N)$, Válida>Inválida $(V>I)$ e Inválida $>$ Válida $(I>V)$

Quadro 3. Representação das áreas neurais envolvidas com a Atenção Automática e Atenção Voluntária, nas condições de base (válida, neutra e inválida)

Quadro 4. Representação das áreas neurais envolvidas com a Atenção Automática e Atenção Voluntária, nas condições de base (válida, neutra e inválida), da análise de conjunção 


\section{LISTA DE TABELAS}

Tabela 1. Peso dos itens da Escala Visual Analógica de Humor.

Tabela 2. Resultados do teste-t pareado para a Escala Visual Analógica de Humor antes de depois do exame de Ressonância Magnética funcional.

Tabela 3. Resultados da Análise de Variância da sessão treino tendo como fatores o Tipo de Atenção (automática e voluntária), Validade do E1 (válida, neutra e inválida).

Tabela 4. Média ( \pm e.p.m.) dos tempos de reação para a validade do E1 nas posições válida, neutra e inválida

Tabela 5. Média ( \pm e.p.m.) dos tempos de reação para o tipo de atenção e a validade do $\mathrm{E} 1$ nas posições válida, neutra e inválida.

Tabela 6. Resultados da Análise de Variância da sessão prova tendo como fatores o Tipo de Atenção (automática e voluntária), Validade do E1 (válida, neutra e inválida).

Tabela 7. Média ( \pm e.p.m.) dos tempos de reação para a validade do E1 nas posições válida, neutra e inválida.

Tabela 8. Média ( \pm e.p.m.) dos tempos de reação para o tipo de atenção e a validade do E1 nas posições válida, neutra e inválida.

Tabela 9. Movimentos oculares 


\section{LISTA DE ABREVIATURAS E SÍMBOLOS}

A1

A2

A3

ABEP

AG

AIE

ANOVA

BA

BDI

BOLD

C

D

Dp

E

E1

E2

EPI

Epm

$\mathbf{F}$

FEAT

FEF

FLAIR

FLIP

FLIRT

FMUSP

FOV

FSL

GI

GLM

$\mathrm{HC}$
Run1 do teste de atenção automática

Run2 do teste de atenção automática

Run3 do teste de atenção automática

Associação Brasileira de Empresas e Pesquisa

Algoritmos Genéticos

Assincronias entre o Início dos Estímulos

Análise de Variância para Medidas Repetidas

Área de Brodmann

Inventário de Depressão de Beck

Contraste dependente do nível de oxigenação sanguínea (Blood

Oxygenation Level Dependent)

Controle

Direita

Desvio padrão médio

Esquerda

Estímulo Precedente

Estímulo Alvo

Imagem eco-planar (Echo-Planar Imaging)

Erro padrão médio

Razão entre o quadrado da média do efeito e o do erro

Ferramentas de Análise para Ressonância Magnética funcional

(FMRI Expert Analysis Tool)

Campo Ocular Frontal

Imagem Estrutural (Fluid Attenuated Inversion Recovery)

Ângulo de Inclinação

Ferramenta de Registro Linear

Faculdade de Medicina da Universidade de São Paulo

Campo de Visão (Field of View)

Programa para a análise de áreas cerebrais

Graus de liberdade

Modelo Linear Geral

Hospital das Clínicas 


$\begin{array}{ll}\text { HRP } & \text { Resposta Hemodinâmica Cerebral } \\ \text { I } & \text { Inválida } \\ \text { IET } & \text { Intervalo entre as Tentativas } \\ \text { IFg } & \text { Giro Frontal Inferior } \\ \text { IL } & \text { Índice de Lateralidade } \\ \text { IPL } & \text { Lobo Parietal Inferior } \\ \text { IPs } & \text { Sulco Intraparietal } \\ \text { IR } & \text { Inversão da Recuperação } \\ \text { LEDs } & \text { Diodo emissor de luz (Light Emitting Diodes) } \\ \text { MFg } & \text { Giro Frontal Médio } \\ \text { MNI } & \text { Montreal Neurologic Institute } \\ \text { N } & \text { Neutra } \\ \mathbf{p} & \text { Nível de significância } \\ \text { PF } & \text { Ponto de Fixação } \\ \text { RM } & \text { Ressonância Magnética } \\ \text { RMf } & \text { Ressonância Magnética functional } \\ \text { ROI } & \text { Região de Interesse } \\ \text { SPL } & \text { Lobo Parietal Superior } \\ \text { T } & \text { Tesla } \\ \text { TAM } & \text { Tamanho do cluster com efeito BOLD em voxels } \\ \text { TE } & \text { Tempo ao eco } \\ \text { TPJ } & \text { junção temporoparietal } \\ \text { TR } & \text { Tempo de Reação } \\ \text { Tr } & \text { Tempo de repetição } \\ \text { V } & \text { Válida } \\ \text { V1 } & \text { Run1 do teste de atenção voluntária } \\ \text { V2 } & \text { Run2 do teste de atenção voluntária } \\ \text { V3 } & \text { Run3 do teste de atenção voluntária } \\ \text { VAMS } & \text { Escala Visual Analógica de Humor } \\ \text { VBM } & \text { Morfometria baseada em voxel (Voxel Based Morphometry) } \\ \text { VFC } & \text { Córtex Frontal Ventral } \\ \mathbf{Z} & \text { detatística estimando o efeito BOLD do } \\ & \end{array}$




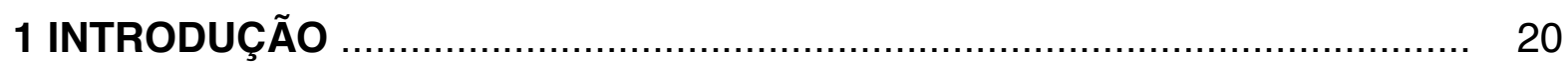

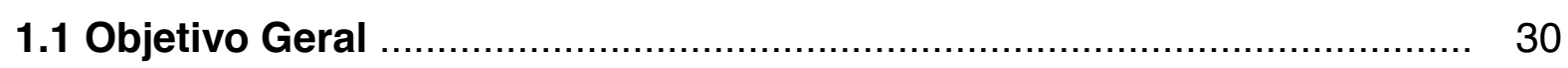

1.2 Objetivos Específicos .................................................................. 30

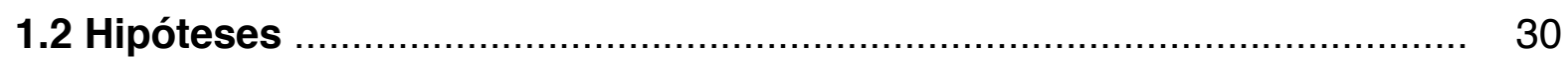

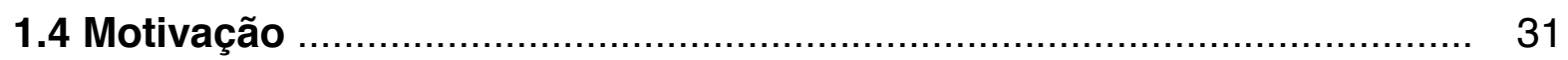

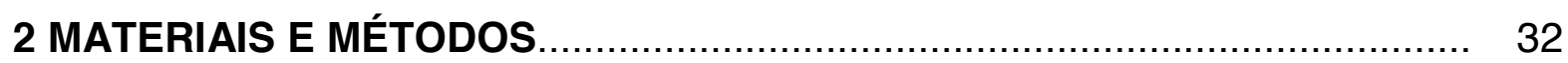

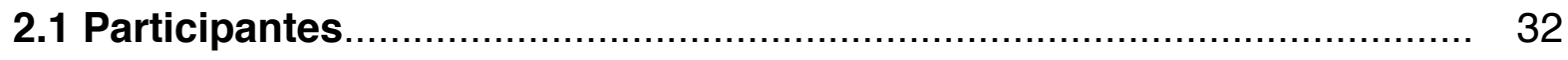

2.2 Entrevista: questionários e escalas ………...................................... 33

2.3 Tarefa Comportamental ..................................................................... 37

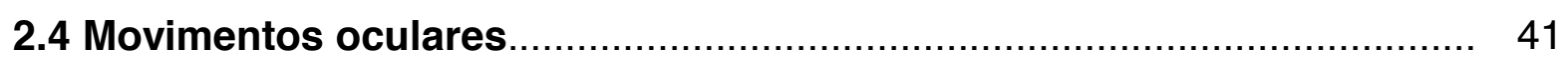

2.5 Ressonância Magnética (RM)........................................................... 44

2.5.1 Posicionamento dos voluntários...................................................... 45

2.5.2 Parâmetros de Aquisição das Imagens de RM................................. 45

2.5.3 Instrumentos para coleta de dados comportamentais na RMf............. 46

2.5.4 Paradigma de RMf.................................................................. 47

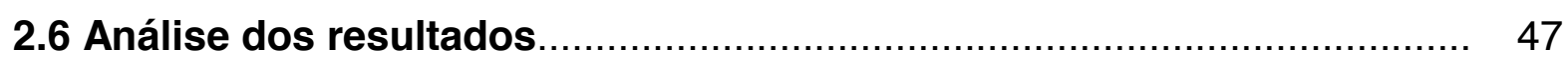

2.6.1 Entrevista: questionários e escalas............................................... 47

2.6.2 Tarefa Comportamental.......................................................... 48

2.6.3 Movimentos Oculares............................................................ 48

2.6.4 Ressonância Magnética............................................................... 51

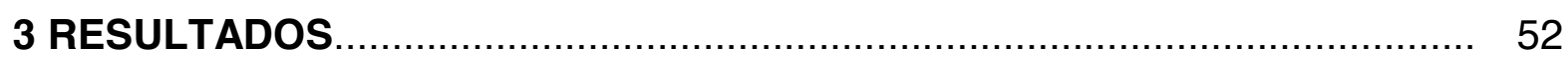

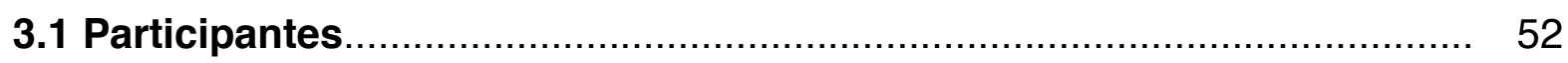

3.2 Entrevista: questionários e escalas................................................... 52

3.3 Tarefa Comportamental.................................................................... 55

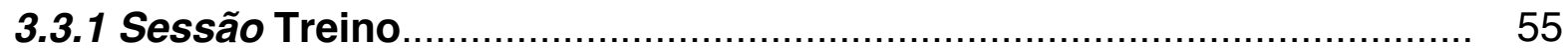

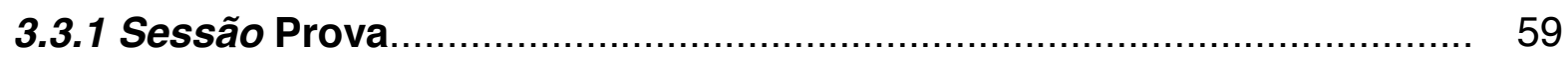

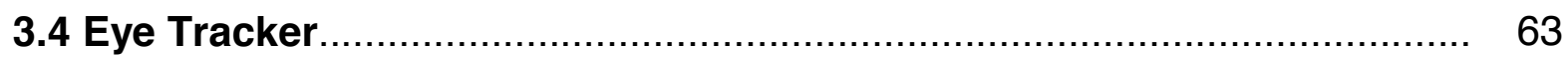

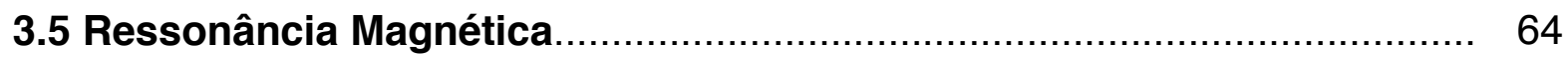

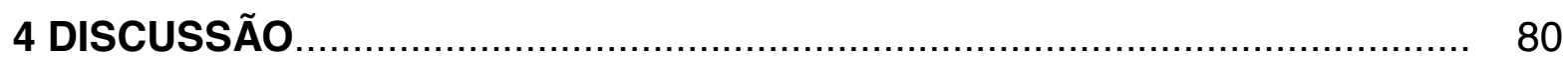

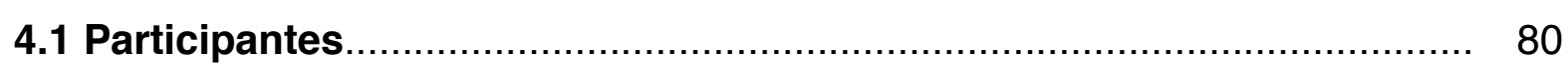

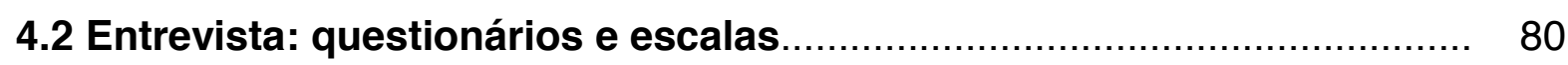


4.3 Tarefa Comportamental.............................................................. 81

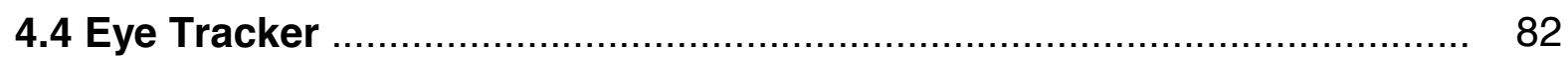

4.5 Ressonância Magnética Funcional.................................................. 83

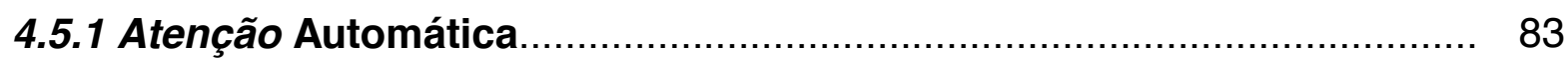

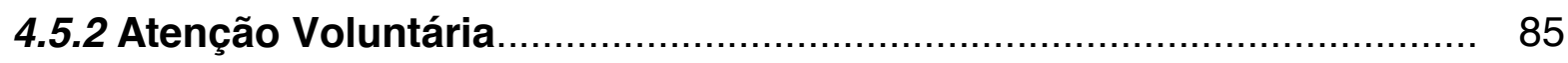

4.5.3 Diferenças da ativação cerebral associada à mobilização da atenção automática e da atenção voluntária ..................................................... 86

4.5.4 Semelhanças da ativação cerebral associada à mobilização da atenção automática e da atenção voluntária............................................ 90

4.5.5 Modelo Neuroanatômico da Atenção Visuoespacial ............................ 92

4.6 Diferenças entre o nosso estudo e os estudos prévios........................... 94

4.7 Comentários sobre a tarefa utilizada no estudo ..................................... 96

4.8 Limitação do estudo .................................................................................. 96

4.9 Direções Futuras ......................................................................... 97

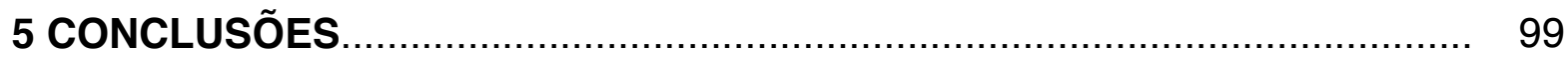

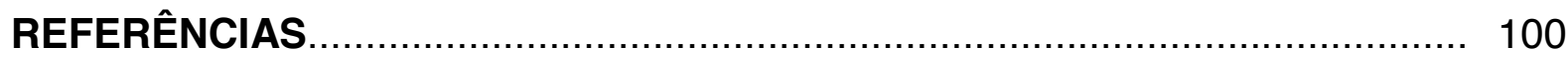

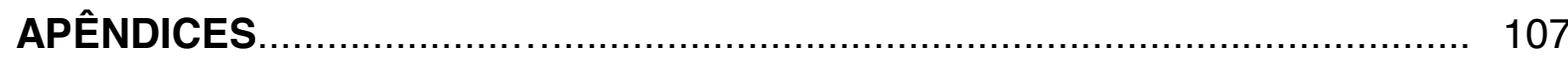

APÊNDICE A - Termo de Consentimento Livre e Esclarecido........................... 108

APÊNDICE B - Questionário de Identificação................................................... 110

APÊNDICE C1 - Classificação Socioeconômica................................................ 111

APÊNDICE C2 - Classificação Socioeconômica................................................ 112

APÊNDICE D - Questionário de Edinburgh (adaptado)..................................... 113

APÊNDICE E - Teste de Acuidade Visual...................................................... 114

APÊNDICE F - Teste de Ishihara para daltonismo........................................ 115

APÊNDICE G - Inventário de Depressão de Beck......................................... 116

APÊNDICE H - Perguntas sobre saúde........................................................ 119

APÊNDICE I - Escala Visual Analógica de Humor - VAMS pré-RMf................... 120

APÊNDICE J - Escala Visual Analógica de Humor - VAMS pós-RMf.................. 121

APÊNDICE K - Entrevista pós-RMf............................................................... 122

APÊNDICE L - Instrução do Experimento de Atenção Automática e Voluntária.. 123

APÊNDICE M - Algoritmos Genéticos...................................................... 124

APÊNDICE N - Análise de dados - RMf...................................................... 127

APÊNDICE O - Dados demográficos.......................................................... 131

APÊNDICE P - Resultados das Perguntas a Respeito da Saúde........................ 132 
APÊNDICE Q - Tempo de Reação da Sessão Treino do Experimento de Atenção Automática e Atenção Voluntária

APÊNDICE R - Teste t para variáveis independentes.

APÊNDICE S - Tempo de Reação da Sessão Prova do Experimento de Atenção Automática e Atenção Voluntária

APÊNDICE T - Comparação entre o Tempo de Reação da Sessão Treino e o Tempo de Reação da Sessão Prova dos Experimentos de Atenção Automática e Atenção Voluntária.

\section{APÊNDICE U}

APÊNDICE U1 - Atenção Automática - Tentativas Válida versus Neutra $(V>N)$.. 137

APÊNDICE U2 - Atenção Automática - Tentativas Inválida versus Neutra (I>N). 139

APÊNDICE U3 - Atenção Automática - Tentativas Válida versus Inválida $(V>I)$.. 140

APÊNDICE U4 - Atenção Automática - Tentativas Inválida versus Válida ( $(>V)$ ). 143

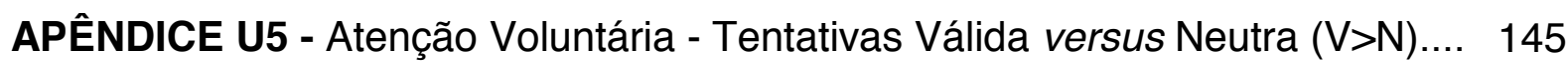

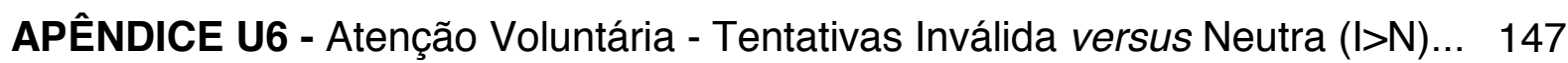

APÊNDICE U7 - Atenção Voluntária - Tentativas Inválida versus Válida (I>V)... 149

APÊNDICE U8 - Atenção Automática versus Atenção Voluntária - Experimento de Atenção Automática versus Atenção Voluntária $(A>V)$

APÊNDICE U9 - Atenção Automática versus Atenção Voluntária - Experimento de Atenção Voluntária versus Atenção Automática $(\mathrm{V}>\mathrm{A})$.

APÊNDICE U10 - Atenção Automática - Todas as Condições Experimentais de Base (Válida, Neutra e Inválida).

APÊNDICE U11 - Atenção Voluntária - Todas as Condições Experimentais de Base (Válida, Neutra e Inválida)

APÊNDICE U12 - Análise de Conjunção da Atenção Automática e da Atenção Voluntária. 


\section{INTRODUÇÃO}

Prestar atenção é focalizar a consciência em uma tarefa principal única e colocar as outras menos importantes em segundo plano. Ou seja, a atenção pode ser considerada como uma atividade neural que facilita o processamento de uma determinada informação e inibe o processamento de informações concorrentes (Posner, 1980). Se a atenção é direcionada para um local específico no ambiente, as informações provenientes dessa região serão privilegiadas. Nesse caso fala-se que a atenção foi orientada para esse local do espaço.

A orientação da atenção espacial é um mecanismo antigo desenvolvido para selecionar a informação de um determinado local e posteriormente processar essas informações.

É feita a distinção entre os dois tipos de orientação da atenção: orientação automática da atenção e orientação voluntária da atenção (Jonides, 1981; Posner, 1980; Posner, Cohen, 1984).

A orientação da atenção automática, também conhecida como atenção reflexa (exógena, bottom-up) refere-se à orientação involuntária ou automática da atenção, e é desencadeada por eventos inesperados no ambiente, mesmo que o sujeito esteja atento à outra fonte de estimulação. Além disso, não é necessário um controle consciente, ocorrendo de modo involuntário (Gazzaniga et al.,1998; Posner, 1980; Posner, Cohen, 1984). Permite uma reação rápida e eficiente por parte do sujeito.

Em testes de atenção automática uma pista periférica é apresentada em um dos locais do alvo. A pista não é preditiva com relação ao local de aparecimento do alvo, assumindo que a atenção será atraída automaticamente.

A pista periférica produz facilitação no local de aparecimento em Assincronias entre o Início dos Estímulos (AIE) curtas, consequentemente, os sujeitos respondem mais rapidamente durante a tarefa comportamental. Quando esta assincronia ultrapassa $250 \mathrm{~ms}$, a resposta é mais lenta ao alvo apresentado no local da pista. Este fenômeno, que ocorre exclusivamente nos testes de atenção automática, é chamado de Inibição de Retorno (Klein, 2000; Posner, Cohen, 1984). Muller e Findlay (1988), Muller e Rabbitt (1989) observaram que os efeitos da atenção automática podem ser encontrados em AlEs curtas, entre 50-200 ms. 
A orientação voluntária da atenção, também conhecida como endógena ou top down, refere-se à orientação controlada da atenção. Ela necessita de mais tempo para ocorrer. As AIEs para a orientação da atenção voluntáriamdependeriam de um tempo maior do que da atenção automática, a partir de 250 ms (Muller, Findlay, 1988; Muller, Rabbitt, 1989). É geralmente usada em tarefas mais complexas ou não familiares (Gazzaniga et al., 1998; Nahas, Xavier, 2004; Posner, 1980; Posner, Cohen, 1984). Pode ser utilizada em tarefas que requerem planejamento ou tomada de decisões, tarefas que envolvam componentes de solução de problemas, tarefas mal aprendidas ou que contenham novas sequências, tarefas perigosas ou tecnicamente difíceis (Helene, Xavier, 2003).

A orientação da atenção automática e da atenção voluntária pode ser avaliada pelos procedimentos desenvolvidos por Posner e seus colaboradores (Posner, 1980; Posner, Cohen, 1984). O sujeito é instruído a manter o olhar fixo num ponto central na tela de um monitor de vídeo ao longo de todo o teste e pressionar uma tecla com o dedo indicador assim que um alvo visual for apresentado em regiões periféricas ao ponto de fixação. Antes do aparecimento do alvo visual pode aparecer um estímulo precedente representado por uma pista periférica ou por uma pista central.

Nos testes de atenção automática haverá uma mudança abrupta do brilho de um dos quadrados (isto direciona a atenção dos sujeitos para o local de forma automática) e nos testes de atenção voluntária, uma cabeça de seta central aparecerá (esta direciona a atenção do sujeito de maneira voluntária para o lado indicado). Essas pistas podem acontecer à esquerda ou à direita do ponto de fixação. Elas podem sinalizar corretamente o local de aparecimento do alvo (condição válida), ou podem sinalizar incorretamente o local de aparecimento do alvo (condição inválida).

Nesses testes é medido o tempo decorrido entre a apresentação do alvo e o início da resposta motora a ele. Este tempo é chamado de tempo de reação (Nahas, Xavier, 2004). O tempo de reação ao estímulo alvo sinalizado corretamente pelo estímulo precedente é menor do que o tempo de reação sinalizado incorretamente pelo estímulo precedente (Castro-Barros et al., 2008; Henderson, Macquistan, 1993; Nahas, Xavier, 2004; Posner, 1980). Esta diferença no tempo de reação é denominada efeito de validade. A mobilização da atenção sinalizada corretamente para o mesmo lado, nas tarefas de tempo de reação simples, facilita o 
processamento local do estímulo alvo e dificulta o processamento do lado oposto (Jonides, 1981; Posner, Cohen, 1984).

Alguns estudos têm utilizado uma pista neutra. Esta pista indica que o estímulo alvo pode aparecer em qualquer um dos lados da tela do computador. Desta forma, é possível calcular o benefício ou o custo da atenção. O benefício atencional é calculado pela diferença entre a condição neutra menos a condição válida, onde se observa uma diminuição do tempo de reação por orientar a atenção para o local de aparecimento do estímulo alvo. O custo atencional é calculado pela diferença entre o tempo de reação da condição inválida menos a condição neutra, onde se observa um aumento do tempo de reação por retirar a atenção do local de aparecimento do estímulo alvo (Henderson, 1991; Kim et al., 1999; Righi, Ribeiro-doValle, 2011)

Uma questão importante nas pesquisas comportamentais é entender como a atenção está alocada no espaço e as redes neurais envolvidas em diferentes tarefas experimentais.

Vários métodos têm sido desenvolvidos para permitir o mapeamento do funcionamento do cérebro humano nos testes de atenção. Há diversas técnicas para produzir informações a respeito de atividade cerebral associada às regiões distintas. Duas classes básicas da técnica são as que estão relacionadas com a atividade elétrica do cérebro e às consequências fisiológicas ou metabólicas da atividade cerebral alterada (Matthews, Jezzard, 2004).

A Ressonância Magnética (RM), utilizada no presente estudo, está relacionada com a segunda categoria e é utilizada para produzir imagens estruturais dos órgãos, incluindo o Sistema Nervoso Central, além de fornecer informações sobre o estado físico-químico dos tecidos, sua vascularização e perfusão. A RM funcional (RMf) é uma técnica que mede alterações hemodinâmicas associadas à atividade neural. A introdução desta técnica e a difusão de seu uso trouxe um grande impacto nas pesquisas em neurociência cognitiva básica (Logothetis, 2008).

As principais vantagens da técnica são, por exemplo, sua natureza nãoinvasiva, alta resolução têmporo-espacial (relativa) e a capacidade de demonstrar toda a rede de áreas cerebrais envolvidas quando os indivíduos realizam tarefas específicas (Logothetis, 2008). 
A RMf pode se basear em várias técnicas. A principal envolve mensurações de sinal BOLD (blood oxygenation level dependente contrast - contraste dependente do nível de oxigenação sanguínea), medida indireta da atividade neuronal. Com o aumento da atividade neuronal ocorre o aumento localizado no fluxo e no volume sanguíneo. A distribuição de oxigênio é aumentada, causando mudanças no local de concentração relativa da desoxihemoglobina, a qual altera o sinal da ressonância, em sequências BOLD. Esta resposta hemodinâmica é lenta em relação aos fenômenos elétricos neuronais, e atinge seu máximo após alguns segundos do início do estímulo. O mapeamento espacial e a mensuração da atividade indireta de populações de milhares de neurônios no cérebro requerem o entendimento da mudança hemodinâmica que relaciona à atividade neuronal ao sinal BOLD mensurado (Birn et al., 2001).

O sinal BOLD pode ser utilizado apenas para determinar mudanças hemodinâmicas, associadas a diferentes estados cognitivos. A técnica possui alta resolução espacial, da ordem de milímetros (ou sub-milimétricas em equipamentos de alto campo, ou com aquisição dedicadas à regiões localizadas do cérebro) e com resolução temporal de poucos segundos (ou milissegundos em equipamentos de alto desempenho, ou com aquisições dedicadas à regiões localizadas do cérebro) (Matthews, Jezzard, 2004). Para Muftuler e Nalcioglu (2000), a capacidade de adquirir imagens em 3D com efetiva resolução temporal é na ordem de 100-200 ms.

A estratégia em um experimento de RMf é baseada na intervenção de um sistema (cérebro) e na observação na modulação da resposta do sistema (efeito BOLD), resultante de uma provocação (tarefa cognitiva) (Amaro, Baker, 2006). Em geral, o pesquisador precisa decidir detalhadamente o que é esperado em seu experimento e o desenho experimental que será empregado.

Os desenhos de estudo com RMf incluem estratégias de comparação cognitiva (subtração, fatorial, paramétrica, análise de conjunção) e as possibilidades de apresentação dos estímulos (desenhos em bloco, relacionado ao evento, relacionado ao evento rápido, misto) Vide Figura 1 (Amaro, Barker, 2006).

A RMf relacionada à eventos, utilizada nesse estudo, tem sido aplicada como meio de observar a evolução temporal da resposta neuronal para um estímulo. 0 estímulo ocorrerá em uma duração curta e múltiplas tentativas estão separadas por longos Intervalos entre as Tentativas (IETs) (Huettel, 2009). O interesse por esse tipo de estudo se justifica pela capacidade de detectar as respostas de tentativas 
individuais (Henson, 2006), já que pretendemos analisar o comportamento e comparar as condições válidas separadamente das condições inválidas e neutras, em relação à resposta temporal, que será descrita posteriormente.
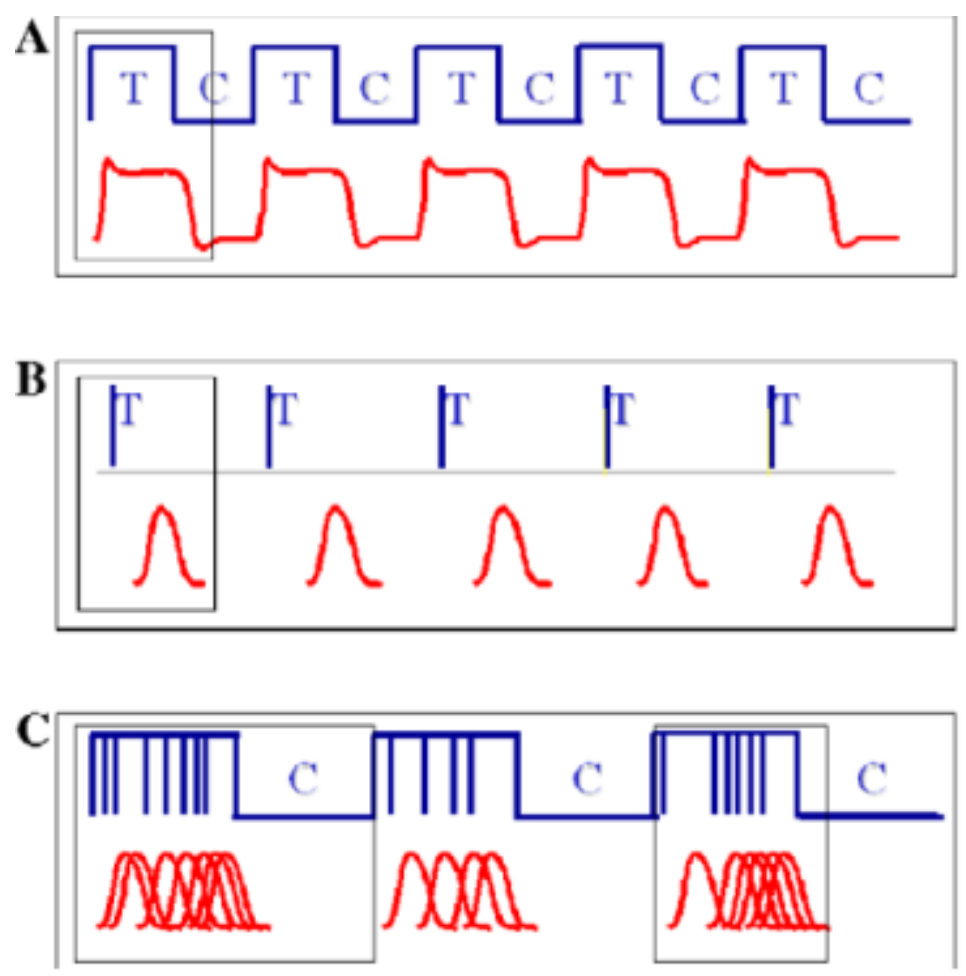

Figura 1. Representa o desenho de diferentes formas de apresentação dos estímulos. (A) Desenho em bloco: os blocos de estímulos são alternados com os blocos controles. (B): Desenho relacionado ao evento: cada estímulo é realizado uma vez e alternado com os controles. (C) Desenho misto: uma combinação entre as técnicas (figura modificada do artigo de Amaro, Barker, 2006). A letra T representa as tentativas e a C representa os controles.

No planejamento de experimento de RMf é necessário levar em conta as limitações temporais e as características da Resposta Hemodinâmica Cerebral (HRP). Essa resposta leva certo tempo para apresentar o seu efeito máximo, de 2 a 3 segundos, após o aparecimento de um determinado estímulo (Amaro, Barker, 2006).

Além disso, para uma melhor randomização e sequenciamento de estímulos que serão utilizados em diferentes condições experimentais, um novo método tem sido utilizado em estudos de RMf relacionada ao evento, conhecido como modelos de algoritmos genéticos, desenvolvido por Wager e Nichols (2003). 
A finalidade deste método é analisar a capacidade de maximizar o poder estatístico e não estatístico (validade psicológica) das propriedades dos desenhos de RMf (Wager, Nichols, 2003). Até o momento, não há estudos na literatura com o uso deste método nas tarefas desenvolvidas por Posner (1980).

Outro passo importante relacionado com a caracterização da relação entre o disparo neuronal e a mensuração no sinal de RMf é avaliar a linearidade da mensuração do sinal BOLD na resposta da estimulação neural (Birn et al., 2001). A característica básica da resposta para estímulos curtos é não linear, ou seja, o IET (Intervalo entre as Tentativas) deve ser igual ou maior do que 4 segundos (Glover, 1999). No método de Wagner, Nichols (2003), acima citado, há possibilidade de solucionar estas questões.

Alguns estudos têm sido realizados com a técnica de RMf visando relacionar os efeitos comportamentais da atenção com as áreas cerebrais ativadas.

Acredita-se que a atenção é uma propriedade geral de todo o cérebro, mas estudos feitos com neuroimagem têm demostrado áreas importantes para a atenção.

Petersen e Posner (2012), Posner et al. (2006) descreveram regiões específicas relacionadas com a atenção, como as redes de alerting, orienting e executive (Figura 2). As redes e áreas neuronais envolvidas com o alerting podem ser observadas no tálamo, no córtex parietal posterior e no córtex frontal. A rede de orienting envolve as áreas do colículos superior, pulvinar do tálamo, junção temporoparietal, lobo parietal superior e campo ocular frontal. Por último, a rede de executive está relacionada com as áreas do giro do cíngulo anterior e o córtex préfrontal. 


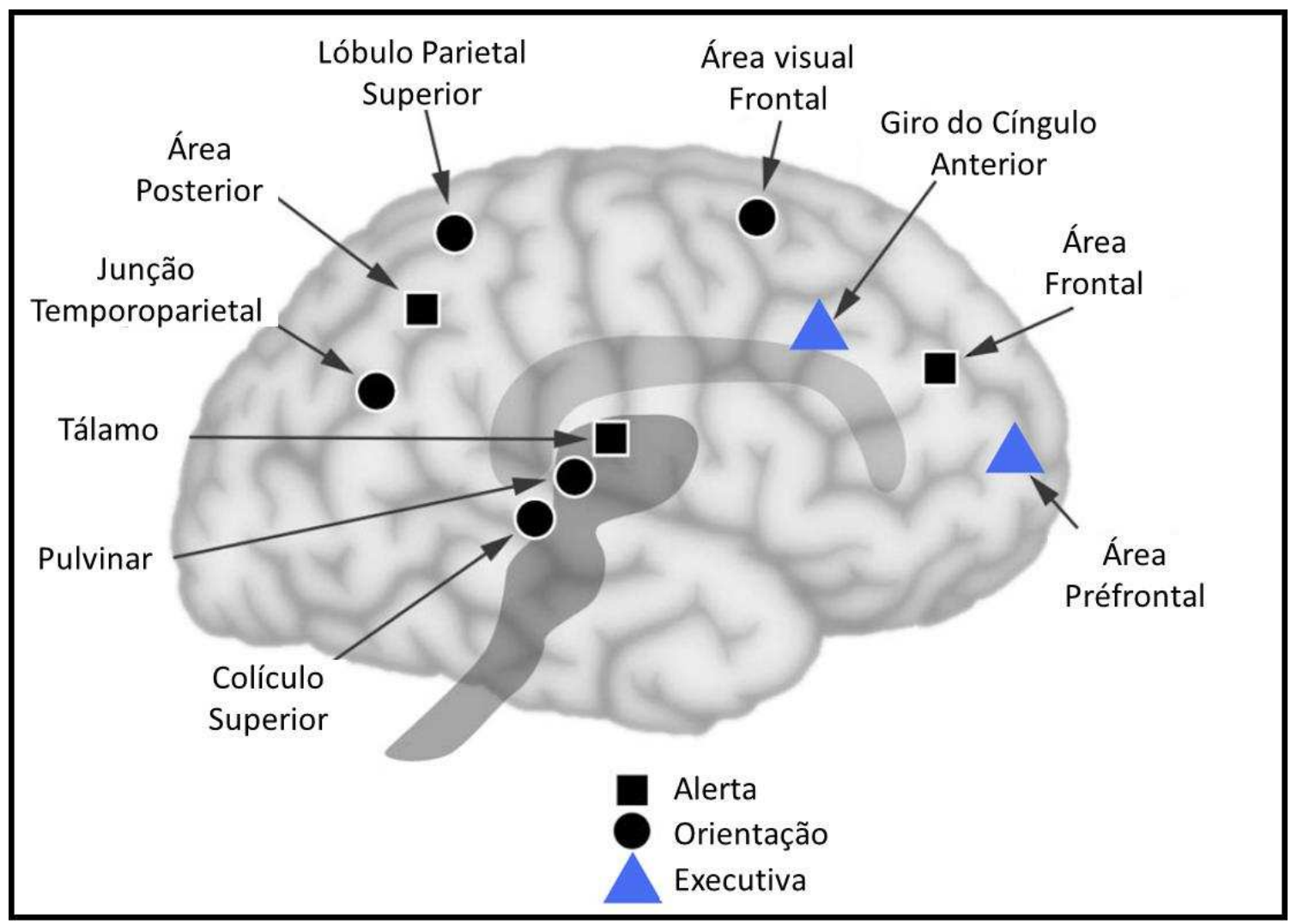

Figura 2. Áreas corticais envolvendo as três redes atencionais: alerting, orienting e executive (Posner et al., 2006). Utilização autorizada pelo autor.

Redes cerebrais fronto-parietais tem sido demonstradas como importantes para a orientação da atenção espacial, embora não haja um consenso sobre a existência de um único sistema atencional ou de dois sistemas atencionais anatomicamente e funcionalmente diferentes, envolvendo a Atenção Automática e a Atenção Voluntária.

Uma visão comum na literatura no que se refere a orientação da atenção automática e a orientação da atenção voluntária é que estas consistem em orientar um único sistema atencional e os dois modos estão em competição contínua para controlar a atenção (Godijn, Theeuwes, 2002; Yantis, Jonides, 1990). Em cada momento, o vencedor da competição entre atenção automática e voluntária determina o local para o qual a atenção será direcionada (Chica et al., 2013)

Vários autores encontraram evidências de que as mesmas áreas estão envolvidas com orientação da atenção automática e com orientação da atenção voluntária (Kim et al., 1999; Nobre et al., 1997; Pellen et al., 2004; Rosen et al., 1999). 
Kim et al. (1999), realizando um desenho experimental em bloco, demonstraram uma rede neural comum para os testes de atenção. Os componentes desta rede incluía o córtex parietal posterior, área pré-motora lateral (campo ocular frontal), giro do cíngulo, tálamo, estriado, e adicionalmente, a área motora suplementar, córtex temporooccipital, giro temporal médio e inferior, a ínsula anterior e o córtex pré-frontal dorsolateral.

Pellen et al. (2004) demonstraram a mesma rede neural para ambos os tipos de atenção, mas com o desenho experimental relacionada à eventos. A rede frontoparietal estava envolvida, consistindo na ativação do córtex pré-motor, córtex parietal posterior, córtex frontal medial e córtex frontal inferior direito.

Uma possibilidade diferente a ser considerada é que a atenção automática e atenção voluntária são mediadas por dois sistemas atencionais diferentes, ou seja, dependeriam de redes neurais distintas (Berger et al., 2005; Briand, Klein, 1987; Corbetta et al., 2008; Corbetta, Shulman, 2002; Hahn et al., 2006; Kincade et al., 2005; Klein, Hansen, 1990; Lu, Dosher, 2000; Prinzmental et al., 2005; Riggio, Kirsner, 1997; Umiltá et al., 1991).

Na revisão clássica, de Corbetta e Shulman (2002), descreveu-se evidências de que os diferentes sistemas atencionais participavam de redes neurais distintas que interagiam entre si (Figura 3a). O primeiro sistema, conhecido como atenção voluntária, estava relacionado com as redes frontoparietal dorsal bilateral, incluindo córtex parietal posterior (ao longo do sulco intraparietal) e córtex frontal (campo ocular frontal). O outro sistema, também conhecido como atenção automática, estava envolvido com as redes frontoparietal ventral direita, que incluía o córtex temporoparietal (junção temporoparietal) e o córtex frontal ventral (giro frontal inferior e giro frontal médio).

Corbetta e Shulman (2002) propuseram um Modelo Neuroanatômico do Controle Atencional (Figura 3b). De acordo com este modelo, o primeiro sistema rede frontoparietal dorsal bilateral - estaria envolvido no controle voluntário da atenção, e as áreas do sulco intraparietal e do campo ocular frontal estariam relacionadas com a seleção do estímulo/resposta direcionada a um objetivo.

O segundo sistema - rede frontoparietal ventral - estaria fortemente lateralizado para o hemisfério cerebral direito. Seria responsável pela detecção de estímulos relevantes e trabalharia como um mecanismo de alerta. Este circuito envolveria o primeiro sistema, quando o estímulo é detectado fora do foco de 
processamento (local não atendido). Desta forma, nesta situação, dependeria de uma interação entre a junção temporoparietal e do sulco intraparietal. As outras áreas - giro frontal inferior e giro frontal médio - poderia estar envolvidas na avaliação de novos estímulos (Corbetta, Shulman, 2002).

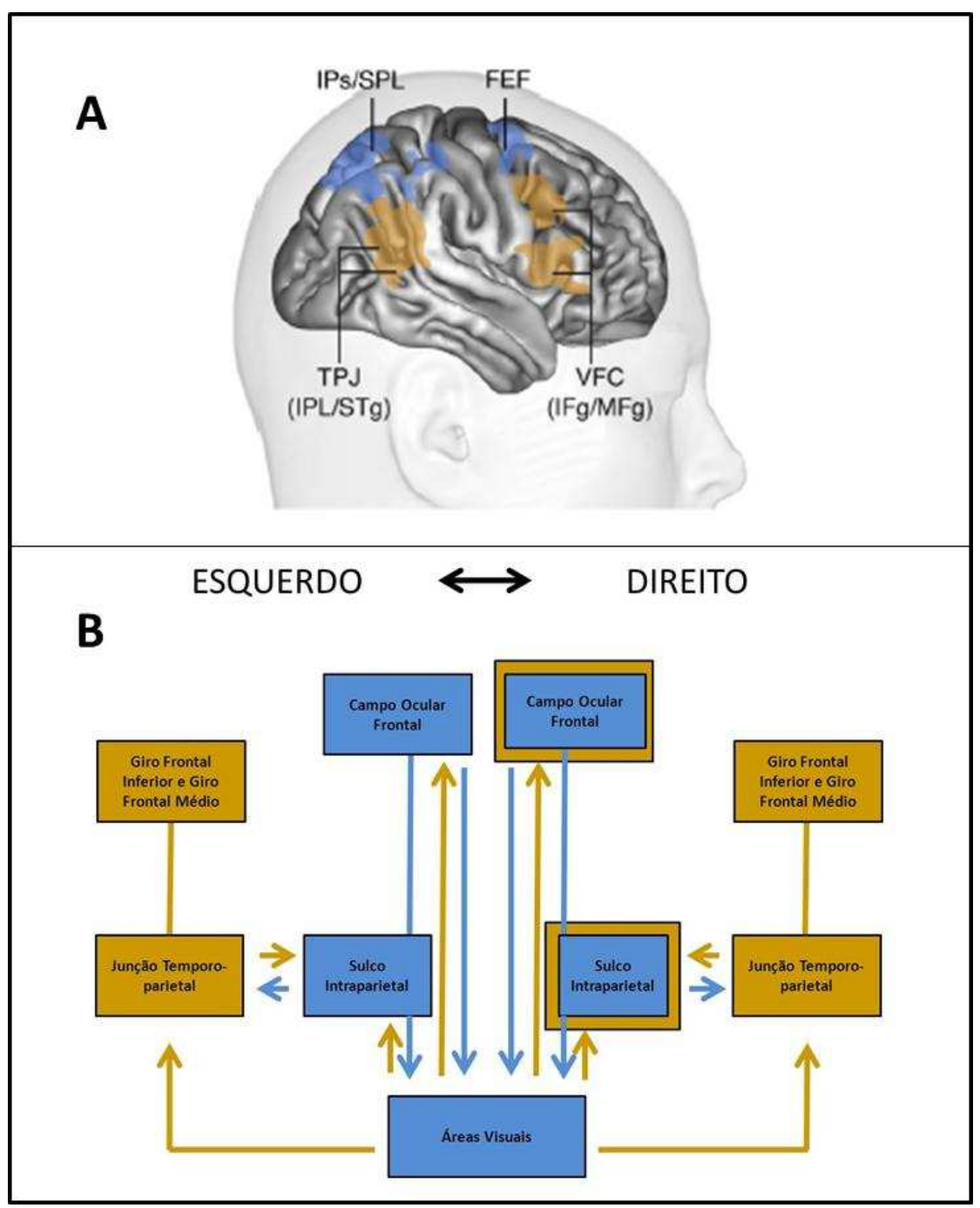

Figura 3. Modelo Neuroanatômico do controle atencional. (A) Áreas em azul indica a rede frontoparietal dorsal representada pelo campo ocular frontal, lobo parietal superior e sulco intraparietal. Áreas em marrom indica a rede frontoparietal ventral representada pela junção temporoparietal (lobo parietal inferior e giro temporal superior) e córtex frontal ventral (giro frontal inferior e giro frontal médio). FEF frontal eye field (campo ocular frontal), IPs - intraparietal sulcus (sulco intraparietal), SPL - superior parietal lobule (lobo parietal superior), TPJ temporoparietal junction (junção temporoparietal), IPL inferior parietal lobule (lobo parietal inferior), STG - superior temporal gyrus (giro temporal superior), VFC ventral frontal cortex (córtex frontal ventral), IFg - inferior frontal gyrus (giro frontal inferior), MFg - middle frontal gyrus (giro frontal médio). (B) Modelo Neuroanatômico do controle da atenção voluntária e da atenção automática (Figura A retirada do artigo de Chica et al., 2013 e a Figura B modificada do artigo de Corbetta, Shulman, 2002). 
A avaliação destes dois sistemas é um desafio às técnicas de neuroimagem. Quanto estes autores postulam relações de precedência e papéis específicos em nós destes sistemas, atingem os limites das técnicas atuais, baseadas em medidas de associação e não de causalidade. Por outro lado, extrapolam relações com base em experimentos onde técnicas convergentes mostram ser plausível a segregação de subfunções atencionais em áreas distintas no cérebro.

Existem alguns estudos na literatura pontuando aspectos, ou hipóteses, derivadas deste modelo neuroanatômico. Um estudo comparou o efeito BOLD das redes neurais da atenção automática e voluntária, utilizando uma metodologia que separa o sinal neural relacionado com a pista e o sinal neural relacionado com o alvo. Neste estudo, observou-se áreas diferentes de ativação para os diferentes testes de atenção. Na atenção voluntária, com a presença da pista, estavam envolvidas as redes frontoparietal dorsal bilateral (sulco intraparietal e campo ocular frontal), as redes frontoparietal ventral (giro supramarginal e giro frontal inferior), córtex occipital lateral e giro fusiforme anterior. $\mathrm{Na}$ presença do alvo inválido foi observado o envolvimento do campo ocular frontal e o giro supramarginal. $\mathrm{Na}$ atenção automática, com a presença da pista, estiveram presentes as redes frontopariental dorsal, córtex occipital lateral, giro fusiforme anterior e giro temporal médio. Na presença do alvo inválido, o campo ocular frontal também estava envolvido com a reorientação da atenção (Kincade et al., 2005).

Hahn et al. (2006) demonstraram que as redes neurais envolvidas na orientação da atenção automática eram áreas temporais (junção temporoparietal bilateral, ínsula anterior e posterior direita, giro fusiforme bilateral), áreas frontais (giro do cíngulo e giro pré-central direito) e áreas occipitais (giro lingual e cúneos). $\mathrm{Na}$ orientação da atenção voluntária, diferentes áreas estariam envolvidas: parietais (sulco intraparietal esquerdo, lobo parietal superior e inferior esquerdo), frontais (giro frontal médio, incluindo o sulco frontal superior bilateral) e occipitais (giro occipital médio bilateral).

Em investigação recente, os participantes podiam manter a atenção focada para um objeto ou reorientar a atenção para outro local. Quando a atenção era focada para um objeto foi considerado que a atenção estava sustentada e a rede frontoparietal dorsal participava deste processo. Foi possível observar a ativação no sulco intraparietal, lobo parietal superior, campo ocular frontal e nas regiões do córtex occipital. Por outro lado, quando a atenção não permanecia no foco 
provocava ativação nas regiões ventrais, como no giro supramarginal, giro temporal superior e córtex pré-frontal médio e inferior. Quando um evento importante e não esperado acontecia, era evocada a reorientação da atenção e ambas as regiões dorsal e ventral estavam ativadas (Corbetta et al., 2008).

Os estudos descritos acima observaram redes neurais semelhantes e distintas no que se refere aos testes de atenção automática e voluntária.

Mesmo com algum grau de discordância, um recente trabalho de revisão da literatura nos leva a entender que há duas redes neurais distintas envolvendo a atenção automática e voluntária (Chica et al., 2013).

\subsection{Objetivo Geral}

O objetivo deste estudo é identificar áreas cerebrais envolvidas em tarefas de mobilização da atenção voluntária e automática com Ressonância Magnética Funcional relacionada à eventos.

\subsection{Objetivos Específicos}

- Verificar o tempo de reação e a acurácia nos experimentos de atenção automática e da atenção voluntária;

- Verificar a presença do efeito de validade da pista para ambos os experimentos;

- Verificar a fixação ocular durante os experimentos de atenção automática e voluntária, com o uso do eye tracker;

- Analisar as imagens de RMf comparando as condições válida > neutra; inválida > neutra; válida > inválida, e inválida > válida para cada experimento separadamente;

- Analisar as imagens de RMf comparando as condições de base (válida, neutra e inválida) da atenção automática versus atenção voluntária;

- Verificar quais as áreas cerebrais identificadas por RMf participam de tarefas de atenção automática e voluntária nas condições válida, neutra e inválida.

\subsection{Hipóteses}

Acreditamos que as redes neurais envolvidas com a orientação da atenção automática e da atenção voluntária são distintas. Nossa hipótese neuroanatômica, 
nos testes de atenção automática, está relacionada com o envolvimento das redes frontoparietais ventrais à direita (junção temporoparietal, giro frontal médio e giro frontal inferior), e nos testes de atenção voluntária com as redes frontoparietais dorsais bilaterais (lobo parietal superior, campo ocular frontal e sulco intraparietal). Também esperamos encontrar um aumento no tempo de reação no experimento de atenção voluntária em comparação com o experimento de atenção automática.

\subsection{Motivação}

A relevância do presente estudo se deve ao fato de que no Brasil, até o momento, não há evidências de estudos atencionais utilizando o paradigma de Posner (1980) associados ao método de Ressonância Magnética funcional (de alto campo - 3T) integradas com a técnica de eye tracker. Além disso, tivemos a chance de realizar algumas adaptações do desenho experimental para melhorar o poder estatístico dos dados analisados em relação aos dados da literatura.

Nosso desafio foi realizar um estudo de alta tecnologia e custo, de uma maneira não invasiva, para contribuir com o conhecimento sobre o funcionamento cerebral humano. $O$ interesse principal foi contribuir para esclarecer quais áreas cerebrais envolvidas com a orientação da atenção espacial em condições específicas para testar seus compontentes automáticos e voluntários. 


\section{MATERIAIS E MÉTODOS}

O projeto foi aprovado pelo Comitê de Ética e Pesquisa com Seres Humanos do Instituto de Ciências Biomédicas da Universidade de São Paulo, sob o número 982 em 14 de dezembro de 2010.

\subsection{Participantes}

A amostra foi constituída da população de 20 alunos de graduação, com idades entre 18 e 35 anos, de ambos os sexos, da Universidade de São Paulo e da Faculdade de Ciências Sociais e Agrária de Itapeva. Todos os sujeitos participaram voluntariamente da pesquisa e receberam a ajuda de custo para serem transportados ao setor de Ressonância Magnética do Instituto de Radiologia da Faculdade de Medicina da Universidade de São Paulo. O recrutamento dos sujeitos foi realizado através do preenchimento de uma lista de interesse, divulgada em salas de aula, nas instituições citadas acima, para a participação desta pesquisa.

Abaixo se encontram os critérios aplicados para a seleção da amostra utilizada no presente estudo.

\section{Critérios de Inclusão}

- Adultos jovens e saudáveis;

- Destros, de acordo com o questionário de Edinburgh;

- Visão normal ou corrigida para o normal;

- Sem experiência prévia com este tipo de teste e nem conhecimento dos objetivos do experimento;

- Preenchimento do Termo de Consentimento Livre e Esclarecido;

- Presença do efeito de validade na tarefa comportamental durante o treino;

- $80 \%$ de acertos no treino da tarefa comportamental. 


\section{Critérios de Exclusão}

- Participantes que apresentam contra-indicação ao exame de ressonância magnética, tais como: marca-passo, clipe metálico, cirurgias cranianas, implante coclear, prótese de ouvido, claustrofobia, segundo Shellock (2001);

- Uso de medicamento que pode provocar sonolência e/ou dificuldade de concentração;

- Histórico de doenças neurológicas, casos de epilepsia, neurocirurgia, traumas craniados, depressão, entre outras alterações avaliadas durante a entrevista (descrito adiante);

- Histórico de dependência química;

- Participantes que realizaram mais de $10 \%$ de movimentos oculares (sacadas) durante os Experimentos, no aparelho de Ressonância Magnética.

- Presença de artefatos que causem alterações no campo magnético ou quaisquer fontes de variação da susceptibilidade magnética;

Os critérios de seleção foram realizados pela entrevista pessoal, preenchimento de questionários e escalas no setor de Ressonância Magnética.

Os voluntários participaram da entrevista, dos testes comportamentais e do exame de Ressonância Magnética na mesma sessão (Figura 4).

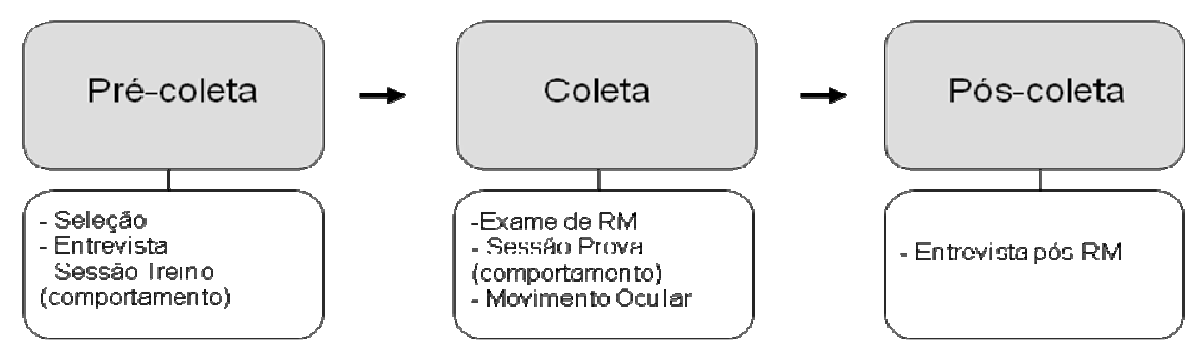

Figura 4. Fluxograma do desenho experimental.

\subsection{Entrevista: questionários e escalas}

Antes da entrevista, todos os voluntários foram solicitados a leitura e preenchimento do Termo de Consentimento Livre e Esclarecido (Apêndice A). Durante a entrevista foram aplicados os seguintes questionários e escalas: 


\section{Dados Pessoais}

Os dados pessoais foram coletados através do questionário de identificação (Apêndice B), consistindo das seguintes informações: nome, sexo, peso, altura, data de nascimento, telefone, e-mail, escolaridade, ocupação, medicação atual, crise convulsiva, alimentação antes do exame, realização anterior do exame de ressonância magnética, apresenta algum fator que possa impossibilitar a realização do exame (clipe metálico, prótese dentária, prótese de ouvido, marca-passo, cirurgias cranianas, doença neurológica, alteração psiquiátrica entre outros).

\section{Classificação socioeconômica}

A avaliação da classificação socioeconômica foi realizada através do preenchimento dos itens de conforto familiar e a instrução do chefe da família que consistem em diferentes pontos. O critério classifica o participante em uma das 8 classes econômicas (A1, A2, B1, B2, C1, C2, D e E). Os critérios foram elaborados com base no levantamento Sócio Econômico da Associação Brasileira de Empresas de Pesquisa (ABEP, 2012). Vide avaliação e as pontuações, respectivamente no Apêndice $C 1$ e no Apêndice $C 2$.

\section{Questionário de Edinburgh}

O índice de lateralidade (IL) foi determinado utilizando o Questionário de Edinburgh (Oldfield, 1971). Os voluntários foram instruídos a marcar a sua lateralidade, de doze atividades, de acordo com a sua preferência, tais como: escrever, desenhar, jogar uma pedra, usar uma tesoura, entre outros. Deverão ser assinaladas duas cruzes (++), em caso de preferência absoluta para um lado. Em caso de preferência de apenas um lado, mas esporadicamente utiliza-se o outro, marcam-se duas cruzes (++) e uma cruz (+) nas colunas apropriadas. Quando a preferência for indistintamente para os dois lados, marcam-se duas cruzes (++) nas duas colunas (Apêndice D).

O IL foi calculado somando-se um ponto para cada cruz assinalada e aplicando-se a fórmula: IL (D-E) / (D+E). Os voluntários foram considerados como destros com a pontuação de $+0,30$ até $+1,00$. 


\section{Acuidade Visual}

A acuidade visual foi testada por meio da identificação correta de letras ou números presentes em uma tabela de leitura posicionada a $50 \mathrm{~cm}$ de distância dos olhos, também conhecida como tabela de leitura para perto (Tabela de Jaeger). Vide Apêndice E.

\section{Daltonismo}

Os voluntários foram submetidos ao Teste de Ishihara para daltonismo. O teste consistiu na apresentação de um cartão com vários círculos com cores ligeiramente diferentes. Alguns círculos estavam agrupados no centro do cartão de forma a exibir um número que somente será visível pelos sujeitos que possuem visão normal (Apêndice F). A finalidade do uso deste teste foi apenas para deixar a amostra o mais homogênea possível.

\section{Inventário para depressão de Beck}

O inventário para depressão de Beck (Apêndice G) é um questionário que consiste em 21 grupos de afirmações. O voluntário deverá marcar um círculo ao redor do número na afirmação que descreve melhor a maneira em que está se sentindo. Deverá ser considerada a semana anterior da entrevista até o dia da entrevista (adaptado para uso local Gorenstein, Andrade, 1996; Gorenstein et al., 1999).

Foi feito um escore global a partir da soma dos escores individuais atribuídos a cada item. Quando foi marcada a resposta SIM na questão 19, o escore deste item não foi somado ao escore total. Os pontos de corte utilizados para o inventário de depressão de Beck foram: (Kendall et al., 1987) menor que 15: normal; 16 a 20: indicativo de disforia; maior que 20: indicativo de depressão. Este questionário foi utilizado apenas como critério de exclusão dos participantes com depressão.

\section{Avaliação do Estado de Saúde}

Apenas para um controle do estado geral dos indivíduos foram feitas 20 perguntas relacionadas as condições de saúde. Os voluntários tinham que responder SIM, caso estivessem de acordo com a afirmativa, ou NÃO, caso não concordassem com a pergunta em questão (Apêndice $\mathrm{H}$ ). 


\section{Avaliação da Enfermagem}

Antes dos voluntários iniciarem o exame de RM, todos foram obrigatoriamente entrevistados pela equipe de enfermagem. Nesta entrevista, os indivíduos foram questionados sobre as condições de saúde e uso de objetos que pudessem causar algum dano ao sujeito e/ou equipamento. Após esta avaliação, todos foram orientados a usar as vestimentas adequadas para a realização do exame.

\section{Escala Visual Analógica de Humor - VAMS pré e VAMS pós RMf}

A Escala Analógica de Humor (Visual Analog Mood Scale-VAMS) é composta por 16 itens de dois estados emocionais antagônicos (Zuardi, Karniol, 1981; Parente et al., 2005 - adaptado para uso local - Guimarães, 1998). O participante marcava o estado emocional no momento da avaliação em uma linha de 10 centímetros que representa uma escala. Os itens são agrupados em 4 fatores: Ansiedade, Sedação, Prejuízo Cognitivo e Desconforto. A aplicação desta escala teve como objetivo mensurar a variação do humor do participante antes (Apêndice I) e depois do exame de RMf (Apêndice J).

As marcações foram medidas para cada linha da esquerda para direita. $O$ valor ponderado dos Itens 4, 6, 8, 9, 10, 12, 14, 16 foi computado valor ponderado = 10 menos a medida obtida. Para os itens $1,2,3,5,7,11,13,15$ o valor ponderado = medida obtida. Cada valor ponderado é multiplicado por seu respectivo peso, descritos na Tabela 1.

Tabela 1. Peso dos itens da Escala Visual Analógica de Humor.

\begin{tabular}{cccccccc}
\hline Item & Peso & Item & Peso & Item & Peso & Item & Peso \\
\hline 1 & 0,77782 & 5 & 0,64236 & 9 & 0,79269 & 13 & 0,69215 \\
2 & 0,79684 & 6 & 0,75456 & 10 & 0,79314 & 14 & 0,70477 \\
3 & 0,58922 & 7 & 0,56842 & 11 & 0,59093 & 15 & 0,72303 \\
4 & 0,69263 & 8 & 0,74407 & 12 & 0,78759 & 16 & 0,64888 \\
\hline
\end{tabular}

Finalmente, os fatores são calculados a partir do resultado dos valores ponderados somando-se os itens através das fórmulas:

Fator ansiedade $=2+8+10$

Fator sedação $=9+12+6+4+16+5+3$

Fator prejuízo cognitivo $=1+11$

Fator desconforto $=15+14+13+7$ 


\section{Entrevista pós RMf}

No final da coleta de dados de RMf, foram realizadas perguntas estruturadas sobre a dificuldade sentida ao longo do procedimento, desconforto e condições gerais da avaliação (Apêndice K).

\subsection{Tarefa Comportamental}

Os voluntários realizaram duas sessões de testes no mesmo dia.

A primeira sessão, chamada treino (fora do equipamento de Ressonância Magnética), foi composta por 42 tentativas para o teste de atenção automática e por 43 tentativas para o teste de atenção voluntária. Esta teve como finalidade familiarizar os voluntários com as condições experimentais e inseri-los ou não para a próxima etapa do estudo. Os voluntários foram incluídos se apresentassem o efeito atencional em ambas as tarefas e se o número de erros fosse menor do que $20 \%$. A duração total desta sessão foi de 15 minutos.

Antes de iniciar esta sessão, os voluntários receberam as instruções do teste por escrito (Apêndice L) e depois oralmente no interior da sala de testes. Eles realizaram 20 tentativas não registradas, antes de iniciar a primeira sessão, com a finalidade de avaliar a compreensão das instruções dadas.

A segunda sessão, chamada de prova (dentro do equipamento de Ressonância Magnética Funcional), foi composta por 3 runs (conjunto de tentativas) para o teste de atenção automática (com 42 tentativas no primeiro run, 45 tentativas no segundo e 40 tentativas no terceiro) e 3 runs para o teste de atenção voluntária (com 43 tentativas no primeiro run, 41 tentativas no segundo e 43 tentativas no terceiro). A sessão prova, no teste de atenção automática, teve duração de 15 minutos, com 5 minutos para cada run. $\mathrm{O}$ teste de atenção voluntária teve a mesma duração que 0 teste de atenção automática.

O número de tentativas e a pseudorandomização das condições nos diferentes testes foram realizadas através da otimização dos algoritmos genéticos, criada por Wager e Nichols (2003). Veja o Apêndice M.

$\mathrm{Na}$ sessão treino, os voluntários foram testados sentados, orientados para manter a cabeça posicionada e os olhos a uma distância de aproximadamente 57 $\mathrm{cm}$ da tela de um notebook. Foram apresentados estímulos visuais nesta tela. 
O braço direito dos voluntários ficou posicionado sobre uma mesa, que possuía duas teclas. Eles mantinham seus dedos indicador e médio apoiados em uma tecla superior e outra inferior, respectivamente.

A geração e o registro das respostas aos estímulos foram realizados por um notebook e um programa elaborado com o aplicativo E-prime ${ }^{\circledR}$ v 1.1 (Psychology Software Tools, inc, Sharpsburg - Pensilvânia, Estados Unidos, http://www.pstnet.com/eprime.cfm).

A posição dos voluntários e o movimento ocular foram monitorados pelo experimentador dentro da sala de experimentos.

\section{Procedimento}

Metade dos voluntários realizou primeiramente os testes de atenção automática e a outra metade realizou o teste de atenção voluntária.

\section{- Atenção Automática}

No teste de atenção automática havia a presença de um Ponto de Fixação (PF) no centro da tela; um losango ao redor do PF; demarcações representadas por 2 anéis (uma do lado direito e outra do lado esquerdo); estímulo precedente (E1) representado por um brilho nas demarcações; e um estímulo alvo (E2) representado por uma linha vertical (Figura 5).

Cada tentativa era iniciada com o aparecimento de um losango (com perímetro quadrado de 1,4 graus e 0,06 graus de borda) e um PF central na tela vazio (com 0,10 graus), por $800 \mathrm{~ms}$, e de um anel a esquerda e outro a direita do PF (com 0,54 graus de diâmetro e 0,06 graus de borda), estes permaneciam na tela durante todo 0 teste, exceto o PF vazio.

Depois aparecia um E1, representado por um brilho de um dos anéis do lado esquerdo ou do lado direito do PF (com 0,10 graus de borda). Este E1 tinha duração de $100 \mathrm{~ms}$. Ainda, depois deste era apresentadoo E2, representado por uma linha vertical (com 0,21 graus de comprimento e 0,06 graus de largura). O E2 tinha uma duração de $50 \mathrm{~ms}$. Entre a apresentação do E1 e E2 havia um Intervalo entre os Estímulos (IEE), ou seja, havia uma Assincronia entre o Início dos Estímulos (AIE) de $150 \mathrm{~ms}$. Em 1/3 das tentativas, havia uma condição neutra (que podemos considerar como uma condição controle), representada pela ausência do E1. Nos outros 2/3 restantes, havia a condição válida em metade das tentativas (o E2 
apareceu na mesma posição do E1) e a condição inválida na outra metade das tentativas (o E2 apareceu na posição oposta ao E1). Os voluntários tinham $1000 \mathrm{~ms}$ para responder ao E2 e foram instruídos a responder tão rápido quanto possível à linha vertical à esquerda com o dedo indicador direito e à linha vertical à direita com o dedo médio direito. Havia um Intervalo entre as Tentativas (IET) de 4, 10 e 16 segundos. Nestes intervalos, o PF era preenchido de branco com a finalidade de sinalizar ao voluntário que o E1 e o E2 ainda não iriam aparecer. Todas as tentativas, sem contar com o IET, duravam 2 segundos. A duração e a pseudorandomização dos IET foram determinadas por meio da otimização dos algoritmos genéticos (Apêndice $M$ ).

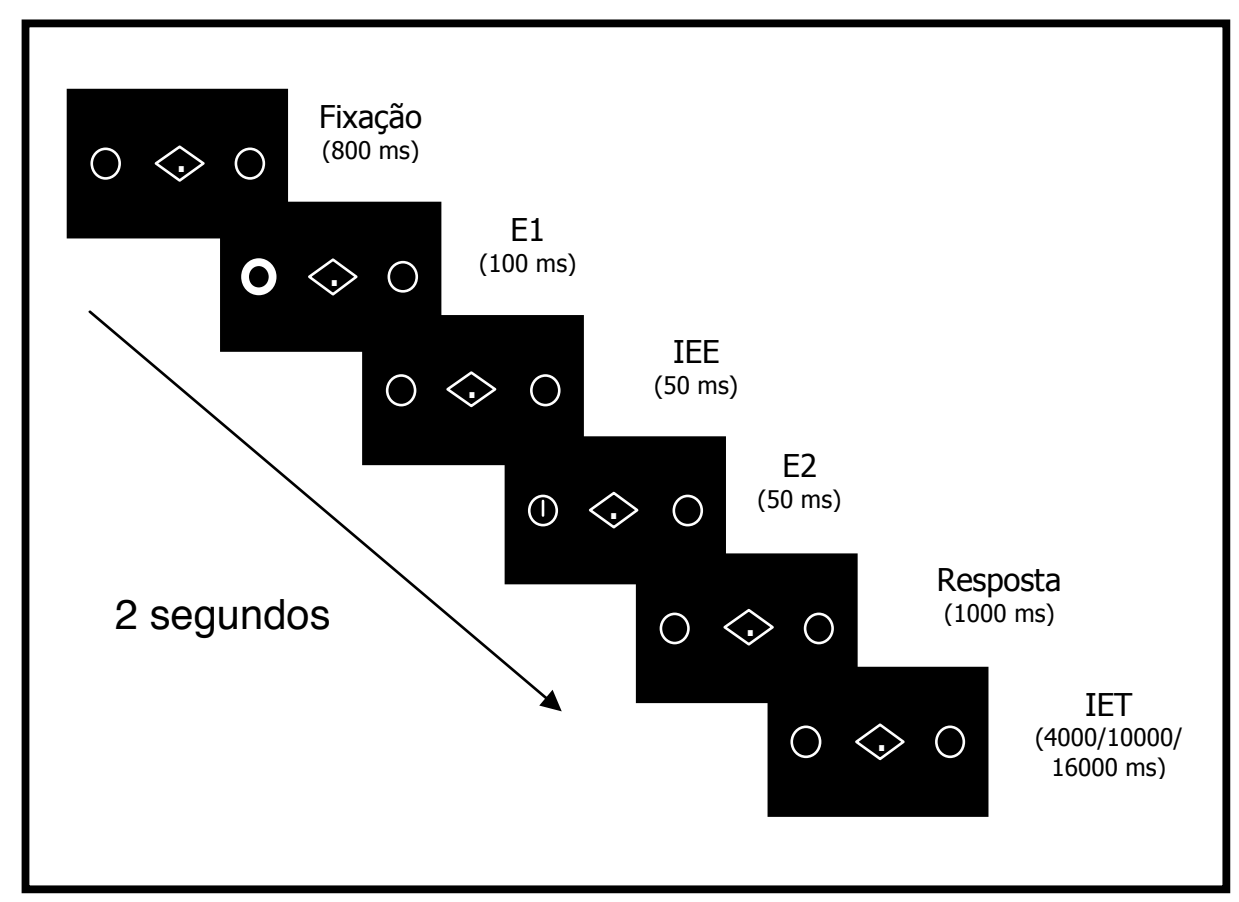

Figura 5. Condições estimulatórias do experimento de Atenção Automática. O estímulo precedente (E1) e estímulo alvo (E2) podiam aparecer do lado esquerdo ou direito do ponto de fixação. Quando o E2 apareceu na mesma posição do E1, chamamos de condição mesma, quando o E2 apareceu do lado oposto ao E1, chamamos de condição oposta, e quando não apareceu o $E 1$, chamamos de condição controle. O TR de 2 segundos representou o aparecimento da Fixação até a Resposta.

\section{- $\quad$ Atenção Voluntária}

Na sessão de teste de atenção voluntária (Figura 6), um losango permaneceu no centro da tela junto ao PF durante toda a tentativa, exceto na condição de aparecimento do E1. O E1 foi representado pela metade do losango (com a metade 
do perímetro quadrado de 0,7 graus e 0,06 graus de borda) formando uma seta à direita ou à esquerda. Um IEE foi utilizado entre o E1 e o E2, com duração de 200 $\mathrm{ms}$, ou seja, com uma AIE de $300 \mathrm{~ms}$. Os voluntários foram instruídos a orientar a atenção para o lado em que a seta apontar e responder tão rápido quanto possível à linha vertical com o dedo indicador direito e com o dedo médio direito. Em 44\% das tentativas ocorreu a condição válida (o E2 apareceu na mesma posição do E1), em $32 \%$ das tentativas ocorreu a condição controle, representada pela ausência do E1 e nos $24 \%$ restantes ocorreu a condição inválida (o E2 apareceu na posição oposta ao E1).

No restante, o procedimento foi idêntico ao do teste de atenção automática.

Foram incluídos para a sessão de imagem, apenas os voluntários que apresentaram uma porcentagem de acertos maior do que $80 \%$ e que demonstraram o efeito de validade em ambas as condições de atenção automática e voluntária na sessão treino.

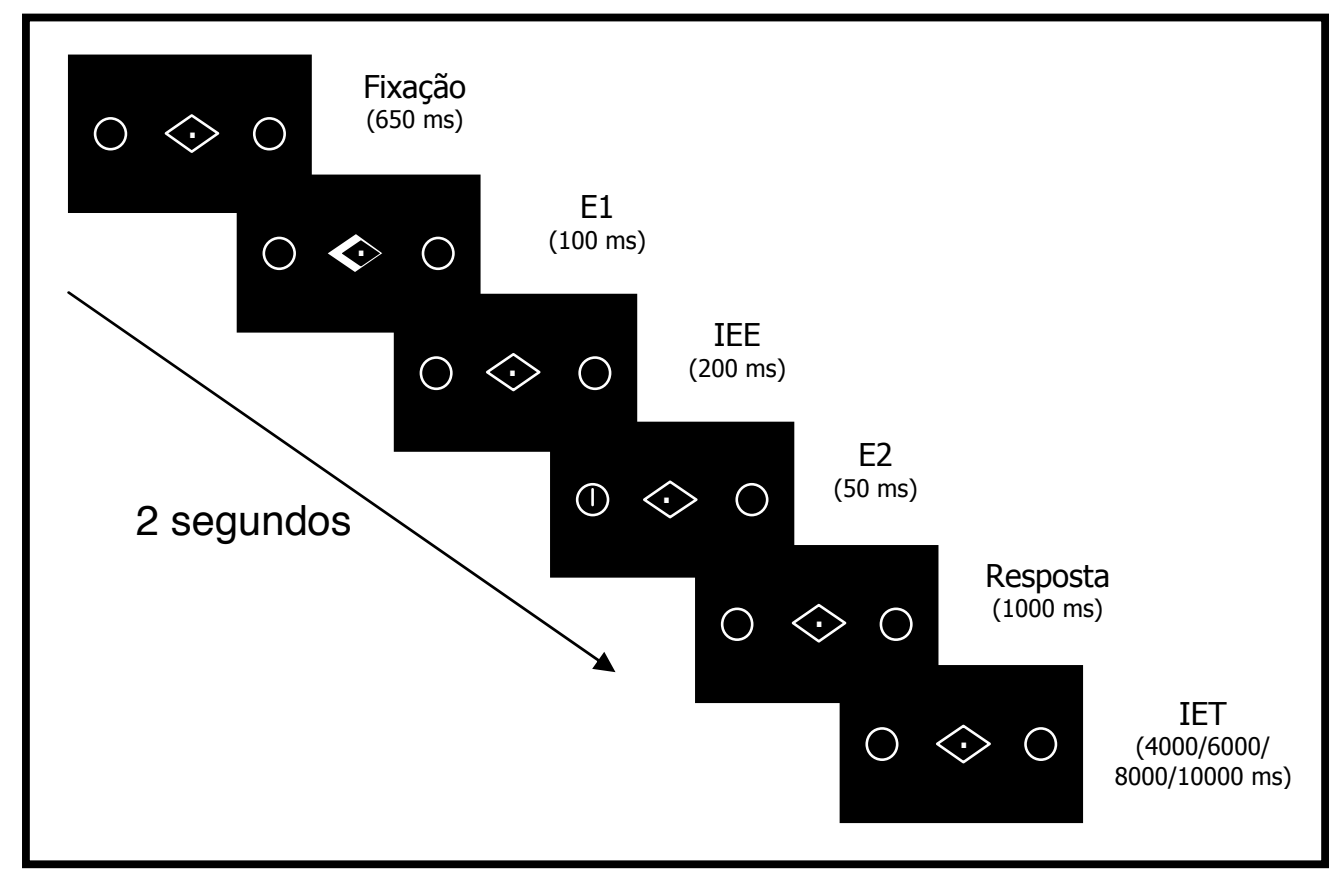

Figura 6. Condições estimulatórias do experimento de Atenção Voluntária. O estímulo precedente (E1) e estímulo alvo (E2) podiam aparecer do lado esquerdo ou direito do ponto de fixação. Quando o E2 apareceu na mesma posição do E1, chamamos de condição válida, quando o E2 apareceu do lado oposto ao E1, chamamos de condição inválida, quando não apareceu o $E 1$, chamamos de condição controle. O TR de 2 segundos representa o aparecimento do preenchimento da Fixação até a Resposta. 


\subsection{Movimentos oculares}

Os movimentos oculares foram coletados com o Eye Tracker (HCET01, Mag Design \& Engeneering, EUA), adaptado para o uso com RMf. O equipamento é composto por uma microcâmera posicionada na bobina de crânio em uma distância de 3 a 5 centímetros à frente do olho do participante. A câmera foi posicionada no olho direito, sem prejudicar a visualização dos estímulos que estavam sendo apresentados na tela de projeção. A Figura 7 mostra o posicionamento do Eye Tracker em relação ao olho do participante dentro da sala de RM.

Os movimentos oculares foram monitorados apenas no exame de RMf. por um computador, IBM-PC Compatível, localizado ao lado da sala da RM.

Tanto o computador que produzia a tarefa comportamental (E-prime) como o que registrava os dados do eye tracker (ViewPoint) estavam sincronizados entre si e com o equipamento de RM.

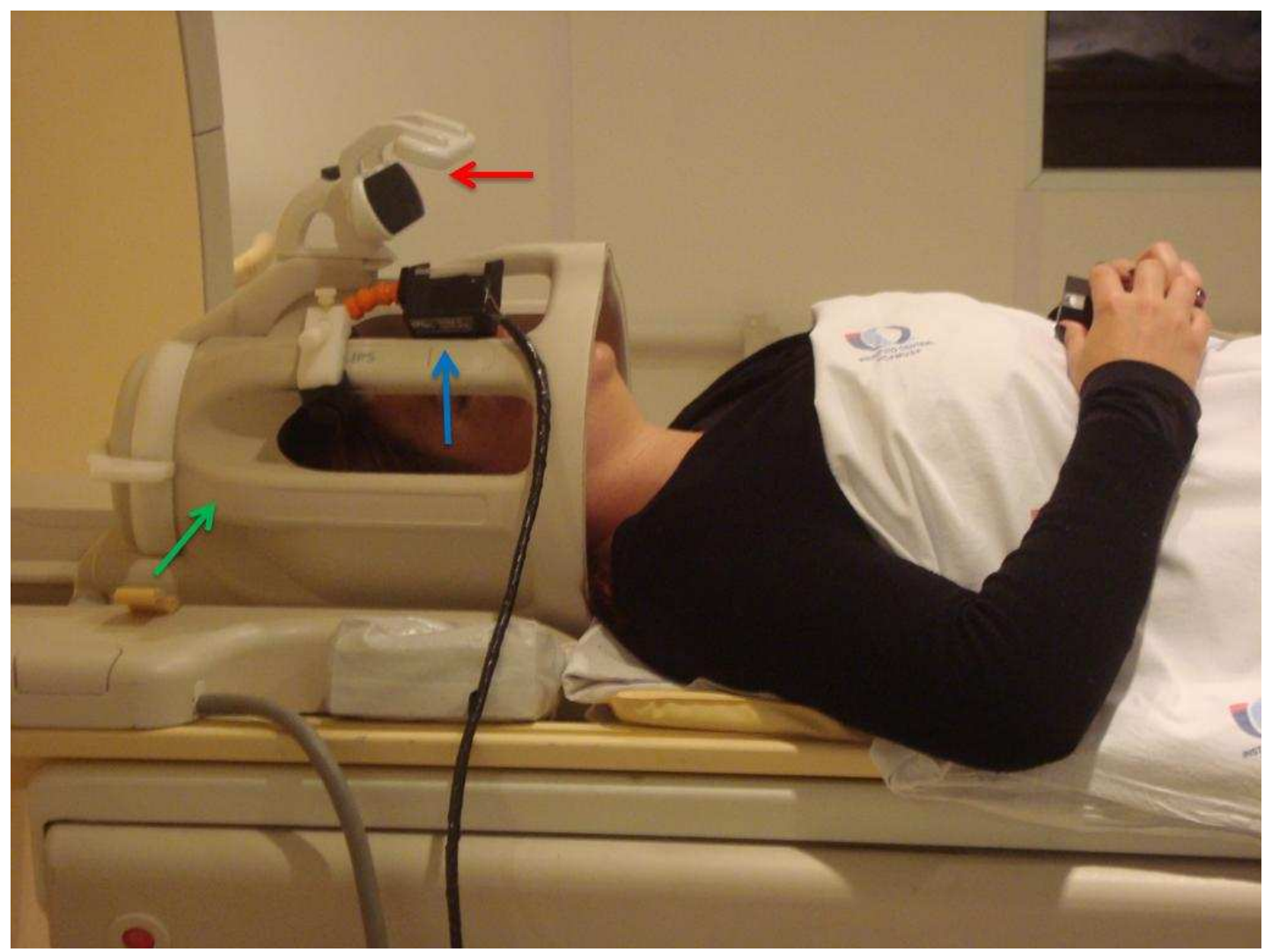

Figura 7. Posicionamento do Eye tracker na Ressonância Magnética (seta azul), posicionamento do espelho refletor (seta vermelha) e posicionamento da bobina de crânio (seta verde). 
A câmera do eye tracker, assim como o cabo de sinal, contém blindagem adequada para impedir a interferência no campo magnético.

Os sinais da câmera foram levados através de um cabo até o painel de penetração ainda no ambiente da Ressonância Magnética, onde esses sinais foram direcionados para um computador armazenar e processar esses dados (fora da sala da Ressonância).

Uma luz Infravermelha (IV), produzida por dois LED (Light Emitting Diode) na câmera do eye tracker, ilumina a pupila do voluntário gerando uma "pupila escura" (dark pupil). Através de um dispositivo de controle, localizado fora do ambiente de RM, é possível ajustar a precisão da "dark pupil", da iluminação do IV e adequar a relação do sinal/ruído da imagem (Figura 8).

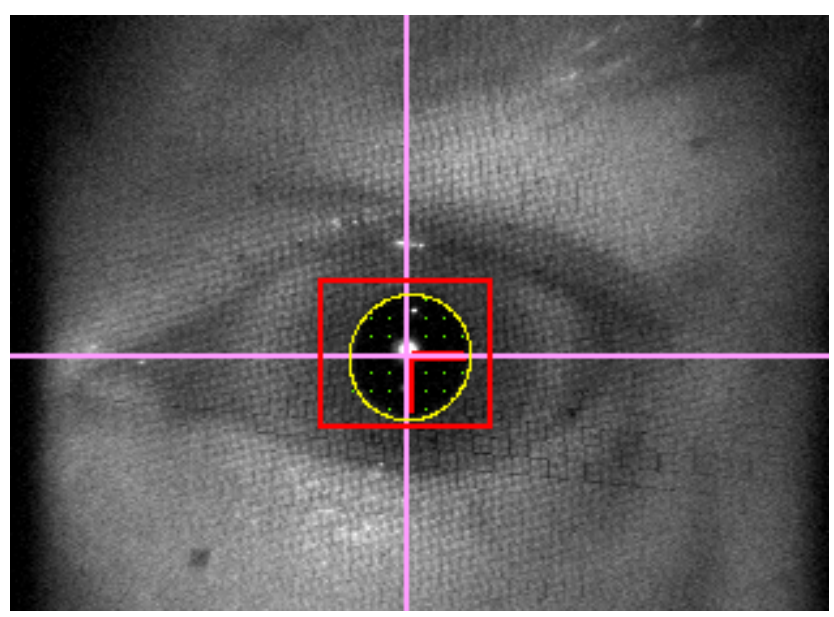

Figura 8. Imagem da delimitação da pupila "dark pupila".

As imagens da pupila foram processadas pelo programa ViewPoint (versão 5, Arrington Research, EUA). Nesta tela é possível verificar algumas janelas (Figura 9):

- Janela EyeCamera: Imagem do olho. Utilizado para ajustar os parâmetros que tornam a pupila mais fácil de distinguir e rastrear.

- Janela EyeSpace: Usado para a calibração dos movimentos oculares. Foram apresentados 16 pontos para a calibração do equipamento (formando uma grade), antes que os voluntários iniciassem a tarefa atencional dentro da RM (Figura 10). Caso fosse necessário, um ajuste manual em pontos específicos foi realizado, de acordo com a característica de cada participante. Para 
facilitar a calibração e reduzir os dados processados, foi feito uma delimitação apenas da pupila.

- Janela Controls: Usado para controlar diferentes parâmetros do equipamento.

- Janela Status: Fornece informações úteis durante a gravação de dados.

- Janela GazeSpace: Mostra um traçado para onde o sujeito está olhando em todos os momentos.

- Janela PenPlot: Monitora informações úteis sobre a direção dos movimentos oculares, assim como as piscadas.

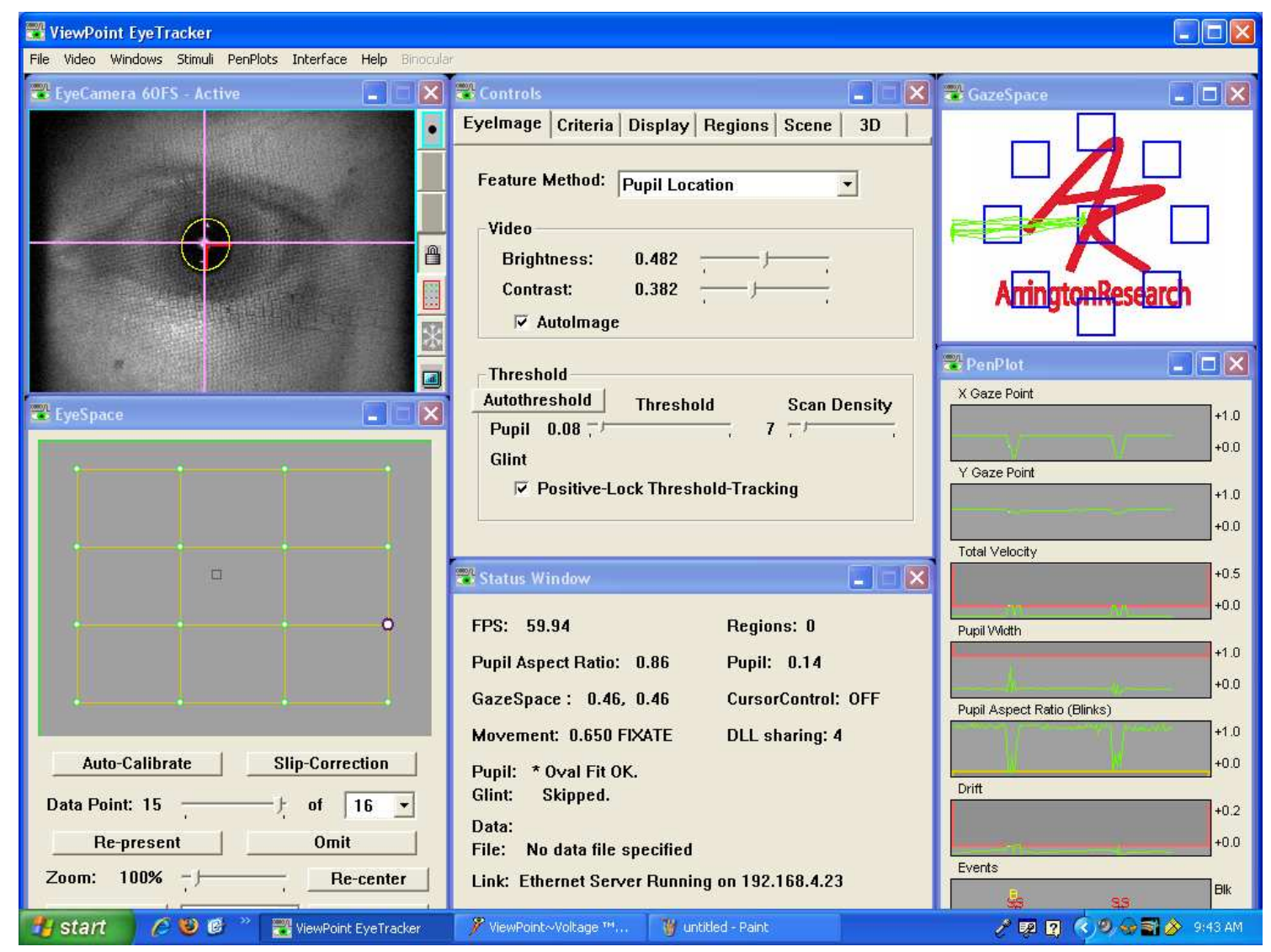

Figura 9. Janelas do programa ViewPoint.

Em toda a coleta de dados, um pesquisador monitorava os movimentos oculares de todos os participantes, na sala situada fora da RM. Quando a pupila deslocava-se da grade era necessário realizar a correção da posição da pupila através do "slip correction". Essa alteração comumente ocorria por um movimento mínimo da cabeça. 


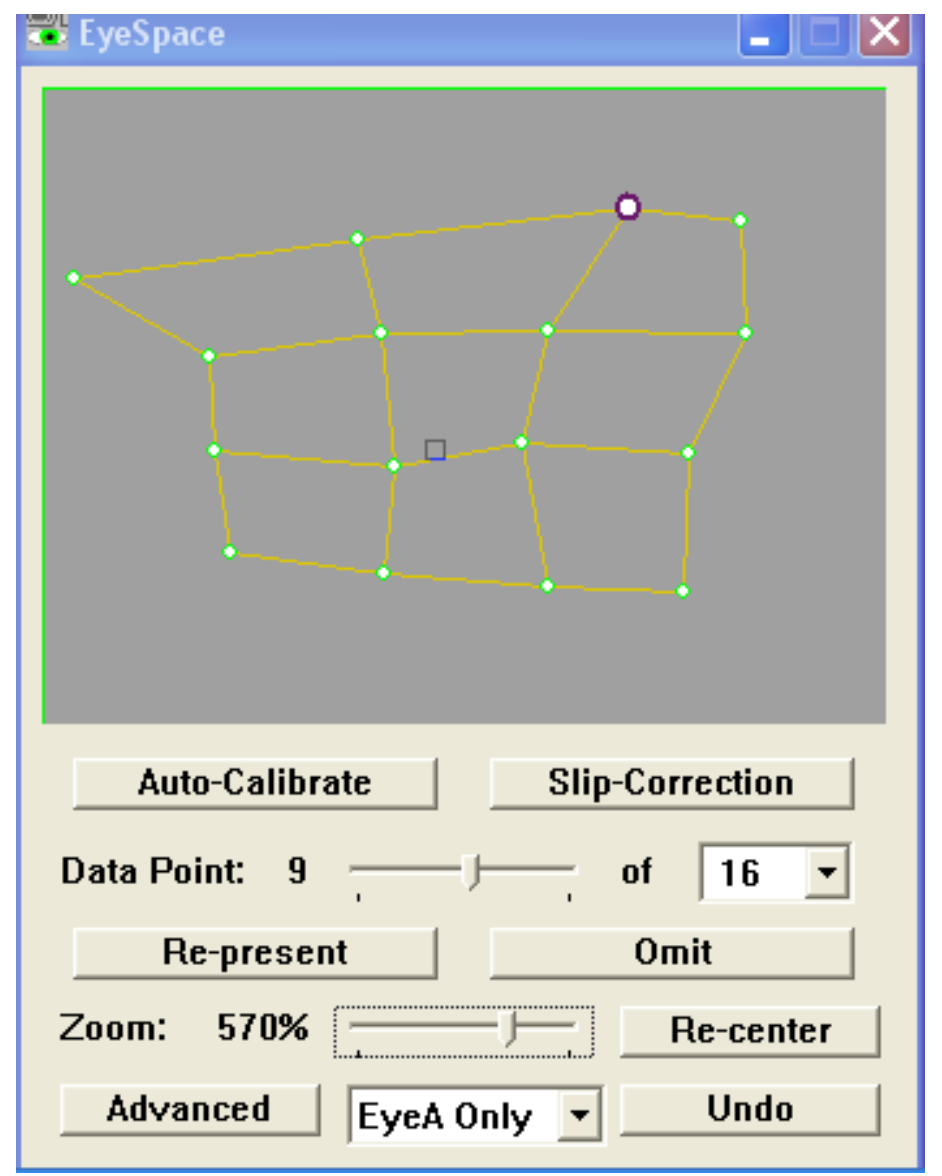

Figura 10. Grade de calibração do eye tracker, com 16 pontos, mostrando a posição da pupila representada por um quadrado pequeno.

Todos os dados do eye tracker foram registrados em um programa txt.

\subsection{Ressonância Magnética (RM)}

Os testes foram realizados no mesmo aparelho de RM 3 Tesla Achieva (Philips - Holanda), do Serviço de RM Instituto de Radiologia - Inrad - do Hospital das Clínicas $(\mathrm{HC})$ da Faculdade de Medicina da Universidade de São Paulo (FMUSP).

Esta máquina teve o seu comportamento aferido ao longo do estudo através de controle de qualidade diário. Este procedimento específico para RMf é baseado no modelo descrito por Simmons et al. (1999). 


\subsubsection{Posicionamento dos voluntários}

Para o exame de RM (estrutural e funcional), os voluntários estavam deitados, sendo adotadas as medidas de contenção leve de movimentos desde a fase inicial até o final dos experimentos. Tais medidas constam de duas fitas adesivas na região frontal da cabeça e dois coxins de espuma fixado nas laterais, proporcionando boa imobilização do segmento cefálico, sem causar desconforto. Aos participantes foi solicitado que permaneçam imóveis, principalmente no segmento cefálico, durante a aquisição das imagens. Ao final do posicionamento, a mesa de RM foi deslocada para o interior do equipamento alcançando o isocentro do magneto.

\subsubsection{Parâmetros de Aquisição das Imagens de RM}

Os voluntários foram submetidos a uma sequência de imagem estrutural, onde ficaram imóveis durante o exame e uma sequência funcional, onde realizaram algumas tarefas na RM. A sequência estrutural foi utilizada apenas para uma inspeção visual, em caso de lesões.

\section{Sequência estrutural}

1. Localização: seqüência de localização em 3 planos, com 5 cores em cada um, $\mathrm{Tr}=$ shortest, $\mathrm{TE}=$ inphase, $\mathrm{t}=$ 0:30.3s, Matrix $256 \times 128$, Espessura: $10 \mathrm{~mm}$, Espaçamento: $10 \mathrm{~mm}$. Caso haja necessidade de reposicionamento, a seqüência será repetida.

2. Calibração: $\mathrm{Tr}=4 \mathrm{~ms}$, $\mathrm{TE}=0,79 \mathrm{~ms}$, Matrix: $96 \times 49, F O V=450 \mathrm{~mm}, \mathrm{t}=00$ : 29s.

3. Volumétrica SPGR com aquisição axial, $\operatorname{Tr}=7 \mathrm{~s}, \mathrm{TE}=3,2 \mathrm{~ms}$, Matrix: $240 \mathrm{x}$ 240, FOV 240 mm, Flip: 8 graus, Fatias: 180 incluindo todo o segmento cefálico, $t=$ 5: $58 \mathrm{~s}$.

4. Flair axial: $T r=11000 \mathrm{~ms}, T E=130 \mathrm{~ms}, I R=2800, F O V=230 \mathrm{~mm}$, Espessura $=5 \mathrm{~mm}$, Espaçamento $=0,5 \mathrm{~mm}, 20$ níveis, $\mathrm{t}=3: 18 \mathrm{~s}$.

5. Sagital FFE: $\operatorname{Tr}=6,0 \mathrm{~ms}, \mathrm{TE}=2,4 \mathrm{~ms}$, Matrix $=272 \times 273, \mathrm{FOV}=160 \mathrm{~mm}, 20$ fatias, Flip $=45$ graus, $\mathrm{t}=00: 51 \mathrm{~s}$. 


\section{Sequência funcional}

As aquisições foram realizadas através de uma sequência T2 ecoplanar (EPI) com aquisição de imagens do cérebro inteiro. Os parâmetros otimizados foram: $\mathrm{Tr}$ $2000 \mathrm{~ms}$, TE $30 \mathrm{~ms}$, Espessura de $3 \mathrm{~mm}$, Espaçamento de 0,3 mm, FOV $240 \mathrm{~mm}$ e Matrix $80 \times 80$, com 38 fatias, precedidas de 5 Tr's referentes ao decaimento do sinal T1 (para evitar efeito de saturação até atingir o estado de equilíbrio), 150 volumes e tempo de 5:08 s para cada run (3 runs para atenção automática e 3 runs para atenção voluntária).

\subsubsection{Instrumentos para coleta de dados comportamentais na RMf}

A maioria dos instrumentos utilizados no ambiente da Ressonância Magnética foi produzida pela empresa Zurc \& Zurc Data Comercial e Serviços Ltda-Me (São Paulo, Brasil), com materiais adequados para que não houvesse qualquer tipo de interferência na imagem da RM. Para a apresentação dos estímulos de forma sincronizada com a aquisição das imagens de RMf utilizou-se:

- Projetor de vídeo multimídia: para a apresentação visual nos testes atencionais, posicionado na sala de comando (fora do ambiente de RM), conectado ao computador. As imagens foram projetadas, através da janela, para a tela que ficou na sala do magneto de RM.

- Espelho refletor: acoplado na bobina de crânio, que permite a visualização dos estímulos na tela de projeção na posição decúbito dorsal. A distância entre o espelho e os olhos do voluntário mede aproximadamente de 10 a $15 \mathrm{~cm}$. Vide Figura 7.

- Tela de projeção: confeccionada de material não ferromagnético, posicionada no interior da sala do magneto, a uma distância de $263 \mathrm{~cm}$ do centro do espelho (acoplado na bobina de crânio). A tela mede $65 \mathrm{~cm}$ de comprimento por 48 $\mathrm{cm}$ de largura e foi observada pelo voluntário por um jogo de espelhos no interior da bobina.

- Caixa trigger: dispositivo com a finalidade de sincronizar com precisão a aquisição da imagem de RMf com o computador. O trigger, quando programado, recebe um sinal do aparelho de RM que indica quando a imagem está sendo adquirida, então o trigger envia um pulso de sincronização ao computador de 
apresentação dos estímulos. Neste computador, um programa executável, no caso o e-prime, aguarda este sinal para iniciar a apresentação dos estímulos.

- Botões de respostas: adaptados ao ambiente de RM, foram utilizados para avaliação das respostas comportamentais. A interface de comunicação foi feita através do painel de apresentação do aparelho de RM e conectado ao computador de apresentação dos estímulos. Os botões de respostas foram posicionados na mão direita do voluntário. Eles foram instruídos a responder tão rápido quanto possível à linha vertical com o dedo indicador direito (botão superior) e com o dedo médio direito (botão inferior). Os dados coletados pelo botão de resposta foram enviados para o programa E-prime ${ }^{\circledR}$ (Psylabs, EUA).

- Computador de apresentação de estímulos: posicionado na sala de comando e conectado ao projetor multimídia, ao trigger e aos botões de respostas, permitindo a sincronização precisa dos estímulos com a aquisição das imagens e a coleta de respostas comportamentais.

- Microcâmera Eye Tracker: O movimento ocular foi monitorado através de uma microcâmera, já mencionada anteriormente.

\subsubsection{Paradigma de RMf}

Na sequência de RMf, os voluntários realizaram os experimentos de atenção automática e de atenção voluntária, no mesmo dia e com duração máxima de 15 minutos cada.

Metade dos voluntários realizou, primeiramente, os testes de atenção automática e a outra metade os testes de atenção voluntária. Estes testes foram descritos anteriormente.

\subsection{Análise dos resultados}

\subsubsection{Entrevista: questionários e escalas}

A análise dos resultados dos questionários e escalas aplicados durante a entrevista foi descrita anteriormente. 


\subsubsection{Tarefa Comportamental}

Para cada voluntário foi calculada a média das medianas dos tempos de reação para cada run, tanto para o teste de atenção automática quanto para o teste de atenção voluntária. Foi avaliado também o número de respostas antecipadas, lentas e incorretas de cada voluntário, para todos os runs.

Os dados do tempo de reação foram submetidos a uma Análise de Variância para Medidas Repetidas (ANOVA). Os fatores considerados foram o tipo de atenção (atenção automática e atenção voluntária) e a validade do estímulo precedente (válida, neutra e inválida). Quando apropriado, esses dados foram adicionalmente tratados com o teste post hoc deTukey. Foi adotado o nível de significância (alfa) de $5 \%$.

Além disso, como em nosso procedimento metade dos voluntários realizou primeiramente os testes de atenção automática e a outra metade realizou o testes de atenção voluntária pensamos se não pudesse haver interferências nos resultados para a segunda tarefa realizada. Desta forma, antes de finalizarmos $100 \%$ da coleta foi realizado um teste t para variáveis independentes de 6 sujeitos que começaram o teste de atenção automática e de 6 sujeitos que iniciaram o teste de atenção voluntária na RMf.

\subsubsection{Movimentos Oculares}

Os movimentos oculares foram analisados através de um programa em ambiente MATLAB® (Mathwork, versão 7.14.0.739).

A filtragem dos dados foi feita através do filtro Butterworth passa-baixa de quarta ordem de $8 \mathrm{~Hz}$ para todos os 3 arquivos de atenção automática e para os 3 arquivos de atenção voluntária de todos os sujeitos.

O sinal bruto foi recortado em trechos separados a partir do início da fixação até o final da resposta.

Após o recorte, foram removidos os artefatos de piscadas produzidos pelo eye tracker.

As sacadas foram detectadas quando a velocidade angular ultrapassava $60^{\circ}$ por segundo e esta velocidade era mantida por mais de $50 \mathrm{~ms}$ (3 quadros). 


\subsubsection{Ressonância Magnética}

\section{$\underline{\text { Análise de dados estruturais }}$}

A análise radiológica das imagens FLAIR (Fluid Attenuated Inversion Recovery) e VBM (Voxel Based Morphometry) foi realizada por um médico radiologista experiente. Os indivíduos com alterações neurológicas ou de imagens em uma destas sequências seriam excluídos do estudo.

\section{Análise de dados de RMf}

A análise das áreas cerebrais ativadas foi feita através do programa FSL (http://www.fmrib.ox.ac.uk/fsl/). O pacote de funções deste software consiste no uso do FEAT (FMRI Expert Analysis Tool) Versão 4.1.

Para as análises de grupo, a imagem T2 EPI de cada sujeito foi registrada no espaço padrão MNI (Montreal Neurologic Institute), com o template 152, utilizandose a ferramenta de registro linear (FLIRT). As imagens EPI de cada sessão para cada sujeito foram pré-processadas utlilizando os procedimentos de correção de movimento, suavização espacial, correção do tempo de aquisição entre as fatias, remoção de voxels em estrutruras extra-encefálicas, filtro temporal passa-alto. Os mapas de ativação individuais de cada uma das aquisições (RUN1, RUN2 e RUN3) foram obtidos por um modelo linear geral (GLM). As respostas produzidas pelo paradigma foram detectadas pela análise da série temporal de cada voxel, que, por hipótese, é a convolução da função estímulo com a função da resposta hemodinâmica canônica dada pela função Gamma (tempo para o pico 6s, desvio padrão 3s). Para atenção automática foi considerado 3 variáveis - EVs (automática válida - V, automática neutra - $\mathrm{N}$ e automática inválida - I) e 4 contrastes $(V>N, I>N$, $\mathrm{V}>\mathrm{I}$ e $\mathrm{I}>\mathrm{V}$ ). $\mathrm{O}$ mesmo foi considerado para atenção voluntária (Figura 11). 


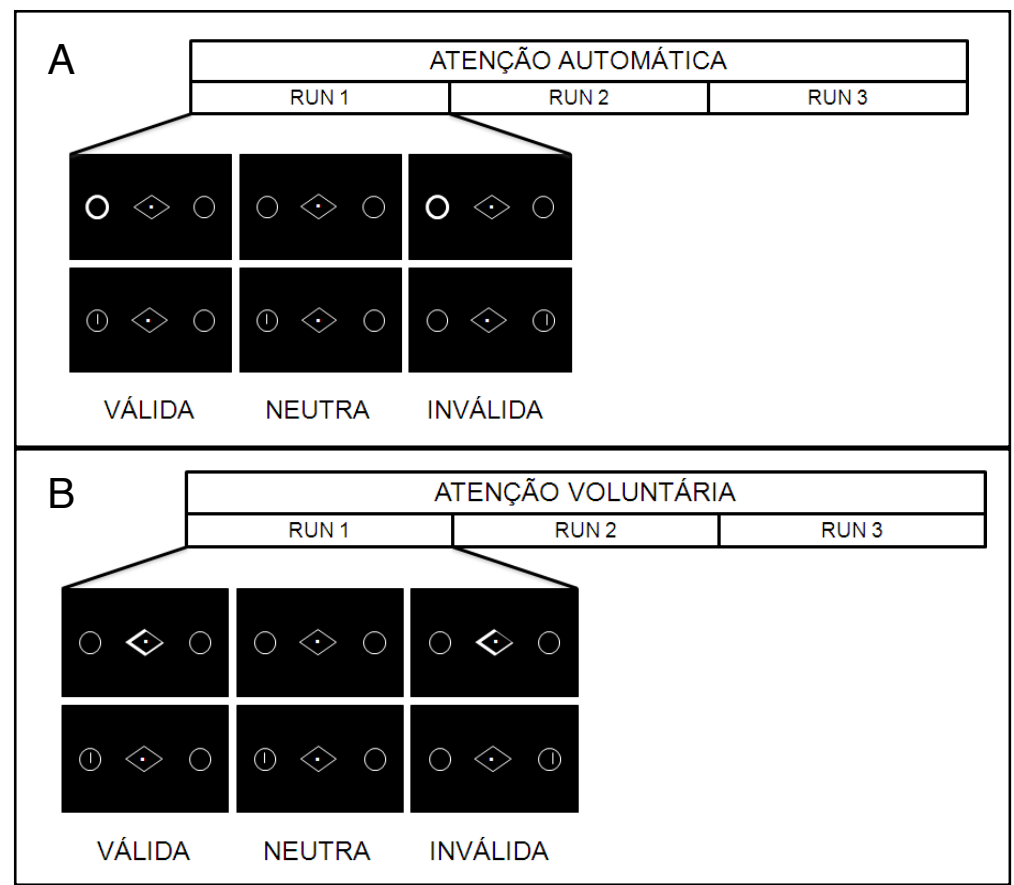

Figura 11. Variáveis consideradas na análise de dados do Experimento de Atenção Automática (A) e do Experimento de Atenção Voluntária (B).

Os mapas de ativação para RUN1, RUN2 e RUN3 foram juntados na análise de grupo para cada sujeito (fixed effect).

As análises de grupos foram realizadas considerando-se tanto a variabilidade entre os sujeitos quanto entre as sessões (mixed effects), o que possibilita generalizar os resultados para as populações das amostras estudadas.

Diferenças nas ativações entre os grupos foram avaliadas por contrastes com teste-t para amostras dependentes (atenção automática > atenção voluntária e atenção voluntária $>$ atenção automática). Para controle de resultados falso positivos, foram considerados significativos os clusters compostos de voxels sobreviventes ao limiar de $Z=2,3$ corrigidos para comparações múltiplas ao nível de significância de $p<0,05$ FWE cluster (Worsley, 2001).

Além desses mapas, analisamos as áreas que poderiam ser semelhantes entre os testes de Atenção Automática e de Atenção Voluntária através da análise de conjunção. Primeiramente, foi considerado para o mapa de Atenção Automática as 3 condições experimentais de base (válida, neutra e inválida). O mesmo procedimento foi realizado para a Atenção Voluntária. 
Após o resultado desses mapas, juntaram-se dois mapas estatísticos, de Atenção Automática e o de Atenção Voluntária, e realizou-se uma nova análise de conjunção (análise de conjunto).

A análise de conjunção foi realizada através de script do FSL (Nichols et al., 2005 ;http://www2.warwick.ac.uk/fac/sci/statistics/staff/academic-research/nichols/scripts/fs/)

Os desenhos das análises podem ser vistos no Apêndice $\mathrm{N}$.

A localização anatômica das áreas cerebrais ativadas foi representada no sistema de coordenadas $\mathrm{MNI}$, no programa fs/view, utilizando o atlas Juelich Histological Atlas e confirmada por inspeção visual de um médico neurorradiologista.

As ilustrações com os mapas das ativações foram construídas no software MRIcron (www.mricron.com, versão 12/2009). 


\section{RESULTADOS}

\subsection{Participantes}

Vinte e oito voluntários foram avaliados. Vinte voluntários foram incluídos na amostra (17 mulheres e 3 homens), com idades entre 19 e 31 anos (média: 21,7 \pm 3,4 ), seis voluntárias foram excluídas por terem errado mais de $25 \%$ das tentativas na sessão treino e outras duas foram excluídas por apresentarem artefato na imagem de Ressonância Magnética (uso de aparelho ortodôntico). Nenhum indivíduo foi excluído com alterações neurológicas. Os dados demográficos dos sujeitos são apresentados no Apêndice $O$.

\subsection{Entrevista: questionários e escalas}

A classificação socioeconômica dos participantes pertencendo à classe A2 foi de $20 \%$, às classes $\mathrm{B} 1$ e $\mathrm{B} 2$ de $30 \%$, à classe $\mathrm{C} 115 \%$ e à classe $\mathrm{C} 2$ foi de $5 \%$. $\mathrm{A}$ distribuição está representada na Figura 12.

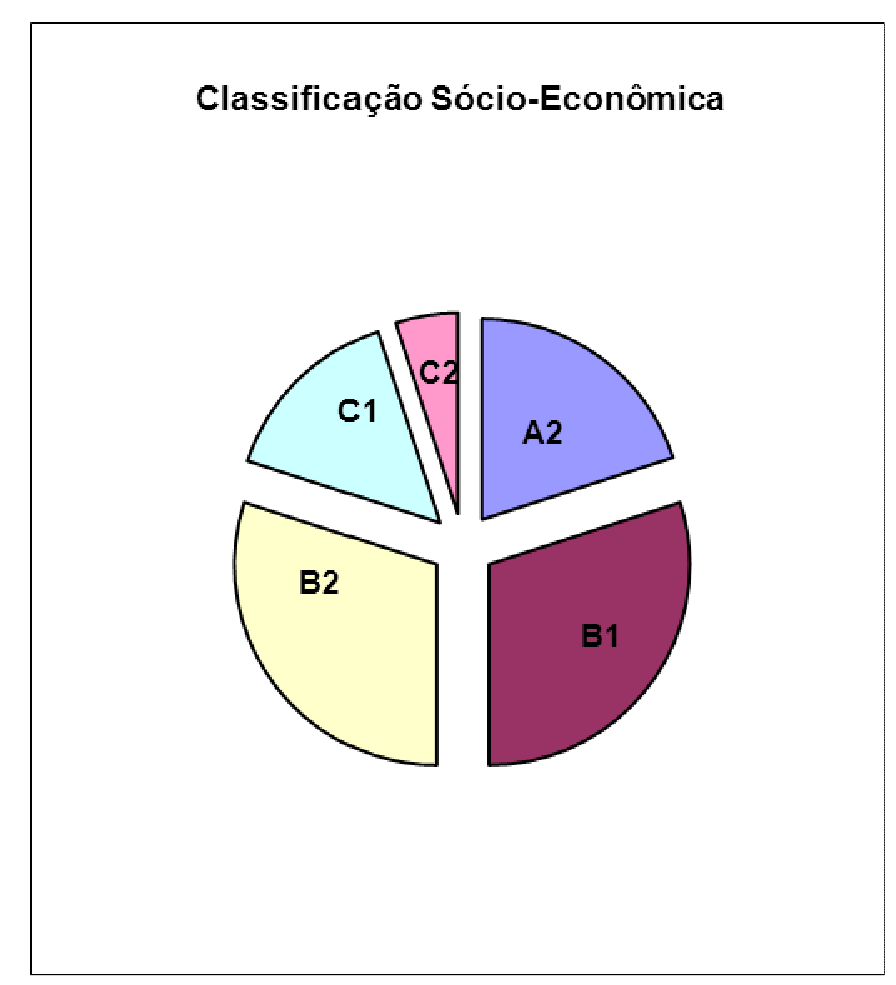

Figura 12. Distribuição dos voluntários por classificação socioeconômica. 
O índice de lateralidade manual dos voluntários incluídos foi de $0,87 \pm 0,09$.

Todos os participantes apresentaram visão normal ou corrigida para o normal com óculos compatíveis com aparelho de RM. Nenhum dos participantes era daltônico.

A avaliação do inventário para depressão de Beck teve uma média de 4,15 \pm 3,9 pontos. A pontuação mínima foi de 0 e a máxima de 13.

$\mathrm{Na}$ avaliação do Estado de Saúde a maioria dos participantes assinalou a resposta "NÃO", representando de uma forma geral condições de saúde adequadas para a realização do exame de RM. Veja com mais detalhes os resultados deste questionário no Apêndice $P$.

A Pontuação da Escala Analógica de Humor é composta pelos fatores Ansiedade, Sedação, Prejuízo Cognitivo e Desconforto. Foi realizado o teste-t pareado para comparar os fatores da escala pré e pós-exame de Ressonância Magnética.

Os resultados mostraram que não houve diferença significativa, antes e depois do exame, para os fatores ansiedade $(p=0,315)$, sedação $(p=0,490)$ e prejuízo cognitivo $(0,922)$. Para o fator desconforto, o resultado foi significativo $(p=$ 0,029), com maior pontuação após o exame. Vide tabela 2 e Figura 13.

Tabela 2. Resultados do teste-t pareado para a Escala Visual Analógica de Humor antes de depois do exame de ressonância magnética funcional. Os resultados significativos estão indicados com dois asteriscos ${ }^{* *}$ ). P, nível de significância.

\begin{tabular}{lccc}
\hline Fator & VAMS pré & VAMS pós & $\mathbf{p}$ \\
\hline Ansiedade & $8,9 \pm 0,9$ & $10,1 \pm 1,2$ & 0,315 \\
Sedação & $17,8 \pm 1,3$ & $18,8 \pm 1,7$ & 0,490 \\
Prejuízo Cognitivo & $6,8 \pm 0,4$ & $6,7 \pm 0,7$ & 0,922 \\
Desconforto & $8,3 \pm 0,9$ & $9,5 \pm 1,0$ & $0,029^{\star \star}$ \\
\hline
\end{tabular}




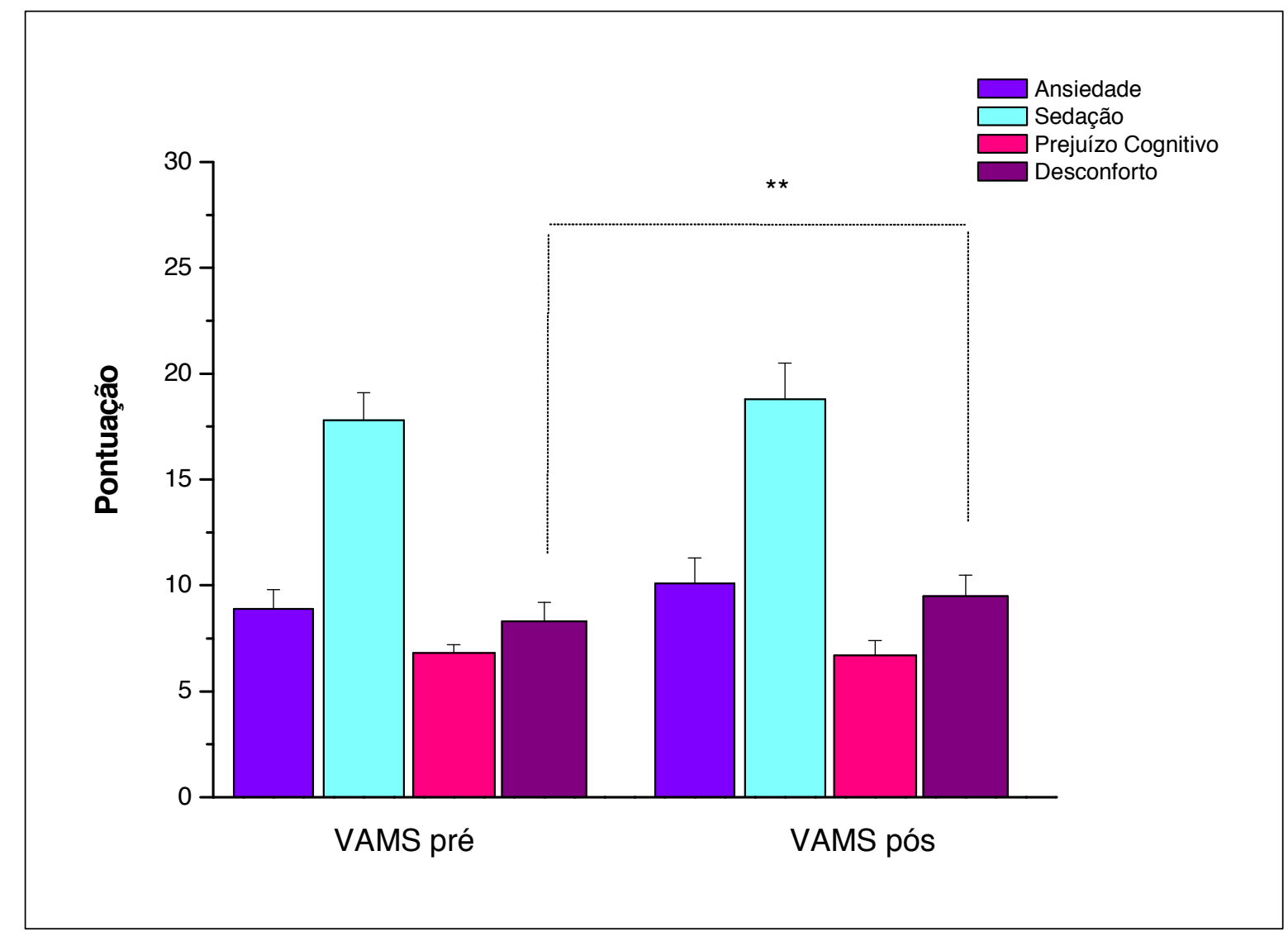

Figura 13. Média ( \pm e.p.m.) da pontuação da Escala Visual Analógica de Humor (VAMS) antes de depois do exame de ressonância magnética funcional. Os resultados significativos estão indicados com dois asteriscos $\left({ }^{* \star}\right)$.

$\mathrm{Na}$ entrevista pós-exame de Ressonância Magnética funcional algumas perguntas foram feitas. Na pergunta "Como você se sentiu de forma geral?", os voluntários responderam "bem" (5 sujeitos), "cansado" (5 sujeitos), "sono" (4 sujeitos), "irritado" (1 pessoa), "atento" (1 pessoa), "tranquilo" (1 pessoa), "desconfortável" (1 pessoa), "normal" (1 pessoa), "confuso" (1 pessoa). Perguntamos se os voluntários voltariam para fazer o exame, 15 sujeitos disseram que "SIM" e 5 disseram que "NÃO". Com relação a tarefa que acharam mais difícil, o experimento de atenção automática foi a resposta mais frequente (12 sujeitos), no experimento de atenção voluntária (4 sujeitos), dificuldade de uma forma geral (1 sujeito) e 3 não apresentaram dificuldades.

Fizemos perguntas quanto a sensação de dor ou desconforto pela posição, pontuadas de 0 (sem dor) a 10 (com muita dor). A nota 0 foi relatada pela maioria dos participantes (12 sujeitos), nota 4 (1 sujeito que apresentou desconforto nas pernas), nota 5 (1 sujeito apresentou dor de cabeça), nota 6 (2 sujeitos, 1 
apresentando dor nas pernas e o outro com dor de cabeça), nota 7 (2 sujeitos, 1 com dor na coluna e o outro com dor de ouvido) e nota 8 (1 sujeito com dor de ouvido e 1 com dor de cabeça).

Também pedimos para que os voluntários dessem uma nota de 0 (ruim) a 10 (excelente) para a impressão que tiveram do exame. A nota máxima (10) foi dada por 7 sujeitos, nota 9 (5 sujeitos), nota 8 (6 sujeitos) e a nota 7 ( 2 sujeitos).

\subsection{Tarefa Comportamental}

\subsubsection{Sessão Treino}

Nesta tarefa os voluntários realizaram apenas 1 run, com objetivo de treinarem os testes de atenção automática e voluntária e incluí-los para o exame de RMf. Como já descrito anteriormente, foram incluídos apenas os voluntários que apresentaram o efeito validade.

\section{Tempo de Reação}

O efeito principal foi obtido para a validade do E1. Ocorreu uma interação entre o tipo de atenção (automática e voluntária) e a validade do E1 (válida, neutra e inválida). Não ocorreu nenhum outro efeito principal ou interação significativa. Os resultados desta análise estão resumidos na Tabela 3 e os tempos de reação dos voluntários analisados no Apêndice $Q$.

Tabela 3. Resultados da Análise de Variância da sessão treino tendo como fatores o Tipo de Atenção (automática e voluntária), Validade do E1 (válida, neutra e inválida). Os resultados significativos estão indicados com dois asteriscos $\left({ }^{* \star}\right)$ e os marginalmente significativos com um asterisco $\left({ }^{*}\right)$. Gl, graus de liberdade. $\mathrm{F}$, razão entre o quadrado da média do efeito e o do erro. $P$, nível de significância. $E 1$, estímulo precedente.

\begin{tabular}{lccc}
\hline EFEITO & Gl & F & P \\
\hline Tipo de Atenção & 1 & 2,237 & 0,151 \\
Validade do E1 & 2 & 59,509 & $<0,001^{\star *}$ \\
Tipo de Atenção X Validade & 2 & 4,729 & $0,014^{\star *}$ \\
\hline
\end{tabular}

Não houve diferença entre os tempos de reação para atenção automática e para atenção voluntária, respectivamente $473 \pm 24$ e $456 \pm 20 \mathrm{~ms}(p=0,151)$. 
Houve diferença significativa para a validade do E1 ( $p<0,001)$. Na condição em que o E1 apareceu na posição válida, o tempo de reação foi menor do que na condição em que o E1 apareceu na posição inválida $(p<0,001)$ e na condição neutra $(p<0,001)$. Na condição em que o E1 apareceu na posição inválida, o tempo de reação não foi diferente daquele na condição neutra $(p=0,802)$. Vide Tabela 4 e Figura 14.

Tabela 4. Média ( \pm e.p.m.) dos tempos de reação para a validade do E1 nas posições válida, neutra e inválida. E1, estímulo precedente.

\begin{tabular}{lccc}
\hline Validade do E1 & Válida & Neutra & Inválida \\
\hline Média & 404 & 498 & 492 \\
e.p.m. & 21 & 23 & 22 \\
\hline
\end{tabular}

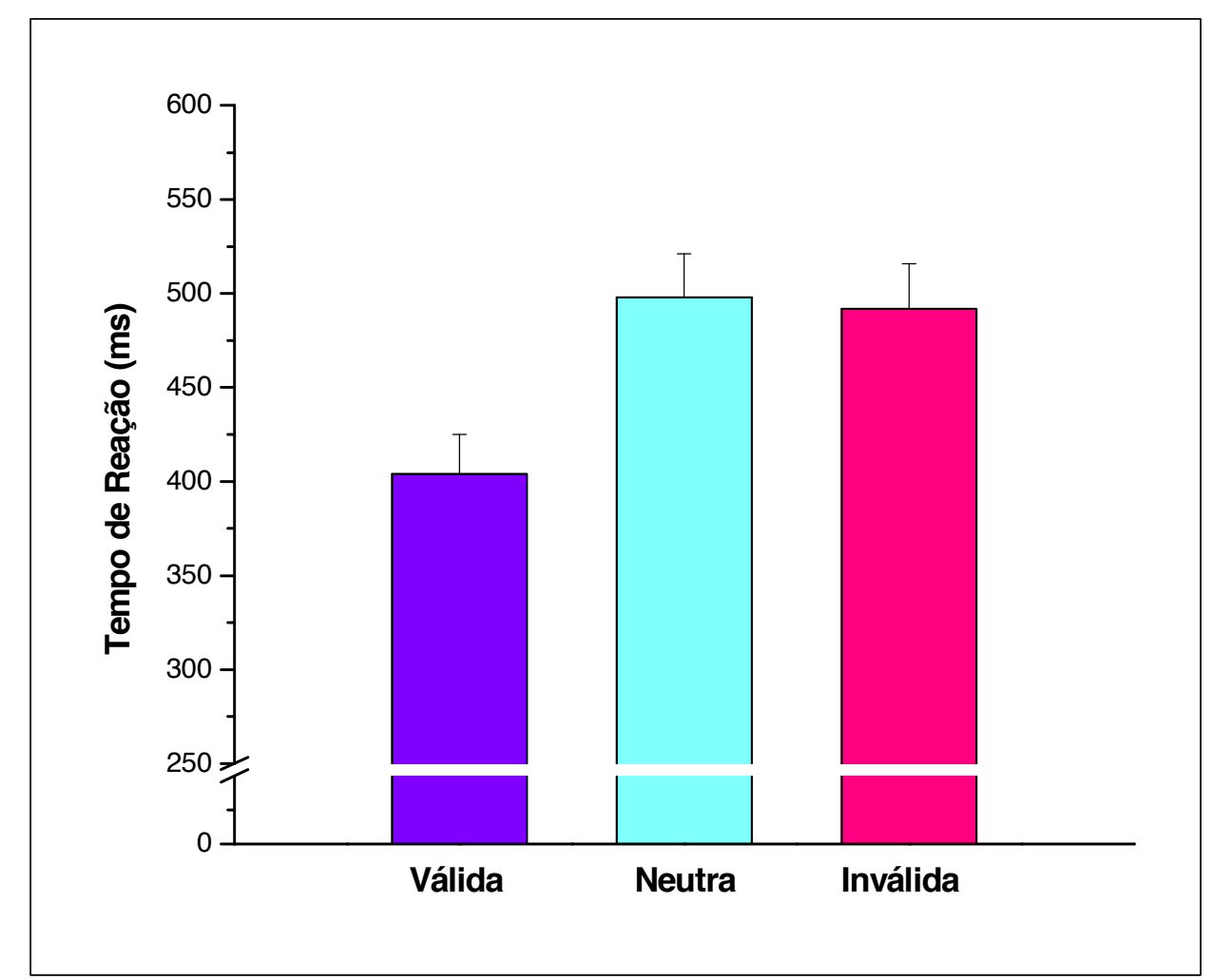

Figura 14. Média ( \pm e.p.m.) dos tempos de reação ao estímulo alvo na condição válida, neutra e inválida $(p<0,01)$,

A interação entre o tipo de atenção e a validade do $E 1$ foi significativa $(p=$ 0,014), indicando que o tempo de reação nas condições de atenção automática e voluntária dependem da validade do E1. O tempo de reação na condição inválida, 
para atenção automática foi maior do que na condição inválida, para atenção voluntária $(p=0,024)$. Não houve diferença significativa na condição válida e na condição neutra para os diferentes tipos de atenção, respectivamente $p=0,422$ e $p=0,924$. Vide Tabela 5 e Figura 15.

Tabela 5. Média ( \pm e.p.m.) dos tempos de reação para o tipo de atenção e a validade do E1 nas posições válida, neutra e inválida.

\begin{tabular}{lccc|ccc}
\hline & \multicolumn{3}{c|}{ Atenção Automática } & \multicolumn{3}{c}{ Atenção Voluntária } \\
\cline { 2 - 7 } & Válida & Neutra & Inválida & Válida & Neutra & Inválida \\
\hline Média & 416 & 492 & 512 & 393 & 504 & 472 \\
e.p.m. & 24 & 25 & 25 & 21 & 23 & 21 \\
\hline
\end{tabular}

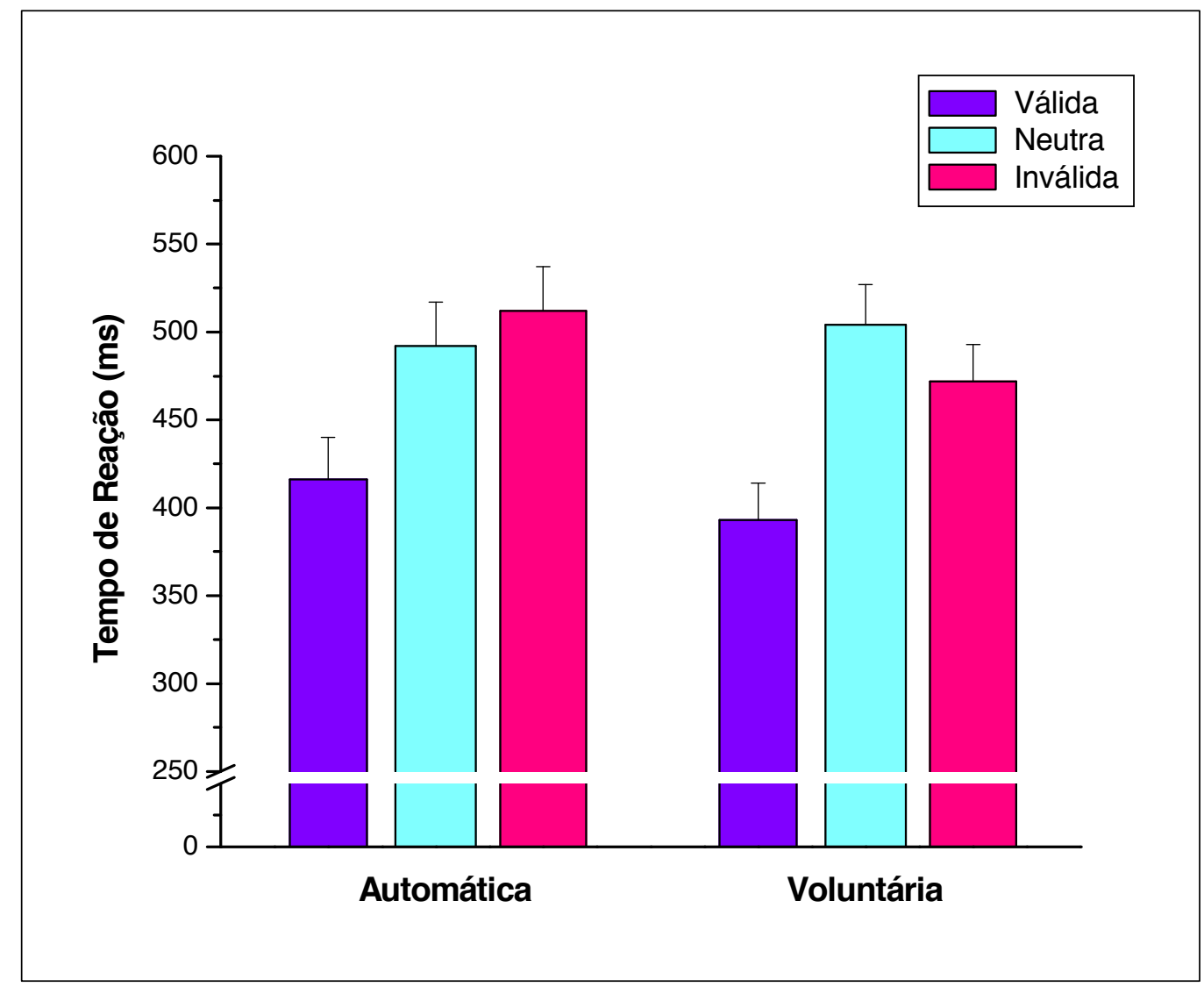

Figura 15. Média ( \pm e.p.m.) dos tempos de reação nos experimentos de atenção automática e de atenção voluntária, nas condições válida, neutra e inválida. Os resultados significativos estão indicados com dois asteriscos $\left({ }^{* \star}\right)$. 


\section{Atenção Automática}

O tempo de reação na condição válida foi menor do que na condição inválida $(p<0,001)$ e na condição neutra $(p<0,001)$. Não houve diferença significativa entre os tempos de reação na condição inválida e na condição neutra ( $p=0,583)$. Vide Tabela 5 e Figura 15.

\section{Atenção Voluntária}

O tempo de reação na condição válida foi menor do que na condição inválida $(p<0,001)$ e na condição neutra $(p<0,001)$. Não houve diferença significativa entre os tempos de reação na condição inválida e na condição neutra ( $p=0,113)$. Vide Tabela 5 e Figura 15.

\section{Efeito de Validade}

O efeito de validade foi encontrado para a atenção automática (96 ms \pm 11 ms) e para a atenção voluntária (79 ms $\pm 14 \mathrm{~ms}$ ). Vide a Figura 16.

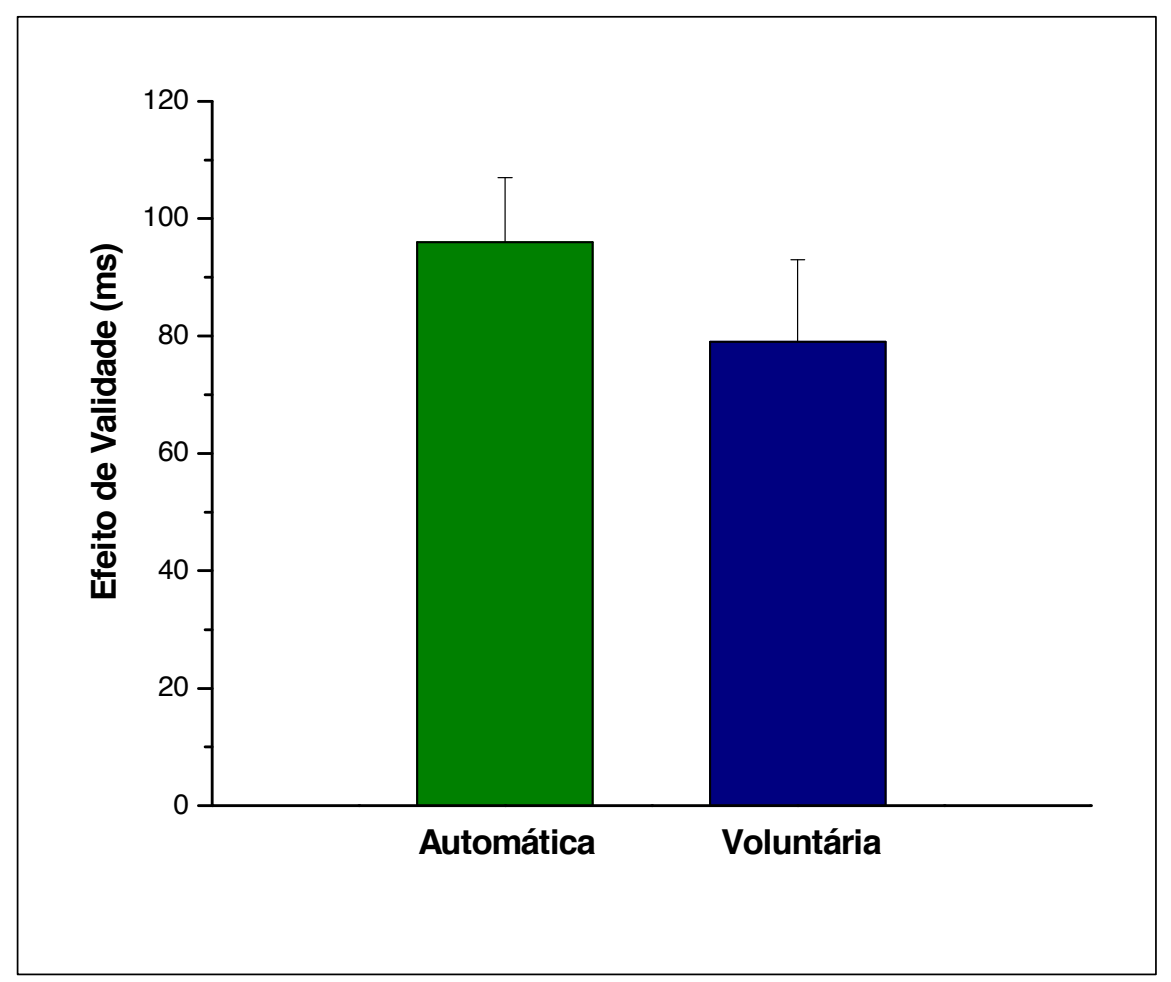

Figura 16. Média ( \pm e.p.m.) do efeito de validade no experimento de atenção automática e no experimento de atenção voluntária. 
Nesta sessão, o registro de erros teve apenas como finalidade incluir os voluntários nos experimentos. Caso apresentassem um índice maior do que $20 \%$, seriam excluídos.

\subsubsection{Sessão Prova}

Os voluntários realizaram 6 runs, 3 para os testes de atenção automática e 3 para os testes de atenção voluntária, dentro do equipamento de Ressonância Magnética.

Nossos resultados mostraram que não houve diferença significativa entre o grupo que realizou primeiramente o teste de atenção automática em comparação com o grupo que realizou este teste secundariamente $(p=0,172)$. O mesmo foi observado para o grupo que iniciou a tarefa com o teste de atenção voluntária ( $p=$ 0,466). Detalhes destes resultados são apresentados no Apêndice R.

Desta forma, finalizamos a coleta com os 20 participantes utilizando este mesmo procedimento.

\section{Tempo de Reação}

O efeito principal foi obtido para o tipo de atenção (automática e voluntária) e para a validade do E1 (válida, neutra e inválida). Ocorreu interação entre o tipo de atenção (automática e voluntária) e a validade do E1 (válida, neutra e inválida). Os resultados desta análise estão resumidos na Tabela 6 e os tempos de reação das voluntárias analisadas no Apêndice S.

Tabela 6. Resultados da Análise de Variância da sessão prova tendo como fatores o Tipo de Atenção (automática e voluntária), Validade do E1 (válida, neutra e inválida). Os resultados significativos estão indicados com dois asteriscos $\left({ }^{\star *}\right)$ e os marginalmente significativos com um asterisco $\left({ }^{*}\right)$. Gl, graus de liberdade. $F$, razão entre o quadrado da média do efeito e o do erro. P, nível de significância. E1, estímulo precedente.

\begin{tabular}{lccc}
\hline EFEITO & Gl & F & P \\
\hline Tipo de Atenção & 1 & 8,576 & $0,008^{\star \star}$ \\
Validade do E1 & 2 & 67,544 & $<0,001^{\star *}$ \\
Tipo de Atenção X Validade & 2 & 19,453 & $<0,001^{\star *}$ \\
\hline
\end{tabular}


Os tempos de reação para atenção automática foram maiores que para atenção voluntária, respectivamente $509 \pm 19$ e $473 \pm 17 \mathrm{~ms}(\mathrm{p}=0,008)$.

Houve diferença significativa para a validade do $E 1(p<0,001)$. Na condição em que o E1 apareceu na posição válida, o tempo de reação foi menor do que na condição em que o E1 apareceu na posição inválida $(p<0,001)$ e na condição neutra $(p<0,001)$. Na condição em que o E1 apareceu na posição inválida, o tempo de reação não foi diferente daquele na condição neutra $(p=0,764)$. Vide Tabela 7 e Figura 17.

Tabela 7. Média ( \pm e.p.m.) dos tempos de reação para a validade do E1 nas posições válida, neutra e inválida. E1, estímulo precedente.

\begin{tabular}{lccc}
\hline Validade do E1 & Válida & Neutra & Inválida \\
\hline Média & 435 & 516 & 522 \\
e.p.m. & 16 & 17 & 19 \\
\hline
\end{tabular}

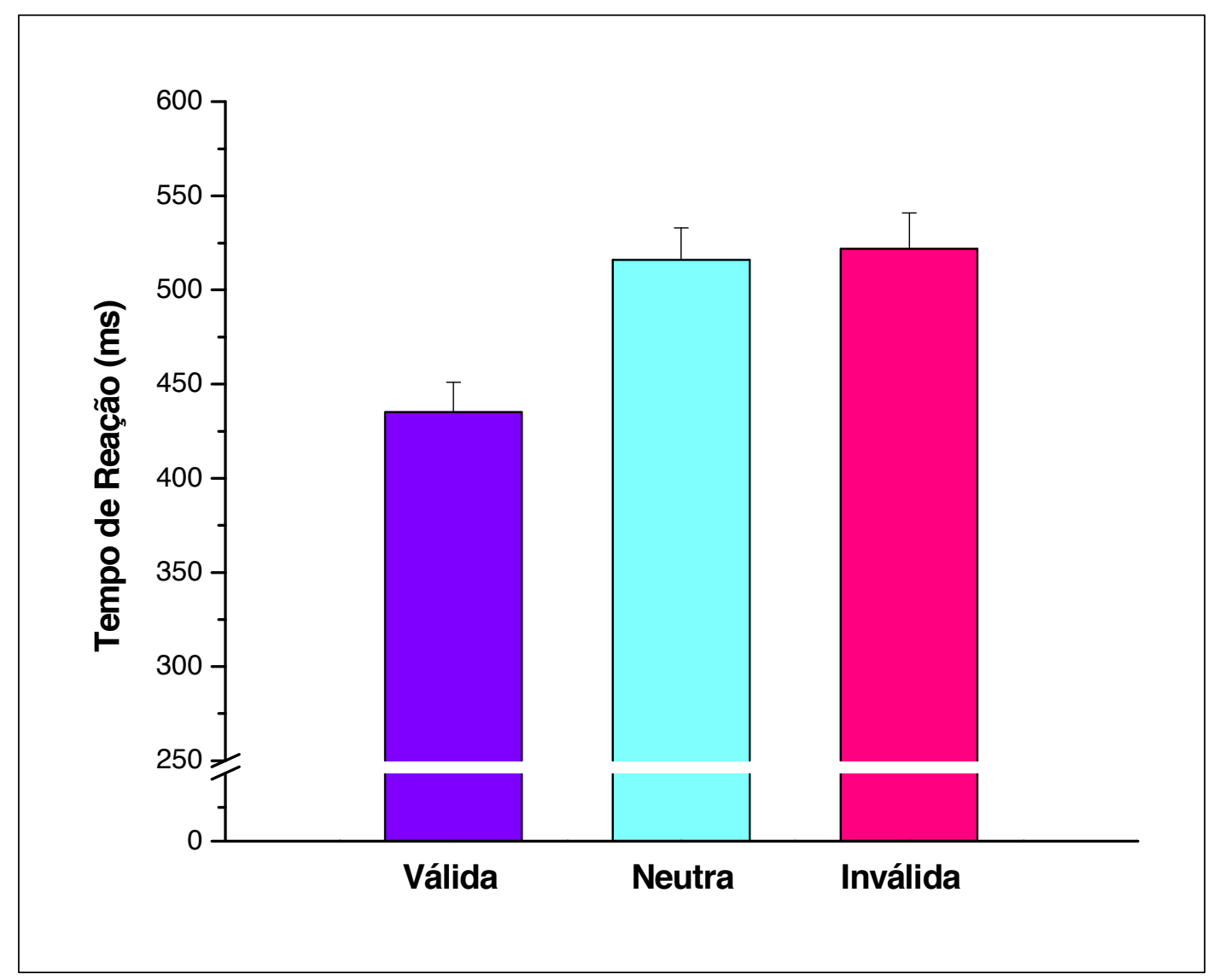

Figura 17. Média ( \pm e.p.m.) dos tempos de reação ao estímulo alvo na condição válida, neutra e inválida. 
A interação entre o tipo de atenção e a validade do $E 1$ foi significativo $(p<$ 0,001 ), indicando que o tempo de reação nas condições de atenção automática e voluntária dependem da validade do E1. O tempo de reação na condição válida, para atenção automática foi maior que na condição válida, para atenção voluntária $(p<0,001)$. O tempo de reação na condição inválida, para atenção automática foi maior que na condição inválida, para atenção voluntária $(p=0,001)$. Não houve diferença significativa na condição neutra para os diferentes tipos de atenção $(p=$ 0,570). Vide Tabela 8 e Figura 18.

Tabela 8. Média ( \pm e.p.m.) dos tempos de reação para o tipo de atenção e a validade do $E 1$ nas posições válida, neutra e inválida.

\begin{tabular}{lccc|ccc}
\hline & \multicolumn{3}{c|}{ Atenção Automática } & \multicolumn{3}{c}{ Atenção Voluntária } \\
\cline { 2 - 7 } & Válida & Neutra & Inválida & Válida & Neutra & Inválida \\
\hline Média & 464 & 507 & 556 & 405 & 525 & 488 \\
e.p.m. & 18 & 19 & 22 & 18 & 19 & 19 \\
\hline
\end{tabular}

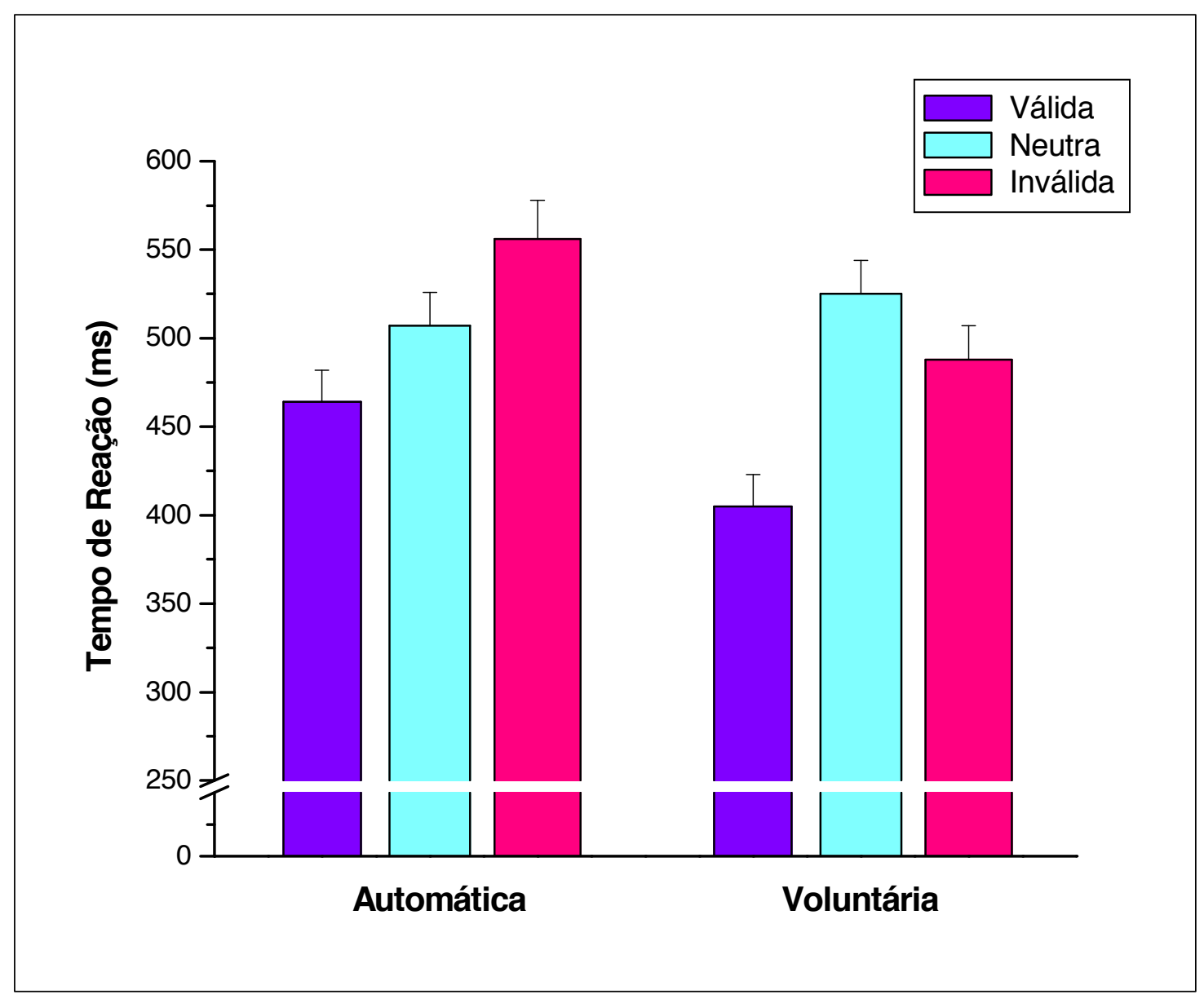

Figura 18. Média ( \pm e.p.m.) dos tempos de reação nos experimentos de atenção automática e de atenção voluntária, nas condições válida, neutra e inválida. 


\section{Atenção Automática}

O tempo de reação na condição válida foi menor que na condição inválida ( $p$ $<0,001)$ e na condição neutra $(p<0,003)$. O tempo de reação na condição inválida foi maior que na condição neutra $(p<0,001)$. Vide Tabela 8.

\section{Atenção Voluntária}

O tempo de reação na condição válida foi menor que na condição inválida ( $p$ $<0,001)$ e na condição neutra $(p<0,001)$. O tempo de reação na condição inválida foi menor que na condição neutra $(p=0,015)$. Vide Tabela 8.

\section{Efeito de Validade}

O efeito de validade foi encontrado para a atenção automática (92 ms \pm 14 ms) e para a atenção voluntária (83 ms $\pm 11 \mathrm{~ms}$ ). Vide Figura 19.

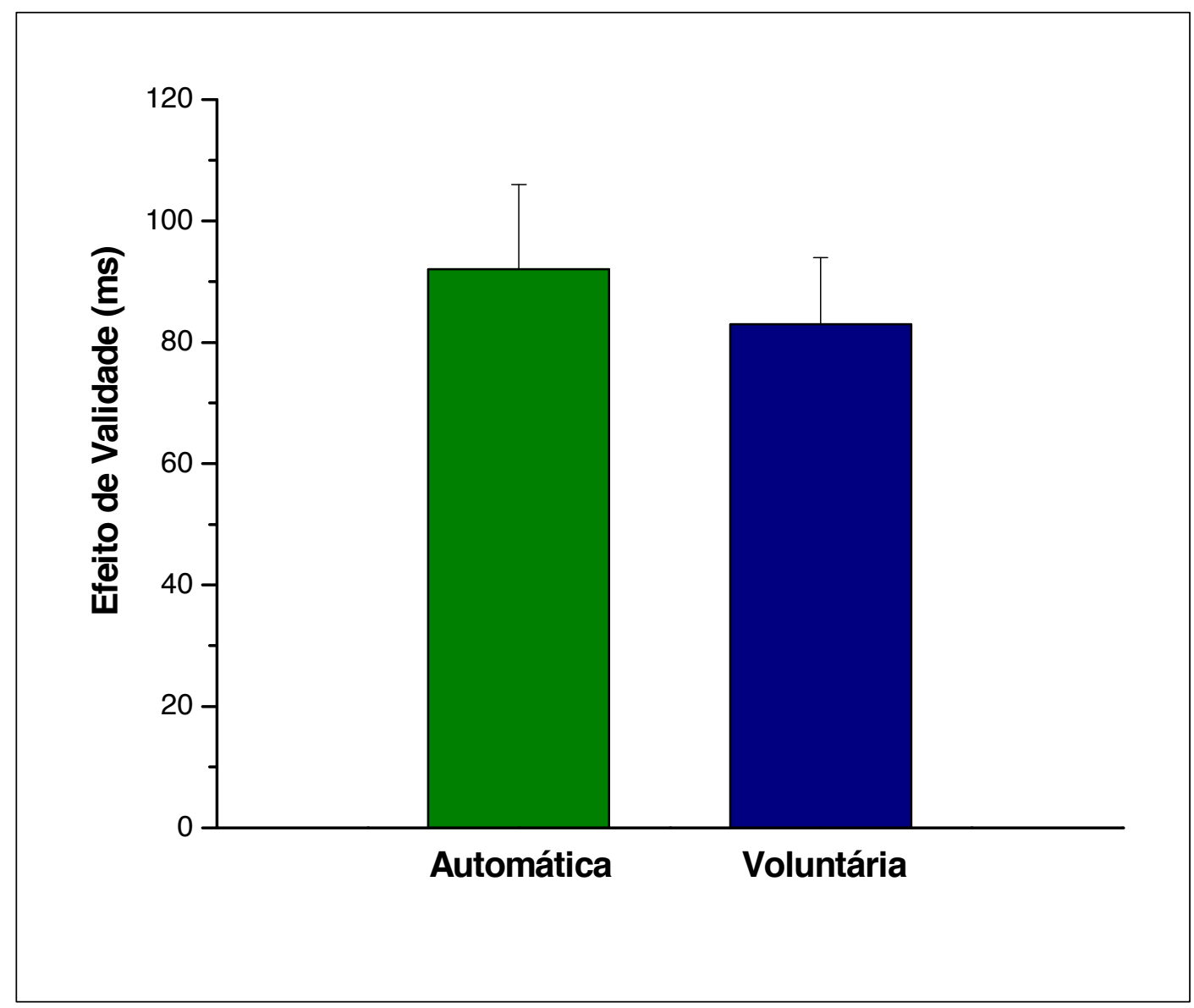

Figura 19. Média ( \pm e.p.m.) do efeito de validade no experimento de atenção automática e no experimento de atenção voluntária. 
No experimento de atenção automática, as porcentagens de erros de inversão e sem registro de resposta foram, respectivamente, 4,4\% e 5,6\%. No experimento de atenção voluntária, as porcentagens de erros de inversão e sem registro de resposta foram, respectivamente, 3,6\% e 6,4\%.

Não houve diferença significativa nos tempos de reação observado entre as tarefas comportamentais fora da RMf (sessão treino) e dentro da máquina (sessão prova) $(p=0,344)$. Vide Figura 20 e Apêndice T.

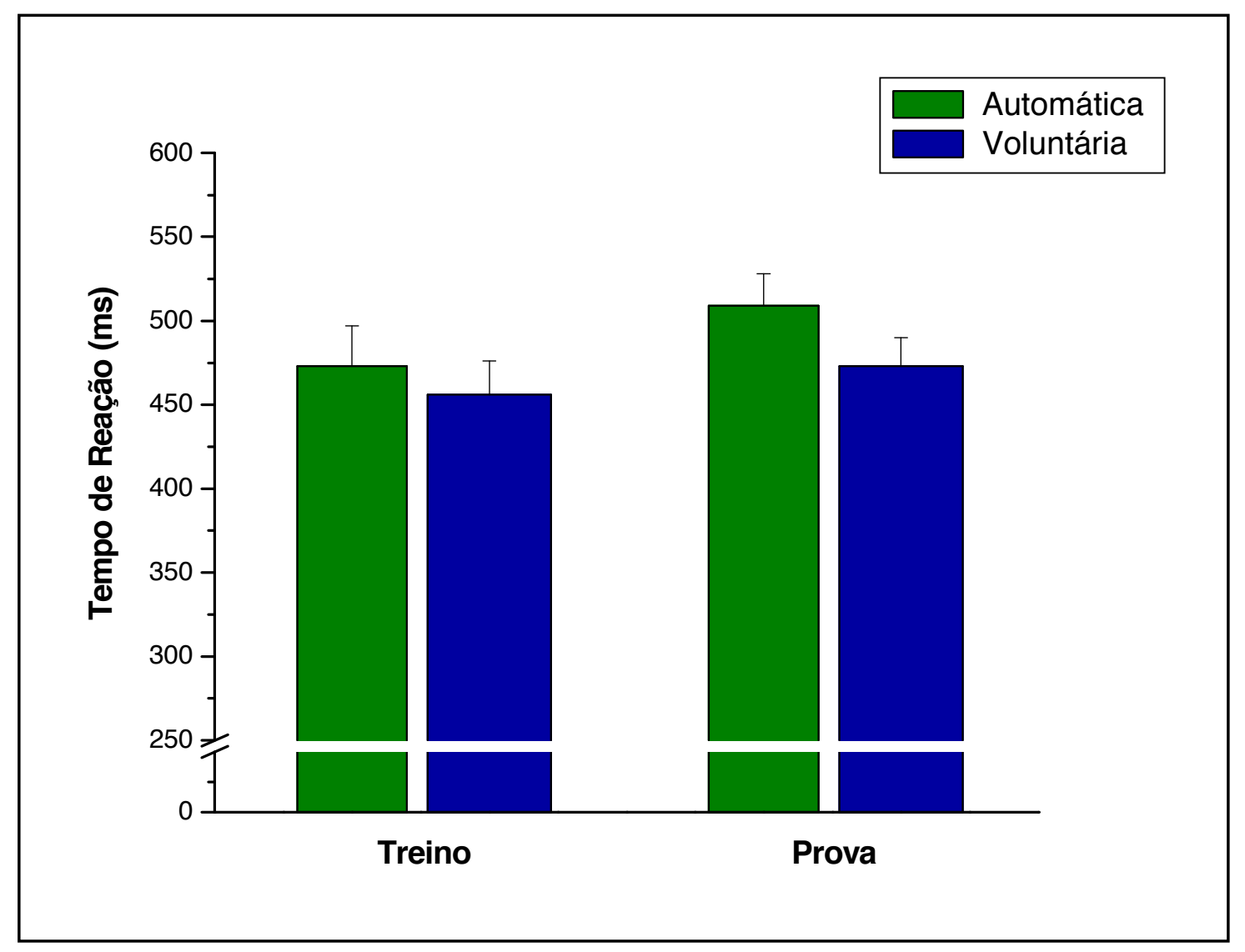

Figura 20. Média ( \pm e.p.m.) dos tempos de reação na Sessão Treino e na Sessão Prova dos Experimentos de atenção automática e dos Experimentos de atenção voluntária.

\subsection{Eye Tracker}

Como descrito anteriormente, o uso do eye tracker teve como finalidade monitorar os movimentos oculares dos participantes para garantirmos que os mesmos estivessem com os olhos fixos no ponto de fixação, durante as tentativas (entre o momento de fixação até a resposta). 
Nossos resultados foram indicativos de que nenhum voluntário foi excluído pelo movimento ocular indicando desvios do PF (acima de 10\%) de todas as tentativas para ambos os Experimentos (Tabela 9).

Tabela 9. Movimentos oculares: representada a quantidade de sacadas obtidas em cada run para os experimentos de atenção automática e de atenção voluntária de todos os sujeitos incluídos na pesquisa. A1 (representa o run1 do teste de atenção automática); A2 (representa o run2 do teste de atenção automática); A3 (representa o run3 do teste de atenção automática); V1 (representa o run1 do teste de atenção voluntária); V2 (representa o run2 do teste de atenção voluntária); V3 (representa o run3 do teste de atenção voluntária); \% sacadas (representa a porcentagem total de sacadas realizadas em todos os runs dos Experimentos de Atenção Automática e de Atenção Voluntária).

\begin{tabular}{c|cccccc|c}
\hline $\begin{array}{c}\text { Sujeito } \\
\text { (código) }\end{array}$ & A1 & A2 & A3 & V1 & V2 & V3 & \% sacadas \\
\hline $\mathbf{7 8 5}$ & 0 & 0 & 0 & 0 & 0 & 0 & 0,0 \\
$\mathbf{8 1 9}$ & 0 & 0 & 0 & 0 & 0 & 0 & 0,0 \\
$\mathbf{8 2 0}$ & 0 & 1 & 0 & 5 & 6 & 0 & 4,7 \\
$\mathbf{8 2 1}$ & 0 & 0 & 0 & 0 & 0 & 0 & 0,0 \\
$\mathbf{8 2 6}$ & 0 & 0 & 0 & 0 & 0 & 1 & 0,4 \\
$\mathbf{8 2 8}$ & 0 & 1 & 0 & 1 & 1 & 0 & 1,2 \\
$\mathbf{8 3 0}$ & 0 & 0 & 0 & 0 & 0 & 0 & 0,0 \\
$\mathbf{8 5 9}$ & 0 & 0 & 0 & 0 & 0 & 0 & 0,0 \\
$\mathbf{8 7 3}$ & 0 & 0 & 1 & 0 & 0 & 0 & 0,4 \\
$\mathbf{8 7 4}$ & 6 & 5 & 7 & 1 & 1 & 0 & 7,8 \\
$\mathbf{8 7 5}$ & 0 & 0 & 0 & 0 & 0 & 0 & 0,0 \\
$\mathbf{8 7 7}$ & 0 & 0 & 0 & 0 & 0 & 1 & 0,4 \\
$\mathbf{8 7 8}$ & 0 & 1 & 0 & 0 & 0 & 0 & 0,4 \\
$\mathbf{8 7 9}$ & 0 & 0 & 0 & 0 & 0 & 0 & 0,0 \\
$\mathbf{8 8 1}$ & 0 & 0 & 0 & 0 & 0 & 0 & 0,0 \\
$\mathbf{8 9 5}$ & 0 & 0 & 0 & 0 & 0 & 1 & 0,4 \\
$\mathbf{1 2 3 3}$ & 1 & 5 & 1 & 0 & 2 & 4 & 5,1 \\
$\mathbf{1 2 3 7}$ & 6 & 1 & 0 & 10 & 3 & 4 & 9,4 \\
$\mathbf{1 2 3 9}$ & 0 & 6 & 2 & 1 & 0 & 2 & 4,3 \\
$\mathbf{1 2 4 1}$ & 0 & 0 & 0 & 0 & 0 & 0 & 0,0 \\
\hline & & & & & & & \\
\hline
\end{tabular}

\subsection{Ressonância Magnética}

\section{Ressonância Magnética Estrutural}

O radiologista avaliou todas as sequências estruturais e não foram encontradas lesões e/ou anormalidades (Apêndice O). 


\section{Ressonância Magnética Funcional}

Os resultados apresentados foram referentes aos experimentos de atenção automática, atenção voluntária e os contrastes entre esses dois experimentos com Imagem por Ressonância Magnética Funcional.

\section{Atenção Automática}

Os resultados dos experimentos de atenção automática foram obtidos para diferentes condições experimentais representadas pelos contrastes das tentativas válida versus neutra, inválida versus neutra, válida versus inválida e inválida versus válida.

\section{Tentativas Válida versus Neutra}

Este contraste define as áreas cerebrais dos alvos que apareceram na mesma posição (válida) depois de uma expectativa espacial e temporal induzidas pela pista (brilho) versus as tentativas em que apareceram os alvos sem nenhuma expectativa espacial (sem pista).

No mapa de grupo, da atenção automática, as regiões que apresentaram o efeito BOLD positivo, na condição válida versus neutra, foram o lobo occipital (estriado) bilateral e cerebelo esquerdo. Vide Figura 21 e Apêndice U1. 


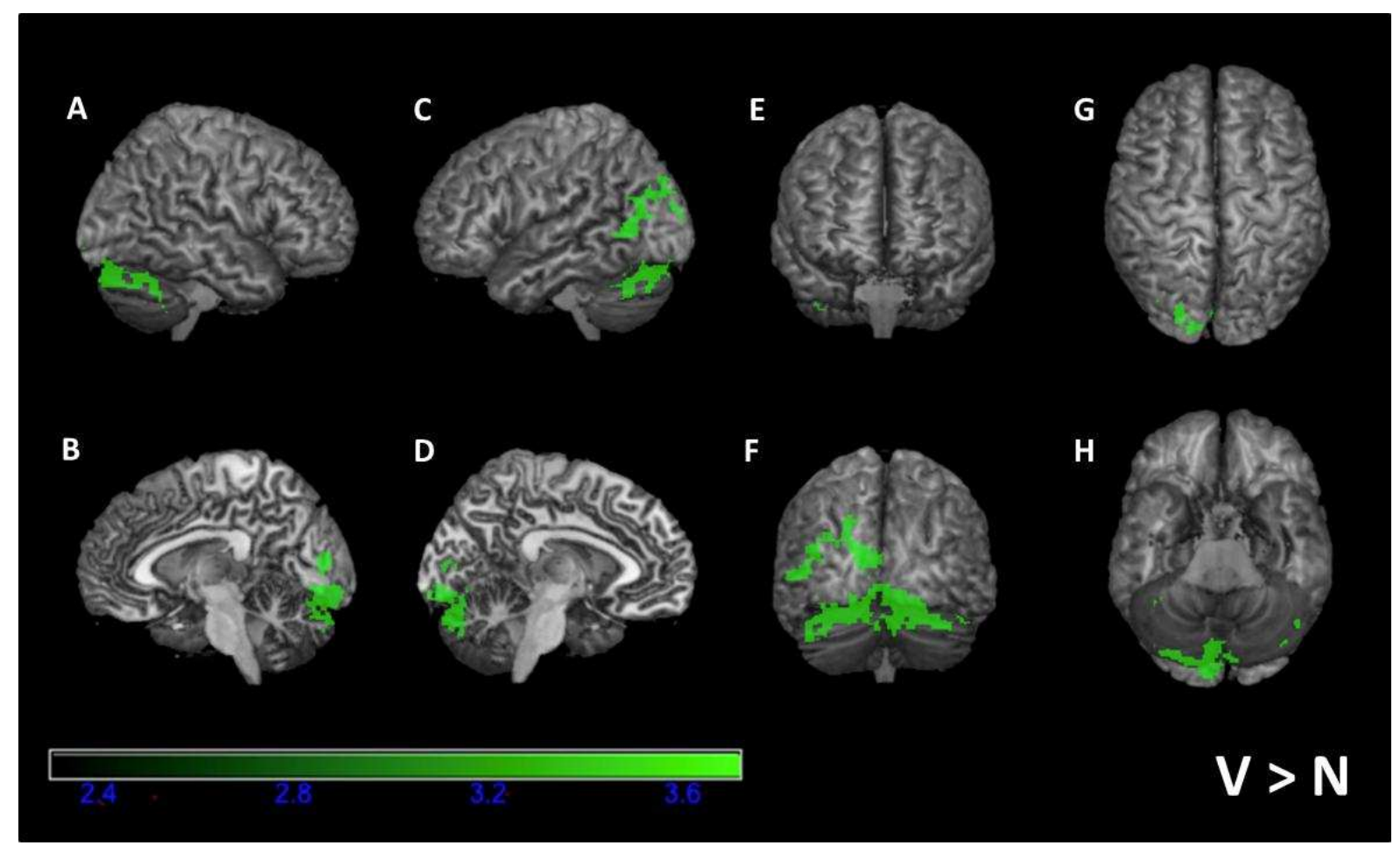

Figura 21. Mapa probabilístico de ativação de grupo do experimento de atenção automática $(\mathrm{N}=20)$ no contraste das tentativas válida versus neutra $(\mathrm{V}>\mathrm{N})$. As imagens mostram as representações tridimensionais do cérebro na vista lateral direita $(A)$, secção esquerda (B), vista lateral esquerda $(C)$, secção direita $(D)$, vista anterior $(E)$, vista posterior $(F)$, vista superior $(G)$ e vista inferior $(H)$. Observase a resposta BOLD positiva no lobo occipital (estriado) bilateral e cerebelo esquerdo (cluster $Z>2,3$; $p<0,05$; escala de ativação $Z=2,3$ a 3,7).

\section{$\underline{\text { Tentativas Inválida versus Neutra }}$}

Este contraste define as áreas cerebrais envolvidas com a reorientação da atenção espacial, ou seja, as áreas foram isoladas quando os alvos apareceram em uma posição não atendida (inválida) depois da expectativa espacial induzida pela pista versus as tentativas que os alvos apareceram sem nenhuma expectativa espacial (sem pista).

No mapa de grupo, da atenção automática, a região que apresentou o efeito BOLD positivo, na condição inválida versus neutra, foi no giro frontal medial bilateral, giro do cíngulo anterior esquerdo, borda do sulco intraparietal direito, giro angular bilateral, giro supramarginal esquerdo, cerebelo bilateral, ponte bilateral, mesencéfalo direito e giro parahipocampal esquerdo. Vide Figura 22 e Apêndice U2. 


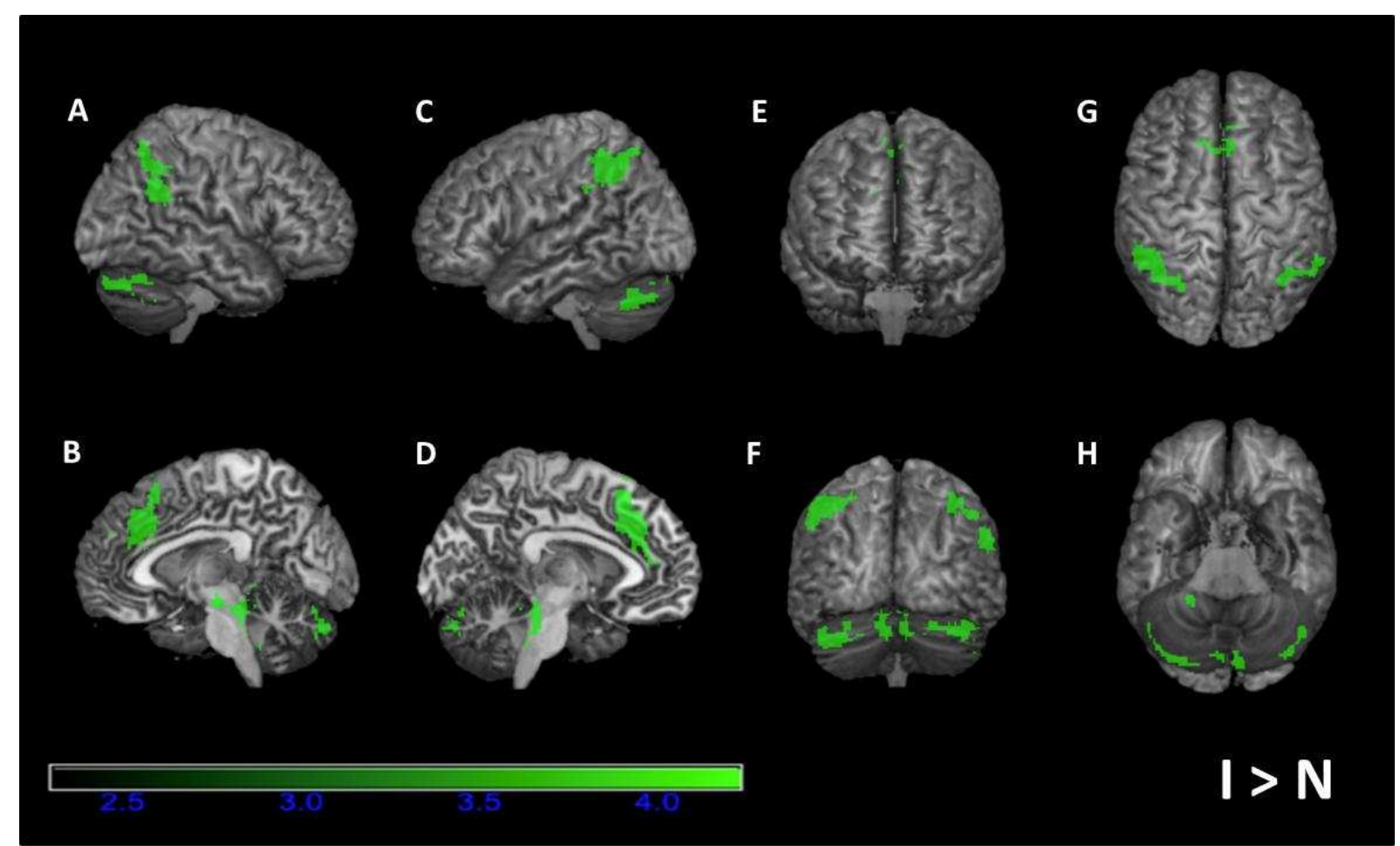

Figura 22. Mapa probabilístico de ativação de grupo do experimento de atenção automática $(\mathrm{N}=20)$ no contraste das tentativas inválida versus neutra $(\mathrm{I}>\mathrm{N})$. As imagens mostram as representações tridimensionais do cérebro na vista lateral direita $(A)$, secção esquerda $(B)$, vista lateral esquerda $(C)$, secção direita $(D)$, vista anterior $(E)$, vista posterior $(F)$, vista superior $(G)$ e vista inferior $(H)$. Observase a resposta BOLD positiva no giro frontal medial bilateral, giro do cíngulo anterior esquerdo, borda do sulco intraparietal direito, giro angular bilateral, giro supramarginal esquerdo, cerebelo bilateral, ponte bilateral, mesencéfalo direito e giro parahipocampal esquerdo (cluster $Z>2,3$; $p<0,05$; escala de ativação $Z=2,3$ a 4,2 ).

Tentativas Válida versus Inválida

Este contraste está relacionado com as áreas cerebrais envolvidas com a orientação espacial da atenção. O estímulo alvo ocorreu na mesma posição (válida) indicada pela pista (brilho do anel).

No mapa de grupo, da atenção automática, a região que apresentou o efeito BOLD positivo, na condição válida versus inválida, foi o lobo occipital (estriado e extraestriado) direito, pólo occipital esquerdo e giro pós central (opérculo parietal) direito. Vide Figura 23 e Apêndice U3. 


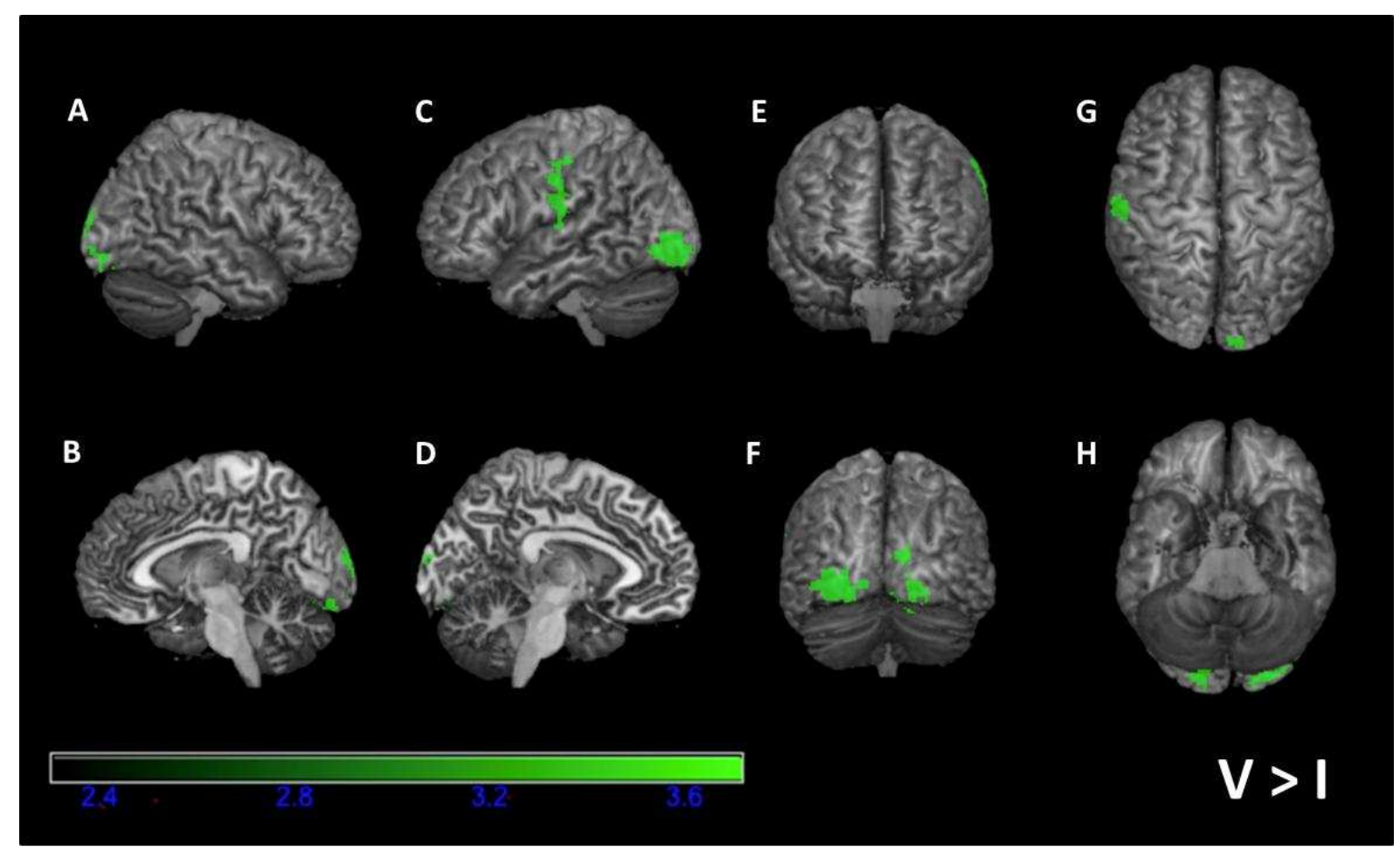

Figura 23. Mapa probabilístico de ativação de grupo do experimento de atenção automática $(\mathrm{N}=20)$ no contraste das tentativas válida versus inválida $(\mathrm{V}>\mathrm{I})$. As imagens mostram as representações tridimensionais do cérebro na vista lateral direita $(A)$, secção esquerda $(B)$, vista lateral esquerda $(C)$, secção direita $(D)$, vista anterior $(E)$, vista posterior $(F)$, vista superior $(G)$ e vista inferior $(H)$. Observase a resposta BOLD positiva no lobo occipital (estriado e extraestriado) direito,pólo occipital esquerdo e giro pós central (opérculo parietal) direito (cluster $Z>2,3 ; p<0,05$; escala de ativação $Z=2,3$ a 3,9).

Tentativas Inválida versus Válida

Este contraste está relacionado com as áreas cerebrais envolvidas com a reorientação espacial da atenção. O estímulo alvo ocorreu na posição oposta (inválida) indicado pela pista (brilho do anel).

No mapa de grupo, da atenção automática, as regiões que apresentaram o efeito BOLD positivo, na condição inválida versus válida, foram o giro frontal medial bilateral, giros órbitos-frontais laterais bilaterais, giro frontal inferior bilateral, giro frontal superior direito, ínsula esquerda, giro supramarginal bilateral e borda do sulco intraparietal direito. Vide Figura 24 e Apêndice U4. 


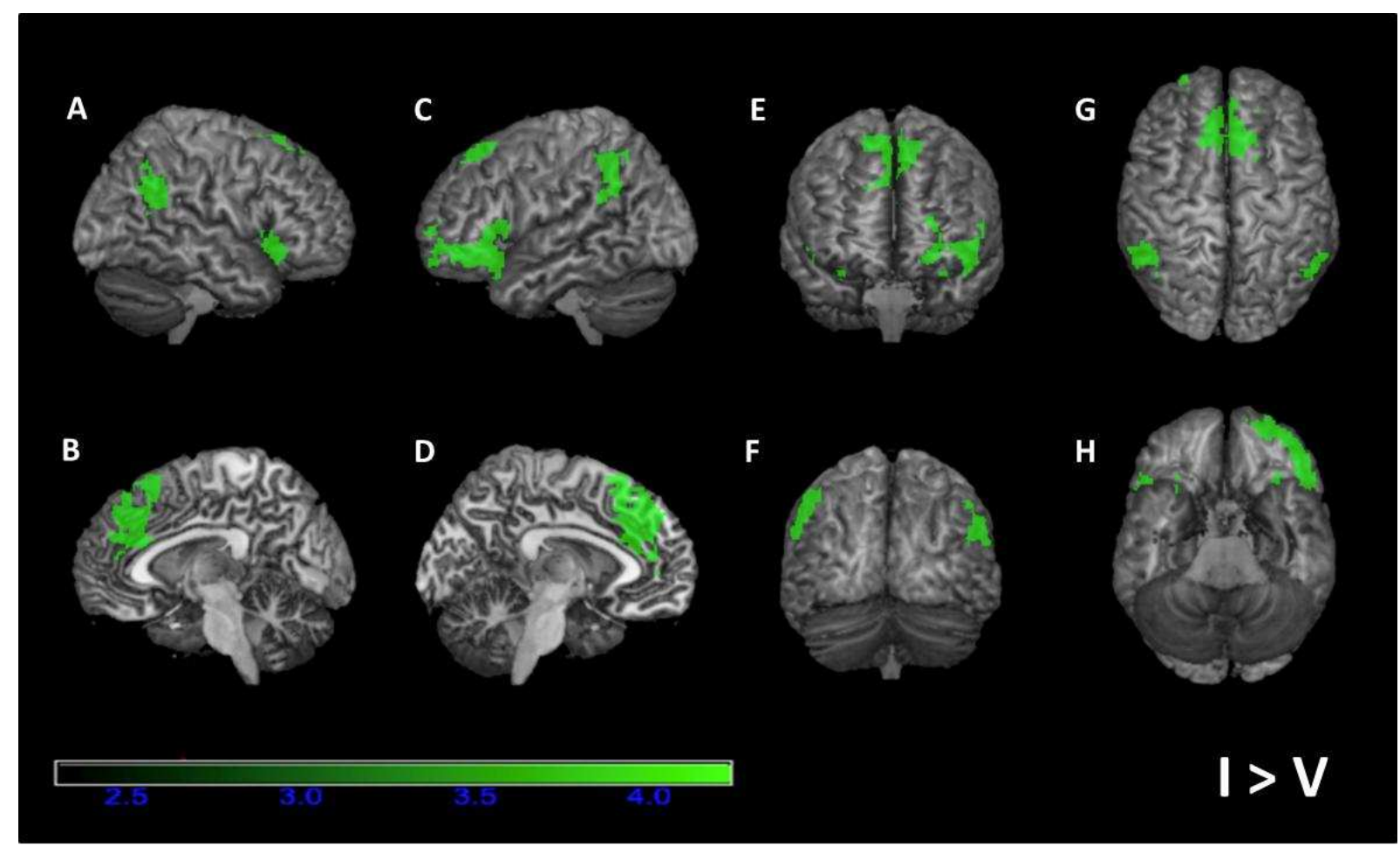

Figura 24. Mapa probabilístico de ativação de grupo do experimento de atenção automática $(\mathrm{N}=20)$ no contraste das tentativas inválida versus válida $(\mathrm{I}>\mathrm{V})$. As imagens mostram as representações tridimensionais do cérebro na vista lateral direita $(A)$, secção esquerda (B), vista lateral esquerda $(C)$, secção direita (D), vista anterior $(E)$, vista posterior $(F)$, vista superior $(G)$ e vista inferior $(H)$. Observase a resposta BOLD positiva no giro frontal medial bilateral, giros órbitosfrontais laterais bilaterais, giro frontal inferior bilateral, giro frontal superior direito, ínsula esquerda, giro supramarginal bilateral e borda do sulco intraparietal direito (cluster $Z>2,3 ; p<0,05$; escala de ativação $Z=2,3$ a 4,2).

\section{Atenção Voluntária}

\section{Tentativas Válida versus Neutra}

Este contraste define as áreas cerebrais dos alvos que apareceram na mesma posição (válida) depois de uma expectativa espacial induzida pela pista (seta) versus as tentativas que apareceram os alvos sem nenhuma expectativa espacial (sem pista).

No mapa de grupo, da atenção voluntária, as regiões que apresentaram o efeito BOLD positivo, na condição válida versus neutra, foram o giro fusiforme (extraestriado) bilateral, giro frontal superior esquerdo, giros órbitos-frontais mediais esquerdo e pré-cuneos esquerdo. Vide Figura 25 e Apêndice U5. 


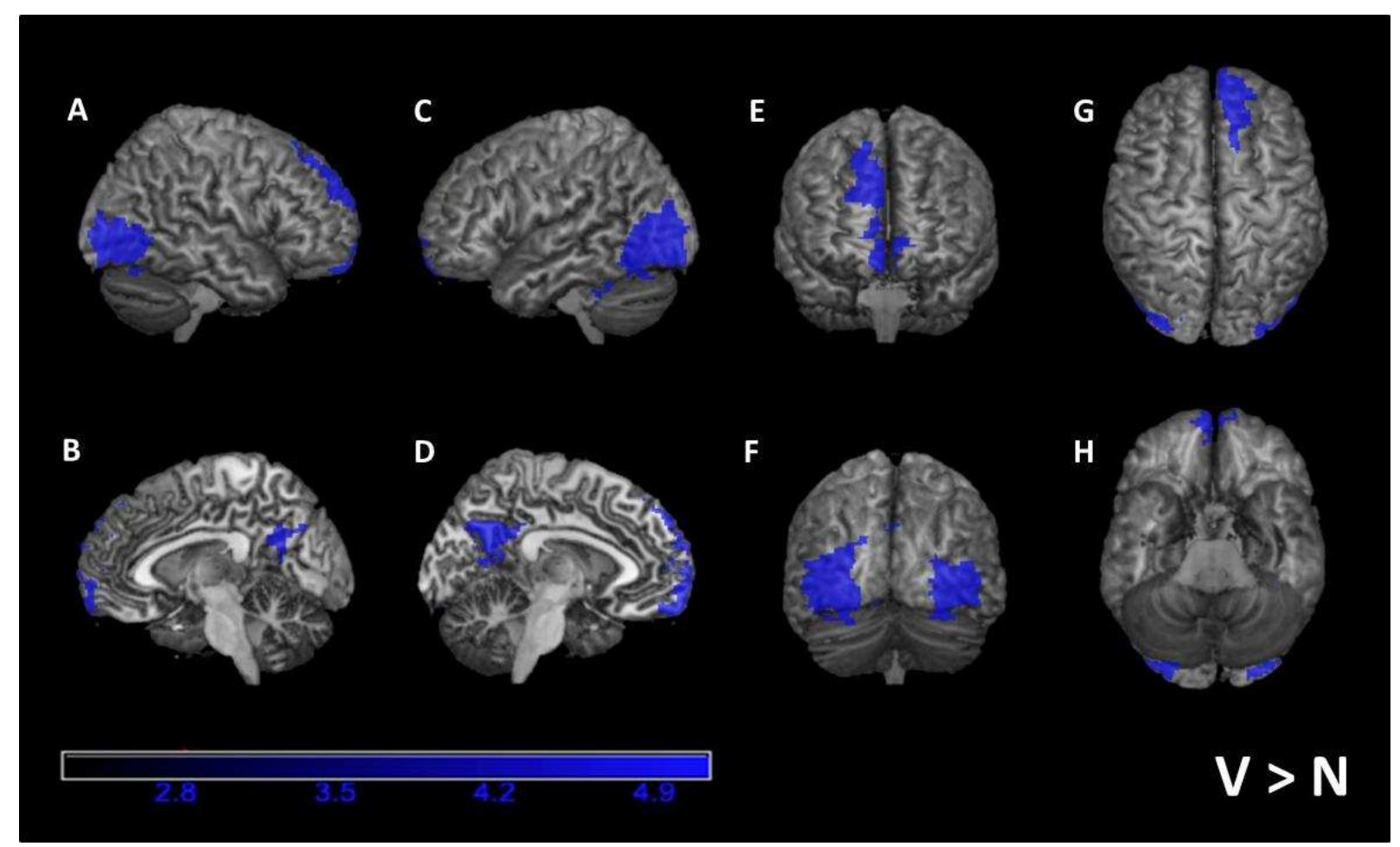

Figura 25. Mapa probabilístico de ativação de grupo do experimento de atenção voluntária $(\mathrm{N}=20)$ no contraste das tentativas válida versus neutra $(\mathrm{V}>\mathrm{N})$. As imagens mostram as representações tridimensionais do cérebro na vista lateral direita $(A)$, secção esquerda (B), vista lateral esquerda $(C)$, secção direita $(D)$, vista anterior $(E)$, vista posterior $(F)$, vista superior $(G)$ e vista inferior $(H)$. Observase a resposta BOLD positiva no giro fusiforme (extraestriado) bilateral, giro frontal superior esquerdo, giros órbitos-frontais mediais esquerdo e pré-cuneos esquerdo (cluster $Z>2,3$; $p<0,05$; escala de ativação $Z=2,3$ a 5,1).

\section{Tentativas Inválida versus Neutra}

Este contraste define as áreas cerebrais envolvidas com a reorientação da atenção espacial, ou seja, as áreas foram isoladas quando os alvos apareceram em uma posição não atendida (inválida) depois da expectativa espacial induzida pela pista central versus as tentativas que os alvos apareceram sem nenhuma expectativa espacial (sem pista).

No mapa de grupo, da atenção voluntária, as regiões que apresentaram o efeito BOLD positivo, na condição inválida versus neutra, foram o giro frontal superior bilateral, lobo occipital (extraestriado) bilateral, giro supramarginal esquerdo, giro frontal Inferior esquerdo, giros órbito-frontais laterais bilateral e pólo temporal esquerdo. Vide Figura 26 e Apêndice U6. 


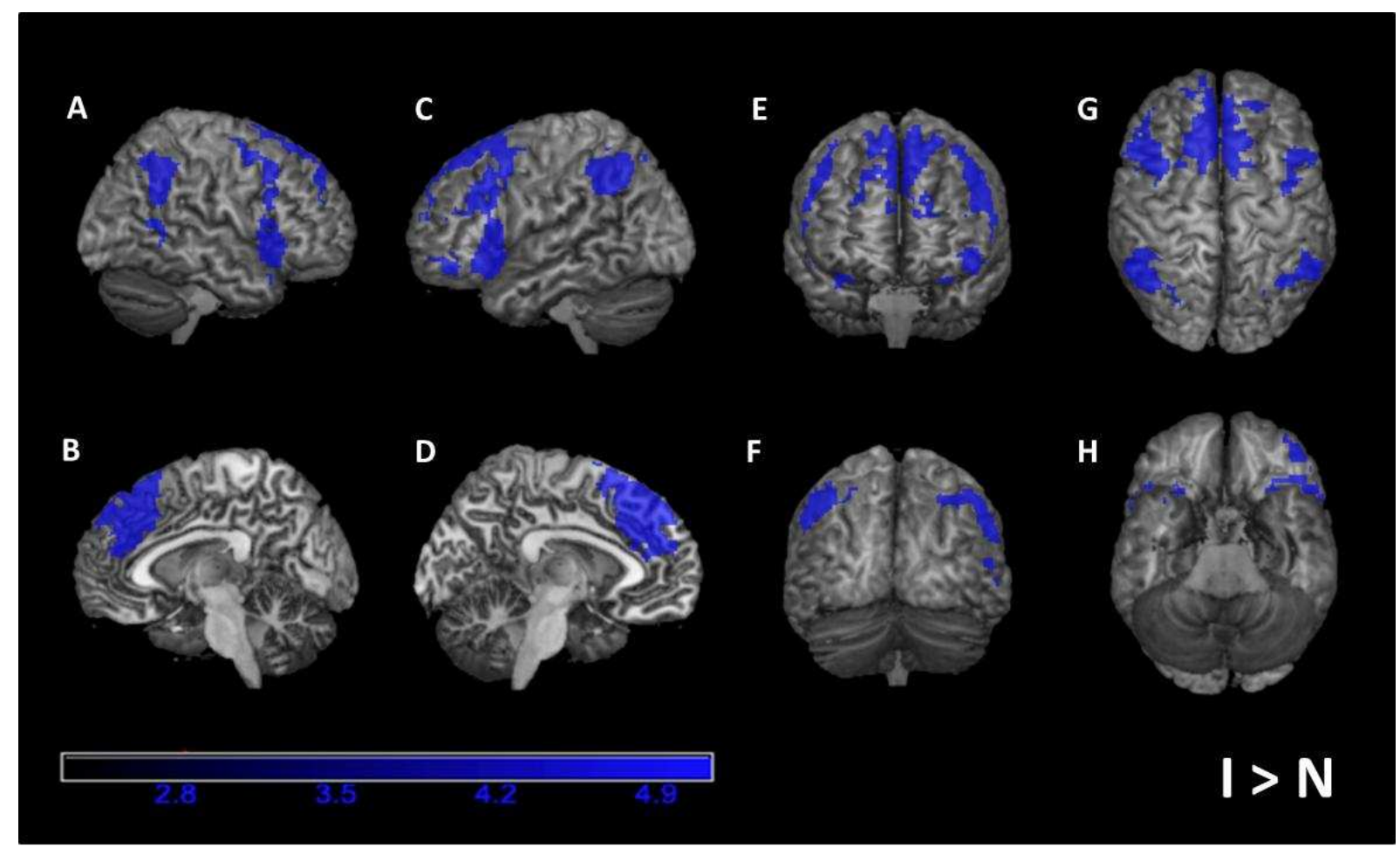

Figura 26. Mapa probabilístico de ativação de grupo do experimento de atenção voluntária $(\mathrm{N}=20)$ no contraste das tentativas inválida versus neutra $(\mathrm{I}>\mathrm{N})$. As imagens mostram as representações tridimensionais do cérebro na vista lateral direita $(A)$, secção esquerda $(B)$, vista lateral esquerda $(C)$, secção direita $(D)$, vista anterior $(E)$, vista posterior $(F)$, vista superior $(G)$ e vista inferior $(H)$. Observase a resposta BOLD positiva no giro frontal superior bilateral, lobo occipital (extraestriado) bilateral, giro supramarginal esquerdo, giro frontal Inferior esquerdo, giros órbito-frontais laterais bilateral e pólo temporal esquerdo (cluster $Z>2,3 ; p<0,05$; escala de ativação $Z=2,3$ a 5,1).

\section{Tentativas Válida versus Inválida}

Este contraste está relacionado com as áreas cerebrais envolvidas com a orientação espacial da atenção. O estímulo alvo ocorreu na mesma posição (válida) indicada pela pista (seta central).

No mapa de grupo, da atenção voluntária, o efeito BOLD positivo não pode ser observado para este contraste.

\section{Tentativas Inválida versus Válida}

Este contraste está relacionado com as áreas cerebrais envolvidas com a reorientação espacial da atenção. O estímulo alvo ocorreu na posição oposta (inválida) à indicada pela pista (seta central).

No mapa de grupo, da atenção voluntária, as regiões que apresentaram o efeito BOLD positivo, na condição inválida versus válida, foram os giros órbito- 
frontais laterais bilaterais, giro frontal médio bilateral, giro frontal superior direito, giro frontal inferior esquerdo, borda do sulco intraparietal bilateral, giro supramarginal bilateral, giro angular esquerdo. Vide Figura 27 e Apêndice U7.

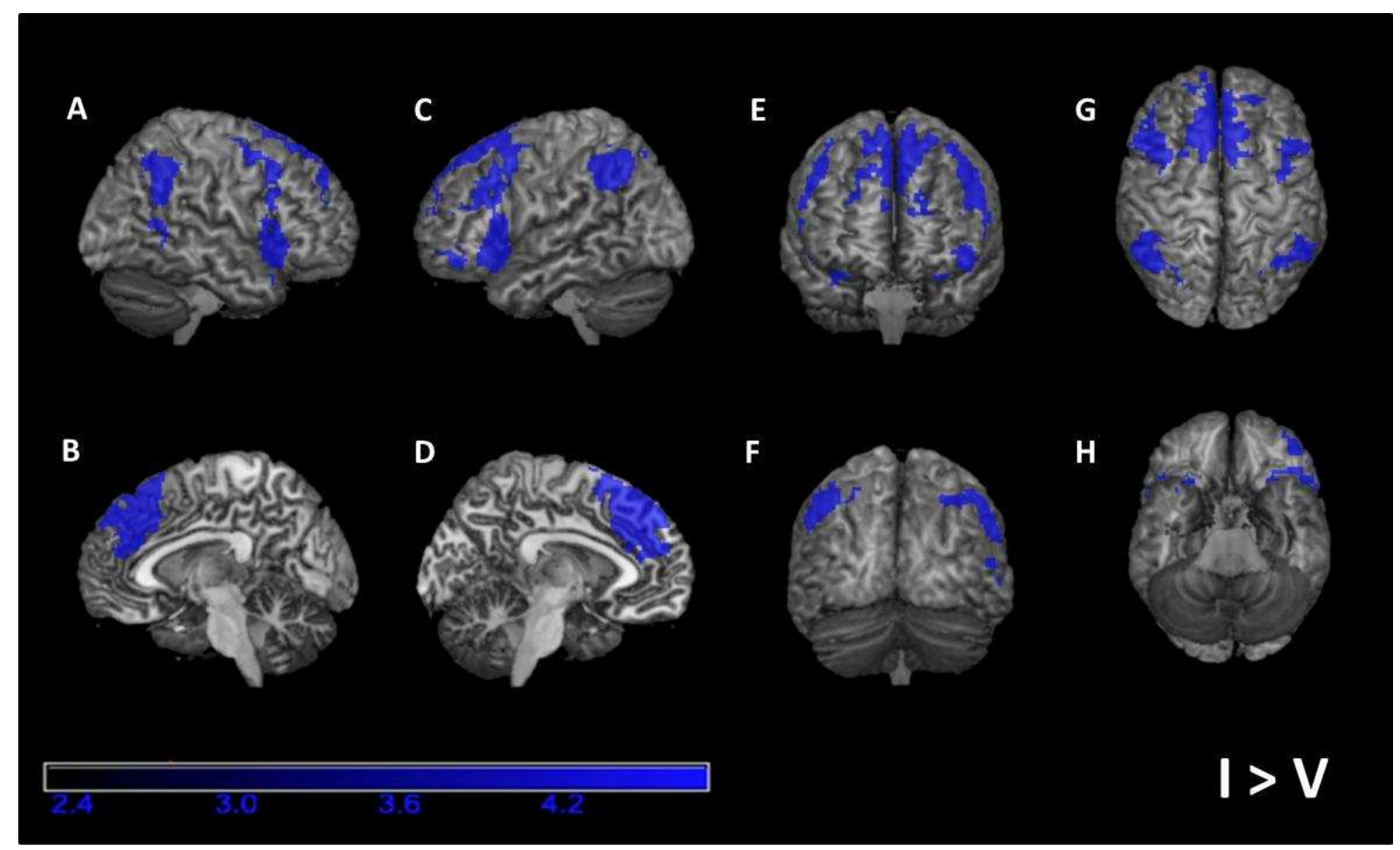

Figura 27. Mapa probabilístico de ativação de grupo do experimento de atenção voluntária $(\mathrm{N}=20)$ no contraste das tentativas inválida versus válida $(\mathrm{I}>\mathrm{V})$. As imagens mostram as representações tridimensionais do cérebro na vista lateral direita $(A)$, secção esquerda $(B)$, vista lateral esquerda $(C)$, secção direita $(D)$, vista anterior $(E)$, vista posterior $(F)$, vista superior $(G)$ e vista inferior $(H)$. Observase a resposta BOLD positiva nos giros órbito-frontais laterais bilaterais, giro frontal médio bilateral, giro frontal superior direito, giro frontal inferior esquerdo, borda do sulco intraparietal bilateral, giro supramarginal bilateral, giro angular esquerdo (cluster $Z>2,3$; $p<0,05$; escala de ativação $Z=2,3$ a 4,7).

Comparação entre a ativação cerebral associada à mobilização da atenção automática e aquela associada à mobilização da atenção voluntária

Nesta comparação realizamos um teste $\mathrm{t}$ pareado para verificar se há diferenças na resposta BOLD entre os testes de Atenção Automática e de Atenção Voluntária. 
Experimento de Atenção Automática versus Atenção Voluntária $(A>V)$

Este contraste define as áreas cerebrais relacionadas com o Experimento de Atenção Automática.

No mapa de grupo, as regiões que apresentaram o efeito BOLD positivo, nos Experimentos de Atenção Automática versus Atenção Voluntária, foram no cuneus bilateral, giro frontal inferior direito, giro pré-central bilateral, giro pós-central esquerdo, giro fusiforme (extraestriado) bilateral, cerebelo bilateral e giro frontal medial direito. Vide Figura 28 e Apêndice U8.

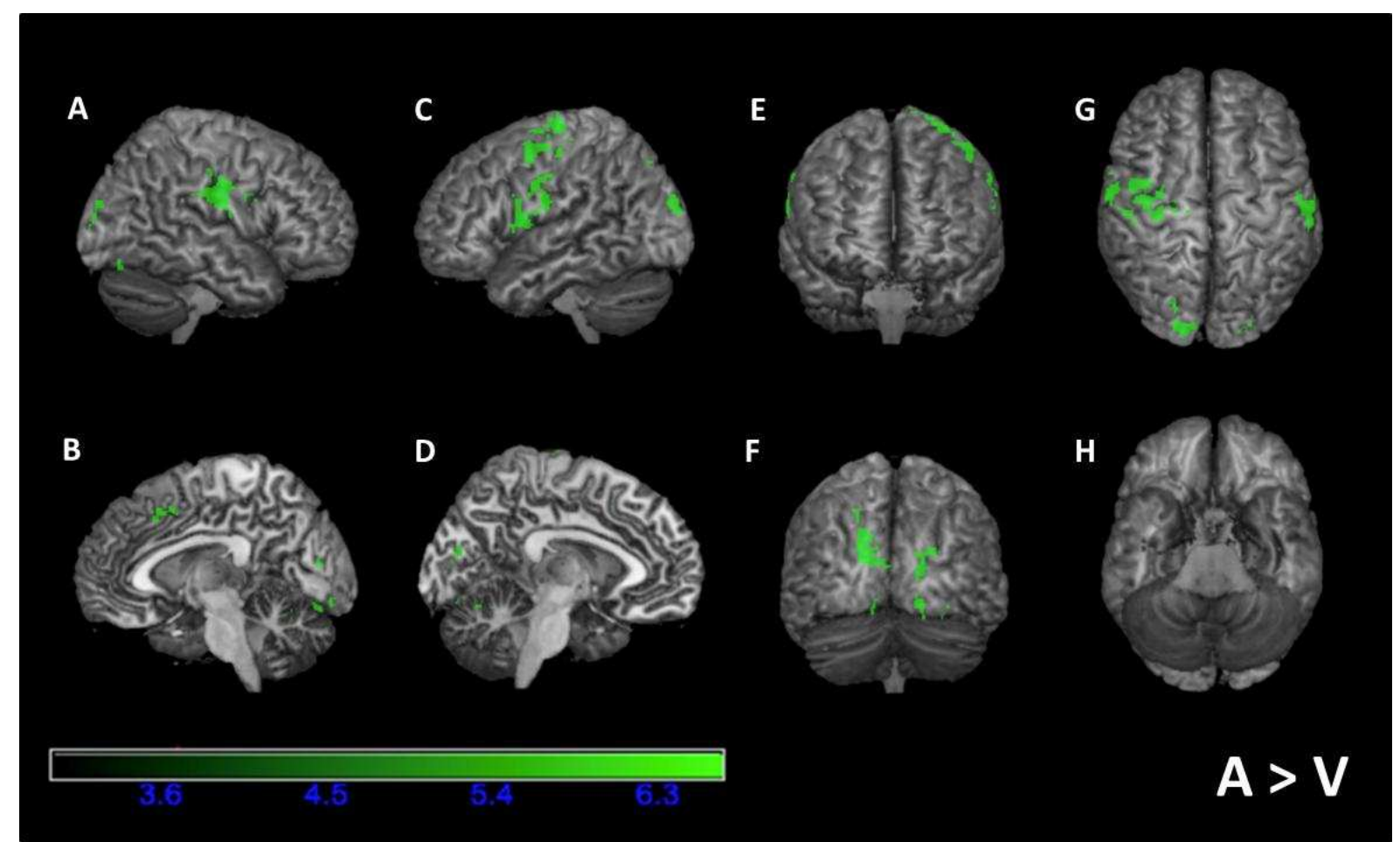

Figura 28. Mapa probabilístico de ativação de grupo dos experimentos de atenção $(\mathrm{N}=20)$ no contraste dos experimentos de atenção automática versus atenção voluntária $(A>V)$. As imagens mostram as representações tridimensionais do cérebro na vista lateral direita $(A)$, secção esquerda $(B)$, vista lateral esquerda $(C)$, secção direita $(D)$, vista anterior $(E)$, vista posterior $(F)$, vista superior $(G)$ e vista inferior (H). Observa-se a resposta BOLD positiva no cuneus bilateral, giro frontal inferior direito, giro pré-central bilateral, giro pós-central esquerdo, giro fusiforme (extraestriado) bilateral, cerebelo bilateral e giro frontal medial direito (cluster $Z>$ 3,0; $p<0,05$; escala de ativação $Z=3,0$ a 6,4).

\section{Experimento de Atenção Voluntária versus Atenção Automática (V>A)}

Este contraste define as áreas cerebrais relacionadas com o Experimento de Atenção Voluntária.

No mapa de grupo, as regiões que apresentaram o efeito BOLD positivo, nos Experimentos de Atenção Voluntária versus Atenção Automática, foram o giro frontal superior bilateral, pólo occipital bilateral, cerebelo bilateral, borda do sulco 
intraparietal direito, giro parahipocampal esquerdo, giro temporal superior e médio esquerdos, giro frontal inferior esquerdo, giro frontal médio bilateral, precuneus esquerdo e giro do cíngulo Posterior bilateral. Vide Figura 29 e Apêndice U9.

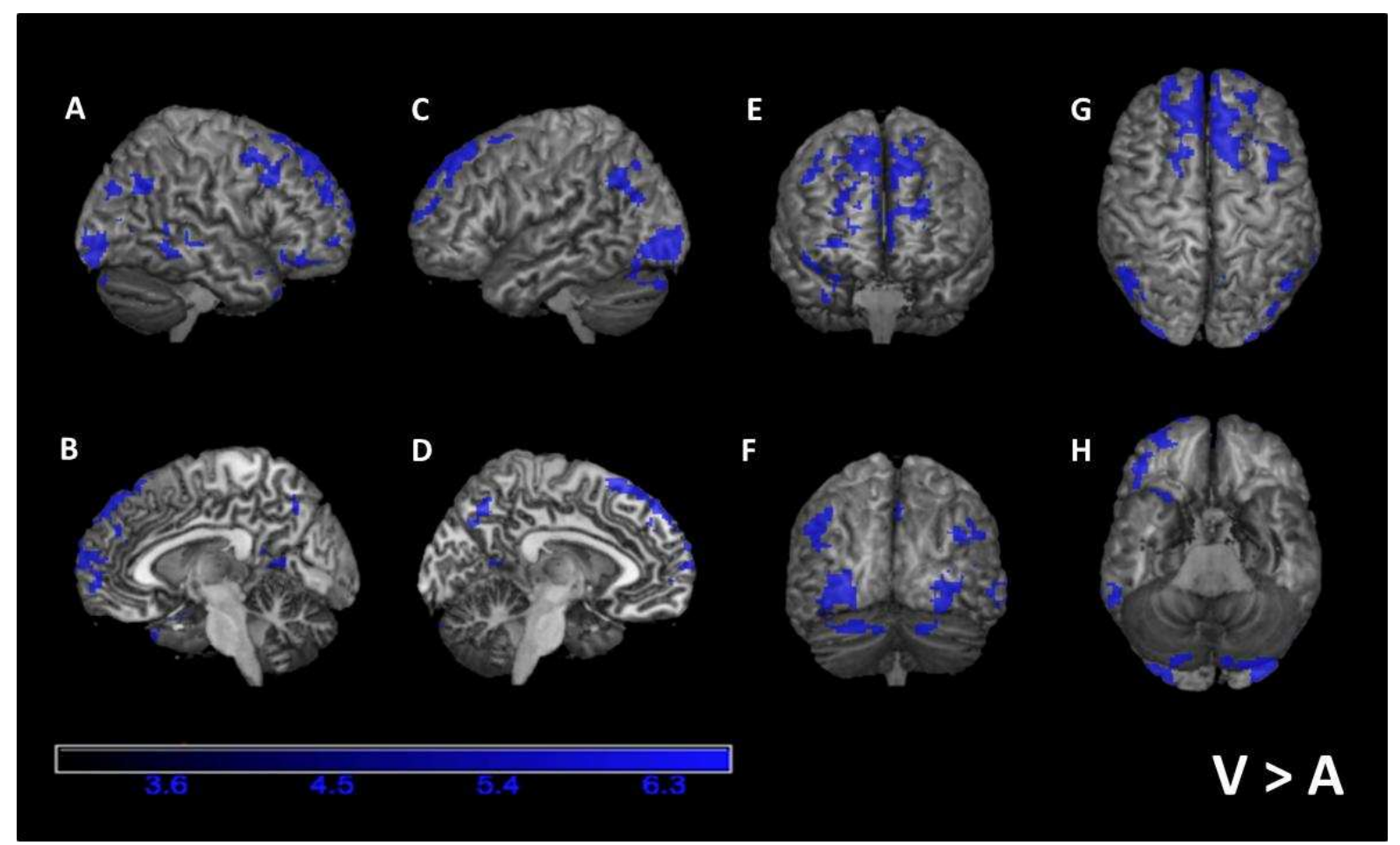

Figura 29. Mapa probabilístico de ativação de grupo dos experimentos de atenção $(\mathrm{N}=20)$ no contraste dos experimentos de atenção voluntária versus atenção automática $(\mathrm{V}>\mathrm{A})$. As imagens mostram as representações tridimensionais do cérebro na vista lateral direita (A), secção esquerda (B), vista lateral esquerda (C), secção direita $(D)$, vista anterior $(E)$, vista posterior $(F)$, vista superior $(G)$ e vista inferior $(\mathrm{H})$. Observa-se a resposta BOLD positiva no giro frontal superior bilateral, pólo occipital bilateral, cerebelo bilateral, borda do sulco intraparietal direito, giro parahipocampal esquerdo, giro temporal superior e médio esquerdos, giro frontal inferior esquerdo, giro frontal médio bilateral, precuneus esquerdo e giro do cíngulo posterior bilateral (cluster $Z>3,0 ; p<0,05$; escala de ativação $Z=3,0$ a $6,4)$.

Comparação do Experimento de Atenção Automática versus Atenção Voluntária $(A>V)$ e de Atenção Voluntária versus Atenção Automática $(V>A)$

Apenas para facilitar a comparação dos resultados dos contrastes descritos acima $(A>V$ e $V>A)$, a Figura 30 representa em verde as áreas relacionadas com 0 teste de Atenção Automática e em azul a Atenção Voluntária. 


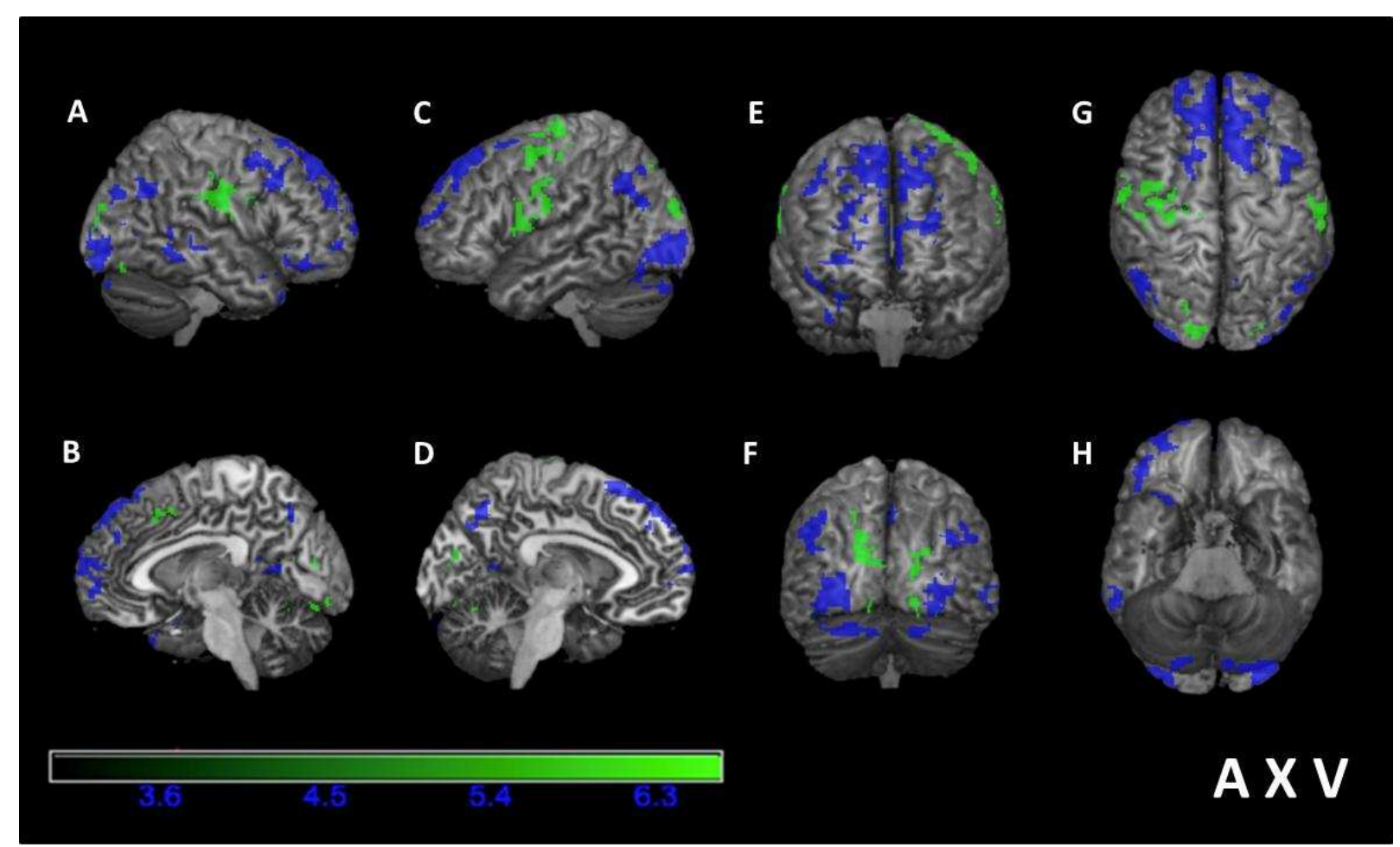

Figura 30. Mapa probabilístico de ativação de grupo dos experimentos de atenção automática e voluntária $(\mathrm{N}=20)$. Em verde, representa as áreas de atenção automática. Em azul, representa as áreas de atenção voluntária. As imagens mostram as representações tridimensionais do cérebro na vista lateral direita $(A)$, secção esquerda (B), vista lateral esquerda (C), secção direita (D), vista anterior $(E)$, vista posterior $(F)$, vista superior $(G)$ e vista inferior $(H)$.

\section{Análise de conjunção da ativação cerebral associada à mobilização da atenção} automática e aquela associada à mobilização da atenção voluntária

Análise de Conjunção do Experimento de Atenção Automática

Esta análise define as áreas cerebrais envolvidas com a orientação da atenção automática, através da sobreposição das três condições experimentais de base (válida, neutra e inválida).

No mapa de grupo, da atenção automática, as regiões que apresentaram o maior tamanho do cluster com efeito BOLD positivo em voxels foram nas Áreas Frontais: giro frontal médio, giro frontal medial, giro pré central bilaterais; giro frontal inferior direito. Áreas Parietais: borda do sulco intraparietal, giro pós central, lobo parietal superior, pré-cuneus, giro angular, giro supramarginal bilaterais; Áreas Temporais: giro temporal médio, giro temporal superior bilaterais; giro temporal inferior direito. Áreas Occipitais: giro fusiforme, giro lingual bilaterais; cuneus direito; giro occipital superior esquerdo. Outras Áreas: Outras áreas: cerebelo, tálamo, 
putâmen, núcleo caudado, mesencéfalo, giro parahipocampal, giro do cíngulo anterior e posterior, ínsula bilaterais. Vide Figura 31 e Apêndice U10.

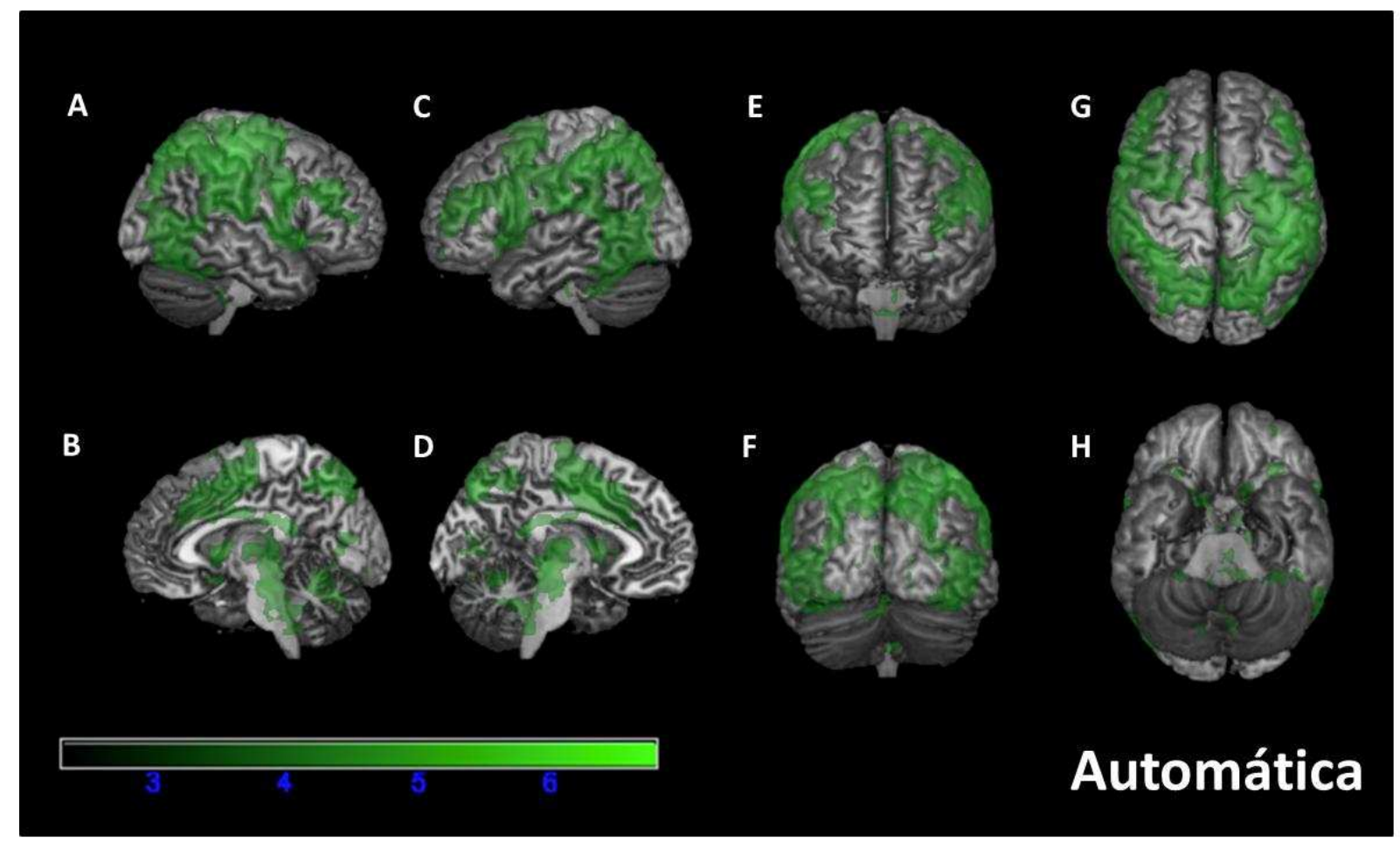

Figura 31. Mapa probabilístico de ativação de grupo dos experimentos de atenção automática $(\mathrm{N}=20)$ com as três condições experimentais de base (válida, neutra e inválida), através da análise de conjunção. As imagens mostram as representações tridimensionais do cérebro na vista lateral direita $(A)$, secção esquerda $(B)$, vista lateral esquerda $(C)$, secção direita $(D)$, vista anterior $(E)$, vista posterior $(F)$, vista superior $(G)$ e vista inferior $(H)$. Observa-se a resposta BOLD positiva nas Áreas Frontais: giro frontal médio, giro frontal medial, giro pré central bilaterais; giro frontal inferior direito. Áreas Parietais: borda do sulco intraparietal, giro pós central, lobo parietal superior, pré-cuneus, giro angular, giro supramarginal bilaterais; Áreas Temporais: giro temporal médio, giro temporal superior bilaterais; giro temporal inferior direito. Áreas Occipitais: giro fusiforme, giro lingual bilaterais; cuneus direito; giro occipital superior esquerdo. Outras Áreas: Outras áreas: cerebelo, tálamo, putâmen, núcleo caudado, mesencéfalo, giro parahipocampal, giro do cíngulo anterior e posterior, ínsula bilaterais (cluster $Z>2,3 ; p<0,05$; escala de ativação $Z=2,3$ a 3,2).

\section{Análise de Conjunção do Experimento de Atenção Voluntária}

Esta análise define as áreas cerebrais envolvidas com a orientação da atenção voluntária, através da sobreposição das três condições experimentais de base (válida, neutra e inválida).

No mapa de grupo, da atenção voluntária, as regiões que apresentaram o maior tamanho do cluster com efeito BOLD positivo em voxels foram nas Áreas Frontais: giro frontal médio, giro frontal medial, giro pré central bilaterais; giro frontal inferior direito. Áreas Parietais: borda do sulco intraparietal, giro pós central, lobo 
parietal superior, pré-cuneus, giro angular, giro supramarginal bilaterais; Áreas Temporais: giro temporal médio, giro temporal superior bilaterais. Áreas Occipitais: giro fusiforme, giro lingual, cuneus bilaterais; giro occipital médio e superior esquerdos. Outras Áreas: cerebelo, tálamo, putâmen, núcleo caudado, mesencéfalo, giro parahipocampal, giro do cíngulo anterior e posterior, ínsula bilaterais; amígdala esquerda. Vide Figura 32 e Apêndice U11.

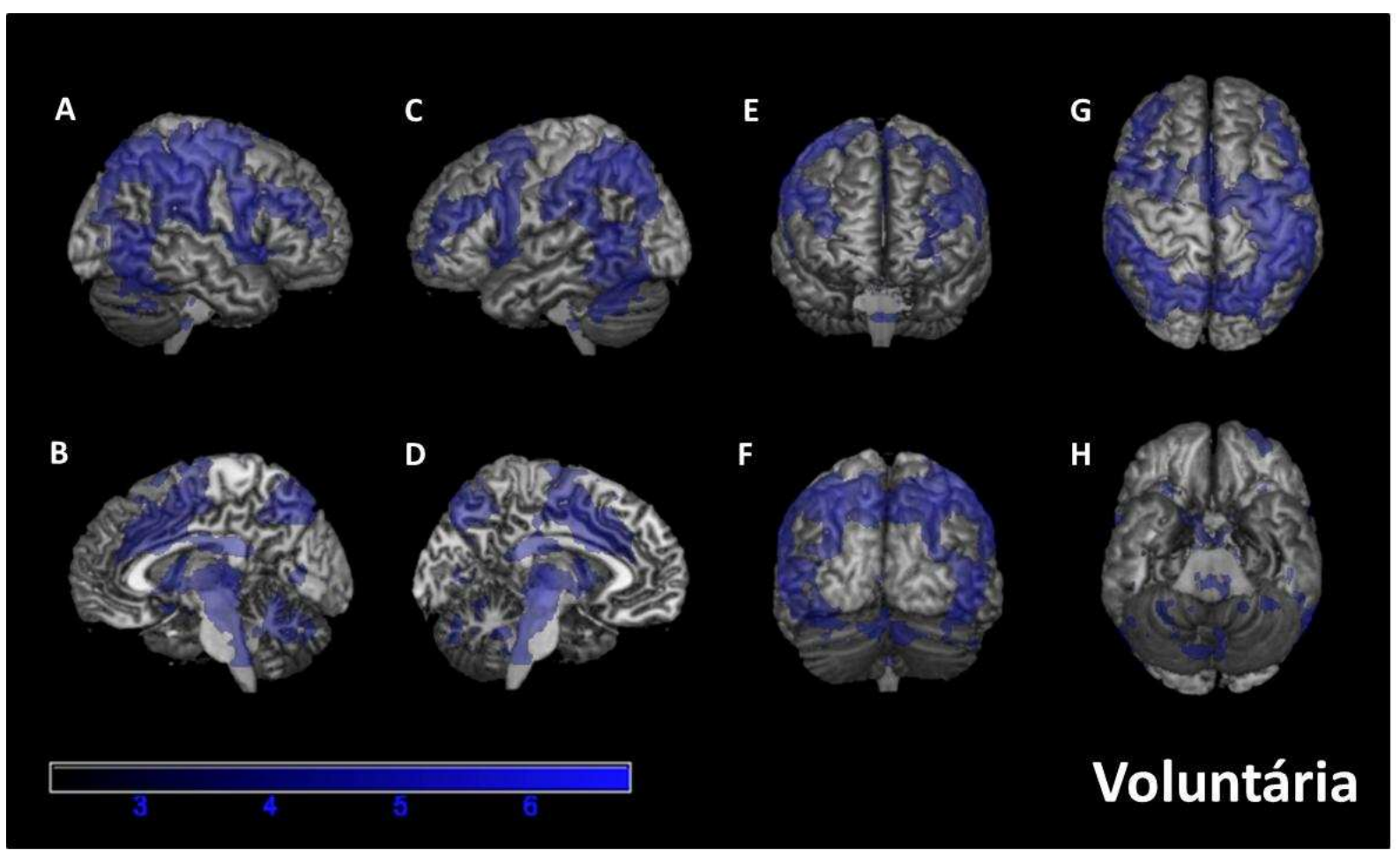

Figura 32. Mapa probabilístico de ativação de grupo dos experimentos de atenção voluntária $(\mathrm{N}=20)$ com as três condições experimentais de base (válida, neutra e inválida), através da análise de conjunção. As imagens mostram as representações tridimensionais do cérebro na vista lateral direita $(A)$, secção esquerda $(B)$, vista lateral esquerda $(C)$, secção direita $(D)$, vista anterior $(E)$, vista posterior $(F)$, vista superior $(G)$ e vista inferior $(H)$. Observa-se a resposta BOLD positiva nas Áreas Frontais: giro frontal médio, giro frontal medial, giro pré central bilaterais; giro frontal inferior direito. Áreas Parietais: borda do sulco intraparietal, giro pós central, lobo parietal superior, pré-cuneus, giro angular, giro supramarginal bilaterais; Áreas Temporais: giro temporal médio, giro temporal superior bilaterais. Áreas Occipitais: giro fusiforme, giro lingual, cuneus bilaterais; giro occipital médio e superior esquerdos. Outras Áreas: cerebelo, tálamo, putâmen, núcleo caudado, mesencéfalo, giro parahipocampal, giro do cíngulo anterior e posterior, ínsula bilaterais; amígdala esquerda (cluster $Z>2,3 ; p<0,05$; escala de ativação $Z=2,3$ a 3,2).

\section{Análise de Conjunção do Experimento de Atenção Automática e Voluntária}

Nesta análise realizamos a conjunção dos mapas, acima demostrados, da Atenção Automática e da Atenção Voluntário. No mapa de grupo, as regiões foram 
muito semelhantes entre esses mapas como as Áreas Frontais: giro frontal médio, giro frontal medial, giro pré central bilaterais; giro frontal inferior direito. Áreas Parietais: borda do sulco intraparietal, giro pós central, lobo parietal superior, précuneus, giro angular, giro supramarginal bilaterais; Áreas Temporais: giro temporal médio, giro temporal superior bilaterais. Áreas Occipitais: giro fusiforme, giro lingual bilaterais, cuneus direito. Outras Áreas: cerebelo, tálamo, mesencéfalo, giro parahipocampal, giro do cíngulo anterior e posterior, ínsula bilaterais. Vide Figura 33 e Apêndice U12.

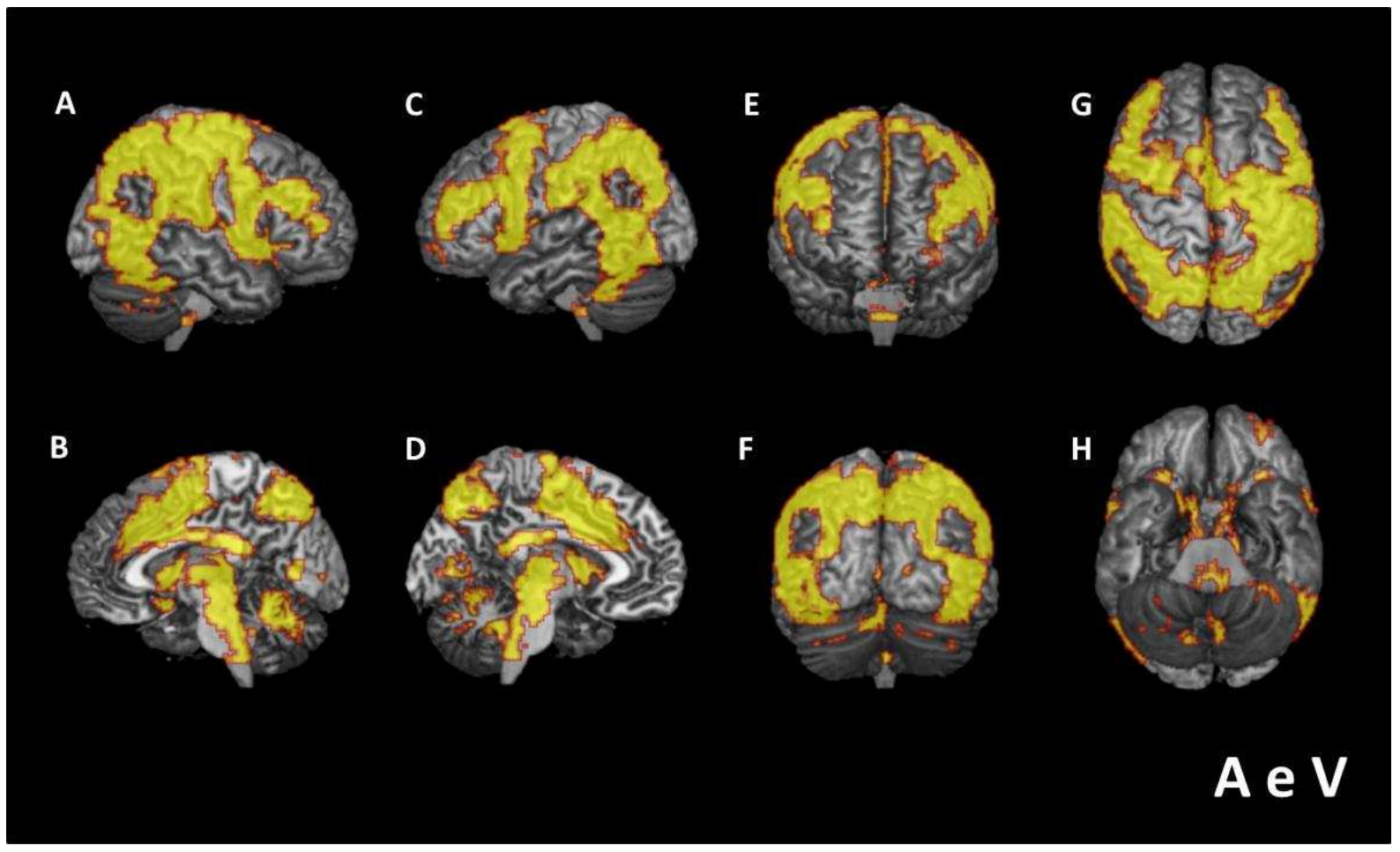

Figura 33. Mapa probabilístico de ativação de grupo dos experimentos de atenção automática e atenção voluntária $(\mathrm{N}=20)$ com as três condições experimentais de base (válida, neutra e inválida), através da análise de conjunção. As imagens mostram as representações tridimensionais do cérebro na vista lateral direita (A), secção esquerda (B), vista lateral esquerda (C), secção direita (D), vista anterior $(E)$, vista posterior $(F)$, vista superior $(G)$ e vista inferior $(H)$. Observa-se a resposta BOLD positiva nas Áreas Frontais: giro frontal médio, giro frontal medial, giro pré central bilaterais; giro frontal inferior direito. Áreas Parietais: borda do sulco intraparietal, giro pós central, lobo parietal superior, pré-cuneus, giro angular, giro supramarginal bilaterais; Áreas Temporais: giro temporal médio, giro temporal superior bilaterais. Áreas Occipitais: giro fusiforme, giro lingual bilaterais, cuneus direito. Outras Áreas: cerebelo, tálamo, mesencéfalo, giro parahipocampal, giro do cíngulo anterior e posterior, ínsula bilaterais (cluster $Z>2,3 ; p<0,05$; escala de ativação $Z=2,3$ a 3,2). 
Para facilitar a visualização das áreas cerebrais envolvidas nos Experimentos de Atenção Automática e Voluntária, fizemos uma sobreposição dos mapas (Figura 34) relacionados aos contrastes $A>V$ e $V>A$ (Figura 30), e da análise de conjução dos Experimentos de Atenção Automática e da Atenção Voluntária (Figura 33).

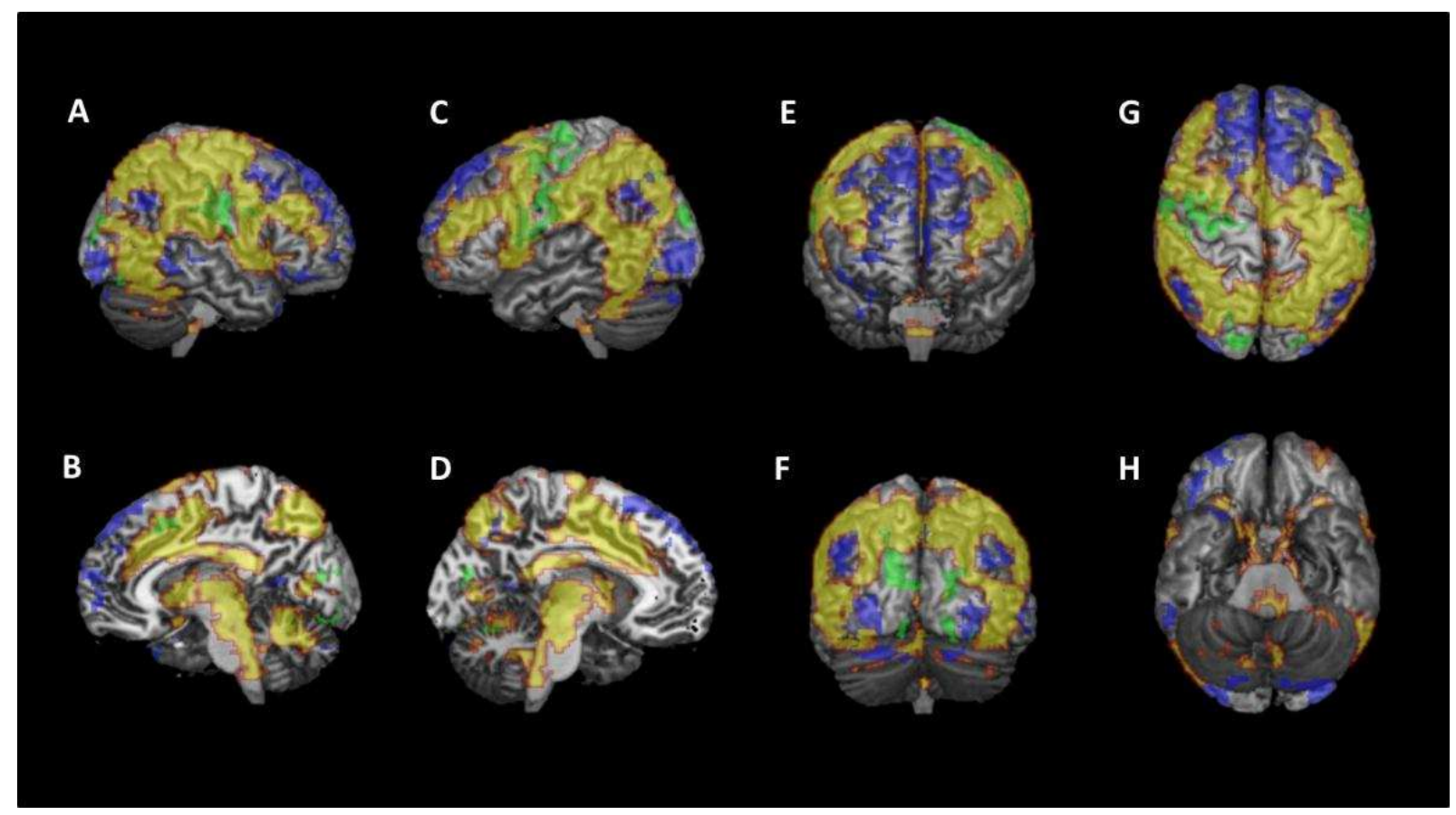

Figura 34. Mapa probabilístico de ativação de grupo dos experimentos de atenção automática e atenção voluntária $(\mathrm{N}=20)$ com a sobreposição dos mapas relacionados aos contrastes $A>V$ (cor verde), $V>A$ (cor azul) e da análise de conjução (cor amarela). As imagens mostram as representações tridimensionais do cérebro na vista lateral direita $(A)$, secção esquerda $(B)$, vista lateral esquerda $(C)$, secção direita $(D)$, vista anterior $(E)$, vista posterior $(F)$, vista superior $(G)$ e vista inferior $(H)$. 


\section{DISCUSSÃO}

O propósito do nosso estudo foi identificar as principais áreas cerebrais ativadas durante a mobilização encoberta da atenção automática e da atenção voluntária nos testes de Posner (1980).

Os resultados que obtivemos sugerem que existem redes neurais semelhantes, relacionadas à atuação da atenção visual automática e à atuação da atenção visual voluntária.

\subsection{Participantes}

Os indivíduos testados em nosso estudo apresentaram idade e escolaridade em uma faixa relativamente estreita (respectivamente, 21,9 $\pm 3,4$ anos e nível superior incompleto), padrão bastante comum na literatura (Asplund et al., 2010; Hahn et al., 2006; Kincade et al., 2005; Vossel et al., 2006;).

\subsection{Entrevista: questionários e escalas}

A entrevista feita com os voluntários visou caracterizar o seu perfil e seguir os critérios estabelecidos para a sua inclusão ou exclusão no estudo. Com isto se minimizou a variabilidade da amostra experimental.

Quanto à avaliação da classificação socioeconômica, percebemos que houve variação entre as classes. Nossos voluntários foram classificados em classes desde A2 até a C2, mas, no entanto, a maioria esteve presente na classe B1 e B2. No ano de 2011, a população da capital de São Paulo foi representada, primeiramente, pela classe C1 (28,4\%) e, na sequência, pela classe B2 (26,2\%). Informações retiradas da ABEP (2012), com base no levantamento de dados sócio econômico de 2011 IBOPE.

Esse resultado poderia ser justificado pelo fato de que na nossa amostra foram selecionados estudantes de graduação de uma universidade particular, com educação formal de no mínimo 12 anos. Atualmente, estudos com neuroimagem demonstraram que a condição socioeconômica de um indivíduo influencia em diferentes áreas de atividade cerebral (Martina et al., 2011). 
$\mathrm{Na}$ escala visual analógica de humor (VAMS), quando realizamos a comparação da escala antes e depois do exame, foi observada uma diferença significativa apenas no fator desconforto (Parente et al., 2005). Este fator representa outros sentimentos e atitudes que incluem: interessado/desinteressado, amistoso/hostil, alegre/triste, satisfeito/insatisfeito. Observamos que a pontuação esteve maior depois do exame de Ressonância Magnética.

Este dado apontou que houve um desconforto dos voluntários provavelmente em razão do tempo do exame de RM, que costumava durar mais de 30 minutos, o que confirma as respostas dos voluntários quando perguntávamos sobre o estado geral após o exame. Alguns relataram cansaço e desconforto.

Apesar do autorrelato avaliado pela VAMS, na entrevista pós-exame de RMf, a maioria dos participantes responderam que realizariam novamente o teste, caso fosse necessário. Os que responderam que não voltariam para realizar o exame poderiam ser justificados pelo simples fato dos voluntários saírem de suas cidades para realizarem o exame em São Paulo. Lembrando que grande parte dos voluntários eram estudantes de graduação, moradores da cidade de Itapeva. Aparentemente, os voluntários aderiram muito bem à realização destas tarefas (Experimentos de Atenção Automática e de Atenção Voluntária).

Os resultados encontrados através desses relatos foram relevantes e podem servir de base para futuras pesquisas, utilizando-se o mesmo procedimento experimental.

\subsection{Tarefa Comportamental}

Conforme esperado, no Experimento de Atenção Automática o tempo de reação na condição em que o estímulo alvo aparecia na mesma posição, condição válida, que o estímulo precedente foi sempre menor do que o tempo de reação na condição em que aparecia na posição oposta, condição inválida, a do estímulo precedente. Semelhantemente, no Experimento de Atenção Voluntária o tempo de reação na condição em que o estímulo alvo aparecia na posição indicada pela pista central foi sempre menor do que o tempo de reação na condição em que aparecia na posição oposta à indicada pela pista central. Esses resultados replicam os achados da literatura (Castro-Barros et al., 2008; Corbetta et al., 2000; Dorich et al., 2009; Hederson, Macquistan, 1993; Nahas, Xavier, 2004; Posner, 1980). 
Na sessão treino assim como na sessão prova do Experimento de Atenção Automática, o tempo de reação na condição válida foi menor do que na condição neutra, indicando um benefício da atenção. Na condição inválida o tempo de reação foi maior do que na condição neutra, indicando um custo da atenção. Esses resultados estão de acordo com a literatura (Castro-Barros et al., 2008; Coull, 1998; Righi, Ribeiro-do-Valle, 2011).

$\mathrm{Na}$ sessão treino assim como na sessão prova do Experimento de Atenção Voluntária, o tempo de reação na condição válida (mesma) foi menor do que na condição neutra, indicando um benefício da atenção. Surpreendentemente, na condição inválida (oposta) o tempo de reação foi menor do que na condição neutra em ambas as sessões deste experimento. Este resultado poderia ser interpretado como indicativo de uma ausência de custo da atenção voluntária. Outra possibilidade é que ele reflita a ausência da influência facilitadora da atenção temporal, que ocorre tardiamente, na condição neutra. Como a pista não era apresentada nesta condição não podia haver a mobilização da atenção temporal. $\mathrm{Na}$ falta da facilitação atencional temporal o tempo de reação na condição neutra seria relativamente longo, podendo inclusive superar aquele da condição inválida. $O$ presente resultado será mais explorado no item 4.6 Comentários sobre a tarefa utilizada no estudo.

\subsection{Eye Tracker}

Como descrito nos resultados, o uso do eye tracker teve como objetivo controlar os movimentos oculares dos voluntários durante as tarefas de mobilização da atenção. Nenhum voluntário foi excluído por esse motivo.

Atualmente, alguns trabalhos publicados com neuroimagem funcional realizam o monitoramento ocular para garantir que os voluntários permaneçam com os olhos fixados em uma determinada cruz ou ponto de fixação durante a tarefa experimental (Doricchi et al., 2010; Hahn et al., 2006; Kincade et al., 2005; entre outros). 


\subsection{Ressonância Magnética Funcional'}

\subsubsection{Atenção Automática}

Demonstramos resposta hemodinâmica em áreas visuais occipitais, em córtex estriado bilateral, e do cerebelo na condição em que o estímulo alvo aparecia na mesma posição que o estímulo precedente (contraste $\mathrm{V}>\mathrm{N}$ ). A ativação das áreas visuais occipitais poderia ser explicada por uma ação facilitadora da atenção. Outra possibilidade é que ela resulte da duplicidade da estimulação sensorial em um mesmo local, conforme sugerido por Peelen et al. (2004) em seu estudo. A ativação do cerebelo é interessante, e não prevista inicialmente. No entanto, a maior parte do cerebelo humano está ligada às redes de associação cerebral e, atualmente, tem sido relacionada como uma região importante para a cognição (Sveljo et al., 2014; Timmann, Daum, 2007), como linguagem e atenção (Buckner, 2013).

$\mathrm{Na}$ condição em que o estímulo alvo aparecia na posição oposta a do estímulo precedente demonstramos uma ativação da região medial do giro frontal superior bilateral, áreas parietais como na borda do sulco intraparietal direito, giro angular bilateral, giro supramarginal esquerdo (contraste $I>N$ ) e no giro frontal inferior bilateral, órbitos-frontais laterais bilaterais, região medial do giro frontal superior bilateral, giro supramarginal bilateral, borda do sulco intraparietal direito e ínsula esquerda (contraste $\mathrm{I}>\mathrm{V}$ ). Estes últimos resultados estão de acordo com os achados de Corbetta e Shulman (2002). Estão também parcialmente de acordo com os achados de Macaluso (2010). O Quadro 1 ilustra esquematicamente estes achados, que podem ser observados em mais detalhe nos Apêndices.

A junção temporoparietal, formada pelos giro supramarginal e giro angular, é ativada durante a reorientação da atenção (Corbetta et al., 2000), independente da expectativa do sujeito (Doricchi et al., 2010). Normalmente, está envolvida em situações comportamentais que o estímulo alvo é detectado no local não atendido. As condições inválidas representadas no nosso estudo pelos contrastes $1>\mathrm{N}$ e $\mathrm{I}>\mathrm{V}$ apresentarem o sinal BOLD positivo nesses locais.

\footnotetext{
1 O termo "ativação" nos dados de Ressonância Magnética funcional se refere à resposta hemodinâmica verificada pelo efeito BOLD positivo.
} 


\begin{tabular}{|c|c|c|c|}
\hline \multicolumn{4}{|c|}{ ATENÇÃO AUTOMÁTICA } \\
\hline Válida > Neutra & Inválida > Neutra & Válida > Inválida & Inválida > Válida \\
\hline $\begin{array}{l}\text { Lobo Frontal } \\
\text { - não encontrado }\end{array}$ & $\begin{array}{l}\text { Lobo Frontal } \\
\text { - giro frontal medial } \\
\text { bilateral }\end{array}$ & $\begin{array}{l}\frac{\text { Lobo Frontal }}{\text { - não encontrado }} \\
\text { na }\end{array}$ & $\begin{array}{l}\text { Lobo Frontal } \\
\text { - giro frontal medial } \\
\text { bilateral } \\
\text { - giros órbitos-frontais } \\
\text { laterais bilaterais } \\
\text { - giro frontal inferior } \\
\text { bilateral } \\
\text { - giro frontal superior } \\
\text { direito }\end{array}$ \\
\hline$\frac{\text { Lobo Parietal }}{\text { - não encontrado }}$ & $\begin{array}{l}\text { Lobo Parietal } \\
\text { - borda do sulco } \\
\text { intraparietal direito } \\
\text { - giro angular bilateral } \\
\text { - giro supramarginal } \\
\text { esquerdo }\end{array}$ & $\begin{array}{l}\text { Lobo Parietal } \\
\text { - giro pós central } \\
\text { (opérculo parietal) } \\
\text { direito }\end{array}$ & $\begin{array}{l}\text { Lobo Parietal } \\
\text { - giro supramarginal } \\
\text { bilateral } \\
\text { - borda do sulco } \\
\text { intraparietal direito }\end{array}$ \\
\hline$\frac{\text { Lobo Temporal }}{\text { - não encontrado }}$ & $\frac{\text { Lobo Temporal }}{\text { - não encontrado }}$ & $\frac{\text { Lobo Temporal }}{\text { - não encontrado }}$ & $\frac{\text { Lobo Temporal }}{\text { - não encontrado }}$ \\
\hline $\begin{array}{l}\text { Lobo Occipital } \\
\text { - Lobo Occipital } \\
\text { (córtex estriado) } \\
\text { bilateral }\end{array}$ & $\frac{\text { Lobo Occipital }}{\text { - não encontrado }}$ & $\begin{array}{l}\text { Lobo Occipital } \\
\text { - lobo occipital } \\
\text { (córtex estriado) } \\
\text { - lobo occipital } \\
\text { (córtex extraestriado) } \\
\text { direito } \\
\text { - pólo occipital } \\
\text { esquerdo }\end{array}$ & $\frac{\text { Lobo Occipital }}{\text { - não encontrado }}$ \\
\hline$\frac{\text { Outras áreas }}{\text { - Cerebelo esquerdo }}$ & $\begin{array}{l}\text { Outras áreas } \\
\text { - giro do cíngulo } \\
\text { anterior esquerdo } \\
\text { - cerebelo bilateral } \\
\text { - ponte bilateral } \\
\text { - mesencéfalo direito } \\
\text { - giro parahipocampal } \\
\text { esquerdo }\end{array}$ & $\frac{\text { Outras áreas }}{\text { - não encontrado }}$ & $\frac{\text { Outras áreas }}{- \text { ínsula esquerda }}$ \\
\hline
\end{tabular}

Quadro 1. Representação das áreas neurais envolvidas com a Atenção Automática, nas condições Válida $>$ Neutra $(V>N)$, Inválida $>$ Neutra $(I>N)$, Válida $>$ Inválida $(V>I)$ e Inválida $>$ Válida $(I>V)$.

Outras regiões, também conhecidas como áreas ventrais, foram observadas em nosso estudo como o giro frontal inferior e a ínsula que respondem para a reorientação e a expectativa da reorientação da atenção.

Não houve, portanto a dominância geral do hemisfério direito relatada por Arrington et al. (2000). Recentemente Dorrichi et al. (2010) também encontraram evidências de ativação bilateral na junção temporoparietal quando contrastaram a condição inválida com a condição neutra (contraste $\mathrm{l}>\mathrm{N}$ ). 
Assim, confirmamos a nossa hipótese neuroanatômica: as áreas cerebrais relacionadas com a reorientação da atenção automática incluem a junção temporoparietal (giro supramarginal e giro angular), giro frontal inferior e ínsula. Entretanto, não evidenciamos maior participação do hemisfério cerebral direito.

\subsubsection{Atenção Voluntária}

Demonstramos ativação das áreas frontais (giro frontal superior e giro órbitos frontais mediais esquerdos), parietais (pré-cuneus) e áreas occipitais (giro fusiforme bilateral) na condição em que o estímulo alvo aparecia no local indicado pela pista (contraste $\mathrm{V}>\mathrm{N}$ ). Esses resultados estão de acordo com achados da literatura. Assim, Kastner et al. (1999) descreveram na condição válida ativação da rede frontoparietal dorsal, Heinze et al. (1994); Kastner et al. (1999) e Martinez et al. (1999) das áreas occipitais. Conforme a nossa hipótese neuroanatômica foi observada a ativação das redes frontoparietais dorsais, mas não tão bem delimitadas como descrevemos anteriormente (na Introdução), onde havia o envolvimento do campo ocular frontal e do sulco intraparietal.

O fato das redes frontoparietais dorsais mostrarem ativação com a apresentação da pista e durante o intervalo que precede a apresentação do estímulo alvo (Kelley et al., 2008) reforça a ideia de seu importante envolvimento na geração dos sinais atencionais.

$\mathrm{Na}$ condição em que o estímulo alvo aparecia no local oposto ao indicado pela pista demonstramos uma ativação giro frontal superior bilateral, giro frontal inferior esquerdo, giros órbito-frontais laterais bilaterais, giro supramarginal esquerdo, pólo temporal esquerdo e lobo occipital (extraestriado) bilateral (contraste $\mathrm{I}>\mathrm{N}$ ) e no contraste $\mathrm{I}>\mathrm{V}$ encontramos regiões muito semelhantes com as descritas anteriormente como o giro frontal superior direito, giro frontal inferior esquerdo, giros órbito-frontais laterais bilaterais, giro frontal médio bilateral, giro supramarginal bilateral, borda do sulco intraparietal bilateral e giro angular esquerdo. O Quadro 2 mostra as áreas cerebrais observadas nos testes de atenção voluntária. 


\begin{tabular}{|c|c|c|c|}
\hline \multicolumn{4}{|c|}{ ATENÇÃO VOLUNTÁRIA } \\
\hline Válida > Neutra & Inválida > Neutra & Válida > Inválida & Inválida > Válida \\
\hline $\begin{array}{l}\text { Lobo Frontal } \\
\text { - giro frontal superior } \\
\text { esquerdo } \\
\text { - giros órbitos-frontais } \\
\text { mediais esquerdo }\end{array}$ & $\begin{array}{l}\text { Lobo Frontal } \\
\text { - giro frontal superior } \\
\text { bilateral } \\
\text { - giro frontal Inferior } \\
\text { esquerdo } \\
\text { - giros órbito-frontais } \\
\text { laterais bilaterais }\end{array}$ & $\begin{array}{l}\frac{\text { Lobo Frontal }}{\text { - não encontrado }} \\
\text { no }\end{array}$ & $\begin{array}{l}\text { Lobo Frontal } \\
\text { - giro frontal superior } \\
\text { direito } \\
\text { - giro frontal inferior } \\
\text { esquerdo } \\
\text { - giros órbito-frontais } \\
\text { laterais bilaterais } \\
\text { - giro frontal médio } \\
\text { bilateral }\end{array}$ \\
\hline $\begin{array}{l}\text { Lobo Parietal } \\
\text { - pré-cuneos } \\
\text { esquerdo }\end{array}$ & $\begin{array}{l}\text { Lobo Parietal } \\
\text { giro supramarginal } \\
\text { esquerdo }\end{array}$ & $\frac{\text { Lobo Parietal }}{\text { - não encontrado }}$ & $\begin{array}{l}\text { Lobo Parietal } \\
\text { - giro supramarginal } \\
\text { bilateral } \\
\text { - borda do sulco } \\
\text { intraparietal bilateral } \\
\text { - giro angular } \\
\text { esquerdo }\end{array}$ \\
\hline$\frac{\text { Lobo Temporal }}{\text { - não encontrado }}$ & $\begin{array}{l}\text { Lobo Temporal } \\
\text {-pólo temporal } \\
\text { esquerdo }\end{array}$ & $\frac{\text { Lobo Temporal }}{\text { - não encontrado }}$ & $\frac{\text { Lobo Temporal }}{\text { - não encontrado }}$ \\
\hline $\begin{array}{l}\text { Lobo Occipital } \\
\text { - giro fusiforme } \\
\text { (córtex extraestriado) } \\
\text { bilateral }\end{array}$ & $\begin{array}{l}\text { Lobo Occipital } \\
\text { - lobo occipital } \\
\text { (córtex extraestriado) } \\
\text { bilateral }\end{array}$ & $\frac{\text { Lobo Occipital }}{\text { - não encontrado }}$ & $\frac{\text { Lobo Occipital }}{\text { - não encontrado }}$ \\
\hline$\frac{\text { Outras áreas }}{\text { - não encontrado }}$ & $\frac{\text { Outras áreas }}{\text { - não encontrado }}$ & $\frac{\text { Outras áreas }}{\text { - não encontrado }}$ & $\frac{\text { Outras áreas }}{\text { - não encontrado }}$ \\
\hline
\end{tabular}

Quadro 2. Representação das áreas neurais envolvidas com a Atenção Voluntária, nas condições Válida $>$ Neutra $(V>N)$, Inválida $>$ Neutra $(I>N)$, Válida $>$ Inválida $(V>I)$ e Inválida $>$ Válida $(\mathrm{I}>\mathrm{V})$.

A observação da resposta hemodinâmica na junção temporoparietal em tarefas de atenção voluntária tem sido constantemente apresentada em situações em que é necessária a detecção do alvo, quando este aparece no local não atendido pela pisca, ou seja, na condição inválida (Corbetta et al., 2000; Corbetta, Shulman, 2002). Essas áreas que têm sido representadas pela reorientação da atenção também foram apresentadas durante a mobilização da atenção automática.

\subsubsection{Diferenças da ativação cerebral associada à mobilização da atenção automática e da atenção voluntária}

Nossos resultados demonstraram que as redes neurais envolvidas com a atenção automática e com a atenção voluntária apresentam algumas diferenças. 
Outros autores encontraram áreas distintas de ativação cerebral (Corbetta, Shulman, 2002; Doricchi et al., 2010). Foi observado que as áreas da atenção automática eram mais lateralizadas para o hemisfério direito e se relacionavam com as redes frontoparietais ventrais (incluindo a junção temporoparietal e o giro frontal inferior). Em nossos experimentos, observarmos o envolvimento do giro frontal inferior direito, mas não das demais áreas.

Se levarmos em consideração que a junção temporoparietal também poderia estar envolvida nos testes de atenção voluntária, provavelmente não seria possível observá-la em nossos experimentos. Isto porque esta análise envolve o contraste de ambos os testes. Desta forma o predomínio da resposta hemodinâmica foi no teste de atenção automática. Kincade et al. (2005) observaram que a junção temporoparietal poderia ser modulada nos testes de atenção voluntária quando o estímulo apresentado fosse relevante.

Nos contrastes mostrados anteriormente, dos testes de atenção automática separados do teste de atenção voluntária, $1>\mathrm{N}$ e $1>\mathrm{V}$, observamos nitidamente $\mathrm{O}$ envolvimento da junção temporoparietal quando os voluntários reorientaram a atenção.

Outras regiões, relacionadas com a atenção automática, também foram observadas no presente trabalho e nos estudos de Hahn et al. (2006), como o giro pré-central e o cúneus bilateral.

De acordo com a literatura, as áreas cerebrais envolvidas com a atenção voluntária estavam relacionadas com as redes frontoparietais dorsais que incluía o lobo parietal superior, sulco intraparietal e campo ocular frontal (Corbetta, Shulman, 2002; Dorrichi et al., 2010; Kastner et al., 2009; Kincade et al., 2005). Nossos resultados demonstraram o envolvimento das redes frontoparietais dorsais, mas não tão bem delimitadas como as dos autores mencionados. Foi possível observarmos o envolvimento do giro frontal superior, borda do sulco intraparietal e pré-cuneus.

Hahn et al. (2006) incluíram em suas pesquisas, de atenção voluntária, uma rede maior no hemisfério cerebral esquerdo, com envolvimento do sulco intraparietal, lobo parietal superior e lobo parietal inferior, pré-cúneos bilateral, giro frontal médio incluindo o sulco frontal superior bilateral e áreas occipitais. Em nosso estudo foi possível verificar áreas muito parecidas com as encontradas neste trabalho como o lobo parietal inferior bilateral (incluindo a borda do sulco intraparietal 
direito), pré-cúneos esquerdo, giro frontal superior e médio bilaterais e as áreas occipitais como o pólo occipital bilateral.

Hopfinger et al. (2000) realizaram um estudo separando o estímulo precedente do estímulo alvo. As áreas encontradas durante a apresentação do estímulo precedente (pista) incluíram o lobo frontal superior e médio, o lobo parietal inferior, o lobo temporal superior, giro occipital lateral e giro do cíngulo posterior. Por outro lado, as áreas envolvidas com a presença do estímulo alvo foram o giro pré e pós central, lobo parietal superior, cuneus e giro lingual.

Outra informação relevante, relacionada com o giro frontal médio direito, citado pelos autores acima, pode correlacionar-se com as duas redes neurais, indicando que esta região pode conter populações neuronais interligando as redes dorsais e ventrais (Fox et al., 2006). Com este achado, podemos imaginar que essas redes não interagem diretamente, mas estão interligadas tendo em comum a participação do giro frontal médio.

Nos testes de atenção voluntária foi possível encontrarmos uma grande parte dessas áreas citadas anteriormente. No entanto, não seria possível distinguirmos o envolvimento das áreas relacionadas com o estímulo precedente em comparação com o estímulo alvo, já que neste estudo não foram separadas essas condições. Esta estratégia significaria maior tempo no interior do aparelho de RM.

A principal distinção entre a rede frontoparietal dorsal e a rede frontoparietal ventral é que a segunda depende da apresentação de um estímulo alvo, refletindo no controle da atenção automática (Macaluso, 2010). Além disso, um sistema de controle adicional é fornecido para interromper o controle da atenção voluntária quando um estímulo saliente ou não esperado ocorre fora do foco atencional (Corbetta et al., 2008).

$\mathrm{Na}$ análise de comparação entre os testes de atenção, não foi possível observarmos predomínio da resposta BOLD no hemisfério direito no Experimento de Atenção Automática, como tem sido descritos pela literatura (Corbetta, Shulman, 2002; Doricchi et al., 2010). Tanto do Experimento de Atenção Automática como no Experimento de Atenção Voluntária, o envolvimento das estruturas cerebrais foram bilaterais. Este achado pode ser devido à técnica empregada neste estudo que envolve campo magnético de 3T, e algoritmo genético para selecionar a melhor sequência de estímulos. Estes pontos representam potencial maior de sensibilidade para a resposta de RMf. 
Quanto às regiões envolvidas em cada um destes testes, foi observado que muitas áreas encontradas eram semelhantes com as descritas por diversos autores.

A literatura descreve envolvimento das redes frontoparietais ventrais (representadas pela junção temporoparietal e giro frontal inferior) na atenção automática (Corbetta, Shulman, 2002; Doricchi et al., 2010; Kincade et al., 2005). No presente estudo, não encontrarmos evidências de ativação na junção temporoparietal, mas foi observada ativação no giro pós-central, localizado em áreas parietais e áreas frontais representadas pelo giro frontal inferior e médio direito, e giro pré-central bilateral. As áreas occipitais do cuneus e do giro fusiforme, e cerebelo bilaterais também estavam presentes.

A ausência de resposta na junção temporoparietal nesta análise de contrastes, $A>V$ e $V>A$, também poderia ser explicada pela participação dessa área nos dois testes (atenção automática e voluntária). Como argumentamis acima, quando contrastadas essas duas condições, áreas que participam de ambas não seriam demonstradas. Por outro lado, na análise de conjunção, esta região deveria ser identificada - como efetivamente o foi. Veja no próximo item as semelhanças entre os testes.

No nosso teste de atenção voluntária, observada por alguns autores como redes frontoparietais dorsais (Corbetta, Shulman, 2002; Dorrichi et al., 2010; Kastner et al., 2009; Kincade et al., 2005), foi possível verificarmos o envolvimento em áreas frontais e áreas parietais. As áreas occipitais foram apresentadas em ambos os testes e encontradas por diversos autores (Hahn et al., 2006; Kincade et al., 2005; Pellen et al., 2004).

Contudo, na análise de contrastes, observamos que as redes neurais, para esses dois tipos de testes de atenção, apresentam algumas áreas cerebrais distintas, com representação cerebral maior em áreas frontoparietooccipitais, nos Experimentos de Atenção Voluntária, já para os Experimentos de Atenção Automática a representação cerebral teve um predomínio em áreas parietooccipitais.

Acreditamos que os testes de atenção voluntária podem não ser puramente voluntários, já que a seta central pode indicar uma tendência automática na direção da orientação depois de algumas tentativas. Similarmente, o experimento de atenção automática pode estar relacionado com um componente voluntário quando os sujeitos reorientam a atenção voluntariamente para o ponto de fixação depois de a atenção ter sido capturada pela pista periférica. 
As áreas encontradas no presente contraste $(A>V$ e $V>A)$ podem ser vistas no Quadro 3.

\begin{tabular}{|c|c|}
\hline ATENÇÃO AUTOMÁTICA & ATENÇÃO VOLUNTÁRIA \\
\hline $\begin{array}{l}\text { Lobo Frontal } \\
\text { - Giro Frontal Inferior direito } \\
\text { - Giro Pré-Central bilateral } \\
\text { - Giro Frontal Medial direito }\end{array}$ & $\begin{array}{l}\text { Lobo Frontal } \\
\text { - Giro Frontal Inferior esquerdo } \\
\text { - Giro Frontal Superior bilateral } \\
\text { - Giro Frontal Médio bilateral }\end{array}$ \\
\hline$\frac{\text { Lobo Parietal }}{\text { - Giro Pós-Central esquerdo }}$ & $\begin{array}{l}\text { Lobo Parietal } \\
\text { - Borda do Sulco Intraparietal direito } \\
\text { - Precuneus esquerdo }\end{array}$ \\
\hline$\frac{\text { Lobo Temporal }}{\text { - Não encontrado }}$ & $\begin{array}{l}\text { Lobo Temporal } \\
\text { - Giro Temporal Superior esquerdo } \\
\text { - Giro Temporal Médio esquerdo }\end{array}$ \\
\hline $\begin{array}{l}\text { Lobo Occipital } \\
\text { - Cuneus bilateral } \\
\text { - Giro Fusiforme (córtex extraestriado) } \\
\text { bilateral }\end{array}$ & $\frac{\text { Lobo Occipital }}{\text { - Pólo Occipital bilateral }}$ \\
\hline$\frac{\text { Outras áreas }}{\text { - Cerebelo bilateral }}$ & $\begin{array}{l}\text { Outras áreas } \\
\text { - Cerebelo bilateral } \\
\text { - Giro Parahipocampal esquerdo } \\
\text { - Giro do Cíngulo Posterior bilateral }\end{array}$ \\
\hline
\end{tabular}

Quadro 3. Representação das áreas neurais envolvidas nos contrastes da Atenção Automática e Atenção Voluntária $(A>V$ e $V>A)$, nas condições de base (válida, neutra e inválida).

\subsubsection{Semelhanças da ativação cerebral associada à mobilização da atenção automática e da atenção voluntária}

Alguns autores não evidenciaram mecanismos neurais distintos para a orientação da atenção automática e voluntária (Kim et al., 1999; Mayer et al., 2004; Peelen et al., 2004; Rosen, 1999).

Kim et al. (1999) observaram que o campo ocular frontal, córtex parietal posterior, giro do cíngulo coordenam todos os aspectos da atenção espacial, entretanto, na tarefa de atenção automática foi possível detectar uma assimetria maior para o lado direito e na tarefa de atenção voluntária um envolvimento maior do córtex parietal posterior e córtex temporooccipital. De qualquer modo, esses resultados foram sugestivos de uma rede comum para esses dois tipos de tarefas. 
Outros autores também demonstraram que uma rede comum de regiões cerebrais estavam envolvidas com a orientação da atenção automática e com a orientação da atenção voluntária. As áreas cerebrais encontradas foram o giro frontal inferior direito, córtex frontal medial (área motora suplementar), córtex cingulado anterior, córtex pré-motor bilateral (incluindo o campo ocular frontal), junção têmporo-parietal direita e pre-cúneos bilateral. A única região que apresentou atividade cerebral diferente foi o giro occipital médio direito. Esse resultado foi sugestivo de que a ativação na região occipital poderia ter sido ocasionada pela diferença física do estímulo precedente representado por uma pista central ou periférica (Peelen et al., 2004).

Em nosso estudo, de acordo com a análise de conjunção, realizada entre os mapas de Atenção Automática e Atenção Voluntária, foi possível observarmos diversas áreas neurais em comum entre ambos os testes.

Deste modo, várias regiões neuroanatômicas apresentaram semelhanças. Foi possível observarmos a resposta BOLD positiva nas áreas frontais: giro pré-central, giro frontal médio, giro frontal medial, todos esses bilateralmente, e giro frontal inferior direito. Mais precisamente, o campo ocular frontal bilateral esteve presente.

Nas áreas parietais houve uma resposta BOLD positiva na borda do sulco intraparietal, giro pós-central, giro angular, giro supramarginal, pré-cuneus, todos bilaterais.

Nas áreas temporais houve resposta BOLD positiva no giro temporal médio bilateral e no giro temporal superior esquerdo.

Finalmente, nas áreas occipitais houve resposta BOLD positiva no giro fusiforme (extraestriado) bilateral e no giro lingual direito.

A porção posterior e anterior do giro do cíngulo também apresentou resposta BOLD positiva bilateral, assim como o giro parahipocampal e a ínsula bilateral.

Áreas subcorticais, como o tálamo e os colículos superiores e inferiores bilaterais, apresentaram o sinal BOLD positivo e o cerebelo bilateral também esteve presente.

As áreas descritas anteriormente podem ser vistas no Quadro 4. 


\section{ATENÇÃO AUTOMÁTICA E VOLUNTÁRIA}

\section{Lobo Frontal}

- Giro Pré-Central bilateral

- Giro Frontal Médio bilateral

- Giro Frontal Inferior direito

- Giro Frontal Medial bilateral

\section{Lobo Temporal}

- Giro Temporal Médio bilateral

- Giro Temporal Superior bilateral

\section{Outras áreas}

- Cerebelo bilateral

- Tálamo bilateral

- Colículos Superiores e Inferiores

- Ínsula bilateral

- Giro do Cíngulo Anterior bilateral

- Giro do Cíngulo Posterior bilateral

- Giro Parahipocampal bilateral

\section{Lobo Parietal}

- Borda do Sulco Intraparietal bilateral

- Giro Pós Central bilateral

- Lobo Parietal Superior bilateral

- Giro Angular bilateral

- Giro Supramarginal bilateral

- Pré-Cuneus bilateral

\section{Lobo Occipital}

- Giro Fusiforme bilateral

- Giro Lingual bilateral

- Cuneus direito

Quadro 4. Representação das áreas neurais envolvidas com a Atenção Automática e Atenção Voluntária, nas condições de base (válida, neutra e inválida), na análise de conjunção, entre os dois tipos de atenção.

Para melhor compreensão dessas semelhanças encontradas, um modelo neuroanatômico será proposto no próximo item.

\subsubsection{Modelo Neuroanatômico da Atenção Visuoespacial}

Muitas áreas que serão descritas adiante, para alguns autores, estavam envolvidas apenas para o controle da mobilização da atenção voluntária ou da mobilização da atenção automática. No entanto, nossos resultados mostraram que as áreas relacionadas com a mobilização da atenção parecem apresentar mais semelhanças do que diferenças. Vide Quadros 3 e 4.

Uma conclusão importante nos estudos de neuroimagem é que a distinção neuropsicológica entre orientação da atenção automática e da atenção voluntária poderá não ser mapeada para diferentes sistemas neurais (Corbetta et al. 2008).

Baseando-se em nossos resultados (Quadro 4) e os encontrados na literatura, pensamos em um possível modelo neuroanatômico de mobilização da atenção visuoespacial, sem distinção entre atenção automática e atenção voluntária. 
O desengajamento da atenção do local de fixação (ponto de fixação) para um novo local aconteceria pelas áreas frontais como o giro frontal superior e giro frontal médio, incluindo o campo ocular frontal, e o lobo parietal superior. As regiões mediais do campo ocular frontal e do lobo parietal superior gerariam sinais para iniciar a mudança da atenção para um novo local. Inclusive as áreas do lobo parietal superior poderiam estar relacionadas não apenas com as mudanças de localização dos estímulos, mas também com as característica e modalidade sensorial dos estímulos (Liu et al., 2003; Serences et al., 2004; Yantis et al., 2002).

As regiões mais laterais do campo ocular frontal e do sulco intraparietal representariam o ato de manter a atenção em um local periférico (Kelley et al., 2008).

A junção temporoparietal (formada pelo giro supramarginal, giro angular e lobo temporal superior) poderia estar envolvida com a detecção do alvo (Corbetta, Shulman, 2002). Esta região apenas seria ativada durante a presença do alvo no local não atendido pela pista, conhecida neste estudo como condição inválida (Indovina, Macaluso, 2004). Alguns autores observaram que esta mesma área à direita é suprimida durante a atenção focada (Shulman et al., 2003; Shulman et al., 2007; Todd et al., 2005). Além dessas áreas, o giro frontal inferior direito também estaria presente durante a reorientação inesperada da atenção (Doricchi et al., 2010).

A ativação das áreas visuais occipitais poderia ser explicada por uma ação facilitadora da atenção, assim como pela presença da forma física dos estímulos (Peelen, 2004). Hopfinger et al. (2000) sugerem a presença do giro lingual durante o aparecimento do estímulo alvo. Enquanto que o giro fusiforme, localizado entre as áreas temporooccipitais, estaria envolvido, na codificação de objetos, dentro do foco atencional (Uncapher et al., 2011).

Outras áreas como o giro do cíngulo anterior $\mathrm{e}$ a ínsula têm sido representadas como regiões atencionais recrutadas na presença de um estímulo não esperado (Shulman et al., 2009).

Além das estruturas corticais, algumas evidências de que as estruturas subcorticas, como o colículo superior, estariam envolvidas na orientação da atenção automática e da atenção voluntária (Bell et al., 2004; Fecteau et al., 2004). O núcleo pulvinar do tálamo teria sido proposto como uma estrutura de passagem (funil) entre as áreas parietais e occipitais (Shipp, 2004). 
Em estudos recentes, como já descritos anteriormente, o envolvimento de áreas cerebelares tem sido relacionada como uma região importante para a cognição (Sveljo et al., 2014; Timmann, Daum, 2007).

A distinção maior que pudemos observar neste estudo foi na análise de contrastes $(A>V$ e $V>A)$. O efeito BOLD positivo esteve presente em áreas frontais, principalmente no giro frontal superior no teste de mobilização da atenção voluntária. O que nos leva a pensar que quando mobilizamos a atenção voluntariamente precisamos realizar a tarefa de modo consciente, alcançando a meta desejada. Portanto, na orientação da atenção automática não seria necessário este planejamento e, consequentemente, não estaria envolvida esta região.

De um modo geral, sugerimos que as redes frontoparietais poderiam estar envolvidas com a mobilização da atenção visuoespacial. Entretando as redes frontoparietais dorsais estariam relacionadas com a orientação da atenção (automática e voluntária) e as redes frontoparientais ventrais com a reorientação da atenção (automática e voluntária).

As áreas frontoparietais envolvidas no controle atencional modulam a atividade de outras regiões perceptuais, como regiões occipitais ou occipitotemporais, para o processamento e reconhecimento de objetos. Sendo assim, o sistema atencional será implantado nas redes frontoparietais enquanto que os efeitos da atenção poderão ser observados em áreas perceptuais do cérebro (Chica et al., 2013).

\subsection{Diferenças entre o nosso estudo e os estudos prévios}

Nosso estudo difere dos estudos anteriores de neuroimagem da literatura de diversas maneiras.

Primeiramente, utilizamos a técnica de imagem funcional relacionada à eventos para determinar a atividade de todo o cérebro nas diferentes condições de orientação da atenção. Outros autores investigaram as áreas de atividade cerebral em experimentos de Atenção Automática e Atenção Voluntária utilizando a análise de ROls (regions of interest) (Doricchi et al., 2010; Hahn et al., 2006; Kincade et al., 2005). Neste tipo de análise apenas regiões cerebrais previamente selecionadas pelo experimentador são avaliadas, o que pode introduzir certo viés nos resultados encontrados (Huettel et al., 2009). 
Nos resultados de Peelen et al. (2004), que não realizaram a análise de ROI, mas sim do cérebro inteiro, em um campo magnético de 1,5 $\mathrm{T}$, não foram demonstradas diferenças relevantes entre a orientação da atenção automática e a orientação da atenção voluntária.

A vantagem de ser utilizado um campo magnético de 3,0 $\mathrm{T}$, como no nosso estudo, é que o aparelho tem o dobro de força do campo magnético ao se comparar com o de 1,5 T. Além disso, apresenta uma velocidade superior refletindo na diminuição de artefatos de movimentos e reduzindo a degradação da imagem (Huang, Castillo, 2009).

Nosso desenho experimental também foi diferente. Avaliamos nos mesmos indivíduos as áreas cerebrais ativadas quando a atenção automática era mobilizada e quando a atenção voluntária era mobilizada. Mais comumente na literatura (por exemplo, Dorichi et al., 2010) indivíduos diferentes foram utilizados nos testes de atenção automática e de atenção voluntária. Além disso, adaptamos as tarefas de Posner utilizando IETs longos (4, 10 e 16 segundo), tempo suficiente para a curva hemodinâmica apresentar o seu efeito máximo, após o aparecimento dos estímulos utilizados.

Em segundo lugar, colhemos dados de neuroimagem apenas dos indivíduos que apresentaram o efeito atencional automático e o efeito atencional voluntário na sessão treino. Desta maneira aumentamos a chance de ter uma mobilização eficiente da atenção espacial na sessão de prova.

Em terceiro lugar, monitoramos em todas as tentativas, por meio de um eyetracker, os movimentos oculares dos participantes.

Em quarto lugar, utilizamos o método dos algoritmos genéticos (Wager, Nichols, 2003) para aumentar o poder estatístico da amostra e otimizar a sequência de apresentação dos estímulos na sessão em que fizemos a imagem funcional relacionada à eventos. Este método foi utilizado por Greene et al. (2009) para investigar o controle neural da atenção automática mobilizada por pistas sociais. No entanto, ele parece não ter sido utilizado ainda em estudos que empregaram o procedimento de Posner (1980).

Em resumo, nossos experimentos apresentam aspectos de incorporação de novas tecnologias e evolução metodológica que, acredimos, podem ter trazido algumas vantagens, com potencial impacto em revelar nuances que não foram observadas em pesquisas anteriores. Nosso desenho experimental apresentou IETs 
longos,o que muitos trabalhos não levaram em consideração. No tipo de análise empregada foi possível encontrarmos importantes áreas cerebrais através da resposta BOLD positiva com a análise do cérebro inteiro. Os experimentos empregados foram mais complexos, já que o desenho experimental era de imagem funcional relacionada à eventos (o que permite a análise de cada condição separadamente) e também foi utilizado o método de algoritmos genéticos (para otimizar a sequência de apresentação dos estímulos). Mais do que isso, todos os dados foram coletados em um ambiente com campo magnético relativamente alto $(3,0 \mathrm{~T})$ e monitoramos em toda a sessão de testes os movimentos oculares dos participantes, permitindo assim análise mais fidedigna dos nossos resultados.

\subsection{Comentários sobre a tarefa utilizada no estudo}

Nos testes de atenção visual desenvolvidos por Posner (1980), o voluntário mantem o olhar em um ponto de fixação e reage a estímulos apresentados em dois locais demarcados na tela, um do lado esquerdo e outro do lado direito deste ponto. A condição neutra é representada pelo piscar simultâneo das duas demarcações nos testes de atenção automática (Kim et al., 1999; Righi, Ribeiro-do-Valle, 2011) e pelo piscar de duas cabeças de setas centrais nos testes de atenção voluntária (Castro-Barros et al., 2010; Kim et al., 1999). Nesta condição, o estímulo alvo tem a mesma probabilidade de ocorrer na demarcação do lado esquerdo ou naquela do lado direito do ponto de fixação. Em nosso estudo, a condição neutra foi caracterizada pela ausência de qualquer estimulação prévia ao alvo, conforme feito também por Castro-Barros et al. (2008). Desta forma, evitamos aumentar o sinal BOLD simplesmente pelo aumento da área estimulada pela pista dupla e garantimos uma condição controle mais adequada.

\subsection{Limitações do estudo}

Neste estudo, as tentativas foram analisadas como um todo $(\mathrm{E} 1+\mathrm{E} 2)$. Alguns autores analisaram as áreas cerebrais ativadas na presença do estímulo precedente separadamente do estímulo alvo (Kincade et al., 2005). Futuramente, podemos adaptar os nossos experimentos para analisar as influências do E1 e do E2 isoladamente. Esta necessidade (maior separação temporal entre E1 e E2) 
implicaria em mudanças radicais em relação às tarefas já estudadas. Este risco dificultaria a comparação e seguimento racional lógico das hipósteses aqui apresentadas. Entretanto, para melhor entendimento destes componentes, é importante planejamento de estudos que envolvam a possibilidade de lidar com as características cognitivas e atencionais de estímulos do tipo E1 e E2 utilizados.

\subsection{Direções Futuras}

Temos o interesse futuro de aplicar a metodologia do presente estudo em diferentes condições experimentais e acrescentar outros tipos de análises para obtermos maior precisão dos nossos resultados.

A análise de conectividade funcional tem sido utilizada em regiões cerebrais de interesse $(\mathrm{ROI})$ de uma determinada rede neural. Em uma próxima etapa poderíamos aplicar esta análise nas diferentes tarefas atencionais utilizadas.

Um passo importante seria analisarmos apenas as tentativas que os sujeitos acertaram, já que no nosso desenho experimental, relacionada à eventos, esta análise é permitida. Também, alguns sujeitos foram excluídos pelo aumento da porcentagem de erros para sua inclusão. Estes dados merecem ser investigados futuramente.

Como vimos, o método de RMf é capaz de determinar áreas cerebrais em atividade, nas diferentes condições experimentais. Os experimentos realizados foram aplicados em indivíduos saudáveis, mas é de grande interesse observamos populações clínicas específicas que apresentam alterações no sistema atencional. Um trabalho desafiador seria verificar as redes neurais atencionais, com a metodologia experimental empregada neste estudo, de pacientes com transtorno de atenção e hiperatividade. Até o momento não há evidências na literatura utilizando as tarefas de Posner associadas com os métodos de neuroimagem. Esses dados poderiam ajudar a entender as alterações apresentadas nesta doença e auxiliaria a desenvolver novos métodos de tratamentos para uma possível evolução do quadro clínico.

Para finalizarmos, também temos o interesse de avaliar a integração entre as redes neurais de movimentação ocular e da atenção. De acordo com a teoria prémotora da atenção, os mecanismos responsáveis pela atenção espacial e os 
envolvidos na programação da movimentação ocular (sacadas) são basicamente os mesmos (Sheliga et al., 1995). 


\section{CONCLUSÕES}

Podemos considerar que as redes frontoparietais são áreas importantes para executar a função de mobilização da atenção visuoespacial. Nossos resultados, assim como os da literatura, ainda não estão claros para definir se há um sistema atencional único ou se existem dois sistemas atencionais diferentes tanto anatomicamente quanto funcionalmente, envolvendo a Atenção Automática e a Atenção Voluntária.

De acordo com o nosso desenho experimental, as redes neurais da Atenção Automática e da Atenção Voluntária são muito semelhantes ou interagem durante toda a tarefa atencional. Apesar de encontrarmos diferenças entre as tarefas comportamentais, não foi possível observamos essas distinções nas áreas cerebrais estudadas.

Conclui-se que nas tarefas de mobilização da atenção automática e da atenção voluntária, com o uso da RMf, há o envolvimento das mesmas áreas cerebrais incluindo as redes frontoparietais dorsais $\mathrm{e}$ as redes frontoparietais ventrais. A principal distinção observada foi a atividade no giro frontal superior nas tarefas de mobilização da atenção voluntária.

Sugerimos que as redes frontoparietais dorsais estão mais envolvidas com a orientação da atenção e as redes frontoparietais ventrais com a reorientação da atenção tanto para mobilizar a Atenção Automática como para mobilizar a Atenção Voluntária. 


\section{REFERÊNCIAS}

Amaro E, Barker GJ. Study design in fMRI: basic principles. Brain and Cogn. 2006;60:220-32.

Arrington CM, Carr TH, Mayer AR, Rao SM. Neural mechanisms of visual attention: object-based selection of a region in space. J Cogn Neurosci. 2000;12:106-17.

Asplund CL, Todd JJ, Snyder AP, Marois R. A central role for the lateral prefrontal cortex in goal-directed and stimulus-driven attention. Nat Neurosci. 2010;13(4):50712.

Associação Brasileira de Empresas de Pesquisa, ABEP, 2012. [cited 2011 apr. 11]. Available from: http://www.abep.org.br/.

Bell $\mathrm{AH}$, Fecteau JH, Munoz DP. Using auditory and visual stimuli to investigate the behavioral and neuronal consequences of reflexive covert orienting. J Neurophysiol. 2004;91:2172-84.

Berger A, Henik A, Rafal R. Competition between endogenous and exogenous orienting of visual attention. J Exp Psychol Gen. 2005;2:207-21.

Birn RM, Saad ZS, Bandettini PA. Spatial heterogeneity of the nonlinear dynamics in the FMRI BOLD response. Neuroimage. 2001;14:817-26.

Briand KA, Klein RM. Is Posner's "beam" the same as Treisman's "glue"?: On the relation between visual orienting and feature integration theory. J Exp Psychol Hum Percept Perform. 1987;13:228-41.

Buckner RL. The cerebellum and cognitive function: 25 years of insight from anatomy and neuroimaging. Neuron. 2013;80:807-15.

Castro-Barros BA, Lacerda AM, Righi LL, Ribeiro-do-Valle LE. Lateral asymmetry of voluntary attention orienting. Braz J Med Biol Res. 2010;43:745-58.

Castro-Barros BA, Righi LL, Grechi G, Ribeiro-do-Valle LE. Interlateral asymmetry in the time course of the effect of a peripheral prime stimulus. Brain Cogn. 2008;66(3):265-79.

Chica AB, Bartolomeo P, Lupiánez J. Two cognitive and neural systems for endogenous and exogenous spatial attention. Behav Brain Res. 2013;237:107-23.

Coull JT. Neural correlates of attention and arousal: insights from electrophysiology, functional neuroimaging and psychopharmacology. Prog Neurobiol. 1998; 55(4):34361.

\footnotetext{
* De acordo com:

International Committee of Medical Journal Editors. [Internet]. Uniform requirements for manuscripts submitted to Biomedical Journal: sample references. [updated 2011 Jul 15]. Available from: http://www.icmje.org
} 
Corbetta M, Kincade M, Ollinger JM, McAvoy MP, Shulman GL. Voluntary orienting is dissociated from target detection in human posterior parietal cortex. Nat Neurosci. $2000 ; 3(3): 292-7$.

Corbetta M, Shulman GL. Control of goal-directed and stimulus-driven attention in the brain. Nat Rev Neurosci. 2002;3:201-15.

Corbetta M, Patel G, Shulman G. The reorienting system of the human brain: from environment to theory of mind. Neuron. 2008;58:306-24.

Doricchi F, Macci E, Silvetti M, Macaluso E. Neural correlates of the spatial and expectancy components of endogenous ans stimulus-driven orienting of attention in the Posner task. Cereb Cortex. 2010;20:1574-85.

Fecteau JH, Bell AH, Munoz DP. Neural correlates of the au- tomatic and goal-driven biases in orienting spatial attention. J Neurophysiol. 2004;92:1728-37.

Fox MD, Corbetta M, Snyder AZ, Vincent JL, Raichle ME. Spontaneous neu- ronal activity distinguishes human dorsal and ventral attention systems. Proc Natl Acad Sci U S A. 2006;103(26):10046-51.

Gazzaniga MS, Ivry RB, Mangun GR. Attention and selective perception Cognitive neuroscience: the biology of the mind. In: Gazzaniga MS, Ivry RB, Mangun GR, editors. New York: Norton; 1998. p. 207-45.

Glover GH. Decovolution of impulse response in event-related BOLD fMRI. Neuroimage. 1999;9:416-29.

Godijn R, Theeuwes. Programming of endogenous and exogenous saccades: evidence for a competitive integration model. J Exp Psychol Hum Percept Perform. 2002;28(5):1039-54.

Gorenstein C, Andrade L. Validation of a Portuguese version of the Beck Depression Inventory and the State-Trait Anxiety Inventory in Brazilian subjects. Braz J Med Biol Res. 1996;29:453-57.

Gorenstein C, Andrade L, Vieira Filho AH, Tung TC e Artes R. Psychometric properties of the Portuguese version of the Beck Depression Inventory on Brazilian college students. J Clin Psychol. 1999;55(5):553-62.

Greene DJ, Mooshagian E, Kaplan EZ, lacoboni M. The neural correlates of social attention: automatic orienting to social and nonsocial cues. Psychol Res. 2009;73:499-11.

Guimarães FG. Escalas analógicas visuais na avaliação de estados subjetivos. Rev Psiquiatr Clín. 1998;25(5):217-22.

Hahn B., Ross TJ, Stein EA. Neuroanatomical dissociation between bottom-up and top-down processes of visuospatial selective attention. Neuroimage. 2006;32:842-53. 
Heinze HJ, Luck SJ, Münte TF, Gös A, Mangun GR, Hillyard. Attention to adjacent and separate positions in space: an electrophysiological analysis. Percept Psychophysics. 1994;56(1):42-52.

Helene, AF, Xavier, GF. A construção da atenção a partir da memória. Rev Bras Psiquiatr. 2003;25(2):12-20.

Henderson JM. Stimulus discrimination following covert attentional orienting yo an exogenous cue. J Exp Psychol Hum Percept Perform. 1991;17(1):91-106.

Henderson JM, Macquistan AD. The spatial distribution of attention following an exogenous cue. Percept Psychophys. 1993;53(2):221-30.

Heson R. Analysis of variance. In: Friston K, et al. editors. Statistical parametric mapping. UK: Elsevier; 2006. p. 193-210.

Hopfinger JB, Buonocore $\mathrm{MH}$, Mangun GR. The neural mechanisms of top-down attentional control. Nat Neurosci. 2000;3(3):284-91.

Huang BY, Castillo M. Neurovascular imaging at 1.5 tesla versus 3.0 tesla. Magn Reson Imaging Clin N Am. 2008;17(1):29-46.

Huettel SA, Song AL, McCarthy G. Functional magnetic resonance imaging. Massachusetts: Sinauer Associates; 2009. p. 293-329.

Indovina I, Macaluso E. Dissociation of stimulus relevance and saliency factors during shifts of visuospatial attention. Cereb Cortex. 2007;17:1701-11.

Jonides J. Voluntary vs. automatic control over the mind's eye's movement. In: Long J, Baddeley AD, editors. Attention and performance IX. Hillsdale, NJ: Erlbaum; 1981. p. 187-203.

Kastner S, Pinsk MA, Weerd RD, Ungerleider LG. Increased activity in human visual cortex during directed attention in the absence of visual stimulation. Neuron. 1999;22:751-61.

Kelley TA, Serences JT, Giesbrecht B, Yantis S. Cortical Mechanisms for Shifting and Holding Visuospatial Attention. Cereb Cortex. 2008;18(1):114-25.

Kendall $\mathrm{P}$, Hollon S, Beck A, Hammen $\mathrm{C}$ e Ingram R. Issues and recommendations regarding use of the Beck Depression Inventory. Cognit Ther Res. 1987;11:289-99.

Klein RM. Inhibition of return. Trends Cogn Sci. 2000;4(4):138-47.

Klein R, Hansen E. Chronometric analysis of apparent spotlight failure in endogenous visual orienting. J Exp Psychol Hum Percept Perform. 1990;16:790-801.

Kincade JM, Abrams RA, Astafiev SV, Shulman GL, Corbetta M. An event-related functional magnetic resonance imaging study of voluntary and stimulus-driven orienting of attention. J Neurosci. 2005;25(18):4593-604. 
Kim YH, Gitelman DR, Nobre AC, Parrish TB, LaBar KS, Mesulam MM. The largescale neural network for spatical attention displays multifunctional overlap but differencial asymmetry. Neuroimage. 1999;9:269-77.

Liu TS, Slotnick SD, Serences JT, Yantis S. Cortical mechanisms of feature-based attentional control. Cereb Cortex. 2003;13(12):1334-43.

Logothetis NK. What we can do and what we cannot do with fMRI. Nature. 2008;453(12):869-78.

Lu ZL, Dosher BA. Spatial attention: different mechanisms for central and peripheral temporal precues? J Exp Psychol Hum Percept Perform. 2000;26(5):1534-48.

Macaluso $\mathrm{E}$. Orienting of spatial attention and the interplay between the senses. Cortex. 2010;46:282-97.

Martina L, Ryan Haynes M, Barter JW, Weinberger DR, Zink CF. Subjective socioeconomic status predicts human ventral striatal response to social status information. Curr Biol. 2011;21(9):794-97.

Martinez A, Anllo-Vento L, Sereno MI, Frank LR, Bruxton RB, Dubowitz DJ, Wong $\mathrm{EC}$, Hinrichs $\mathrm{H}$, Heinze $\mathrm{HJ}$, Hillyard. Involvement of striate and extrastriate visual cortical areas in spatial attention. Nat Neurosci. 1999;2(4):364-9.

Matthews PM, Jezzard P. Functional magnetic resonance imaging. J Neurol Neurosurg. 2004;75:6-12.

Mazziotta J, Toga A, Evans A, Fox P, Lancaster J, Zilles K, et al. A probabilistic atlas and reference system for the human brain: International Consortium for Brain Mapping (ICBM) Phil Trans R Soc Lond B Biol Sci. 2001;356:1293-322.

Mayer AR, Dorflinger JM, Rao SM, Seidenberg M. Neural networks underlying endogenous and exogenous visual-spatial orienting. Neuroimage. 2004;23(2):53441.

Muftuler LT, Nalcioglu O. Improvement of temporal resolution in fMRI using slice phase encode reordered 3D EPI. Magn Reson Med. 2000;44:485-90.

Muller HJ, Findlay JM. The effect of visual attention on peripheral discrimination thresholds in single and multiple elements displays. Acta Psychol. 1988;69(2):12955.

Muller HJ, Rabbitt PMA. Reflexive and voluntary orienting of visual attention: Time course of activation and resistance to interruption. J Exp Psychol Hum Percept Perform. 1989; 15:315-30.

Nahas TR, Xavier GF. Atenção. In: Andrade VM, Santos FL, Bueno OFA. Neuropsicologia hoje. São Paulo: Artes Médicas; 2004. p. 101-24. 
Nichols T, Brett M, Anderson J, Wager T, Poline JB. Valid conjunction inference with the minimum statistic. Neuroimage. 2005;15(3):653-60.

Nobre AC, Sebestyen GN, Giltelman DR, Mesulam MM, Frackowiak RS, Frith CD. Functional localization of the system for visuospatial attention using pósitron emission tomography. Brain. 1997;120:515-33.

Oldfield RC. The assessment and analysis of handedness: The Edinburgh Inventory. Neuropsychologia. 1971;9:97-113.

Parente ACBV, Garcia-Leal C, Del-Ben CM, Guimarães FS, Graeff FG. Subjective and neurovegetative changes in healthy volunteers and panic patients performing simulated public speaking. Eur Neuropsychopharmacol. 2005;15:663-71.

Peelen MV, Heslenfeld DJ, Theeuwes J. Endogenous and exogenous attention shifts are mediated by the same large-scale neural network. Neuroimage. 2004;22:822-30.

Petersen SE, Posner MI. The attention system of the human brain: 20 years after. Annu. Rev. Neurosci. 2012;35:73-89.

Posner MI. Orienting of attention. Q J Exp Psychol. 1980;32:3-25.

Posner MI, Cohen Y. Components of visual orienting. In: Bouwma H, Bowhuis DG, editors. Attentional and performace X. Hillsdale, NJ: Erlbaum; 1984. p. 531-56.

Posner MI, Sheese BE, Odludas Y, Tang YY. Analyzing and shaping human attention network. Neural Netw. 2006;19:1422-29.

Prinzmetal W, McCool C, Park S. Attention: reaction time and accuracy reveal different mechanisms. J Exp Psychol Gen. 2005;134:73-92.

Riggio L, Kirsner K. The relationship between central cues and peripheral cues in covert visual orientation. Percept Psychophysics. 1997;59:885-99.

Righi LL; Ribeiro-do-Valle LE. Automatic attention lateral asymmetry in visual discrimination tasks. Psychol Res. 2011;75:24-34.

Rosen AC, RAO SM, Caffarra P, Scaglioni A, Bobholz JA, Woodley SJ et al. Neural basis of endogenous and exogenous spatial orienting: a functional MRI study. J Cogn Neurosci. 1999;11:135-52.

Serences JT, Schwarzbach J, Courtney SM, Golay X, Yantis S. Control of objectbased attention in human cortex. Cereb Cortex. 2004;14(12):1346-57.

Shellock FG. Your information resource for MRI safety, bioeffects and patient management. In: Shellock R, D Services I, Frank G. Shellock PD, editors. 2001.

Shipp S. The brain circuitry of attention. Trends Cogn Sci. 2004;8:223-30. 
Shulman GL, Astafiev SV, Franke D, Pope DL, Snyder AZ, McAvoly MP et al. Interaction of stimulus-driven reorienting and expectation in ventral and dorsal frontoparietal and basal ganglia-cortical networks. J Neurosci. 2009;29(14):4392-407.

Shulman GL, Astafiev SV, McAvoy MP, d'Avossa G, Corbetta M. Right TPJ deactivation during visual search: functional significance and support for a filter hypothesis. Cereb. Cortex. 2007;17:2625-33.

Shulman GL, McAvoy MP, Cowan MC, Astafiev SV, Tansy AP, d'Avossa G, Corbetta M. Quantitative analysis of attention and detection signals during visual search. J. Neurophysiol. 2003;90:3384-97.

Simmons A, Moore E, Williams SC. Quality control for functional magnetic resonance imaging using automated data analysis and Shewhart charting. Magn Reson Med. 1999;41(6):1274-8.

Sheliga BM, Riggio L, Rizzolatti. Spatial attention and eye movements. Exp Brain Res. 1995;105(2):261-75.

Sveljo O, Culié M, Koprivsek K, Lueié M. The functional neuroimaging evidence of cerebellar involvement in the simple cognitive task. Brain Imaging and Behav. 2014.

Timmann D, Daum I. Cerebellar contributions to cognitive functions: A progress report after two decades of research. Cerebellum. 2007;6:159-62.

Todd JJ, Fougnie D, Marois R. Visual short-term memory load suppresses temporoparietal junction activity and induces inattentional blind- ness. Psychol Sci. 2005;16:965-72.

Umiltà C, Riggio L, Dascola I, Rizzolatti G. Differential effects of central and peripheral cues on the reorienting of spatial attention. Eur $\mathrm{J}$ Cogn Psychol. $1991 ; 3: 247-67$.

Uncapher MR, Benjamin Hutchinson J, Wagner AD. Dissociable Effects of Top-Down and Bottom-Up Attention during Episodic Encoding. J Neurosci. 2011;31:12613-28.

Vossel S, Thiel CM, 2006, Fink GR. Cue validity modulates the neural correlates of covert endogenous orienting of attention in parietal and frontal cortex. Neuroimage. 2006;32:1257-64.

Wager TD, Nichols EN. Optimization of experimental desing in fMRI: a general framework using a genetic algorithm. Neuroimage. 2003;18:293-300.

Worsley KJ. Statistical analysis of activation images. In: Jezzard P, Mathews PM, Smith SM, editors. Functional MRI: an introduction to methods. New York: Oxford University Press; 2001. p. 251-70.

Zuardi AW, Karniol IG. Transcultural evaluation of a self-evaluation scale of subjective states. J Bras Psiquiatr. 1981;131:403-6. 
Yantis S, Jonides J. Abrupt visual onsets and selective attention: voluntary versus automatix allocation. J Exp Psychol Hum Percept Perform. 1990;16(1):121-34.

Yantis S, Schwarzbach J, Serences JT, Carlson RL, Steinmetz MA, Pekar JJ et al. Transient neural activity in human parietal cortex during spatial attention shifts. Nat Neurosci. 2002;5(10):995-1002. 


\section{APÊNDICES}




\section{APÊNDICE A - Termo de Consentimento Livre e Esclarecido TERMO DE CONSENTIMENTO LIVRE E ESCLARECIDO}

ESTUDO: Evolução Temporal e Espacial da Atenção Automática e Voluntária com Ressonância Magnética Funcional

Você está sendo convidado(a) a participar do projeto de pesquisa acima citado. O documento abaixo contém todas as informações necessárias sobre a pesquisa que estamos fazendo. Sua colaboração neste estudo será de muita importância para nós, mas se desistir a qualquer momento, isso não causará nenhum prejuízo a você.

$\mathrm{Eu}$,

profissão...................................................., residente e domiciliado na............................................................ portador da Cédula de

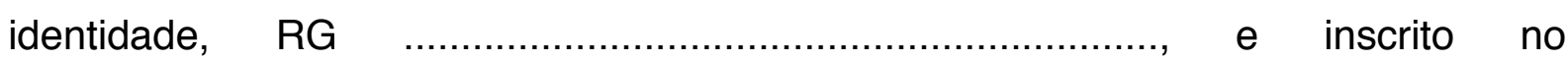
CPF/MF............................. nascido(a) em __ $/$ ___ abaixo assinado(a), concordo de livre e espontânea vontade em participar como voluntário(a) do estudo "Evolução Temporal e Espacial da Atenção Automática e Voluntária com Ressonância Magnética Funcional". Declaro que obtive todas as informações necessárias, bem como todos os eventuais esclarecimentos quanto às dúvidas por mim apresentadas.

Estou ciente que:

I) $\quad$ estudo se faz necessário para que se possam determinar como a apresentação de estímulos visuais influencia no funcionamento do cérebro. Será realizada 1 sessão de teste, com duração de aproximadamente uma hora e trinta minutos;

II) A participação neste projeto não tem objetivo de me submeter a um tratamento, bem como não me acarretará qualquer ônus pecuniário com relação aos procedimentos médico-clínico-terapêuticos efetuados com o estudo;

III) Tenho a liberdade de desistir ou de interromper a colaboração neste estudo no momento em que desejar, sem necessidade de qualquer explicação;

IV) A desistência não causará nenhum prejuízo à minha saúde ou bem estar físico. Não virá interferir no atendimento ou tratamento médico; 
V) Os resultados obtidos durante este ensaio serão mantidos em sigilo, mas concordo que sejam divulgados em publicações científicas, desde que meus dados pessoais não sejam mencionados;

VI) Caso eu desejar, poderei pessoalmente tomar conhecimento dos resultados, ao final desta pesquisa.

( ) Desejo conhecer os resultados desta pesquisa.

( ) Não desejo conhecer os resultados desta pesquisa.

VII) Concordo que o material poderá ser utilizado em outros projetos desde que autorizado pela Comissão de Ética deste Instituto e pelo responsável por esta pesquisa.

( ) Sim ou ( ) Não

VIII ) Poderei contatar a Secretaria da Comissão de Ética em Pesquisa com Seres Humanos - ICB/USP -, no Fone 3091.7733 ou contatar o pesquisado, no Fone (13) 81247996 para recursos ou reclamações em relação ao presente estudo.

São Paulo, de de $20 \ldots . .$.

Voluntário (a):

Telefone (contato):

Testemunha 1 :

Nome / RG / Telefone

Testemunha 2 :

Nome / RG / Telefone

Responsável pelo Projeto:

Thaís Santos Contenças 
APÊNDICE B - Questionário de Identificação

\section{IDENTIFICAÇÃO}

Data: $. . . . . . . . \ldots \ldots / \ldots \ldots \ldots . . \quad$ ID:

Nome

Sexo: masc fem Altura:......... Peso:........ D N: .................. Idade:

Telefone para contato:

e-mail:

Escolaridade:

Ocupação: ............................................ Lateralidade:

Medicação atual:

Crise Convulsiva:

Alimentação antes do exame:

Já passou pela enfermagem? Já fez RM antes?

Clipe metálico ( ), prótese dentária/correlato ( ), prótese ouvido ( ), marca-passo ( ),Cirurgias cranianas ( ), doença neurológica ( ), alteração psiquiátrica ( ).

Obs: 
APÊNDICE C1- Classificação Socioeconômica

\section{Questionário para classificação socioeconômica}

\section{Instrução do chefe da família}

_ analfabeto / primário completo

primário completo / ginasial incompleto ginasial completo / colegial incompleto colegial completo / superior incompleto

_ superior completo

Itens de conforto Familiar - critério ABEP (Associação brasileira de empresas de pesquisa)

\begin{tabular}{|l|c|c|c|c|c|c|c|}
\hline \multicolumn{1}{|c|}{ Itens de posse } & Não tem & \multicolumn{6}{c|}{ Quantidade possuída } \\
\hline & 0 & 1 & 2 & 3 & 4 & 5 & 6 e+ \\
\hline automóvel & & & & & & & \\
\hline televisor em cores & & & & & & & \\
\hline rádio (excluindo o do carro) & & & & & & & \\
\hline banheiro & & & & & & & \\
\hline empregada mensalista & & & & & & & \\
\hline aspirador de pó & & & & & & & \\
\hline máquina de lavar roupa & & & & & & & \\
\hline vídeo cassete ou DVD & & & & & & & \\
\hline geladeira comum ou c/ freezer & & & & & & & \\
\hline
\end{tabular}




\section{APÊNDICE C2 - Classificação Socioeconômica}

A classificação socioeconômica é realizada de acordo com a somatória dos pontos de todos os itens de conforto familiar e a escolaridade do chefe de família. Após a somatória dos itens, o resultado final será correspondente a classificação socioeconômica (Tabela 1).

\section{PONTUAÇÃO DOS ITENS}

\section{Instrução do chefe da família}

(0) analfabeto / primário completo

(1) primário completo / ginasial incompleto

(2) ginasial completo / colegial incompleto

(4) colegial completo / superior incompleto

(8) superior completo

Itens de conforto Familiar - critério ABEP (Associação brasileira de empresas de pesquisa)

\begin{tabular}{|l|c|l|l|l|l|l|l|}
\hline \multicolumn{1}{|c|}{ Itens de posse } & Não tem & \multicolumn{5}{|c|}{ Quantidade possuída } \\
\hline & 0 & 1 & 2 & 3 & 4 & 5 & 6 e+ \\
\hline automóvel & 0 & 4 & 7 & 9 & 9 & 9 & 9 \\
\hline televisor em cores & 0 & 1 & 2 & 3 & 4 & 4 & 4 \\
\hline rádio (excluindo o do carro) & 0 & 1 & 2 & 3 & 4 & 4 & 4 \\
\hline banheiro & 0 & 4 & 5 & 6 & 7 & 7 & 7 \\
\hline empregada mensalista & 0 & 3 & 4 & 4 & 4 & 4 & 4 \\
\hline aspirador de pó & 0 & 2 & 2 & 2 & 2 & 2 & 2 \\
\hline máquina de lavar roupa & 0 & 2 & 2 & 2 & 2 & 2 & 2 \\
\hline vídeo cassete ou DVD & 0 & 2 & 2 & 2 & 2 & 2 & 2 \\
\hline geladeira comum ou c/ freezer & 0 & 4 & 4 & 4 & 4 & 4 & 4 \\
\hline
\end{tabular}

Tabela 1. Classificação Socioeconômica.

\begin{tabular}{c|c|c|c|c|c}
\hline Classificação & Pontuação & Média (Renda) & Classificação & Pontuação & Média (Renda) \\
\hline A1 & $42-46$ & $\mathrm{R} \$ 12.926,00$ & C1 & $18-22$ & $\mathrm{R} \$ 1.541,00$ \\
\hline A2 & $35-41$ & $\mathrm{R} \$ 8.418,00$ & $\mathrm{C} 2$ & $14-17$ & $\mathrm{R} \$ 1.024,00$ \\
\hline B1 & $29-34$ & $\mathrm{R} \$ 4.418,00$ & $\mathrm{D}$ & $8-13$ & $\mathrm{R} \$ 714,00$ \\
\hline B2 & $23-28$ & $\mathrm{R} \$ 2.565,00$ & $\mathrm{E}$ & $0-7$ & $\mathrm{R} \$ 477,00$ \\
\hline
\end{tabular}


APÊNDICE D - Questionário de Edinburgh (adaptado)

Nome

Idade anos

Você já teve alguma tendência a ser canhoto?

Existe algum canhoto na sua família?

Indicar a preferência manual nas atividades abaixo. Assinale ++ na coluna apropriada quando a preferência for tão forte que você nunca use a outra mão. Assinale $++e+$ nas colunas apropriadas quando preferir usar uma das mãos mas de vez em quando também usar a outra. Assinale ++ nas duas colunas quando usar indistintamente qualquer uma das mãos.

\begin{tabular}{|l|l|l|}
\hline ATIVIDADES & DIREITA & ESQUERDA \\
\hline Escrever & & \\
\hline Desenhar & & \\
\hline Jogar uma pedra & & \\
\hline Usar uma tesoura & & \\
\hline Usar um pente & & \\
\hline Usar uma escova de dentes & & \\
\hline Usar uma faca (sem o uso do garfo) & & \\
\hline Usar uma colher & & \\
\hline Usar um martelo & & \\
\hline Usar uma chave de fendas & & \\
\hline Usar uma raquete de ping-pong & & \\
\hline Usar uma faca (com o garfo) & & \\
\hline Usar uma vassoura (mão superior) & & \\
\hline Usar um rodo (mão superior) & & \\
\hline Acender um fósforo & & \\
\hline Abrir um vidro com tampa (mão que segura a tampa) & & \\
\hline Distribuir cartas & & \\
\hline Enfiar a linha na agulha (mão que segura a linha) & & \\
\hline Total & & \\
\hline
\end{tabular}

Quociente de Lateralidade $[(D-E) /(D+E)]$

Dominância Pedal (chutar uma bola)

Dominância Visual Apontando

Acuidade Visual

OE

Fotografando

Visão de Cores

Duração do Sono

Horário Preferido para Acordar

Data da Última Menstruação

Regularidade do Ciclo

Medicamentos em Uso

Hábito de Brincar com Jogos Eletrônicos

Observações 
APÊNDICE E - Teste de Acuidade Visual (Tabela de Leitura para Perto)

\section{TABELA DE LEITURA PARA PERTO}

$0.37 \mathrm{~m}$

$0.50 \mathrm{~m}$

$0.62 \mathrm{~m}$

$0.75 \mathrm{~m}$

$1.00 \mathrm{~m}$

$1.25 \mathrm{~m}$

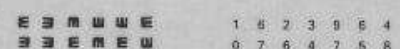

J 1

J 2

$$
\begin{array}{lllllllll}
\exists & \mathbf{E} & \boldsymbol{M} & \boldsymbol{M} & 7 & 8 & 3 & 4 & 7 \\
\text { E } & \mathbf{I} & \mathbf{W} & \mathrm{E} & 6 & 9 & 7 & 5 & 2
\end{array}
$$

$$
\begin{array}{llllllll}
\mathbf{E} & \boldsymbol{W} & \mathbf{E} & \mathbf{m} & 8 & 5 & 4 & 9 \\
\mathbf{W} & \mathbf{m} & \mathbf{m} & \mathbf{E} & 3 & 2 & 7 & 6
\end{array}
$$

$$
\exists \quad \exists \quad \mathrm{m} \quad \mathrm{E} \quad \begin{array}{lllll}
6 & 7 & 2 & 6
\end{array}
$$$$
\text { W E W I } \quad \begin{array}{lllll}
\text { W } & 8 & 5 & 9
\end{array}
$$

$$
\begin{array}{llllllll}
\mathrm{m} & \mathrm{E} & \boldsymbol{W} & \exists & 8 & 4 & 6 & 2 \\
\mathrm{~m} & \Xi & \mathrm{E} & \boldsymbol{W} & 7 & 3 & 8 & 6
\end{array}
$$

\begin{tabular}{|c|c|}
\hline $0.37 \mathrm{~m}$ & $\begin{array}{l}\text { A visio fo mais importante sentido do ser humano. Atraves dela recebemos mais da melade } \\
\text { das informacies que nos chegam do mundo exterior. }\end{array}$ \\
\hline $0.50 \mathrm{~m}$ & Oexame oftalmológico, feito periodicamente, garante urna boa saúde ocular \\
\hline $0.62 \mathrm{~m}$ & Através dele, podem ser detectadas doenças como o glaucoma, diabetes e \\
\hline $.75 \mathrm{~m}$ & hipertensão arterial, entre outras. $\mathrm{O}$ diagnóstico precoce destas \\
\hline $00 \mathrm{~m}$ & doenças evita que danos sejam causados aos \\
\hline $25 \mathrm{~m}$ & olhos e a outras partes do organismo. \\
\hline
\end{tabular}

\section{TABELA DE LEITURA PARA PERTO}


APÊNDICE F - Teste de Ishihara para daltonismo

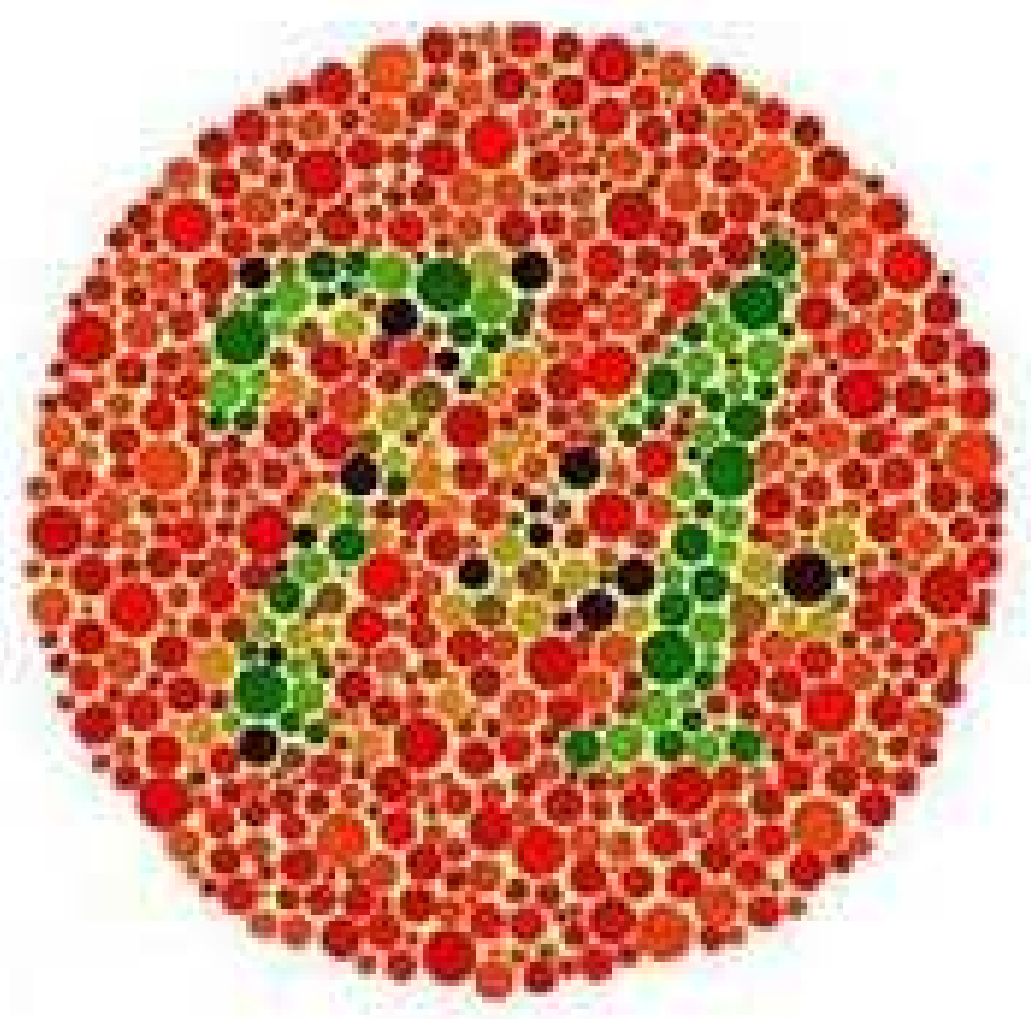




\section{APÊNDICE G - Inventário de Depressão de Beck}

\section{Inventário de Depressão de Beck - BDI}

Este questionário consiste em 21 grupos de afirmações. Depois de ler cuidadosamente cada grupo, faça um círculo em torno do número $(0,1,2$, ou 3$)$ próximo à afirmação, em cada grupo, que descreve melhor a maneira que você tem se sentido na última semana, incluindo hoje. Se várias afirmações num grupo parecerem se aplicar igualmente bem, faça um círculo na que melhor se aplique. Tome o cuidado de ler todas as afirmações, em cada grupo, antes de fazer a sua escolha.

1. 0 Não me sinto triste.

1 Eu me sinto triste.

2 Estou sempre triste e não consigo sair disto.

3 Estou tão triste ou infeliz que não consigo suportar.

2. 0 Não estou especialmente desanimado quanto ao futuro.

1 Eu me sinto desanimado quanto ao futuro.

2 Acho que nada tenho a esperar.

3 Acho o futuro sem esperança e tenho a impressão de que as coisas não podem melhorar.

3. 0 Não me sinto um fracasso.

1 Acho que fracassei mais do que uma pessoa comum.

2 Quando olho para trás, na minha vida, tudo o que posso ver é um monte de fracassos.

3 Acho que, como pessoa, sou um completo fracasso.

4. 0 Tenho tanto prazer em tudo como antes.

1 Não sinto mais prazer nas coisas como antes.

2 Não encontro um prazer real em mais nada.

3 Estou insatisfeito ou aborrecido com tudo.

5. 0 Não me sinto especialmente culpado.

1 Eu me sinto culpado grande parte do tempo.

2 Eu me sinto culpado na maior parte do tempo.

3 Eu me sinto sempre culpado.

6. 0 Não acho que esteja sendo punido.

1 Acho que posso ser punido.

2 Creio que vou ser punido.

3 Acho que estou sendo punido. 
7. 0 Não me sinto decepcionado comigo mesmo.

1 Estou decepcionado comigo mesmo.

2 Estou enojado de mim.

3 Eu me odeio.

8. 0 Não me sinto de qualquer modo pior que os outros.

1 Sou crítico em relação a mim por minhas fraquezas ou erros.

2 Eu me culpo sempre por minhas falhas.

3 Eu me culpo por tudo de mau que acontece.

9. 0 Não tenho quaisquer idéias de me matar.

1 Tenho idéias de me matar, mas não as executaria.

2 Gostaria de me matar.

3 Eu me mataria se tivesse oportunidade.

10. 0 Não choro mais do que o habitual.

1 Choro mais agora do que costumava.

2 Agora, choro o tempo todo.

3 Costumava ser capaz de chorar, mas agora não consigo mesmo que o queira.

11. 0 Não sou mais irritado agora do que já fui.

1 Fico aborrecido ou irritado mais facilmente do que costumava.

2 Atualmente sinto-me irritado o tempo todo.

3 Não me irrito mais com as coisas que costumavam me irritar.

12. 0 Não perdi o interesse pelas outras pessoas.

1 Estou menos interessado pelas outras pessoas do que costumava estar.

2 Perdi a maior parte do meu interesse pelas outras pessoas.

3 Perdi todo o meu interesse nas outras pessoas.

13. 0 Tomo decisões tão bem quanto antes.

1 Adio as tomadas de decisões mais do que costumava.

2 Tenho mais dificuldade em tomar decisões do que antes.

3 Não consigo mais tomar decisões.

14. 0 Não acho que minha aparência esteja pior do que costumava ser.

1 Estou preocupado por estar parecendo velho ou sem atrativos.

2 Acho que há mudanças permanentes na minha aparência que me fazem parecer sem atrativos.

3 Acredito que pareço feio. 
15. 0 Posso trabalhar tão bem quanto antes.

1 Preciso de um esforço extra para fazer alguma coisa.

2 Tenho que me esforçar muito para fazer alguma coisa.

3 Não consigo mais fazer nenhum trabalho.

16. 0 Consigo dormir tão bem como o habitual.

1 Não durmo tão bem quanto costumava.,

2 Acordo uma a duas horas mais cedo do habitualmente e tenho dificuldade em voltar a dormir.

3 Acordo várias horas mais cedo do que costumava e não consigo voltar a dormir.

17. 0 Não fico mais cansado do que o habitual.

1 Fico cansado com mais facilidade do que costumava.

2 Sinto-me cansado ao fazer qualquer coisa.

3 Estou cansado demais para fazer qualquer coisa.

18. 0 Meu apetite não está pior do que o habitual.

1 Meu apetite não é tão bom quanto costumava ser.

2 Meu apetite está muito pior agora.

3 Não tenho mais nenhum apetite.

19. 0 Não tenho perdido muito peso, se é que perdi algum recentemente.

1 Perdi mais do que 2 quilos e meio.

2 Perdi mais do que 5 quilos.

3 Perdi mais do que 7 quilos.

Estou tentando perder peso de propósito, comendo menos: Sim ( ) Não ( )

20. 0 Não estou mais preocupado com minha saúde do que o habitual.

1 Estou preocupado com problemas físicos tais como dores, indisposição do estômago ou prisão de ventre.

2 Estou muito preocupado com problemas físicos e é difícil pensar em outra coisa.

3 Estou tão preocupado com meus problemas físicos que não consigo pensar em qualquer outra coisa.

21. 0 Não notei qualquer mudança recente no meu interesse por sexo.

1 Estou menos interessado por sexo do que costumava estar.

2 Estou muito menos interessado em sexo atualmente.

3 Perdi completamente o interesse por sexo. 
APÊNDICE H - Perguntas sobre Saúde

\section{PERGUNTAS A RESPEITO DE SUA SAÚdE:}

\begin{tabular}{|c|c|c|c|}
\hline 1. & Tem dores de cabeça freqüentes? & SIM $\square$ & $\mathrm{NÃO} \square$ \\
\hline 2. & Tem falta de apetite? & SIM $\square$ & NÃO $\square$ \\
\hline 3. & Dorme mal? & SIM $\square$ & NÃO $\square$ \\
\hline 4. & Assusta-se com facilidade? & SIM $\square$ & NÃO \\
\hline 5. & Tem tremores na mão? & SIM $\square$ & NÃO $\square$ \\
\hline 6. & Sente-se nervoso (a), tenso(a) ou preocupado (a)? & $\operatorname{SIM} \square$ & NÃO $\square$ \\
\hline 7. & Tem má digestão? & $\mathrm{SIM} \square$ & NÃO \\
\hline 8. & Tem dificuldade de pensar com clareza? & $\mathrm{SIM} \square$ & NÃO $\square$ \\
\hline 9. & Tem se sentido triste ultimamente? & SIM $\square$ & NÃO $\square$ \\
\hline 10. & Tem chorado mais do que de costume? & $\operatorname{SIM} \square$ & NÃO $\square$ \\
\hline 11. & $\begin{array}{l}\text { Encontra dificuldades para realizar com satisfação as suas atividades } \\
\text { diárias? }\end{array}$ & SIM $\square$ & NÃO $\square$ \\
\hline 12. & Tem dificuldades para tomar decisões? & SIM $\square$ & NÃO \\
\hline 13. & $\begin{array}{l}\text { Tem dificuldades no serviço (seu trabalho é penoso, Ihe causa } \\
\text { sofrimento)? }\end{array}$ & SIM $\square$ & NÃO $\square$ \\
\hline 14. & É incapaz de desempenhar um papel útil em sua vida? & $\mathrm{SIM} \square$ & NÃO $\square$ \\
\hline 15. & Tem perdido o interesse pelas coisas? & $\mathrm{SIM} \square$ & NÃO $\square$ \\
\hline 16. & Você se sente uma pessoa inútil, sem préstimo? & $\mathrm{SIM} \square$ & NÃO $\square$ \\
\hline 17. & Tem tido a idéia de acabar coma vida? & SIM $\square$ & NÃO $\square$ \\
\hline 18. & Sente-se cansado (a) o tempo todo? & $\mathrm{SIM} \square$ & NÃO $\square$ \\
\hline 19. & Tem sensações desagradáveis no estômago? & $\mathrm{SIM} \square$ & NÃO $\square$ \\
\hline 20. & Você se cansa com facilidade? & SIM $\square$ & NÃO $\square$ \\
\hline
\end{tabular}


APÊNDICE I - Escala Visual Analógica de Humor - VAMS pré RMf

\section{A M S - PRE}

INSTRUÇÕES: Avalie como você se sente agora em relação aos itens abaixo e marque cada linha com um traço vertical no ponto que melhor descreve seus sentimentos. O centro de cada linha indica como você habitualmente se encontra e as extremidades indicam o máximo de cada condição.

ALERTA

CALMO

FORTE

CONFUSO

ÁGIL

APÁTICO

SATISFEITO

PREOCUPADO

RACIOCÍNIO

DIFÍCIL

TENSO

ATENTO

INCAPAZ

ALEGRE

HOSTIL

INTERESSADO

RETRAÍDO
SONOLENTO

AGITADO

FRACO

COM IDÉIAS

CLARAS

DESAJEITADO

DINÂMICO

INSATISFEITO

TRANQUILO

PERSPICAZ

RELAXADO

DISTRAÍDO

CAPAZ

TRISTE

AMISTOSO

DESINTERESSADO

SOCIÁVEL 
APÊNDICE J - Escala Visual Analógica de Humor - VAMS pós RMf

\section{A M S - PóS}

INSTRUÇÕES: Avalie como você se sente agora em relação aos itens abaixo e marque cada linha com um traço vertical no ponto que melhor descreve seus sentimentos. O centro de cada linha indica como você habitualmente se encontra e as extremidades indicam o máximo de cada condição.

ALERTA

CALMO

FORTE

CONFUSO

ÁGIL

APÁTICO

SATISFEITO

PREOCUPADO

RACIOCÍNIO

DIFÍCIL

TENSO

ATENTO

INCAPAZ

ALEGRE

HOSTIL

INTERESSADO

RETRAÍDO
SONOLENTO

AGITADO

FRACO

COM IDÉIAS

CLARAS

DESAJEITADO

DINÂMICO

INSATISFEITO

TRANQUILO

PERSPICAZ

RELAXADO

DISTRAÍDO

CAPAZ

TRISTE

AMISTOSO

DESINTERESSADO

SOCIÁVEL 


\section{APÊNDICE K - Entrevista pós-RMf}

\section{ENTREVISTA PÓS-EXAME RMF}

1. Como você se sentiu de uma forma geral?

2. Você voltaria para fazer o exame?

Tempo de resposta ( ) $<2$ seg ( ) $>2$ seg

3. Qual tarefa achou mais difícil de fazer?

4. Que tipo de estratégia você usou para fazer as tarefas?

5. Diga três palavras que falou durante o exame.

6. Sentiu dor ou sensação desconfortável pela posição? Pontuar de 0 a 10.

7. O (A) Sr. (a) gostaria de perguntar algo sobre o exame ?

8. Dê uma nota de 0 (ruim) a 10 (excelente) para a sua impressão do exame.

\section{OBSERVAÇÕES}

1. Quanto tempo o sujeito ficou na máquina?

2. Fez estrutural no mesmo dia?

3. Possíveis problemas ocorridos.

Entrevistador(a): 
APÊNDICE L - Instrução do Experimento de Atenção Automática e Voluntária

\section{INSTRUÇÕES DOS EXPERIMENTOS}

\section{PARTE I}

1. Você será testado, sentado, em uma sala com iluminação reduzida de modo a reduzir interferências externas.

2. Sua tarefa será manter sempre o olhar em um pequeno ponto no centro da tela de um monitor de vídeo, responder o mais rápido possível com o dedo indicador direito, quando aparecer uma linha vertical no interior da circunferência do lado esquerdo da tela, e pressionar com o dedo médio direito quando aparecer uma linha vertical no interior da circunferência do lado direito.

\section{Teste de Atenção A}

3. Em algumas tentativas haverá uma variação do brilho de uma das circunferências presentes na tela.

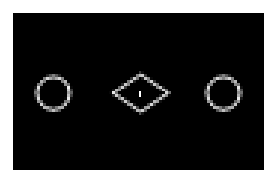

Fixação

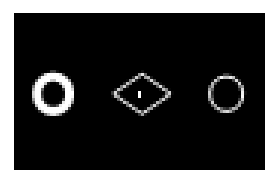

Brilho

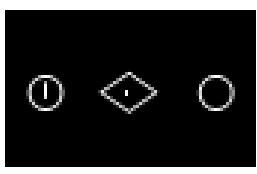

Linha Vertical

\section{Teste de Atenção B}

4. Em algumas tentativas haverá uma seta central indicando o lado que você deverá orientar sua atenção, mas mantenha sempre o olhar no ponto de fixação central na tela.

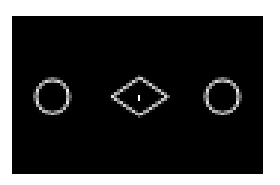

Fixação

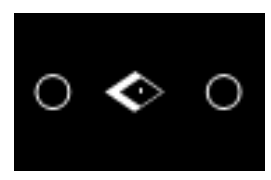

Seta

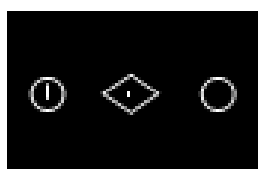

Linha Vertical

\section{PARTE II}

- Você realizará os mesmos testes da sessão anterior, mas será realizado deitado, na máquina de Ressonância Magnética.

- É importante que durante todo o teste você não mexa a cabeça para não borrar a imagem. 


\section{APÊNDICE M - Algoritmos Genéticos}

Os Algoritmos Genéticos ( $A G$ ) são uma classe particular de algoritmos evolutivos que usam técnicas de biologia evolutiva para resolver problemas, resultando em uma melhor solução.

Wagner e Nichols (2003) utilizaram os AG para otimizar a sequência de estímulos de estudos de Ressonância Magnética Funcional relacionada a eventos.

O método é conhecido como Genetic Algorithm: for optimizing experimental trial design, particularly rapid event-related $f M R I$ e está disponível na página http://psych.colorado.edu/ tor/Software/genetic_algorithms.html.

Este método pode ser usado para melhorar as propriedades estatísticas e não estatísticas (validade psicológica) dos desenhos experimentais. Os autores elaboram um script dos AG para ser utilizado juntamente com o programa Matlab. Os exemplos dos scripts foram criados pelos autores (Wagner e Nichols, 2003) e adaptado de acordo com as nossas necessidades experimentais.

Utilizamos um script para o teste de atenção automática e outro para o teste de atenção voluntária. No script escolhido, é necessário inserir o número de condições experimentais, a porcentagem de vezes que cada condição deveria ser apresentada, a duração do run, o intervalo entre os estímulos, o tempo de repetição, a quantidade de runs, o número de contrastes e quais contrastes deveriam ser levados em consideração, as demais opções foram mantidas como sugerida pelos autores.

A partir destes dados, o programa dos AG gera uma sequência, considerada ideal, para os experimentos baseado na eficiência do contraste estimado, na eficiência da resposta hemodinâmica e no desenho experimental. A Tabela 1 representa o número de tentativas para cada condição experimental e a Figura 1 representa a geração das sequências dos estímulos e intervalos do Experimento de Atenção Automática. A Tabela 2 e Figura 2 representam o Experimento de Atenção Voluntária.

Após esta etapa, a sequência dos estímulos e intervalos foram inseridas no software E-prime® $\vee 1.1$. 
Tabela 1. Número total das tentativas para cada condição (válida, neutra e inválida) do Experimento de Atenção Automática, de acordo com o script dos AG, nos diferentes runs (run 1, run 2 e run 3).

\begin{tabular}{lccc}
\hline Automática & Run 1 & Run 2 & Run 3 \\
\hline Válida & 14 & 15 & 12 \\
Neutra & 15 & 15 & 14 \\
Inválida & 13 & 15 & 14 \\
\hline Total & $\mathbf{4 2}$ & $\mathbf{4 5}$ & $\mathbf{4 0}$ \\
\hline
\end{tabular}

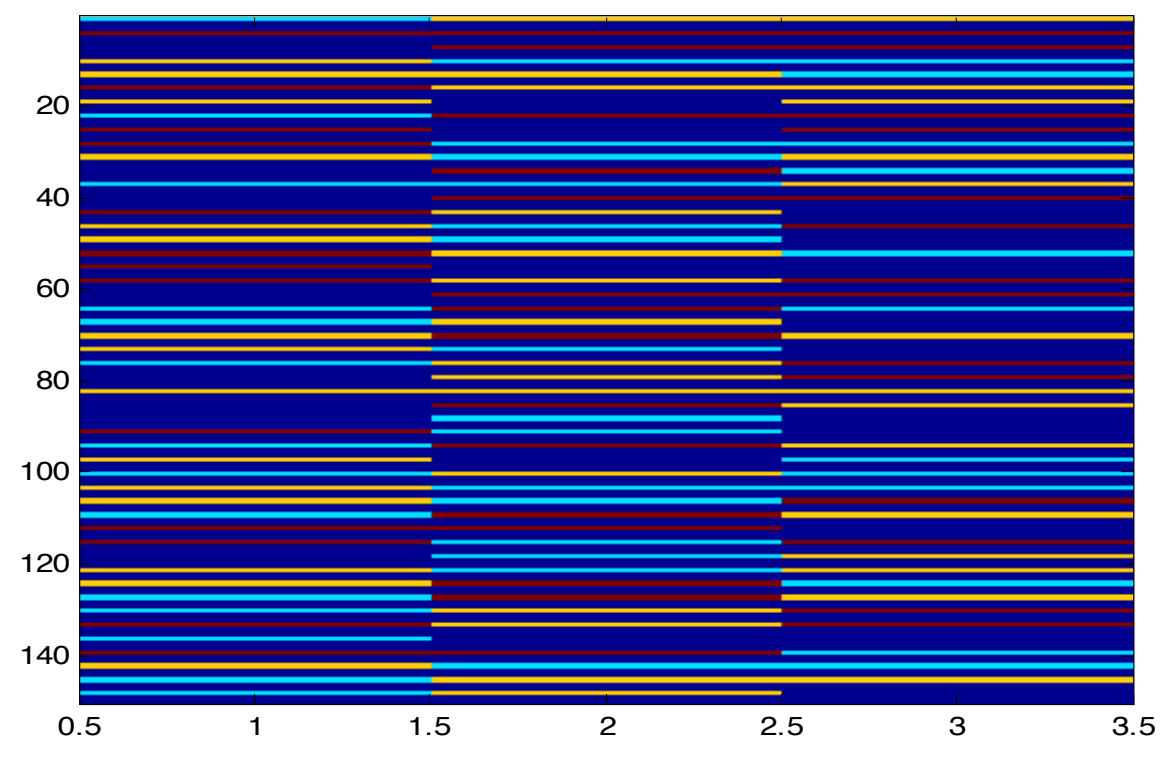

Figura 1. Geração das sequências dos estímulos e intervalos do Experimento de Atenção Automática, com os AG. As pseudorandomizações das tentativas estão representadas em diferentes cores. Azul claro representa a condição válida; Amarelo representa a condição neutra; Vermelho representa a condição inválida; Azul marinho representa os intervalos entre as condições (4, 10 e 16 segundos). Cada linha representa 2 segundos.

Tabela 2. Número total das tentativas para cada condição (válida, neutra e inválida) do Experimento de Atenção Voluntária, de acordo com o script dos AG, nos diferentes runs (run 1, run 2 e run 3).

\begin{tabular}{lccc}
\hline Voluntária & Run 1 & Run 2 & Run 3 \\
\hline Válida & 20 & 19 & 17 \\
Neutra & 13 & 13 & 14 \\
Inválida & 10 & 9 & 12 \\
\hline Total & $\mathbf{4 3}$ & $\mathbf{4 1}$ & $\mathbf{4 3}$ \\
\hline
\end{tabular}




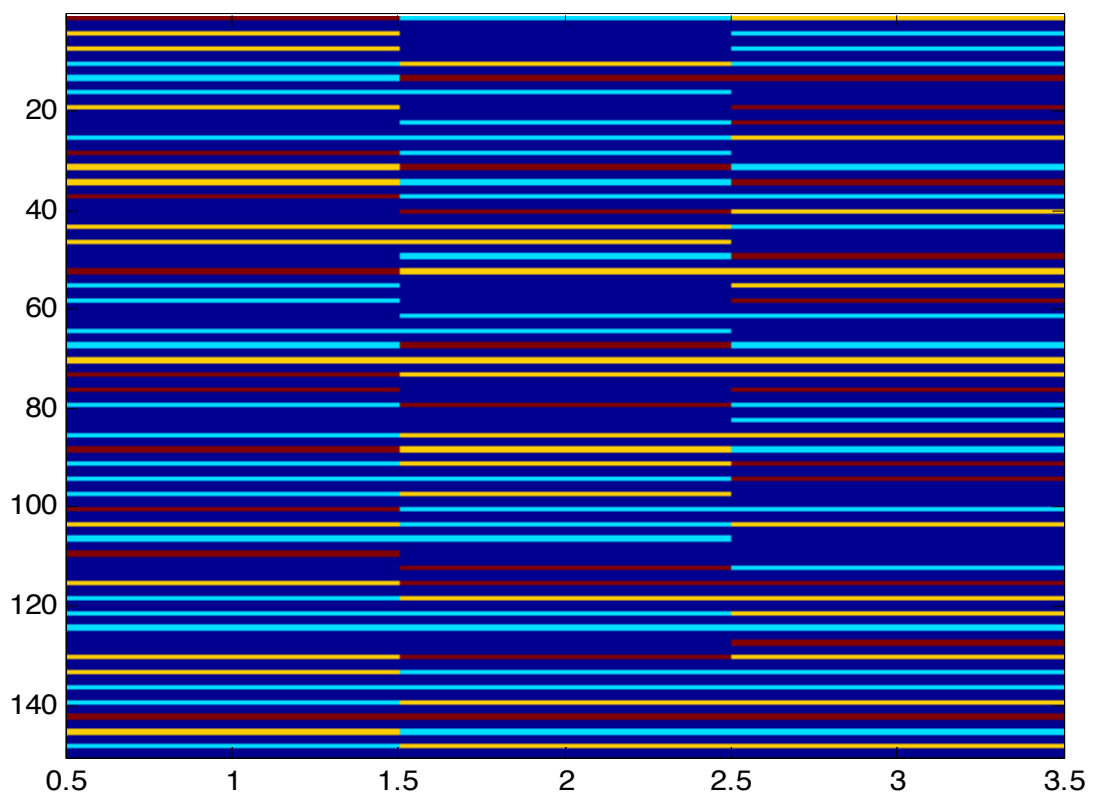

Figura 2. Geração das sequências dos estímulos e intervalos do Experimento de Atenção Voluntária, com os AG. As pseudorandomizações das tentativas estão representadas em diferentes cores. Azul claro representa a condição válida; Amarelo representa a condição neutra; Vermelho representa a condição inválida; Azul marinho representa os intervalos entre as condições (4, 10 e 16 segundos). Cada linha representa 2 segundos. 


\section{APÊNDICE N - Análise de Resultados - RMf}

Primeiro Passo: Mapas de ativação individuais de cada uma das aquisições (RUN1, RUN2 e RUN3). Para atenção automática foi considerado 3 variáveis - EVs (automática válida - $\mathrm{V}$, automática neutra - $\mathrm{N}$ e automática inválida - I) e 4 contrastes $(\mathrm{V}>\mathrm{N}, \mathrm{I}>\mathrm{N}, \mathrm{V}>\mathrm{I}$ e $\mid>\mathrm{V})$. Também foram levadas em consideração as condições da linha de base (Válida, Neutra e Inválida). O mesmo foi considerado para atenção voluntária.

Condições: C1 (cope 1 - válida), C2 (cope 2 - neutra), C3 (cope 3 - inválida), C4 (cope 4 - válida > inválida), C5 (cope 5 - inválida > válida), C6 (cope 6 -válida > neutra) e C7 (inválida $>$ neutra).

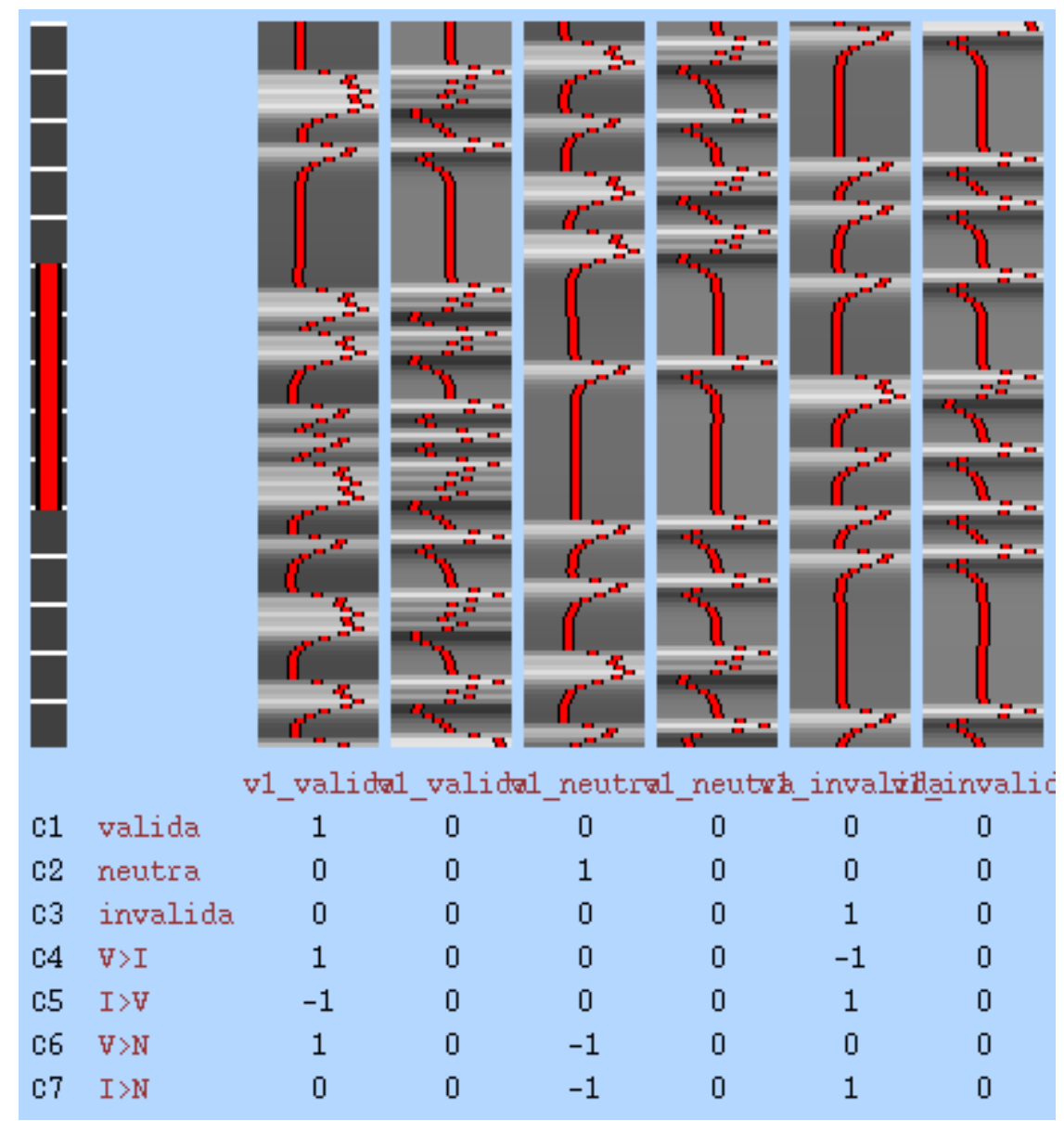


Segundo Passo: Os mapas de ativação foram juntados (RUN1, RUN2 e RUN3) de todos os sujeitos. Foi utilizado o fixed effect, levando em consideração que não houve variação do próprio sujeito entre os RUNS.

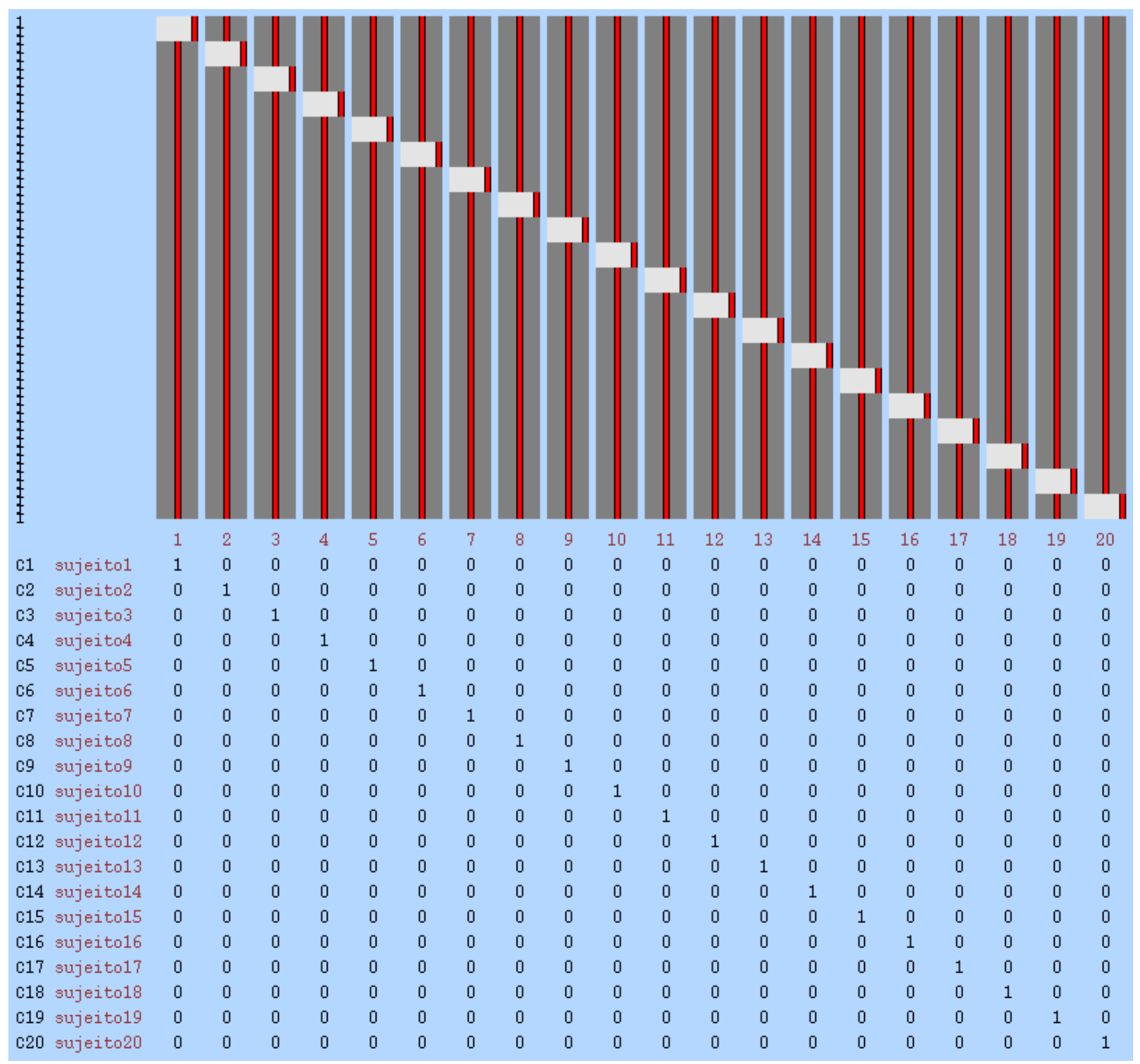


Terceiro Passo: Foi feito a média do grupo, juntando as condições experimentais de todos os sujeitos com o mixed effect. No exemplo abaixo está representado o C5 (cope 5 - Inválida > Válida).

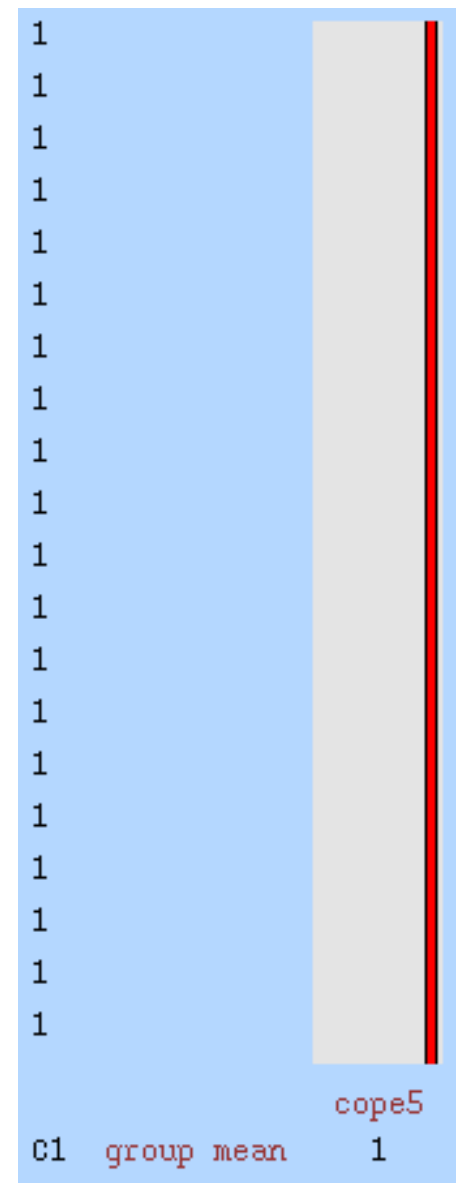


Quarto Passo: Foram levadas em consideração as 3 principais condições de base (Válida, Neutra e Inválida) de todos os sujeitos e nas duas tarefas experimentais (Atenção Automática e Atenção Voluntária). Além disso, realizamos os contrastes da Atenção Automática > Atenção Voluntária e a Atenção Voluntária > Atenção Automática.

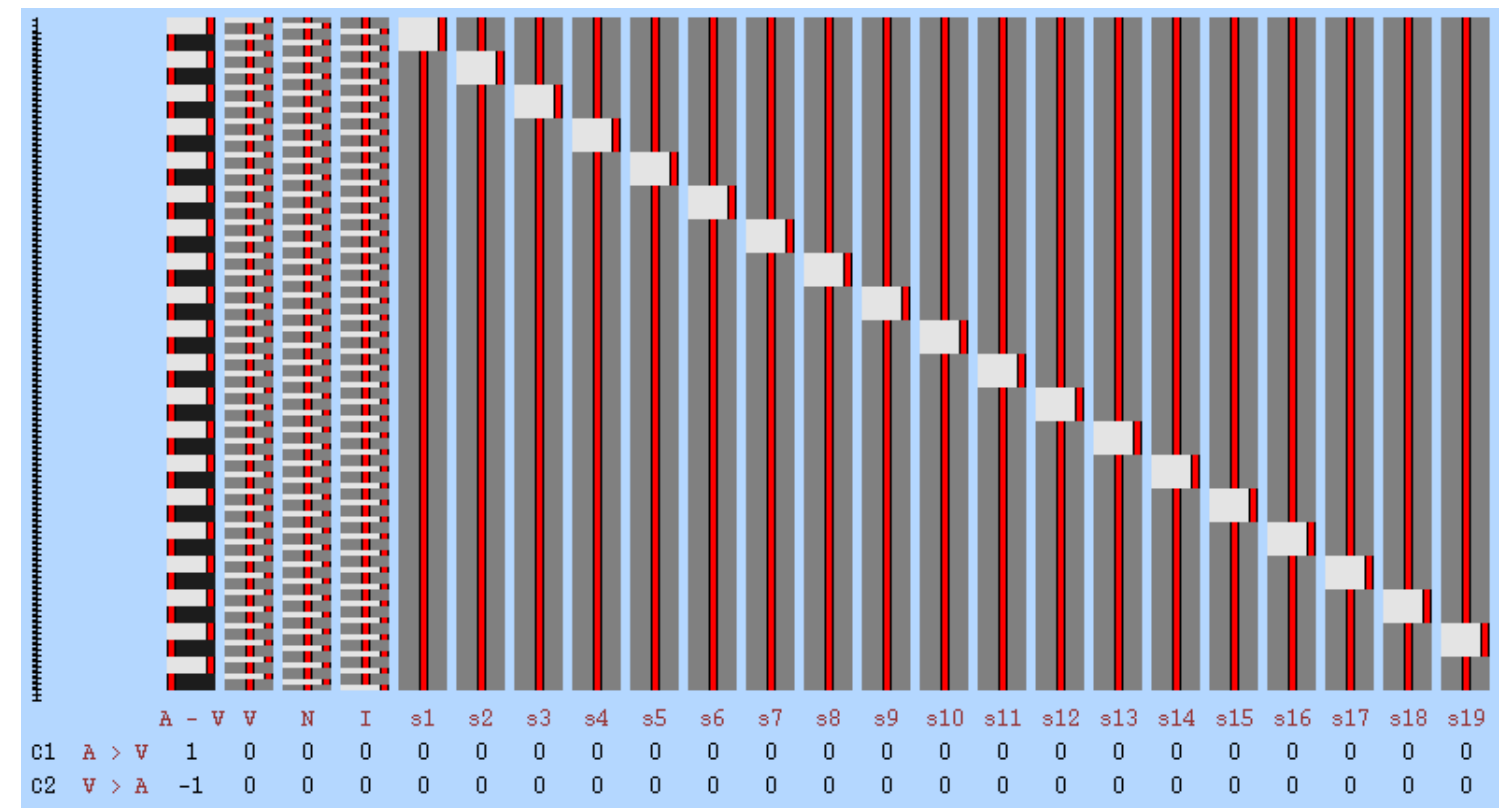

Quinto Passo: Foi feita a análise de conjunção nas 3 principais condições de base (Válida, Neutra e Inválida) de todos os sujeitos nas tarefas de Atenção Automática separadamente da Atenção Voluntária.

Sexto Passo: Após o resultado do quinto passo, uma nova análise de conjunção foi realizada, juntando-se o mapa do Atenção Automática e o da Atenção Voluntária. 
APÊNDICE O - Dados Demográficos

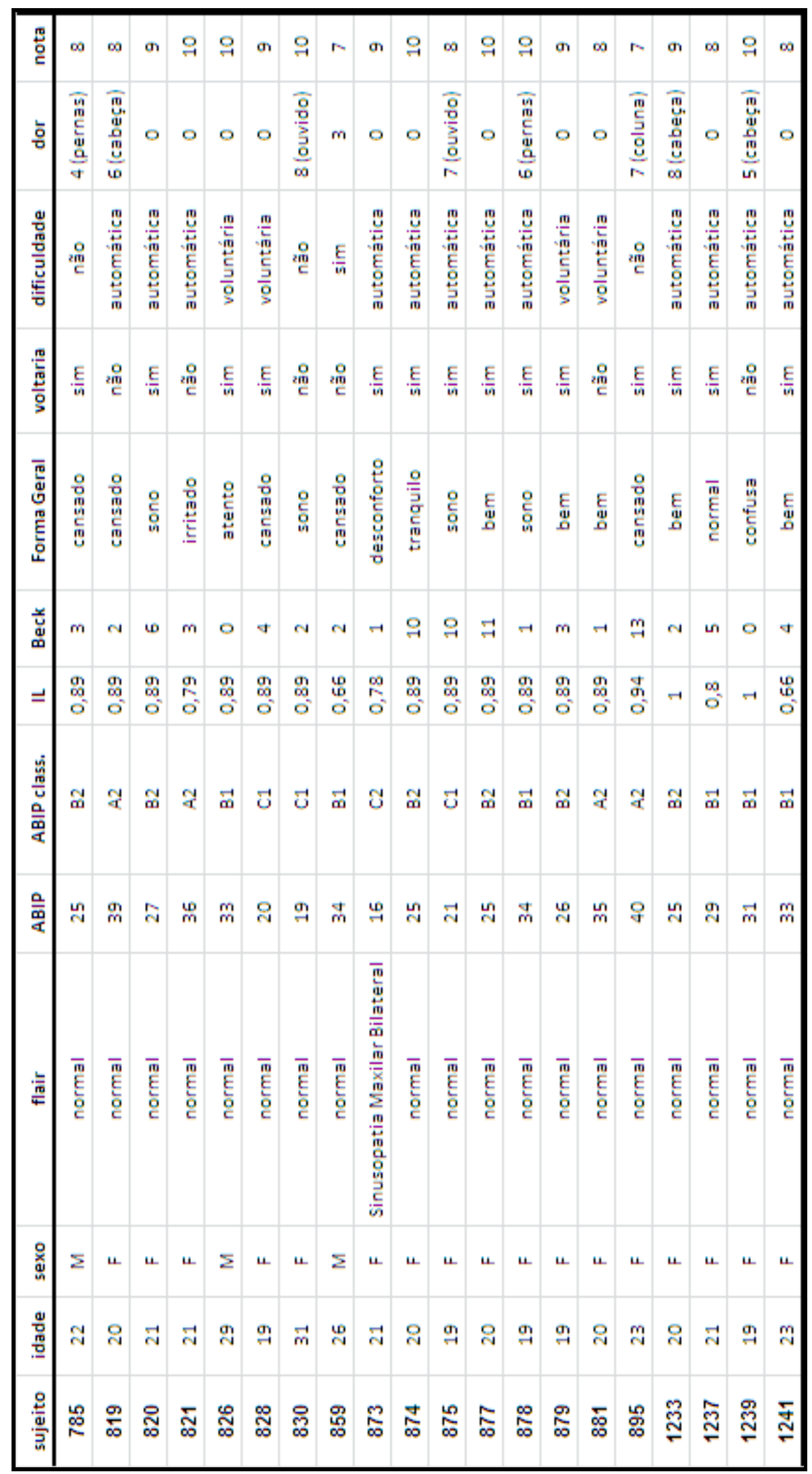


APÊNDICE P - Resultados das Perguntas a Respeito da Saúde

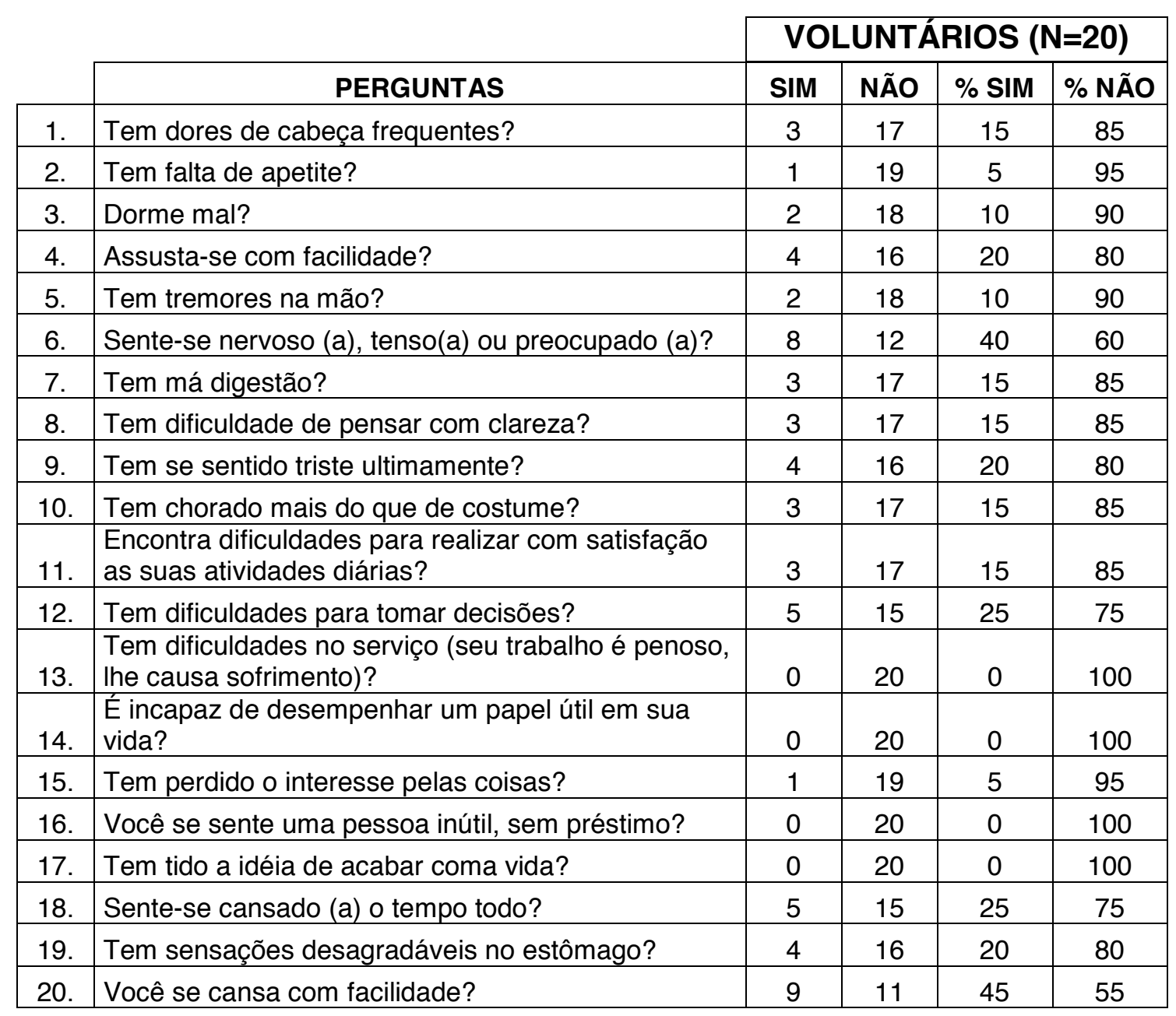

Quadro 1. Este quadro representa as repostas das 20 questões das Perguntas a Respeito da Saúde dos 20 participantes da pesquisa. As porcentagens das respostas "SIM" e NÃO" estão representadas nas duas últimas colunas à direita. 
APÊNDICE Q - Tempo de Reação da Sessão Treino do Experimento de Atenção Automática e Atenção Voluntária.

\begin{tabular}{|c|ccc|ccc|}
\hline & \multicolumn{3}{|c|}{ Atenção Automática } & \multicolumn{3}{c|}{ Atenção Voluntária } \\
\hline TREINO & VÁLIDA & NEUTRA & INVÁLIDA & VÁLIDA & NEUTRA & INVÁLIDA \\
\hline $\mathbf{7 8 5}$ & 371 & 426 & 436 & 345 & 486 & 396 \\
$\mathbf{8 1 9}$ & 604 & 653 & 668 & 624 & 665 & 640 \\
$\mathbf{8 2 0}$ & 398 & 431 & 463 & 288 & 454 & 536 \\
$\mathbf{8 2 1}$ & 461 & 476 & 507 & 299 & 407 & 471 \\
$\mathbf{8 2 6}$ & 530 & 607 & 596 & 395 & 579 & 485 \\
$\mathbf{8 2 8}$ & 525 & 621 & 709 & 530 & 704 & 639 \\
$\mathbf{8 3 0}$ & 373 & 404 & 583 & 440 & 490 & 499 \\
$\mathbf{8 5 9}$ & 264 & 374 & 342 & 252 & 417 & 326 \\
$\mathbf{8 7 3}$ & 377 & 478 & 543 & 351 & 494 & 477 \\
$\mathbf{8 7 4}$ & 454 & 629 & 531 & 423 & 570 & 626 \\
$\mathbf{8 7 5}$ & 521 & 528 & 596 & 479 & 513 & 496 \\
$\mathbf{8 7 7}$ & 338 & 367 & 434 & 319 & 404 & 349 \\
$\mathbf{8 7 8}$ & 630 & 716 & 742 & 456 & 684 & 517 \\
$\mathbf{8 7 9}$ & 400 & 480 & 469 & 413 & 512 & 450 \\
$\mathbf{8 8 1}$ & 365 & 459 & 431 & 463 & 510 & 501 \\
$\mathbf{8 9 5}$ & 330 & 495 & 507 & 355 & 444 & 404 \\
$\mathbf{1 2 3 3}$ & 396 & 414 & 440 & 382 & 438 & 439 \\
$\mathbf{1 2 3 7}$ & 204 & 257 & 333 & 230 & 277 & 280 \\
$\mathbf{1 2 3 9}$ & 438 & 581 & 478 & 408 & 492 & 451 \\
$\mathbf{1 2 4 1}$ & 343 & 446 & 429 & 412 & 537 & 457 \\
\hline Méida & 416 & 492 & 512 & 393 & 504 & 472 \\
\hline $\mathbf{e . p . m .}$ & 24 & 25 & 25 & 21 & 23 & 21 \\
\hline
\end{tabular}


APÊNDICE R - Teste t para variáveis independentes dos 6 primeiros voluntários

Experimento de Atenção Automática $(p=0,172)$

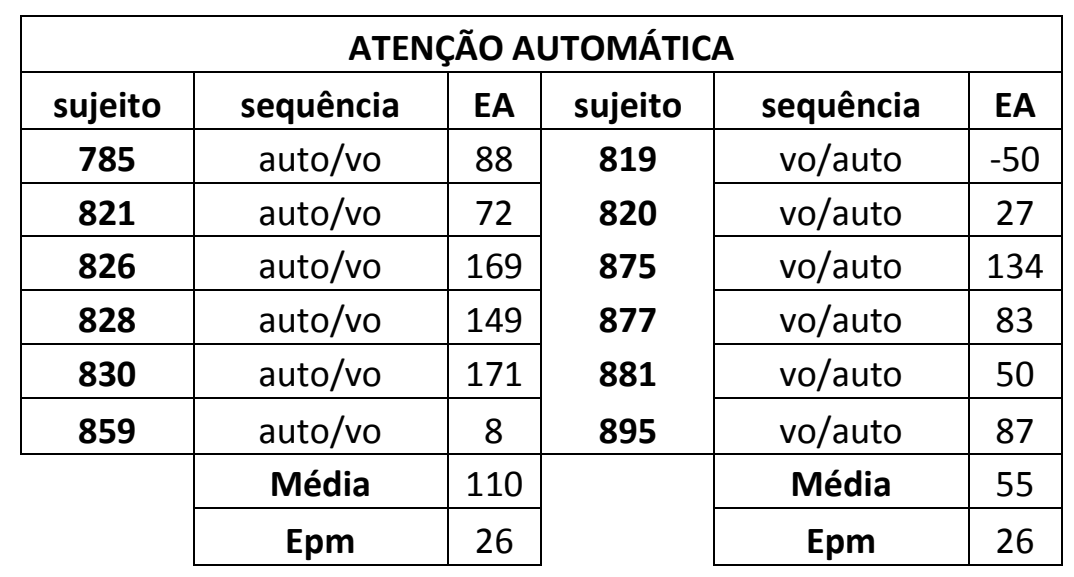

\section{Experimento de Atenção Automática $(p=0,466)$}

\begin{tabular}{|c|c|c|c|c|c|}
\hline \multicolumn{6}{|c|}{ ATENÇÃO VOLUNTÁRIA } \\
\hline sujeito & sequência & EA & sujeito & sequência & EA \\
\hline 819 & vo/auto & 18 & 785 & auto/vo & 86 \\
\hline 820 & vo/auto & 165 & 821 & auto/vo & 180 \\
\hline 875 & vo/auto & 34 & 826 & auto/vo & 48 \\
\hline 877 & vo/auto & 58 & 828 & auto/vo & 195 \\
\hline 881 & vo/auto & 51 & 830 & auto/vo & 84 \\
\hline 895 & vo/auto & 115 & 859 & auto/vo & 16 \\
\hline & Média & 73 & & Média & 101 \\
\hline & Epm & 23 & & Epm & 29 \\
\hline
\end{tabular}


APÊNDICE S - Tempo de Reação da Sessão Prova do Experimento de Atenção Automática e Atenção Voluntária.

\begin{tabular}{|c|ccc|ccc|}
\hline & \multicolumn{3}{|c|}{ Atenção Automática } & \multicolumn{3}{c|}{ Atenção Voluntária } \\
\hline PROVA & VÁLIDA & NEUTRA & INVÁLIDA & VÁLIDA & NEUTRA & INVÁLIDA \\
\hline $\mathbf{7 8 5}$ & 420 & 424 & 507 & 347 & 458 & 433 \\
$\mathbf{8 1 9}$ & 549 & 500 & 499 & 466 & 517 & 484 \\
$\mathbf{8 2 0}$ & 614 & 610 & 641 & 378 & 571 & 543 \\
$\mathbf{8 2 1}$ & 386 & 380 & 458 & 230 & 378 & 410 \\
$\mathbf{8 2 6}$ & 546 & 615 & 715 & 426 & 536 & 474 \\
$\mathbf{8 2 8}$ & 520 & 608 & 669 & 490 & 618 & 684 \\
$\mathbf{8 3 0}$ & 418 & 477 & 589 & 473 & 653 & 557 \\
$\mathbf{8 5 9}$ & 379 & 397 & 387 & 334 & 444 & 350 \\
$\mathbf{8 7 3}$ & 562 & 611 & 721 & 549 & 611 & 634 \\
$\mathbf{8 7 4}$ & 557 & 656 & 675 & 524 & 568 & 551 \\
$\mathbf{8 7 5}$ & 416 & 489 & 551 & 388 & 446 & 421 \\
$\mathbf{8 7 7}$ & 430 & 445 & 513 & 337 & 448 & 395 \\
$\mathbf{8 7 8}$ & 453 & 545 & 635 & 447 & 560 & 555 \\
$\mathbf{8 7 9}$ & 384 & 460 & 544 & 476 & 587 & 534 \\
$\mathbf{8 8 1}$ & 484 & 545 & 534 & 425 & 521 & 476 \\
$\mathbf{8 9 5}$ & 462 & 482 & 548 & 370 & 511 & 485 \\
$\mathbf{1 2 3 3}$ & 460 & 476 & 499 & 431 & 626 & 517 \\
$\mathbf{1 2 3 7}$ & 297 & 363 & 407 & 290 & 373 & 369 \\
$\mathbf{1 2 3 9}$ & 526 & 589 & 589 & 399 & 613 & 456 \\
$\mathbf{1 2 4 1}$ & 420 & 476 & 438 & 332 & 460 & 435 \\
\hline Média & 464 & 507 & 556 & 405 & 525 & 488 \\
\hline $\mathbf{e . p . m .}$ & 18 & 19 & 22 & 18 & 19 & 19 \\
\hline & & & & & & \\
\hline
\end{tabular}


APÊNDICE T - Comparação entre o Tempo de Reação da Sessão Treino e o Tempo de Reação da Sessão Prova dos Experimentos de Atenção Automática e Atenção

Voluntária.

\begin{tabular}{|c|cc|c|cc|}
\hline TREINO & AUTOMÁTICA & VOLUNTÁRIA & PROVA & AUTOMÁTICA & VOLUNTÁRIA \\
\hline $\mathbf{7 8 5}$ & 411 & 409 & $\mathbf{7 8 5}$ & 450 & 413 \\
$\mathbf{8 1 9}$ & 642 & 643 & $\mathbf{8 1 9}$ & 516 & 489 \\
$\mathbf{8 2 0}$ & 431 & 426 & $\mathbf{8 2 0}$ & 622 & 497 \\
$\mathbf{8 2 1}$ & 481 & 392 & $\mathbf{8 2 1}$ & 408 & 339 \\
$\mathbf{8 2 6}$ & 577 & 486 & $\mathbf{8 2 6}$ & 625 & 479 \\
$\mathbf{8 2 8}$ & 618 & 624 & $\mathbf{8 2 8}$ & 599 & 597 \\
$\mathbf{8 3 0}$ & 453 & 476 & $\mathbf{8 3 0}$ & 494 & 561 \\
$\mathbf{8 5 9}$ & 327 & 332 & $\mathbf{8 5 9}$ & 388 & 376 \\
$\mathbf{8 7 3}$ & 466 & 441 & $\mathbf{8 7 3}$ & 631 & 598 \\
$\mathbf{8 7 4}$ & 538 & 539 & $\mathbf{8 7 4}$ & 629 & 547 \\
$\mathbf{8 7 5}$ & 548 & 496 & $\mathbf{8 7 5}$ & 485 & 418 \\
$\mathbf{8 7 7}$ & 380 & 357 & $\mathbf{8 7 7}$ & 463 & 393 \\
$\mathbf{8 7 8}$ & 696 & 552 & $\mathbf{8 7 8}$ & 544 & 521 \\
$\mathbf{8 7 9}$ & 450 & 458 & $\mathbf{8 7 9}$ & 463 & 532 \\
$\mathbf{8 8 1}$ & 418 & 491 & $\mathbf{8 8 1}$ & 521 & 474 \\
$\mathbf{8 9 5}$ & 444 & 401 & $\mathbf{8 9 5}$ & 497 & 455 \\
$\mathbf{1 2 3 3}$ & 417 & 420 & $\mathbf{1 2 3 3}$ & 478 & 525 \\
$\mathbf{1 2 3 7}$ & 265 & 262 & $\mathbf{1 2 3 7}$ & 356 & 344 \\
$\mathbf{1 2 3 9}$ & 499 & 450 & $\mathbf{1 2 3 9}$ & 568 & 489 \\
$\mathbf{1 2 4 1}$ & 406 & 469 & $\mathbf{1 2 4 1}$ & 445 & 409 \\
\hline Média & 473 & 456 & Média & 509 & 473 \\
e.p.m. & 24 & 20 & e.p.m. & 19 & 17 \\
\hline
\end{tabular}

Tabela 1. Resultados da Análise de Variância da sessão treino tendo como fatores a Sessão (treino e prova). Tipo de Atenção (automática e voluntária). Os resultados significativos estão indicados com dois asteriscos $\left({ }^{* *}\right)$. Gl, graus de liberdade. F, razão entre o quadrado da média do efeito e o do erro. P, nível de significância.

\begin{tabular}{lccc}
\hline EFEITO & GI & F & P \\
\hline Sessão (treino e prova) & 1 & 2,493 & 0,130 \\
Tipo de Atenção (automática e voluntária) & 1 & 7,458 & $0,013^{\star *}$ \\
Sessão x Tipo de Atenção & 1 & 2,000 & 0,173 \\
\hline
\end{tabular}




\section{APÊNDICE U}

APÊNDICE U1 - Atenção Automática - Tentativas Válida versus Neutra $(V>N)$

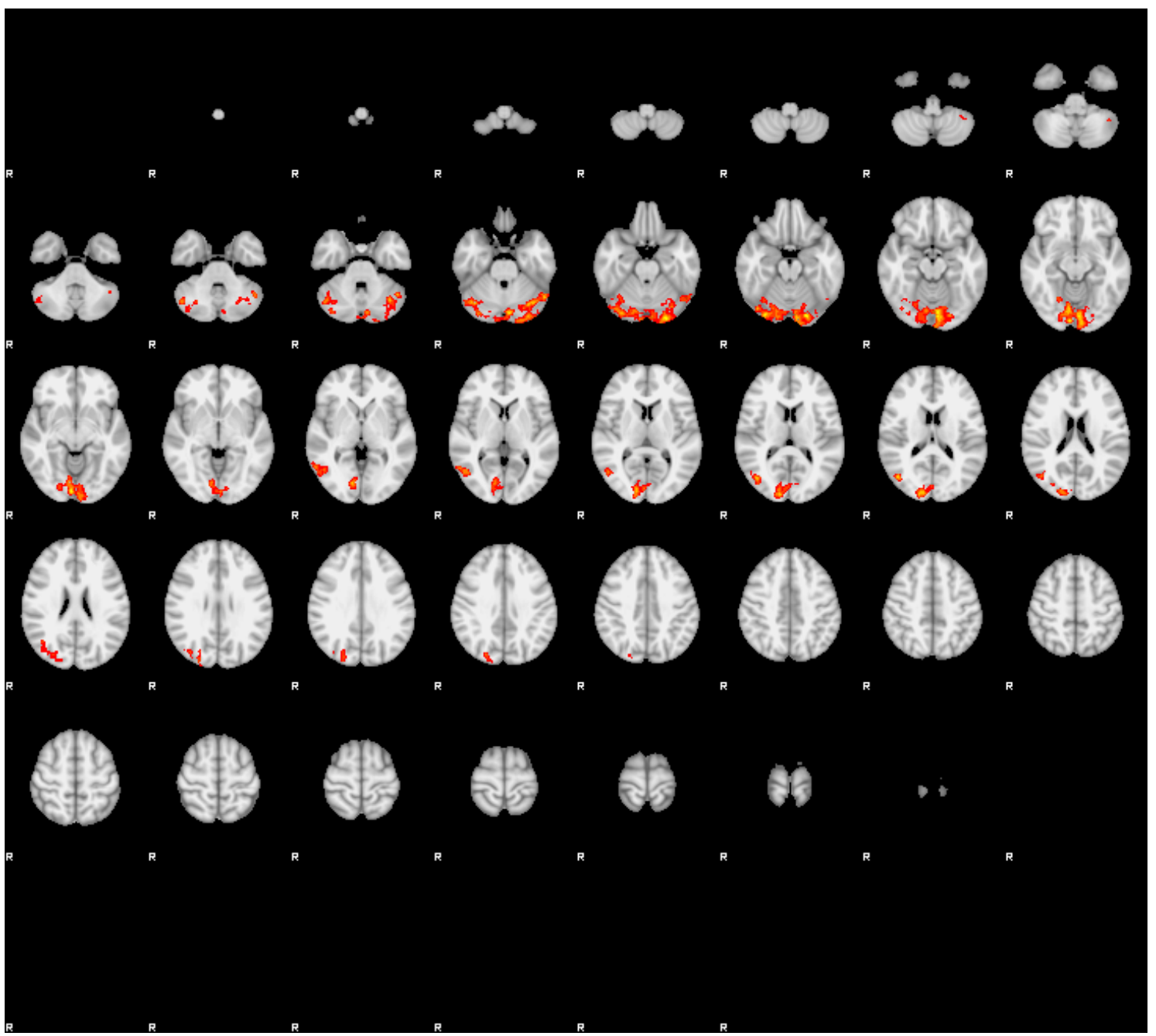

Figura 1. Mapa probabilístico de ativação de grupo do experimento de atenção automática $(\mathrm{N}=20)$ no contraste das tentativas válida versus neutra $(\mathrm{V}>\mathrm{N})$. Observa-se a resposta BOLD positiva no lobo occipital (estriado) bilateral e cerebelo esquerdo (cluster $Z>2,3 ; p<0,05$; escala de ativação $Z=2,3$ a 3,7). 
Tabela 1. Regiões com ativação máxima no contraste das tentativas válida versus neutra $(\mathrm{V}>\mathrm{N})$. BA - área de Brodmann; TAM - tamanho do cluster com efeito BOLD em voxels; Z - nível de significância estatística do estimado efeito BOLD do determinado cluster; $\mathrm{MNI}$ - coordenadas nos eixos X, Y e Z no espaço definido pelo Atlas de Montreal Neurological Institute (Mazziotta et al., 2001).

\begin{tabular}{lccccccc}
\hline REGIÃO CEREBRAL & LADO & BA & TAM & Z & \multicolumn{3}{c}{ MNI } \\
\cline { 6 - 8 } & & & & & X & Y & Z \\
\hline Lobo Occipital (estriado) & D & $17 / 18$ & 4776 & 3,77 & & -90 & -10 \\
Lobo Occipital (estriado) & E & $17 / 18$ & 4776 & 3,59 & -6 & -86 & -14 \\
Lobo Occipital (estriado) & E & $17 / 18$ & 4776 & 3,59 & -6 & -80 & -16 \\
Lobo Occipital (estriado) & E & $17 / 18$ & 4776 & 3,57 & -22 & -84 & -20 \\
Lobo Occipital (estriado) & E & $17 / 18$ & 4776 & 3,57 & -24 & -88 & -24 \\
Cerebelo & E & - & 4776 & 3,51 & -6 & -80 & -28 \\
\hline
\end{tabular}


APÊNDICE U2 - Atenção Automática - Tentativas Inválida versus Neutra (I>N)

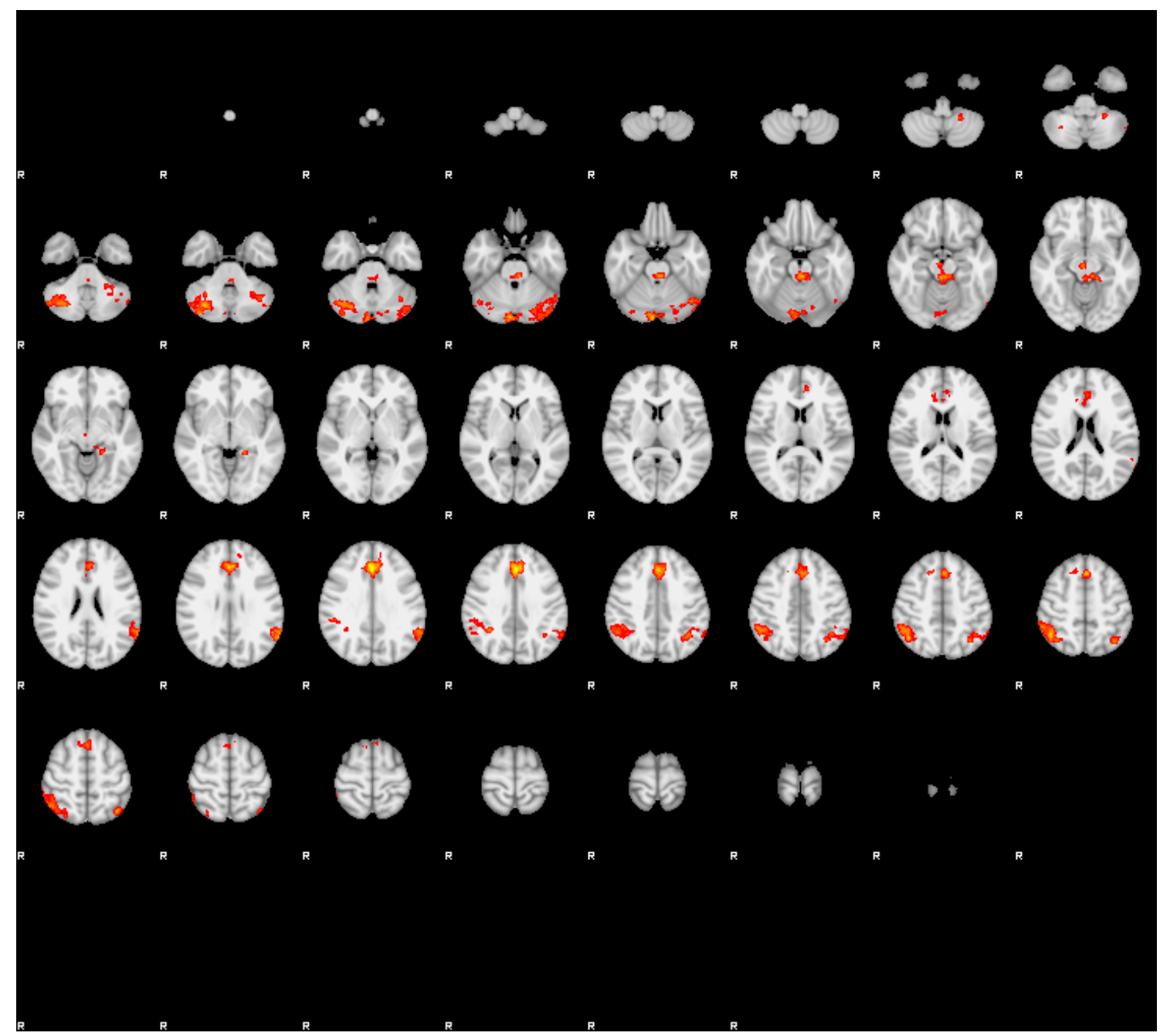

Figura 2. Mapa probabilístico de ativação de grupo do experimento de atenção automática $(\mathrm{N}=20)$ no contraste das tentativas inválida versus neutra $(\mathrm{I}>\mathrm{N})$. Observa-se a resposta BOLD positiva no giro frontal medial bilateral, giro do cíngulo anterior esquerdo, borda do sulco intraparietal direito, giro angular bilateral, giro supramarginal esquerdo, cerebelo bilateral, ponte bilateral, mesencéfalo direito e giro parahipocampal esquerdo (cluster $Z>2,3$; $p<0,05$; escala de ativação $Z=$ $2,3$ a 4,2$)$.

Tabela 2. Regiões com ativação máxima no contraste das tentativas inválida versus neutra (I>N). BA - área de Brodmann; TAM - tamanho do cluster com efeito BOLD em voxels; Z - nível de significância estatística do estimado efeito BOLD do determinado cluster; $\mathrm{MNI}$ - coordenadas nos eixos X, Y e Z no espaço definido pelo Atlas de Montreal Neurological Institute (Mazziotta et al., 2001).

\begin{tabular}{lccccccc}
\hline REGIÃO CEREBRAL & LADO & BA & TAM & Z & \multicolumn{3}{c}{ MNI } \\
\cline { 6 - 8 } & & & & & X & Y & Z \\
\hline Giro Frontal Medial & D & $8 / 9$ & 1247 & 4,29 & & 32 & 32
\end{tabular}




\begin{tabular}{|c|c|c|c|c|c|c|c|}
\hline Giro do Cíngulo Anterior & $\mathrm{E}$ & 24 & 1247 & 3,7 & -4 & 32 & 28 \\
\hline Giro Frontal Medial & - & $8 / 9$ & 1247 & 3,6 & 0 & 24 & 52 \\
\hline Giro Frontal Medial & $\mathrm{E}$ & $8 / 9$ & 1247 & 3,6 & -2 & 24 & 48 \\
\hline Giro Frontal Medial & $\mathrm{E}$ & $8 / 9$ & 1247 & 2,97 & 16 & 24 & 48 \\
\hline Giro do Cíngulo Anterior & $\mathrm{E}$ & 24 & 1247 & 2,84 & -8 & 42 & 12 \\
\hline Borda do Sulco Intraparietal & $\mathrm{D}$ & 7 & 1157 & 3,82 & 44 & -56 & 54 \\
\hline Borda do Sulco Intraparietal & $\mathrm{D}$ & 7 & 1157 & 3,49 & 46 & -50 & 46 \\
\hline Borda do Sulco Intraparietal & $\mathrm{D}$ & 7 & 1157 & 3,44 & 54 & -46 & 50 \\
\hline Giro Angular & $\mathrm{D}$ & 39 & 1157 & 3,42 & 50 & -52 & 46 \\
\hline Borda do Sulco Intraparietal & $\mathrm{D}$ & 7 & 1157 & 3,37 & 32 & -48 & 34 \\
\hline Borda do Sulco Intraparietal & $\mathrm{D}$ & 7 & 1157 & 3,37 & 56 & -46 & 44 \\
\hline Giro Angular & $\mathrm{E}$ & 7 & 817 & 3,62 & -38 & -64 & 56 \\
\hline Giro Angular & $\mathrm{E}$ & 39 & 817 & 3,52 & -66 & -50 & 26 \\
\hline Giro Angular & $\mathrm{E}$ & 39 & 817 & 3,51 & -62 & -58 & 28 \\
\hline Giro Supramarginal & $\mathrm{E}$ & 40 & 817 & 3,44 & -40 & -54 & 43 \\
\hline Giro Supramarginal & $\mathrm{E}$ & 40 & 817 & 3,43 & -62 & -52 & 28 \\
\hline Giro Supramarginal & $\mathrm{E}$ & 40 & 817 & 3,39 & -58 & -52 & 30 \\
\hline Cerebelo & $\mathrm{E}$ & - & 801 & 3,32 & -44 & -64 & -26 \\
\hline Cerebelo & $\mathrm{E}$ & - & 801 & 3,19 & -42 & -78 & -30 \\
\hline Cerebelo & $\mathrm{E}$ & - & 801 & 3,13 & -32 & -68 & -26 \\
\hline Cerebelo & $\mathrm{E}$ & - & 801 & 3,05 & -36 & -60 & -34 \\
\hline Cerebelo & $\mathrm{E}$ & - & 801 & 3,04 & -32 & -84 & -28 \\
\hline Cerebelo & $\mathrm{E}$ & - & 801 & 2,97 & -26 & -44 & -42 \\
\hline Cerebelo & $\mathrm{D}$ & - & 688 & 3,81 & 32 & -68 & -38 \\
\hline Cerebelo & $\mathrm{D}$ & - & 688 & 3,53 & 38 & -80 & -36 \\
\hline Cerebelo & $\mathrm{D}$ & - & 688 & 3,27 & 48 & -68 & -38 \\
\hline Cerebelo & $\mathrm{D}$ & - & 688 & 3,12 & 46 & -64 & -30 \\
\hline Cerebelo & $\mathrm{D}$ & - & 688 & 3,06 & 30 & -56 & -38 \\
\hline Cerebelo & $\mathrm{D}$ & - & 688 & 2,96 & 32 & -76 & -26 \\
\hline Ponte & $\mathrm{E}$ & - & 577 & 3,72 & -2 & -32 & -22 \\
\hline Ponte & $\mathrm{D}$ & - & 577 & 3,53 & 2 & -34 & -16 \\
\hline Ponte & $\mathrm{E}$ & - & 577 & 3,37 & -8 & -32 & -14 \\
\hline Mesencéfalo & $\mathrm{D}$ & & 577 & 3,28 & 4 & -18 & -14 \\
\hline Giro parahipocampal & $\mathrm{E}$ & 35 & 577 & 3,14 & -18 & -40 & -4 \\
\hline Giro parahipocampal & $\mathrm{E}$ & 35 & 577 & 3,1 & -14 & -34 & -10 \\
\hline Cerebelo & $\mathrm{D}$ & - & 428 & 3,78 & 6 & -84 & -24 \\
\hline Cerebelo & $\mathrm{D}$ & - & 428 & 3,57 & 6 & -86 & -34 \\
\hline Cerebelo & $\mathrm{E}$ & - & 428 & 2,91 & -4 & -82 & -26 \\
\hline Cerebelo & $\mathrm{E}$ & - & 428 & 2,79 & -4 & -76 & -18 \\
\hline Cerebelo & $\mathrm{E}$ & - & 428 & 2,67 & -8 & -80 & -30 \\
\hline Cerebelo & $\mathrm{E}$ & - & 428 & 2,38 & -6 & -80 & -36 \\
\hline
\end{tabular}


APÊNDICE U3 - Atenção Automática - Tentativas Válida versus Inválida (V>I)

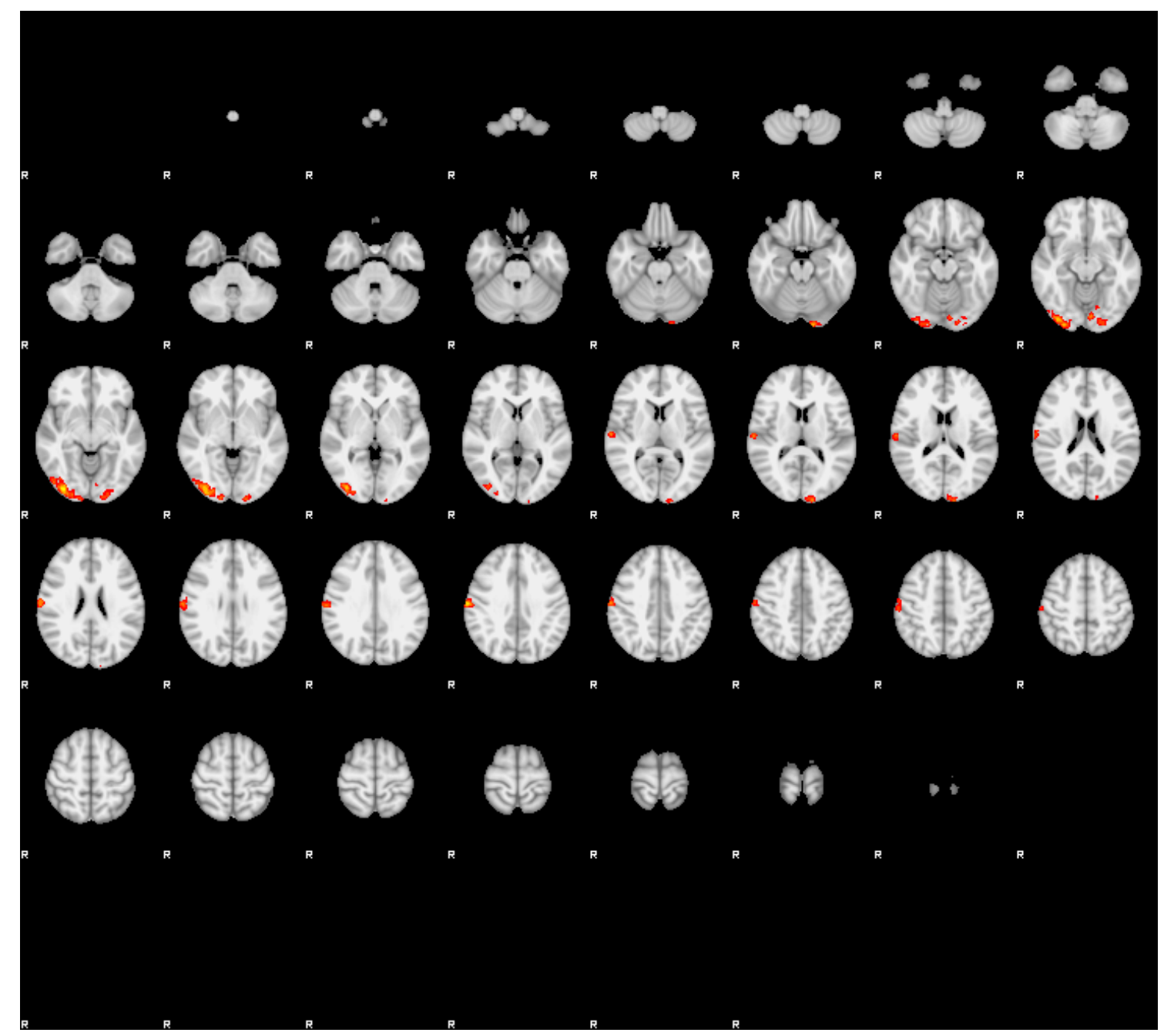

Figura 3. Mapa probabilístico de ativação de grupo do experimento de atenção automática $(\mathrm{N}=20)$ no contraste das tentativas válida versus inválida $(\mathrm{V}>\mathrm{I})$. Observa-se a resposta BOLD positiva no lobo occipital (estriado e extraestriado) direito, pólo occipital esquerdo e giro pós central (opérculo parietal) direito (cluster $Z>2,3 ; p$ $<0,05$; escala de ativação $Z=2,3$ a 3,9).

Tabela 3. Regiões com ativação máxima no contraste das tentativas válida versus inválida $(V>I)$. BA - área de Brodmann; TAM - tamanho do cluster com efeito BOLD em voxels; Z - nível de significância estatística do estimado efeito BOLD do determinado cluster; $\mathrm{MNI}$ - coordenadas nos eixos $\mathrm{X}, \mathrm{Y}$ e $\mathrm{Z}$ no espaço definido pelo Atlas de Montreal Neurological Institute (Mazziotta et al., 2001).

\begin{tabular}{lccccccc}
\hline REGIÃO CEREBRAL & LADO & BA & TAM & Z & \multicolumn{3}{c}{ MNI } \\
\cline { 6 - 8 } & & & & & X & Y & Z \\
\hline Lobo Occipital (extraestriado) & D & $18 / 19$ & 772 & 3,94 & 36 & -86 & -10 \\
Lobo Occipital (extraestriado) & D & $18 / 19$ & 772 & 3,6 & 36 & -86 & -2 \\
Lobo Occipital (extraestriado) & D & $18 / 19$ & 772 & 3,57 & 34 & -92 & -4 \\
Lobo Occipital (extraestriado) & D & $18 / 19$ & 772 & 3,44 & 30 & -94 & -12 \\
Lobo Occipital (extraestriado) & D & $18 / 19$ & 772 & 3,14 & 26 & -90 & -4
\end{tabular}


Lobo Occipital (extraestriado)

Lobo Occipital (estriado)

Pólo Occipital

Pólo Occipital

Pólo Occipital

Pólo Occipital

Pólo Occipital

Giro Pós Central (opérculo

parietal)

Giro Pós Central (opérculo

parietal)

Giro Pós Central (opérculo

parietal)

Giro Pós Central (opérculo

parietal)

Giro Pós Central (opérculo

parietal)

Giro Pós Central (opérculo

parietal)

$\begin{array}{ccccccc}\text { D } & 18 / 19 & 772 & 3,02 & 48 & -78 & -8 \\ \text { D } & 17 / 18 & 474 & 3,43 & -14 & -94 & -20 \\ \text { E } & 17 & 474 & 3,14 & -12 & -102 & 16 \\ \text { E } & 17 & 474 & 3,14 & -12 & -100 & 12 \\ \text { E } & 17 & 474 & 3,08 & -16 & -100 & -4 \\ \text { E } & 17 & 474 & 3,06 & -6 & -84 & -12 \\ \text { E } & 17 & 474 & 2,98 & -8 & -100 & 14 \\ \text { D } & 3 & 469 & 3,65 & 64 & -16 & 36 \\ \text { D } & 3 & 469 & 3,32 & 66 & -16 & 26 \\ \text { D } & 3 & 469 & 3,17 & 62 & -18 & 10 \\ \text { D } & 3 & 469 & 3,16 & 62 & -18 & 14 \\ \text { D } & 3 & 469 & 3,04 & 58 & -24 & 50 \\ \text { D } & 3 & 469 & 2,98 & 58 & -20 & 50\end{array}$


APÊNDICE U4 - Atenção Automática - Tentativas Inválida versus Válida (I>V)

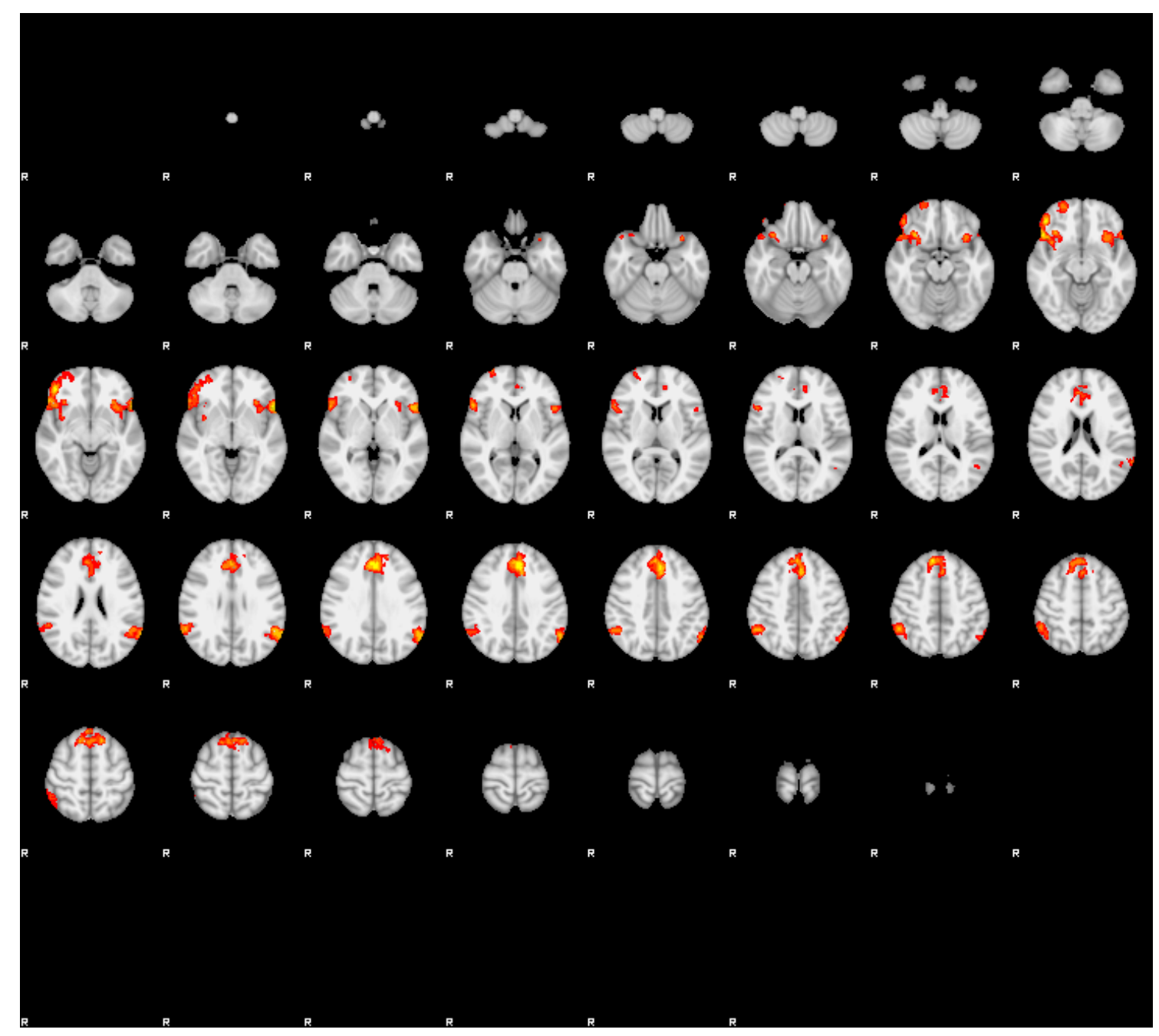

Figura 4. Mapa probabilístico de ativação de grupo do experimento de atenção automática $(\mathrm{N}=20)$ no contraste das tentativas inválida versus válida $(\mathrm{I}>\mathrm{V})$. Observa-se a resposta BOLD positiva no giro frontal medial bilateral, giros órbitos-frontais laterais bilaterais, giro frontal inferior bilateral, giro frontal superior direito, ínsula esquerda, giro supramarginal bilateral e borda do sulco intraparietal direito (cluster $Z>2,3 ; p<0,05$; escala de ativação $Z=2,3$ a 4,2).

Tabela 4. Regiões com ativação máxima no contraste das tentativas inválida versus válida (I>V). BA - área de Brodmann; TAM - tamanho do cluster com efeito BOLD em voxels; $Z$ - nível de significância estatística do estimado efeito BOLD do determinado cluster; $\mathrm{MNI}$ - coordenadas nos eixos $\mathrm{X}, \mathrm{Y}$ e $\mathrm{Z}$ no espaço definido pelo Atlas de Montreal Neurological Institute (Mazziotta et al., 2001).

\begin{tabular}{lccccccc}
\hline REGIÃO CEREBRAL & LADO & BA & TAM & Z & \multicolumn{3}{c}{ MNI } \\
\cline { 6 - 8 } & & & & & X & Y & Z \\
\hline Giro Frontal Medial & E & $8 / 9$ & 2767 & 4,3 & -4 & 34 & 36 \\
Giro Frontal Medial & D & $8 / 9$ & 2767 & 4,06 & 10 & 38 & 48 \\
Giro Frontal Medial & E & $8 / 9$ & 2767 & 3,89 & -4 & 24 & 44 \\
Giro Frontal Medial & D & $8 / 9$ & 2767 & 3,78 & 2 & 38 & 42 \\
Giro Frontal Medial & D & $8 / 9$ & 2767 & 3,6 & -14 & 26 & 56
\end{tabular}


Giro Frontal Medial

Giro Frontal Inferior

Giro Frontal Inferior

Giros Órbitos-Frontais Laterais

Giro Frontal Inferior

Giros Órbitos-Frontais Laterais

Giro Frontal Superior

Giro Frontal Inferior

Ínsula

Giros Órbitos-Frontais Laterais

Giros Órbitos-Frontais Laterais

Giros Órbitos-Frontais Laterais

Giros Órbitos-Frontais Laterais

Giro Supramarginal

Giro Supramarginal

Giro Supramarginal

Giro Supramarginal

Borda do Sulco Intraparietal

Borda do Sulco Intraparietal

Giro Supramarginal

Giro Supramarginal

Giro Supramarginal

Giro Supramarginal

Giro Supramarginal

\begin{tabular}{ccccccc}
$\mathrm{E}$ & $8 / 9$ & 2767 & 3,56 & -6 & 42 & 34 \\
$\mathrm{D}$ & 47 & 1826 & 4,25 & 46 & 40 & -10 \\
$\mathrm{D}$ & 47 & 1826 & 3,94 & 50 & 22 & -12 \\
$\mathrm{D}$ & $11 / 12$ & 1826 & 3,8 & 34 & 24 & -16 \\
$\mathrm{D}$ & 47 & 1826 & 3,8 & 54 & 22 & 4 \\
$\mathrm{D}$ & $11 / 12$ & 1826 & 3,46 & 40 & 14 & -12 \\
$\mathrm{D}$ & 10 & 1826 & 3,32 & 24 & 58 & -12 \\
$\mathrm{E}$ & 47 & 809 & 4,15 & -52 & 18 & -4 \\
$\mathrm{E}$ & 13 & 809 & 3,67 & -32 & 18 & -10 \\
$\mathrm{E}$ & $11 / 12$ & 809 & 3,49 & -32 & 20 & -16 \\
$\mathrm{E}$ & $11 / 12$ & 809 & 3,46 & -30 & 26 & -10 \\
$\mathrm{E}$ & $11 / 12$ & 809 & 3,36 & -32 & 20 & -20 \\
$\mathrm{E}$ & $11 / 12$ & 809 & 3,35 & -32 & 18 & -24 \\
$\mathrm{D}$ & 40 & 807 & 3,78 & 54 & -50 & 46 \\
$\mathrm{D}$ & 40 & 807 & 3,57 & 60 & -50 & 28 \\
$\mathrm{D}$ & 40 & 807 & 3,54 & 64 & -52 & 28 \\
$\mathrm{D}$ & 40 & 807 & 3,26 & 54 & -44 & 26 \\
$\mathrm{D}$ & 40 & 807 & 3,06 & 46 & -56 & 52 \\
$\mathrm{D}$ & 40 & 807 & 2,81 & 46 & -50 & 56 \\
$\mathrm{E}$ & 40 & 698 & 3,87 & -60 & -60 & 32 \\
$\mathrm{E}$ & 40 & 698 & 3,87 & -62 & -56 & 28 \\
$\mathrm{E}$ & 40 & 698 & 3,82 & -54 & -50 & 26 \\
$\mathrm{E}$ & 40 & 698 & 3,82 & -58 & -56 & 34 \\
$\mathrm{E}$ & 40 & 698 & 2,93 & -62 & -48 & 42 \\
$\mathrm{E}$ & 40 & 698 & 2,68 & -58 & -52 & 48 \\
\hline
\end{tabular}


APÊNDICE U5 - Atenção Voluntária - Tentativas Válida versus Neutra $(\mathrm{V}>\mathrm{N})$

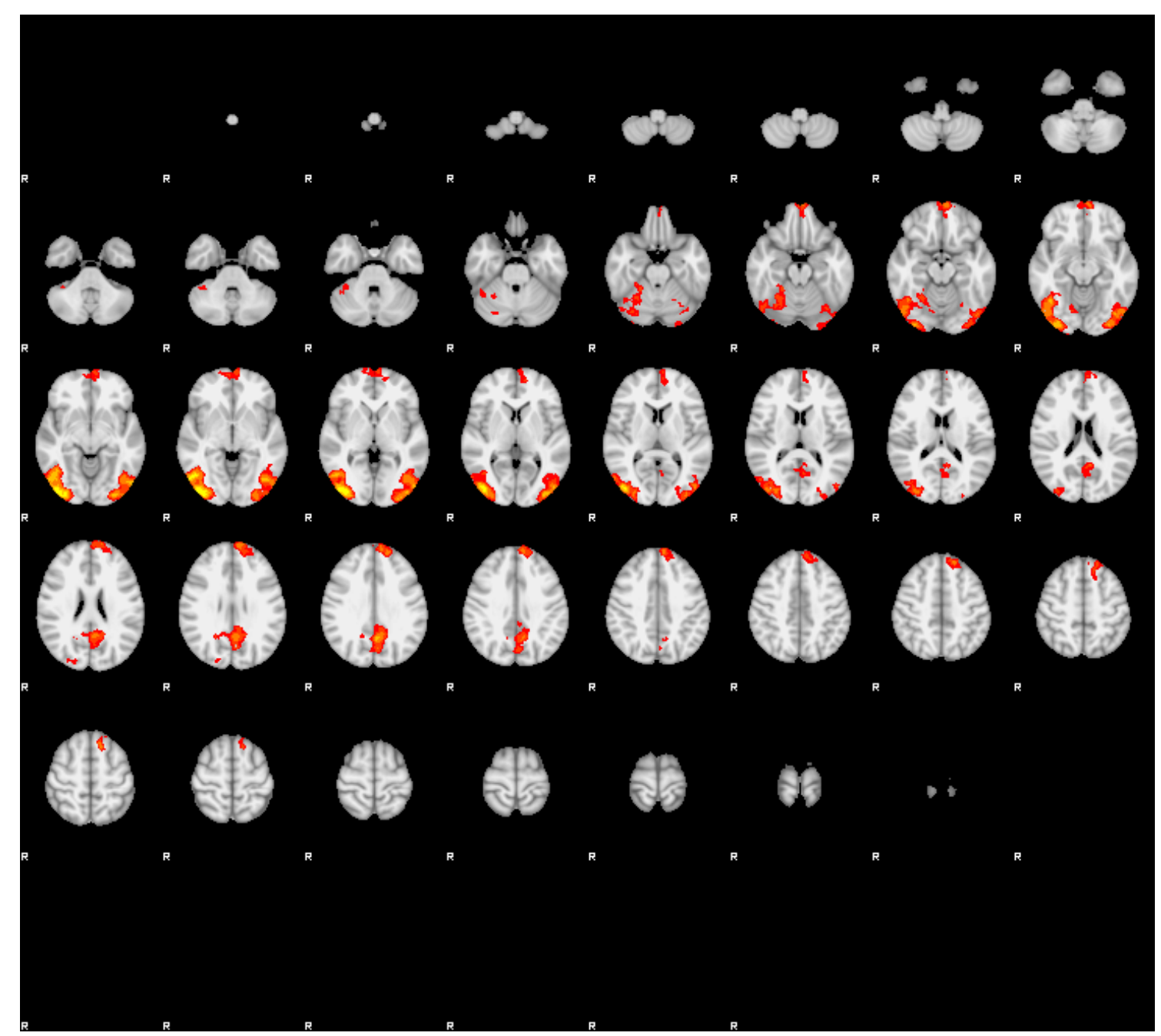

Figura 5. Mapa probabilístico de ativação de grupo do experimento de atenção voluntária $(\mathrm{N}=20)$ no contraste das tentativas válida versus neutra $(\mathrm{V}>\mathrm{N})$. Observa-se a resposta BOLD positiva no giro fusiforme (extraestriado) bilateral, giro frontal superior esquerdo, giros órbitos-frontais mediais esquerdo e pré-cuneos esquerdo (cluster $Z>2,3 ; p<0,05$; escala de ativação $Z=2,3$ a 5,1 ).

Tabela 5. Regiões com ativação máxima no contraste das tentativas válida versus neutra (V>N). BA - área de Brodmann; TAM - tamanho do cluster com efeito BOLD em voxels; Z - nível de significância estatística do estimado efeito BOLD do determinado cluster; $\mathrm{MNI}$ - coordenadas nos eixos $\mathrm{X}, \mathrm{Y}$ e Z no espaço definido pelo Atlas de Montreal Neurological Institute (Mazziotta et al., 2001).

\begin{tabular}{|c|c|c|c|c|c|c|c|}
\hline \multirow[t]{2}{*}{ REGIÃO CEREBRAL } & \multirow[t]{2}{*}{ LADO } & \multirow{2}{*}{ BA } & \multirow[t]{2}{*}{ TAM } & \multirow[t]{2}{*}{ Z } & \multicolumn{3}{|c|}{ MNI } \\
\hline & & & & & $\mathrm{X}$ & $\mathrm{Y}$ & Z \\
\hline Giro Fusiforme (extraestriado) & D & 37 & 3799 & 5,17 & 38 & -90 & -4 \\
\hline Giro Fusiforme (extraestriado) & D & 37 & 3799 & 5,09 & 48 & -66 & -4 \\
\hline Giro Fusiforme (extraestriado) & D & 37 & 3799 & 5,09 & 42 & -86 & -6 \\
\hline Giro Fusiforme (extraestriado) & D & 37 & 3799 & 4,79 & 32 & -90 & -8 \\
\hline Giro Fusiforme (extraestriado) & D & 37 & 3799 & 4,38 & 44 & -58 & -10 \\
\hline Giro Fusiforme (extraestriado) & $\mathrm{D}$ & 37 & 3799 & 4,23 & 44 & -72 & -10 \\
\hline
\end{tabular}


Giro Fusiforme (extraestriado) Giro Fusiforme (extraestriado) Giro Fusiforme (extraestriado) Giro Fusiforme (extraestriado) Giro Fusiforme (extraestriado) Giro Fusiforme (extraestriado) Giro Frontal Superior

Giros Órbitos-Frontais Mediais Giro Frontal Superior

Giro Frontal Superior Giro Frontal Superior

Giros Órbitos-Frontais Mediais Pré-Cuneos

Pré-Cuneos

Pré-Cuneos

Pré-Cuneos

Pré-Cuneos

Pré-Cuneos

\begin{tabular}{ccccccc}
$\mathrm{E}$ & 37 & 2253 & 4,66 & -40 & -88 & 2 \\
$\mathrm{E}$ & 37 & 2253 & 4,47 & -40 & -70 & -2 \\
$\mathrm{E}$ & 37 & 2253 & 4,29 & -32 & -90 & -10 \\
$\mathrm{E}$ & 37 & 2253 & 4,26 & -50 & -74 & -10 \\
$\mathrm{E}$ & 37 & 2253 & 4,26 & -48 & -80 & 4 \\
$\mathrm{E}$ & 37 & 2253 & 4,16 & -50 & -80 & 0 \\
$\mathrm{E}$ & 9 & 1893 & 4 & -8 & 62 & 28 \\
$\mathrm{E}$ & $11 / 12$ & 1893 & 3,88 & -8 & 64 & -14 \\
$\mathrm{E}$ & 8 & 1893 & 3,87 & -16 & 54 & 32 \\
$\mathrm{E}$ & 8 & 1893 & 3,86 & -8 & 54 & 36 \\
$\mathrm{E}$ & 8 & 1893 & 3,85 & -12 & 22 & 56 \\
$\mathrm{E}$ & $11 / 12$ & 1893 & 3,85 & -2 & 64 & -18 \\
$\mathrm{E}$ & 7 & 1360 & 4,34 & -2 & -58 & 32 \\
$\mathrm{E}$ & 7 & 1360 & 3,94 & -10 & -52 & 32 \\
$\mathrm{E}$ & 7 & 1360 & 3,79 & -4 & -72 & 34 \\
$\mathrm{E}$ & 7 & 1360 & 3,57 & -16 & -52 & 26 \\
$\mathrm{E}$ & 7 & 1360 & 3,36 & -8 & -46 & 30 \\
$\mathrm{E}$ & 7 & 1360 & 3,12 & -4 & -62 & 14 \\
\hline
\end{tabular}


APÊNDICE U6 - Atenção Voluntária - Tentativas Inválida versus Neutra (I>N)

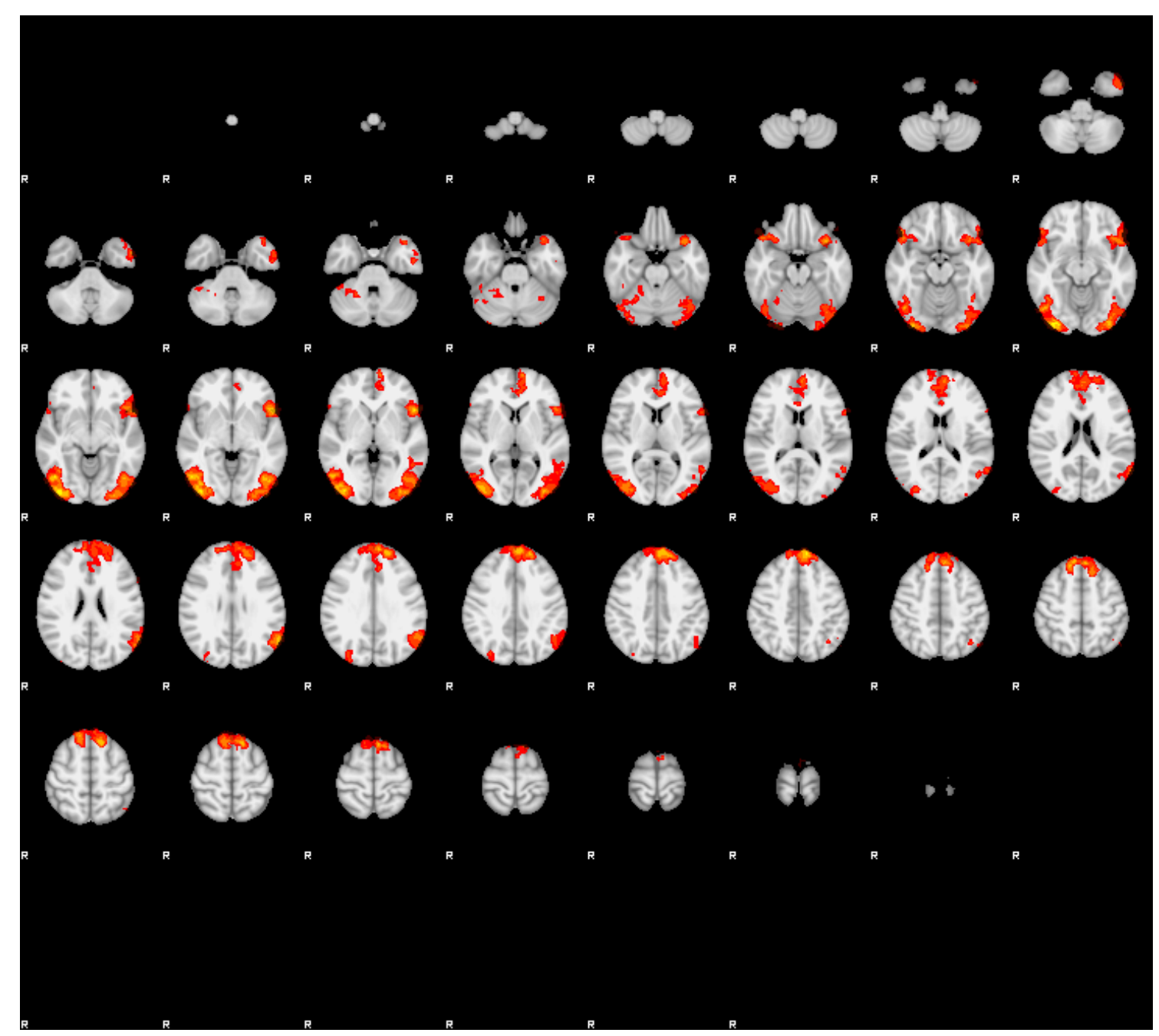

Figura 6. Mapa probabilístico de ativação de grupo do experimento de atenção automática $(\mathrm{N}=20)$ no contraste das tentativas inválida versus neutra $(\mathrm{I}>\mathrm{N})$. Observa-se a resposta BOLD positiva no giro frontal superior bilateral, lobo occipital (extraestriado) bilateral, giro supramarginal esquerdo, giro frontal Inferior esquerdo, giros órbito-frontais laterais bilateral e pólo temporal esquerdo (cluster $Z>2,3 ; p<0,05$; escala de ativação $Z=2,3$ a 5,1 ).

Tabela 6. Regiões com ativação máxima no contraste das tentativas inválida versus neutra (I>N). BA - área de Brodmann; TAM - tamanho do cluster com efeito BOLD em voxels; Z - nível de significância estatística do estimado efeito BOLD do determinado cluster; $\mathrm{MNI}$ - coordenadas nos eixos $\mathrm{X}, \mathrm{Y}$ e $\mathrm{Z}$ no espaço definido pelo Atlas de Montreal Neurological Institute (Mazziotta et al., 2001).

\begin{tabular}{lccccccc}
\hline REGIÃO CEREBRAL & LADO & BA & TAM & Z & \multicolumn{3}{c}{ MNI } \\
\cline { 6 - 8 } & & & & & X & Y & Z \\
\hline Giro Frontal Superior & E & 8 & 5482 & 4,77 & -10 & 52 & 44 \\
Giro Frontal Superior & E & 8 & 5482 & 4,57 & -2 & 52 & 38 \\
Giro Frontal Superior & E & 8 & 5482 & 4,56 & -6 & 54 & 38 \\
Giro Frontal Superior & E & 8 & 5482 & 4,44 & -12 & 26 & 58
\end{tabular}




\begin{tabular}{lccccccc} 
Giro Frontal Superior & $\mathrm{D}$ & 6 & 5482 & 4,35 & 14 & 36 & 54 \\
Giro Frontal Superior & $\mathrm{E}$ & 6 & 5482 & 4,29 & -6 & 38 & 50 \\
Lobo Occipital (extraestriado) & $\mathrm{E}$ & 19 & 4272 & 4,4 & -34 & -86 & -12 \\
Giro Supramarginal & $\mathrm{E}$ & 40 & 4272 & 4,29 & -60 & -62 & 26 \\
Lobo Occipital (extraestriado) & $\mathrm{E}$ & 19 & 4272 & 4,26 & -40 & -70 & -4 \\
Giro Supramarginal & $\mathrm{E}$ & 40 & 4272 & 4,19 & -60 & -58 & 26 \\
Lobo Occipital (extraestriado) & $\mathrm{E}$ & 19 & 4272 & 4,15 & -38 & -86 & -4 \\
Lobo Occipital (extraestriado) & $\mathrm{E}$ & 19 & 4272 & 4,15 & -48 & -74 & -4 \\
Lobo Occipital (extraestriado) & $\mathrm{D}$ & 19 & 3763 & 5,12 & 32 & -88 & -10 \\
Lobo Occipital (extraestriado) & $\mathrm{D}$ & 19 & 3763 & 5,07 & 38 & -88 & -10 \\
Lobo Occipital (extraestriado) & $\mathrm{D}$ & 19 & 3763 & 4,64 & 52 & -68 & -8 \\
Lobo Occipital (extraestriado) & $\mathrm{D}$ & 19 & 3763 & 4,4 & 46 & -68 & -14 \\
Lobo Occipital (extraestriado) & $\mathrm{D}$ & 19 & 3763 & 4,36 & 48 & -80 & 2 \\
Giro Frontal Inferior & $\mathrm{E}$ & 47 & 2045 & 4,78 & -52 & 18 & -2 \\
Giros Orbito-Frontais Laterais & $\mathrm{E}$ & $11 / 12$ & 2045 & 4,19 & -34 & 16 & -22 \\
Giro Frontal Inferior & $\mathrm{E}$ & 47 & 2045 & 3,96 & -46 & 18 & -12 \\
Giro Frontal Inferior & $\mathrm{E}$ & 47 & 2045 & 3,88 & -42 & 20 & -12 \\
Pólo Temporal & $\mathrm{E}$ & 22 & 2045 & 3,59 & -52 & 2 & -40 \\
Pólo Temporal & $\mathrm{E}$ & 22 & 2045 & 3,52 & -46 & 2 & -46 \\
Giros Orbito-Frontais Laterais & $\mathrm{D}$ & $11 / 12$ & 527 & 3,79 & 48 & 22 & -18 \\
Giros Orbito-Frontais Laterais & $\mathrm{D}$ & $11 / 12$ & 527 & 3,76 & 50 & 28 & -16 \\
Giros Orbito-Frontais Laterais & $\mathrm{D}$ & $11 / 12$ & 527 & 3,62 & 50 & 18 & -14 \\
Giros Orbito-Frontais Laterais & $\mathrm{D}$ & $11 / 12$ & 527 & 3,51 & 38 & 24 & -20 \\
Giros Orbito-Frontais Laterais & $\mathrm{D}$ & $11 / 12$ & 527 & 3,29 & 30 & 20 & -20 \\
Giros Orbito-Frontais Laterais & $\mathrm{D}$ & $11 / 12$ & 527 & 2,91 & 58 & 22 & -2 \\
\hline
\end{tabular}


APÊNDICE U7 - Atenção Voluntária - Tentativas Inválida versus Válida (I>V)

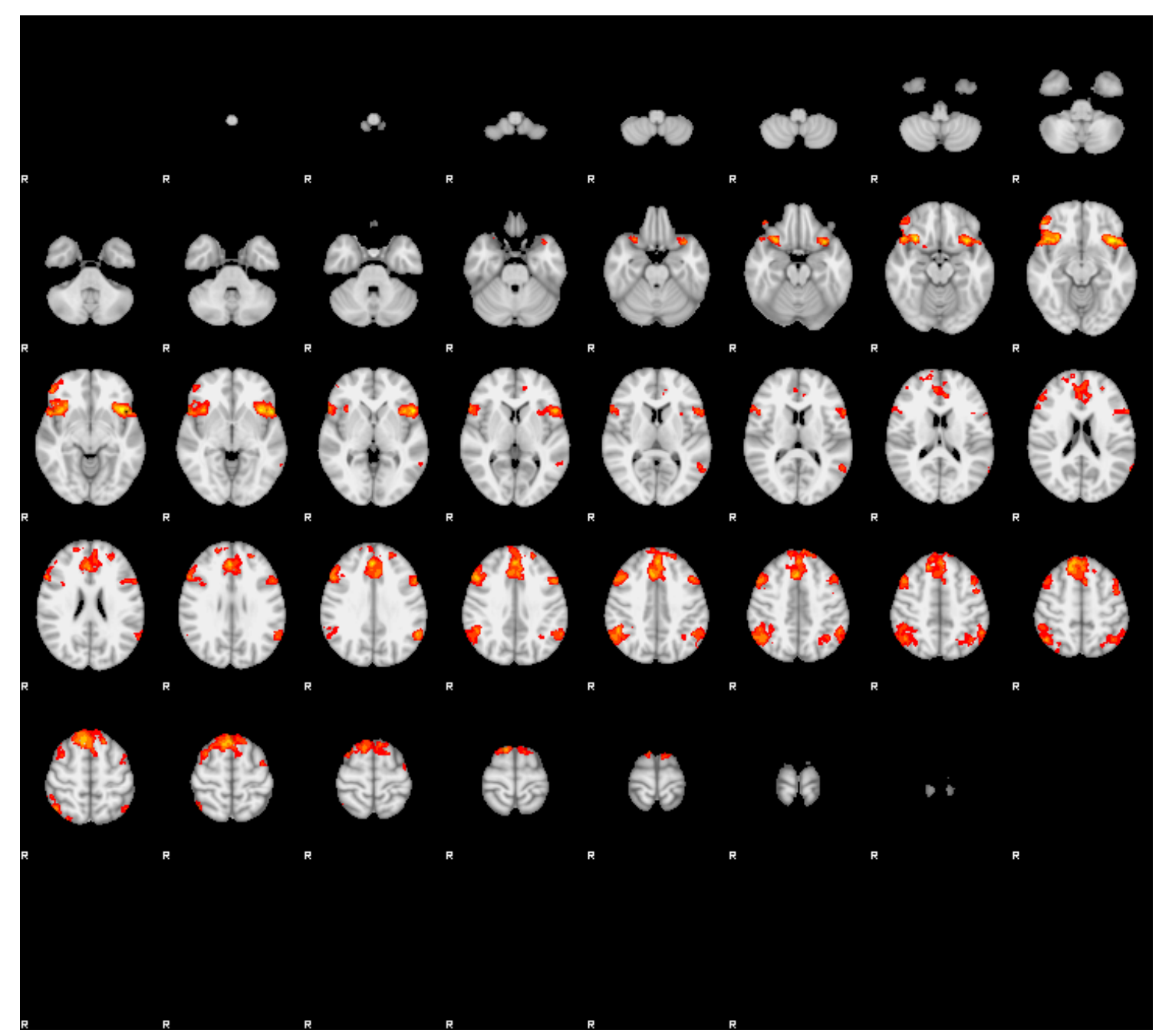

Figura 7. Mapa probabilístico de ativação de grupo do experimento de atenção automática $(\mathrm{N}=20)$ no contraste das tentativas inválida versus válida $(\mathrm{I}>\mathrm{V})$. Observa-se a resposta BOLD positiva nos giros órbito-frontais laterais bilaterais, giro frontal médio bilateral, giro frontal superior direito, giro frontal inferior esquerdo, borda do sulco intraparietal bilateral, giro supramarginal bilateral, giro angular esquerdo (cluster $Z>2,3 ; p<0,05$; escala de ativação $Z=2,3$ a 4,7).

Tabela 7. Regiões com ativação máxima no contraste das tentativas inválida versus válida (I>V). BA - área de Brodmann; TAM - tamanho do cluster com efeito BOLD em voxels; Z - nível de significância estatística do estimado efeito BOLD do determinado cluster; $\mathrm{MNI}$ - coordenadas nos eixos $\mathrm{X}, \mathrm{Y}$ e $\mathrm{Z}$ no espaço definido pelo Atlas de Montreal Neurological Institute (Mazziotta et al., 2001).

\begin{tabular}{lcccccccc}
\hline REGIÃO CEREBRAL & LADO & BA & TAM & Z & \multicolumn{3}{c}{ MNI } \\
\cline { 6 - 8 } & & & & & X & Y & Z \\
\hline Giros Orbito-Frontais Laterais & D & $11 / 12$ & 7547 & 4,54 & & 32 & 22 & -14 \\
Giros Orbito-Frontais Laterais & D & $11 / 12$ & 7547 & 4,46 & & 10 & 24 & 58 \\
Giros Orbito-Frontais Laterais & D & $11 / 12$ & 7547 & 4,41 & 2 & 38 & 32
\end{tabular}


Giros Orbito-Frontais Laterais Giro Frontal Médio Giro Frontal Superior Giro Frontal Inferior Giro Frontal Inferior Giro Frontal Inferior Giros Orbito-Frontais Laterais Giros Orbito-Frontais Laterais Giro Frontal Médio Borda do Sulco Intraparietal Giro Supramarginal Borda do Sulco Intraparietal Borda do Sulco Intraparietal Borda do Sulco Intraparietal Giro Supramarginal Borda do Sulco Intraparietal Borda do Sulco Intraparietal Borda do Sulco Intraparietal Borda do Sulco Intraparietal Giro Angular

$\begin{array}{ccccccc}\text { D } & 11 / 12 & 7547 & 4,37 & 32 & 24 & -10 \\ \text { D } & 46 & 7547 & 4,32 & 50 & 20 & 34 \\ \text { D } & 6 & 7547 & 4,26 & 4 & 28 & 60 \\ \text { E } & 11 / 47 & 2190 & 4,79 & -40 & 20 & -10 \\ \text { E } & 11 / 47 & 2190 & 4,63 & -50 & 18 & -2 \\ \text { E } & 47 & 2190 & 4,41 & -38 & 18 & -4 \\ \text { E } & 11 / 12 & 2190 & 4,33 & -34 & 18 & -16 \\ \text { E } & 11 / 12 & 2190 & 4,16 & -34 & 16 & -22 \\ \text { E } & 9 & 2190 & 3,67 & -54 & 16 & 32 \\ \text { D } & 11 / 47 & 1365 & 4,01 & 46 & -62 & 54 \\ \text { D } & 11 / 47 & 1365 & 3,88 & 50 & -46 & 40 \\ \text { D } & 11 / 47 & 1365 & 3,79 & 46 & -58 & 42 \\ \text { D } & 7 & 1365 & 3,12 & 50 & -44 & 52 \\ \text { D } & 7 & 1365 & 2,95 & 30 & -74 & 56 \\ \text { E } & 40 & 1178 & 3.85 & -56 & -52 & 32 \\ \text { E } & 40 & 1178 & 3,53 & -52 & -50 & 46 \\ \text { E } & 40 & 1178 & 3,52 & -48 & -52 & 40 \\ \text { E } & 40 & 1178 & 3,45 & -40 & -60 & 50 \\ \text { E } & 40 & 1178 & 3,32 & -52 & -50 & 38 \\ \text { E } & 39 & 1178 & 3,25 & -52 & -56 & 38\end{array}$


APÊNDICE U8 - Atenção Automática versus Atenção Voluntária - Experimento de Atenção Automática versus Atenção Voluntária $(A>V)$

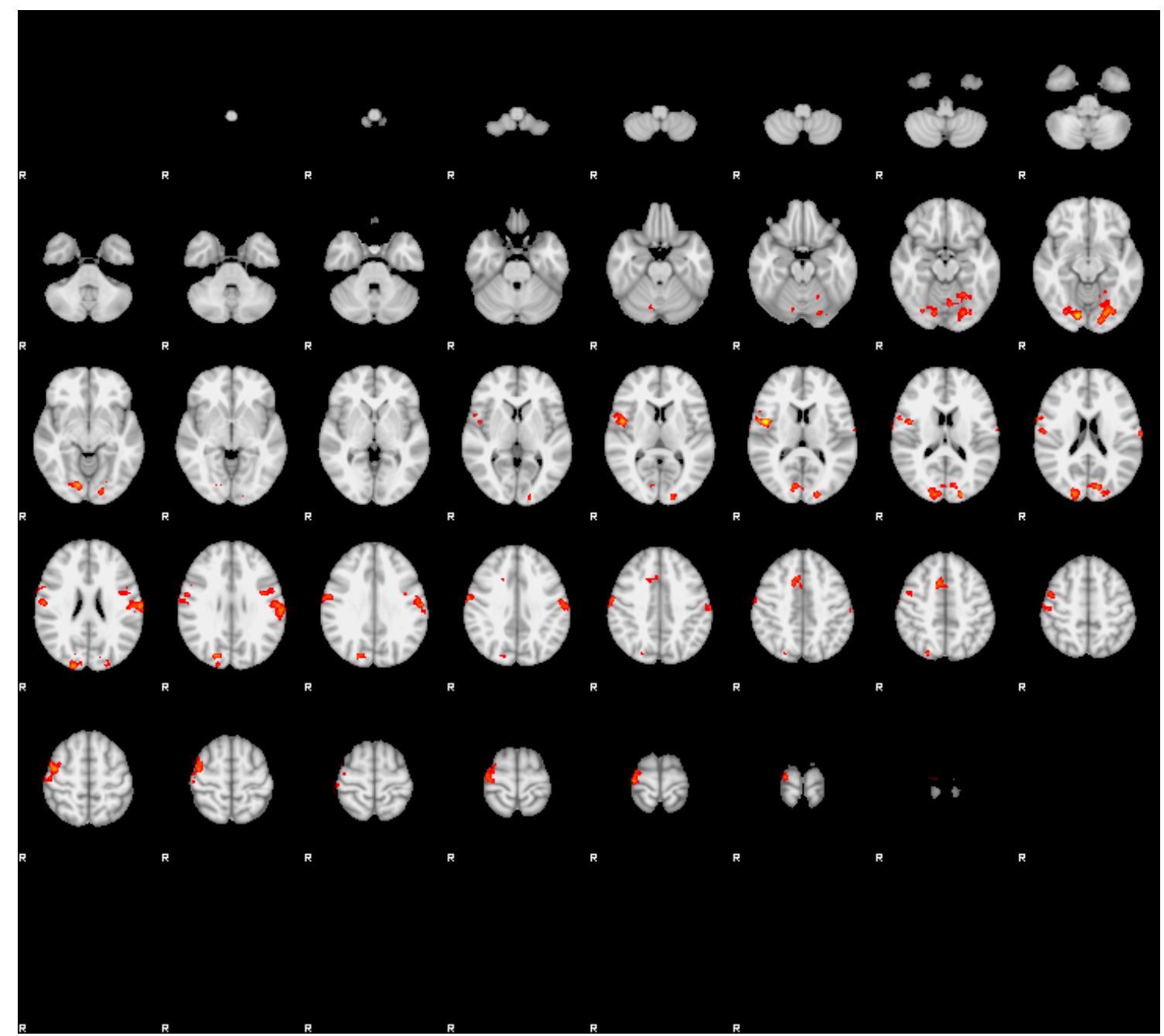

Figura 8. Mapa probabilístico de ativação de grupo dos experimentos de atenção $(\mathrm{N}=20)$ no contraste dos experimentos de atenção automática versus atenção voluntária $(A>V)$. Observa-se a resposta BOLD positiva no cuneus bilateral, giro frontal inferior direito, giro pré-central bilateral, giro pós-central esquerdo, giro fusiforme (extraestriado) bilateral, cerebelo bilateral e giro frontal medial direito (cluster $Z>$ 2,3; $p<0,05$; escala de ativação $Z=3,0$ a 6,6).

Tabela 8. Regiões com ativação máxima no contraste dos experimentos de atenção automática versus atenção voluntária $(A>V)$. BA - área de Brodmann; TAM tamanho do cluster com efeito BOLD em voxels; $Z$ - nível de significância estatística do estimado efeito BOLD do determinado cluster; $\mathrm{MNI}$ - coordenadas nos eixos X, Y e Z no espaço definido pelo Atlas de Montreal Neurological Institute (Mazziotta et al., 2001).

\begin{tabular}{lcccccccc}
\hline REGIÃO CEREBRAL & LADO & BA & TAM & Z & \multicolumn{3}{c}{ MNI } \\
\cline { 6 - 9 } & & & & & X & Y & Z \\
\hline Cuneus & E & 19 & 713 & 5,26 & -18 & -92 & 14 \\
Cuneus & D & 19 & 713 & 4,95 & 16 & -92 & 18
\end{tabular}




\begin{tabular}{lccccccc} 
Cuneus & E & 19 & 713 & 4,93 & -12 & -82 & 18 \\
Cuneus & $\mathrm{D}$ & 19 & 713 & 4,84 & 20 & -92 & 24 \\
Cuneus & $\mathrm{D}$ & 19 & 713 & 4,81 & 20 & -80 & 30 \\
Cuneus & $\mathrm{E}$ & 19 & 713 & 4,39 & -16 & -96 & 6 \\
Giro Frontal Inferior & $\mathrm{D}$ & $11 / 47$ & 684 & 6,55 & 48 & 2 & 12 \\
Giro Pré-Central & $\mathrm{D}$ & 4 & 684 & 4,56 & 62 & -6 & 38 \\
Giro Pós-Central & $\mathrm{D}$ & 3 & 684 & 4,53 & 58 & -12 & 24 \\
Giro Pré-Central & $\mathrm{D}$ & 4 & 684 & 4,4 & 62 & -8 & 42 \\
Giro Pré-Central & $\mathrm{D}$ & 4 & 684 & 4,39 & 70 & -2 & 26 \\
Giro Pré-Central & $\mathrm{D}$ & 4 & 684 & 4,35 & 58 & -2 & 30 \\
Giro Pós-Central & $\mathrm{E}$ & 3 & 648 & 4,98 & -64 & -22 & 28 \\
Giro Pós-Central & $\mathrm{E}$ & 3 & 648 & 4,83 & -64 & -18 & 26 \\
Giro Pós-Central & $\mathrm{E}$ & 3 & 648 & 4,72 & -60 & -16 & 26 \\
Giro Pós-Central & $\mathrm{E}$ & 3 & 648 & 4,69 & -60 & -18 & 34 \\
Giro Pós-Central & $\mathrm{E}$ & 3 & 648 & 4,64 & -64 & -26 & 30 \\
Giro Pré-Central & $\mathrm{E}$ & 4 & 648 & 4,56 & -40 & 0 & 30 \\
Giro Pré-Central & $\mathrm{D}$ & 4 & 646 & 5,4 & 44 & -6 & 58 \\
Giro Pré-Central & $\mathrm{D}$ & 4 & 646 & 4,73 & 38 & -12 & 66 \\
Giro Pré-Central & $\mathrm{D}$ & 4 & 646 & 4,7 & 34 & -22 & 72 \\
Giro Pré-Central & $\mathrm{D}$ & 4 & 646 & 4,56 & 34 & -18 & 70 \\
Giro Pré-Central & $\mathrm{D}$ & 4 & 646 & 4,33 & 40 & 0 & 60 \\
Giro Pré-Central & $\mathrm{D}$ & 4 & 646 & 4,24 & 24 & -18 & 76 \\
Giro Fusiforme (extraestriado) & $\mathrm{E}$ & 37 & 479 & 5 & -22 & -78 & -12 \\
Giro Fusiforme (extraestriado) & $\mathrm{E}$ & 37 & 479 & 4,83 & -16 & -88 & -12 \\
Giro Fusiforme (extraestriado) & $\mathrm{E}$ & 37 & 479 & 4,8 & -30 & -76 & -12 \\
Giro Fusiforme (extraestriado) & $\mathrm{E}$ & 37 & 479 & 4,71 & -26 & -74 & -12 \\
Cerebelo & $\mathrm{E}$ & - & 479 & 4,16 & -22 & -54 & -16 \\
Cerebelo & $\mathrm{E}$ & - & 479 & 4,07 & -4 & -66 & -16 \\
Giro Fusiforme (extraestriado) & $\mathrm{D}$ & 37 & 280 & 5,96 & 14 & -82 & -12 \\
Giro Fusiforme (extraestriado) & $\mathrm{D}$ & 37 & 280 & 4,32 & 30 & -76 & -14 \\
Giro Fusiforme (extraestriado) & $\mathrm{D}$ & 37 & 280 & 3,91 & 24 & -72 & -14 \\
Cerebelo & $\mathrm{D}$ & - & 280 & 3,6 & 12 & -72 & -22 \\
Giro Frontal Medial & $\mathrm{D}$ & 6 & 186 & 4,65 & 12 & 12 & 46 \\
Giro Frontal Medial & $\mathrm{D}$ & 6 & 186 & 4,45 & 6 & 20 & 44 \\
Giro Frontal Medial & $\mathrm{D}$ & 6 & 186 & 3,53 & 18 & 18 & 38 \\
\hline & & & & & & &
\end{tabular}


APÊNDICE U9 - Atenção Automática versus Atenção Voluntária - Experimento de Atenção Voluntária versus Atenção Automática $(\mathrm{V}>\mathrm{A})$

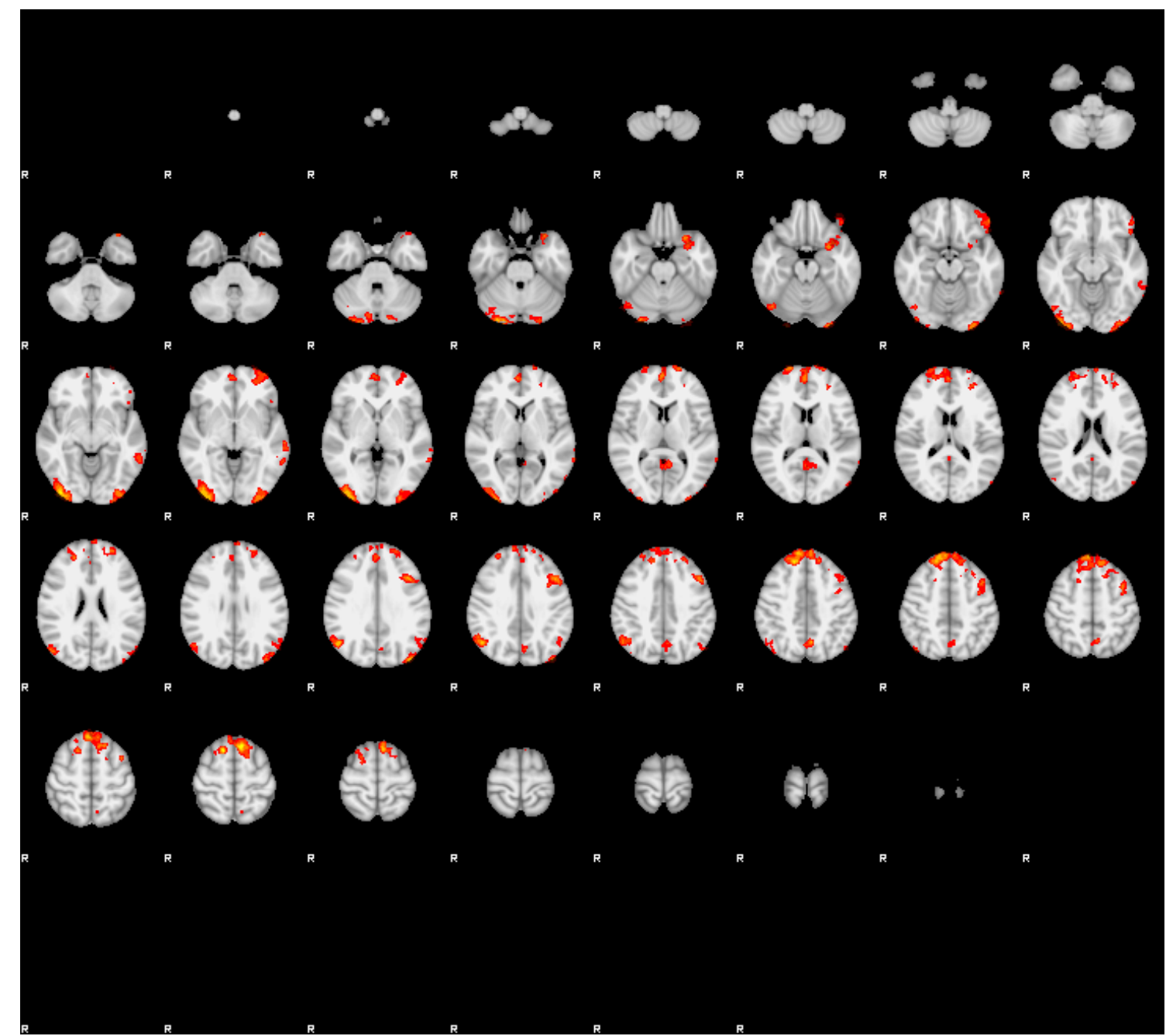

Figura 9. Mapa probabilístico de ativação de grupo dos experimentos de atenção $(\mathrm{N}=20)$ no contraste dos experimentos de atenção voluntária versus atenção automática (V>A). Observa-se a resposta BOLD positiva no giro frontal superior bilateral, pólo occipital bilateral, cerebelo bilateral, borda do sulco intraparietal direito, giro parahipocampal esquerdo, giro temporal superior e médio esquerdos, giro frontal inferior esquerdo, giro frontal médio bilateral, precuneus esquerdo e giro do cíngulo posterior bilateral (cluster $Z>2,3 ; p<0,05$; escala de ativação $Z=3,0$ a $6,6)$. 
Tabela 9. Regiões com ativação máxima no contraste dos experimentos de atenção voluntária versus atenção automática $(\mathrm{V}>\mathrm{A})$. BA - área de Brodmann; TAM tamanho do cluster com efeito BOLD em voxels; $Z$ - nível de significância estatística do estimado efeito BOLD do determinado cluster; $\mathrm{MNI}$ - coordenadas nos eixos X, Y e Z no espaço definido pelo Atlas de Montreal Neurological Institute (Mazziotta et al., 2001).

\begin{tabular}{|c|c|c|c|c|c|c|c|}
\hline \multirow[t]{2}{*}{ REGIÃO CEREBRAL } & \multirow[t]{2}{*}{ LADO } & \multirow[t]{2}{*}{ BA } & \multirow[t]{2}{*}{ TAM } & \multirow[t]{2}{*}{ Z } & \multicolumn{3}{|c|}{ MNI } \\
\hline & & & & & $\mathrm{X}$ & $\mathrm{Y}$ & $Z$ \\
\hline Giro Frontal Superior & $\mathrm{E}$ & $6 / 8$ & 3886 & 6,65 & -8 & 22 & 60 \\
\hline Giro Frontal Superior & D & $6 / 8$ & 3886 & 6,2 & 16 & 40 & 46 \\
\hline Giro Frontal Superior & D & $6 / 8$ & 3886 & 6,08 & 10 & 50 & 46 \\
\hline Giro Frontal Superior & D & $6 / 8$ & 3886 & 5,66 & 6 & 36 & 56 \\
\hline Giro Frontal Superior & $\mathrm{E}$ & $6 / 8$ & 3886 & 5,59 & -40 & 18 & 34 \\
\hline Giro Frontal Superior & D & $6 / 8$ & 3886 & 5,41 & 6 & 46 & 52 \\
\hline Pólo Occipital & D & 17 & 1328 & 6,63 & 40 & -90 & -8 \\
\hline Pólo Occipital & D & 17 & 1328 & 5,93 & 36 & -94 & -2 \\
\hline Cerebelo & D & - & 1328 & 5,73 & 22 & -90 & -30 \\
\hline Cerebelo & D & - & 1328 & 5,49 & 30 & -88 & -28 \\
\hline Pólo Occipital & D & 17 & 1328 & 5,17 & 32 & -96 & 4 \\
\hline Cerebelo & D & - & 1328 & 4,74 & 36 & -88 & -30 \\
\hline Pólo Occipital & $\mathrm{E}$ & 17 & 1236 & 5,46 & -28 & -98 & -2 \\
\hline Pólo Occipital & $\mathrm{E}$ & 17 & 1236 & 5,4 & -34 & -92 & -10 \\
\hline Pólo Occipital & $\mathrm{E}$ & 17 & 1236 & 5,3 & -40 & -86 & 32 \\
\hline Pólo Occipital & $\mathrm{E}$ & 17 & 1236 & 5,26 & -28 & -94 & -18 \\
\hline Cerebelo & $\mathrm{E}$ & - & 1236 & 4,6 & -24 & -88 & -30 \\
\hline Pólo Occipital & $\mathrm{E}$ & 17 & 1236 & 4,5 & -30 & -98 & -10 \\
\hline Borda do Sulco Intraparietal & D & 7 & 485 & 5,77 & 50 & -64 & 32 \\
\hline Borda do Sulco Intraparietal & D & 7 & 485 & 4,66 & 48 & -74 & 24 \\
\hline Borda do Sulco Intraparietal & D & 7 & 485 & 4,6 & 52 & -72 & 24 \\
\hline Borda do Sulco Intraparietal & D & 7 & 485 & 4,34 & 44 & -72 & 48 \\
\hline Borda do Sulco Intraparietal & D & 7 & 485 & 4,31 & 44 & -60 & 40 \\
\hline Borda do Sulco Intraparietal & D & 7 & 485 & 3,61 & 42 & -78 & 42 \\
\hline Giro Parahipocampal & $\mathrm{E}$ & 35 & 312 & 5,35 & -28 & 6 & -22 \\
\hline Giro Parahipocampal & $\mathrm{E}$ & 35 & 312 & 5,1 & -28 & 18 & -26 \\
\hline Giro Temporal Superior & $\bar{E}$ & 22 & 312 & 4,43 & -36 & 22 & -38 \\
\hline Giro Temporal Superior & $\mathrm{E}$ & 22 & 312 & 3,99 & -38 & 10 & -20 \\
\hline Giro Temporal Superior & $\mathrm{E}$ & 22 & 312 & 3,44 & -38 & 18 & -22 \\
\hline Giro Temporal Médio & $\mathrm{E}$ & 21 & 272 & 4,63 & -62 & -50 & -6 \\
\hline Giro Temporal Médio & $\mathrm{E}$ & 21 & 272 & 4,52 & -64 & -26 & -4 \\
\hline Giro Temporal Médio & $\mathrm{E}$ & 21 & 272 & 4,36 & -64 & -32 & -4 \\
\hline Giro Temporal Médio & $\mathrm{E}$ & 21 & 272 & 4,3 & -68 & -48 & 6 \\
\hline Giro Temporal Médio & $\mathrm{E}$ & 21 & 272 & 4,27 & -60 & -44 & -8 \\
\hline Giro Temporal Médio & $\mathrm{E}$ & 21 & 272 & 3,91 & -66 & -48 & 0 \\
\hline Giro Frontal Inferior & $\mathrm{E}$ & 47 & 268 & 4,59 & -50 & 38 & -16 \\
\hline Giro Frontal Inferior & $\mathrm{E}$ & 47 & 268 & 4,13 & -40 & 46 & -18 \\
\hline Giro Frontal Inferior & $\mathrm{E}$ & 47 & 268 & 3,98 & -48 & 26 & -14 \\
\hline Giro Frontal Inferior & $\mathrm{E}$ & 47 & 268 & 3,95 & -44 & 42 & -18 \\
\hline Giro Frontal Médio & $\mathrm{E}$ & 46 & 268 & 3,84 & -36 & 48 & -14 \\
\hline Giro Frontal Inferior & $\bar{E}$ & 47 & 268 & 3,23 & -46 & 26 & -4 \\
\hline Precuneus & $\mathrm{E}$ & 7 & 241 & 5,2 & -6 & -62 & 44 \\
\hline Precuneus & $\mathrm{E}$ & 7 & 241 & 4,27 & -6 & -60 & 52 \\
\hline Precuneus & $\mathrm{E}$ & 7 & 241 & 4,04 & -6 & -70 & 36 \\
\hline Precuneus & - & 7 & 241 & 3,65 & 0 & -64 & 52 \\
\hline Precuneus & $E$ & 7 & 241 & 3,58 & -8 & -60 & 60 \\
\hline Giro Frontal Superior & D & $6 / 8$ & 203 & 6,32 & 14 & 18 & 60 \\
\hline Giro Frontal Médio & D & $6 / 8$ & 203 & 4,32 & 20 & 8 & 64 \\
\hline Giro Frontal Médio & D & $6 / 8$ & 203 & 3,8 & 26 & 16 & 64 \\
\hline Giro Frontal Superior & D & $6 / 8$ & 203 & 3,33 & 24 & 14 & 58 \\
\hline
\end{tabular}




\begin{tabular}{lllllllc} 
Giro do Cíngulo Posterior & E & 31 & 196 & 4,46 & -6 & -54 & 8 \\
Giro do Cíngulo Posterior & $\mathrm{D}$ & 31 & 196 & 4,13 & 2 & -54 & 10 \\
Giro do Cíngulo Posterior & $\mathrm{E}$ & 31 & 196 & 3,94 & -2 & -58 & 12 \\
Giro do Cíngulo Posterior & $\mathrm{D}$ & 31 & 196 & 3,63 & 0 & -46 & 16 \\
\hline
\end{tabular}


APÊNDICE U10 - Atenção Automática - Todas as Condições Experimentais de Base (Válida, Neutra e Inválida)

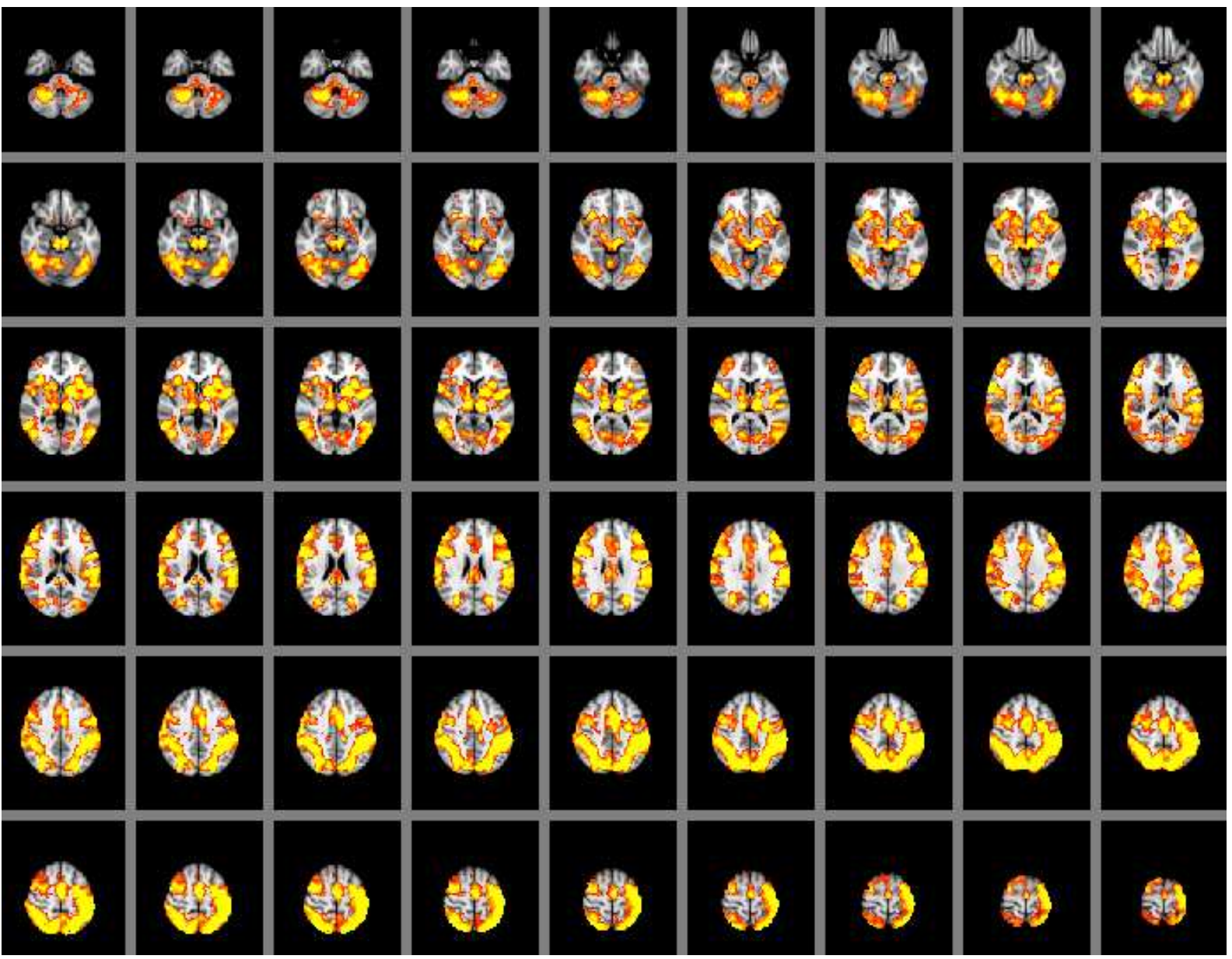

Figura 10. Mapa probabilístico de ativação de grupo, com a análise de conjunção, do Experimento de Atenção Automática $(\mathrm{N}=20)$. Observa-se a resposta BOLD nas Áreas Frontais: giro frontal médio, giro frontal medial, giro pré central bilaterais; giro frontal inferior direito. Áreas Parietais: borda do sulco intraparietal, giro pós central, lobo parietal superior, pré-cuneus, giro angular, giro supramarginal bilaterais; Áreas Temporais: giro temporal médio, giro temporal superior bilaterais; giro temporal inferior direito. Áreas Occipitais: giro fusiforme, giro lingual bilaterais; cuneus direito; giro occipital superior esquerdo. Outras Áreas: Outras áreas: cerebelo, tálamo, putâmen, núcleo caudado, mesencéfalo, giro parahipocampal, giro do cíngulo anterior e posterior, ínsula bilaterais (cluster > 2,3; $p<0,05$; escala de ativação $Z=2,3$ a 6,8). 
Tabela 10. Regiões com ativação máxima no contraste dos experimentos de atenção voluntária versus atenção automática $(\mathrm{V}>\mathrm{A})$. BA - área de Brodmann; TAM tamanho do cluster com efeito BOLD em voxels; $Z$ - nível de significância estatística do estimado efeito BOLD do determinado cluster; $\mathrm{MNI}$ - coordenadas nos eixos X, Y e Z no espaço definido pelo Atlas de Montreal Neurological Institute (Mazziotta et al., 2001).

\begin{tabular}{|c|c|c|c|c|c|c|c|}
\hline \multirow[t]{2}{*}{ REGIÃO CEREBRAL } & \multirow[t]{2}{*}{ LADO } & \multirow[t]{2}{*}{ BA } & \multirow[t]{2}{*}{ TAM } & \multirow[t]{2}{*}{ Z } & \multicolumn{3}{|c|}{ MNI } \\
\hline & & & & & $\mathrm{X}$ & $\mathrm{Y}$ & Z \\
\hline Borda do Sulco Intraparietal & $\mathrm{E}$ & 7 & 18928 & 6,73 & -43 & -36 & 44 \\
\hline Giro Pós-Central & $\mathrm{E}$ & 3 & 22568 & 6,71 & -47 & -32 & 42 \\
\hline Tálamo & $\mathrm{E}$ & - & 6048 & 6,09 & -11 & -18 & 9 \\
\hline Giro Pré-Central & $\mathrm{E}$ & 4 & 22314 & 6,02 & -43 & -22 & 62 \\
\hline Ínsula & $\mathrm{E}$ & 13 & 10394 & 6,01 & -35 & 20 & 4 \\
\hline Lobo Parietal Superior & D & 7 & 18970 & 5,97 & 28 & -60 & 52 \\
\hline Lobo Parietal Superior & D & 7 & 9733 & 5,97 & 29 & -60 & 52 \\
\hline Lobo Parietal Superior & $\mathrm{E}$ & 7 & 9544 & 5,97 & -25 & -63 & 50 \\
\hline Borda do Sulco Intraparietal & $\mathrm{E}$ & 7 & 20382 & 5,95 & -33 & -46 & 45 \\
\hline Borda do Sulco Intraparietal & $\mathrm{E}$ & 7 & 52074 & 5,95 & -41 & -50 & 64 \\
\hline Giro Frontal Médio & $\mathrm{E}$ & 46 & 19224 & 5,89 & -27 & -2 & 52 \\
\hline Cerebelo & D & - & 11338 & 5,80 & 19 & -52 & -28 \\
\hline Pre-cuneus & $\mathrm{E}$ & 19 & 16666 & 5,73 & -23 & -64 & 50 \\
\hline Ínsula & $\mathrm{E}$ & 13 & 9336 & 5,69 & -37 & 18 & -1 \\
\hline Giro Pós-Central & D & 3 & 16299 & 5,68 & 49 & -32 & 48 \\
\hline Giro Pós-Central & D & 3 & 16844 & 5,56 & 49 & -33 & 50 \\
\hline Borda do Sulco Intraparietal & D & 7 & 25204 & 5,52 & 35 & -44 & 48 \\
\hline Giro do Cíngulo Anterior & $\mathrm{E}$ & 32 & 11886 & 5,48 & -7 & 2 & 45 \\
\hline Giro Supramarginal & $\mathrm{E}$ & 40 & 3384 & 5,40 & -55 & -40 & 36 \\
\hline Ínsula & $\mathrm{E}$ & 13 & 11090 & 5,32 & -35 & 22 & 0 \\
\hline Giro Frontal Medial & $E$ & 9 & 8236 & 5,26 & -9 & 8 & 48 \\
\hline Giro Frontal Inferior & D & 47 & 13940 & 5,19 & 35 & 26 & 2 \\
\hline Giro Pré-Central & $\mathrm{E}$ & 4 & 5080 & 5,19 & -31 & -10 & 68 \\
\hline Tálamo & D & - & 6089 & 5,17 & 11 & -18 & 9 \\
\hline Giro Temporal Médio & D & 46 & 11551 & 5,11 & 53 & -54 & 4 \\
\hline Giro Temporal Superior & $\mathrm{E}$ & $6 / 8$ & 7620 & 5,11 & -51 & 0 & 4 \\
\hline Putâmen & $\mathrm{E}$ & - & 5886 & 4,99 & -21 & 10 & 4 \\
\hline Giro Frontal Médio & D & 46 & 29716 & 4,97 & 49 & 38 & 22 \\
\hline Ínsula & D & 13 & 5274 & 4,97 & 36 & 24 & 2 \\
\hline Cerebelo & $\mathrm{E}$ & - & 1532 & 4,96 & -3 & -62 & -18 \\
\hline Giro Fusiforme & $\mathrm{E}$ & 37 & 4462 & 4,92 & -43 & -62 & -18 \\
\hline Giro Pós-Central & D & 3 & 10652 & 4,88 & 59 & -14 & 31 \\
\hline Giro Supramarginal & D & 40 & 1924 & 4,86 & 43 & -40 & 38 \\
\hline Giro Frontal Medial & - & $8 / 9$ & 144 & 4,85 & 0 & -4 & 56 \\
\hline Giro Frontal Medial & D & $8 / 9$ & 5606 & 4,85 & 1 & -4 & 56 \\
\hline Giro Temporal Superior & D & 22 & 8248 & 4,85 & 63 & -36 & 20 \\
\hline Pré-Cuneus & $\mathrm{E}$ & 7 & 5968 & 4,81 & -21 & -73 & 31 \\
\hline Cerebelo & D & - & 204 & 4,75 & 10 & -52 & -26 \\
\hline Ínsula & D & 13 & 7972 & 4,75 & 35 & 24 & 0 \\
\hline Cerebelo & D & - & 7519 & 4,72 & 19 & -57 & -23 \\
\hline Giro Temporal Médio & $\mathrm{E}$ & 21 & 10398 & 4,65 & -47 & -70 & 9 \\
\hline Giro Frontal Medial & - & $8 / 9$ & 322 & 4,62 & 0 & 2 & 50 \\
\hline Giro Frontal Medial & D & $8 / 9$ & 9194 & 4,62 & 1 & 2 & 50 \\
\hline Giro Occipital Médio & $\mathrm{E}$ & 17 & 7792 & 4,59 & -35 & -71 & -12 \\
\hline Giro Frontal Medial & - & $8 / 9$ & 128 & 4,59 & 0 & 4 & 52 \\
\hline Giro Frontal Medial & D & $8 / 9$ & 8150 & 4,59 & 1 & 4 & 52 \\
\hline Giro Fusiforme & D & 37 & 5616 & 4,54 & 34 & -62 & -12 \\
\hline Giro Occipital Médio & $\mathrm{E}$ & 17 & 2260 & 4,54 & -47 & -70 & -2 \\
\hline Giro Fusiforme & $\mathrm{E}$ & 37 & 930 & 4,44 & -35 & -73 & -12 \\
\hline Cerebelo & $\mathrm{E}$ & - & 3674 & 4,38 & -43 & -62 & -21 \\
\hline
\end{tabular}




\begin{tabular}{|c|c|c|c|c|c|c|c|}
\hline Núcleo Caudado & D & - & 2548 & 4,32 & 11 & 10 & 0 \\
\hline Giro Angular & D & 39 & 354 & 4,32 & 33 & -64 & 36 \\
\hline Giro Lingual & D & 18 & 2562 & 4,32 & 29 & -76 & -12 \\
\hline Giro do Cíngulo Posterior & D & 31 & 2060 & 4,27 & 7 & -40 & 22 \\
\hline Cuneus & D & 19 & 3730 & 4,24 & 13 & -71 & 13 \\
\hline Giro Pós-Central & $\mathrm{E}$ & 3 & 768 & 4,22 & -49 & -20 & 12 \\
\hline Giro Lingual & D & 18 & 603 & 4,22 & 33 & -73 & -8 \\
\hline Giro Temporal Inferior & D & 20 & 3414 & 4,19 & 46 & -68 & 2 \\
\hline Giro do Cíngulo Posterior & $\mathrm{E}$ & 31 & 1032 & 4,17 & -7 & -40 & 22 \\
\hline Giro Lingual & $\mathrm{E}$ & 18 & 2748 & 4,16 & -27 & -71 & -9 \\
\hline Giro Fusiforme & D & 37 & 2497 & 4,14 & 49 & -51 & -16 \\
\hline Cerebelo & $\mathrm{E}$ & - & 5472 & 4,14 & -33 & -48 & -26 \\
\hline Cerebelo & D & - & 140 & 4,13 & 2 & -63 & -16 \\
\hline Putâmen & D & - & 5156 & 4,10 & 17 & 16 & -5 \\
\hline Cerebelo & D & - & 385 & 4,05 & 33 & -55 & -35 \\
\hline Cerebelo & D & - & 84 & 4,04 & 14 & -53 & -35 \\
\hline Putâmen & $\mathrm{E}$ & - & 836 & 4,01 & -27 & 16 & 5 \\
\hline Pré-Cuneus & - & 7 & 200 & 3,99 & 0 & -62 & 52 \\
\hline Cerebelo & D & - & 380 & 3,96 & 28 & -57 & -35 \\
\hline Giro Temporal Médio & $\mathrm{D}$ & 21 & 660 & 3,96 & 33 & -75 & 24 \\
\hline Cerebelo & $\mathrm{E}$ & - & 124 & 3,94 & -1 & -63 & -13 \\
\hline Cerebelo & - & - & 257 & 3,84 & 0 & -58 & -12 \\
\hline Giro Frontal Medial & - & $8 / 9$ & 50 & 3,93 & 0 & -11 & 50 \\
\hline Giro Frontal Medial & D & $8 / 9$ & 374 & 3,93 & 1 & -11 & 50 \\
\hline Giro Parahipocampal & D & 34 & 587 & 3,91 & 14 & -33 & 0 \\
\hline Giro do Cíngulo Anterior & $\mathrm{E}$ & 32 & 1832 & 3,88 & -11 & 24 & 28 \\
\hline Cerebelo & - & - & 106 & 3,86 & 0 & -60 & -15 \\
\hline Cerebelo & - & - & 56 & 3,79 & 0 & -63 & -13 \\
\hline Núcleo Caudado & $\mathrm{E}$ & - & 416 & 3,78 & -11 & 8 & 8 \\
\hline Giro Angular & $\mathrm{E}$ & 39 & 224 & 3,77 & -33 & -71 & 31 \\
\hline Giro Parahipocampal & $\mathrm{E}$ & 35 & 222 & 3,74 & -15 & -29 & -5 \\
\hline Cerebelo & $\mathrm{E}$ & - & 498 & 3,70 & -15 & -70 & -31 \\
\hline Cerebelo & D & - & 165 & 3,69 & 10 & -48 & -20 \\
\hline Mesencéfalo & - & - & 71 & 3,62 & 0 & -26 & -4 \\
\hline Giro do Cíngulo Anterior & D & 32 & 2008 & 3,59 & 10 & 38 & 26 \\
\hline Cerebelo & $\mathrm{D}$ & - & 399 & 3,56 & 31 & -50 & -40 \\
\hline Cerebelo & D & - & 169 & 3,55 & 29 & -63 & -31 \\
\hline Giro Occipital Superior & $\mathrm{E}$ & 19 & 668 & 3,54 & -31 & -85 & 22 \\
\hline Putâmen & $\mathrm{E}$ & - & 576 & 3,53 & -17 & 10 & -12 \\
\hline Cerebelo & $\mathrm{E}$ & - & 532 & 3,42 & -29 & -66 & -35 \\
\hline Putâmen & D & - & 676 & 3,38 & 15 & 18 & -12 \\
\hline Claustrum & D & - & 214 & 3,33 & 34 & 2 & 10 \\
\hline Cerebelo & $\mathrm{E}$ & - & 420 & 3,29 & -27 & -66 & -35 \\
\hline Cerebelo & $\mathrm{E}$ & - & 796 & 3,26 & -9 & -43 & -45 \\
\hline Cerebelo & E & - & 232 & 3,17 & -3 & -56 & -26 \\
\hline Cerebelo & D & - & 118 & 3,13 & 4 & -69 & -20 \\
\hline Giro Lingual & $\mathrm{D}$ & 18 & 144 & 2,96 & 27 & -60 & 4 \\
\hline Giro Lingual & $\mathrm{E}$ & 18 & 88 & 2,95 & -25 & -67 & 4 \\
\hline Cerebelo & $E$ & & 28 & 2,82 & -3 & -45 & -37 \\
\hline Giro Pós-Central & D & 3 & 10 & 2,74 & 61 & -12 & 13 \\
\hline Cerebelo & $\mathrm{E}$ & - & 196 & 2,73 & -1 & -48 & -18 \\
\hline Cerebelo & - & - & 32 & 2,67 & 0 & -48 & -21 \\
\hline Cerebelo & D & - & 6 & 2,60 & 2 & -69 & -31 \\
\hline Cuneus & - & 19 & 50 & 2,59 & 0 & -78 & 16 \\
\hline Cerebelo & - & - & 24 & 2,55 & 0 & -65 & -26 \\
\hline Cuneus & - & 19 & 2 & 2,52 & 0 & -72 & 12 \\
\hline Cerebelo & - & - & 2 & 2,43 & 0 & -48 & -26 \\
\hline Giro do Cíngulo Anterior & - & 32 & 8 & 2,43 & 0 & 36 & 24 \\
\hline Cerebelo & $\mathrm{D}$ & & 2 & 2,36 & 4 & -62 & -40 \\
\hline
\end{tabular}


APÊNDICE U11 - Atenção Voluntária - Todas as Condições Experimentais de Base (Válida, Neutra e Inválida)

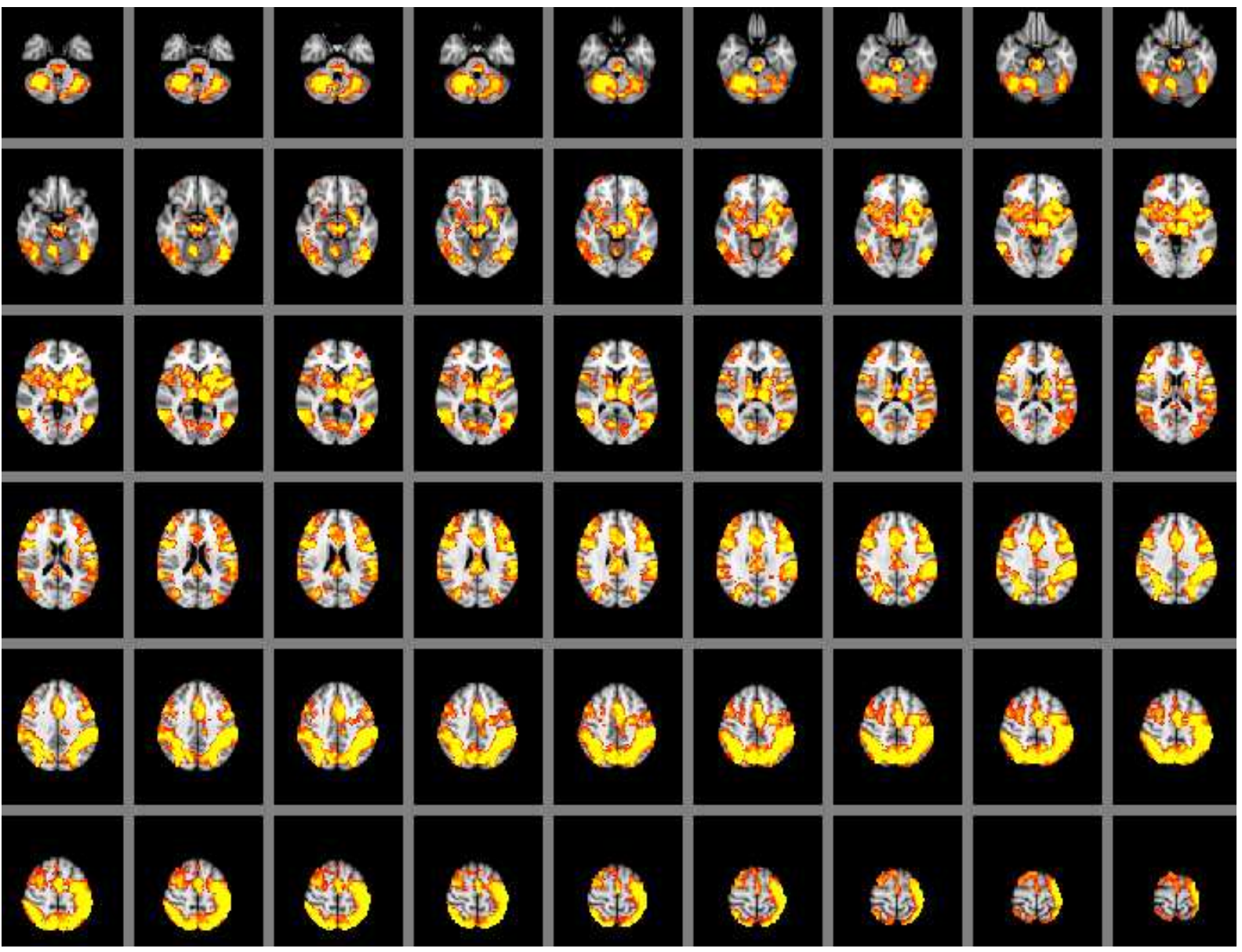

Figura 11. Mapa probabilístico de ativação de grupo, com a análise de conjunção, do Experimento de Atenção Voluntária $(\mathrm{N}=20)$. Observa-se a resposta BOLD nas Áreas Frontais: giro frontal médio, giro frontal medial, giro pré central bilaterais; giro frontal inferior direito. Áreas Parietais: borda do sulco intraparietal, giro pós central, lobo parietal superior, pré-cuneus, giro angular, giro supramarginal bilaterais; Áreas Temporais: giro temporal médio, giro temporal superior bilaterais. Áreas Occipitais: giro fusiforme, giro lingual, cuneus bilaterais; giro occipital médio e superior esquerdos. Outras Áreas: cerebelo, tálamo, putâmen, núcleo caudado, mesencéfalo, giro parahipocampal, giro do cíngulo anterior e posterior, ínsula bilaterais; amígdala esquerda (cluster $>2,3 ; p<0,05$; escala de ativação $Z=2,3$ a 6,7$)$. 
Tabela 11. Regiões com ativação máxima no contraste dos experimentos de atenção voluntária versus atenção automática $(\mathrm{V}>\mathrm{A})$. BA - área de Brodmann; TAM tamanho do cluster com efeito BOLD em voxels; $Z$ - nível de significância estatística do estimado efeito BOLD do determinado cluster; $\mathrm{MNI}$ - coordenadas nos eixos X, Y e Z no espaço definido pelo Atlas de Montreal Neurological Institute (Mazziotta et al., 2001).

\begin{tabular}{|c|c|c|c|c|c|c|c|}
\hline \multirow[t]{2}{*}{ REGIÃO CEREBRAL } & \multirow[t]{2}{*}{ LADO } & \multirow[t]{2}{*}{ BA } & \multirow[t]{2}{*}{ TAM } & \multirow[t]{2}{*}{ Z } & \multicolumn{3}{|c|}{ MNI } \\
\hline & & & & & $\mathrm{X}$ & $\mathrm{Y}$ & Z \\
\hline Borda do Sulco Intraparietal & $\mathrm{E}$ & 7 & 19610 & 6,69 & -39 & -42 & 48 \\
\hline Giro Pós Central & $\mathrm{E}$ & 3 & 17244 & 6,34 & -47 & -32 & 42 \\
\hline Tálamo & $\mathrm{E}$ & - & 7214 & 6,31 & -13 & -20 & -6 \\
\hline Borda do Sulco Intraparietal & D & 7 & 9151 & 6,27 & 31 & -56 & 52 \\
\hline Borda do Sulco Intraparietal & D & 7 & 18554 & 6,09 & 28 & -58 & 54 \\
\hline Borda do Sulco Intraparietal & $\mathrm{E}$ & 7 & 21112 & 6,04 & -31 & -48 & 42 \\
\hline Lobo Parietal Superior & $\mathrm{E}$ & 7 & 9656 & 6,02 & -33 & -58 & 54 \\
\hline Tálamo & $\mathrm{E}$ & - & 52316 & 6,00 & -13 & -20 & -1 \\
\hline Giro Pré Central & $\mathrm{E}$ & 4 & 24394 & 5,89 & -29 & -6 & 58 \\
\hline Pré-Cuneus & D & 7 & 19551 & 5,86 & 31 & -64 & 40 \\
\hline Giro Pré Central & $\mathrm{E}$ & 4 & 9176 & 5,76 & -59 & 8 & 31 \\
\hline Cerebelo & D & - & 9468 & 5,74 & 17 & -50 & -28 \\
\hline Giro Frontal Medial & $\mathrm{E}$ & $8 / 9$ & 12776 & 5,63 & -7 & 4 & 50 \\
\hline Lobo Parietal Superior & D & 7 & 18031 & 5,61 & 31 & -56 & 48 \\
\hline Giro do Cíngulo Posterior & D & 31 & 305 & 5,52 & 10 & -52 & -26 \\
\hline Giro Temporal Médio & D & 21 & 11715 & 5,52 & 57 & -52 & 2 \\
\hline Giro Pré Central & $\mathrm{E}$ & 4 & 18152 & 5,49 & -29 & -7 & 56 \\
\hline Ínsula & $\mathrm{E}$ & 13 & 9034 & 5,48 & -39 & 16 & 0 \\
\hline Giro Frontal Médio & $\mathrm{E}$ & 46 & 10682 & 5,42 & -55 & -64 & 4 \\
\hline Ínsula & $\mathrm{E}$ & 13 & 14444 & 5,38 & -35 & 20 & 0 \\
\hline Pré-Cuneus & $\mathrm{E}$ & 7 & 16340 & 5,30 & -7 & -74 & 45 \\
\hline Putâmen & $\mathrm{E}$ & - & 7496 & 5,28 & -27 & 0 & 4 \\
\hline Giro Supramarginal & $\mathrm{E}$ & 40 & 4124 & 5,15 & -37 & -43 & 38 \\
\hline Tálamo & D & - & 6452 & 5,15 & 9 & -20 & 9 \\
\hline Giro Occipital Médio & $\mathrm{E}$ & 17 & 5046 & 5,13 & -47 & -64 & -9 \\
\hline Giro Angular & $\mathrm{D}$ & 39 & 592 & 5,11 & 35 & -60 & 36 \\
\hline Giro Frontal Médio & D & 46 & 28016 & 5,09 & 45 & 40 & 22 \\
\hline Giro Frontal Medial & $\mathrm{E}$ & $8 / 9$ & 7568 & 5,08 & -7 & 4 & 52 \\
\hline Cerebelo & D & - & 9586 & 5,08 & 33 & -57 & -28 \\
\hline Giro Temporal Médio & $\mathrm{E}$ & 21 & 2738 & 5,03 & -55 & -65 & -1 \\
\hline Giro Pós Central & D & 3 & 10055 & 5,00 & 46 & -32 & 48 \\
\hline Cerebelo & D & - & 466 & 4,89 & 31 & -63 & -31 \\
\hline Cerebelo & $\mathrm{E}$ & - & 5530 & 4,88 & -37 & -52 & -31 \\
\hline Giro Temporal Superior & $\mathrm{D}$ & 22 & 8286 & 4,86 & 49 & -52 & 12 \\
\hline Giro Frontal Medial & - & $8 / 9$ & 156 & 4,85 & 0 & -2 & 56 \\
\hline Giro Frontal Medial & D & $8 / 9$ & 4074 & 4,85 & 1 & -2 & 56 \\
\hline Giro Frontal Medial & $\mathrm{E}$ & $8 / 9$ & 7248 & 4,81 & -5 & 6 & 54 \\
\hline Giro Temporal Superior & $\mathrm{E}$ & 22 & 8328 & 4,78 & -51 & 0 & 2 \\
\hline Cerebelo & D & - & 1872 & 4,74 & 35 & -46 & -40 \\
\hline Giro Frontal Inferior & D & 47 & 9760 & 4,73 & 43 & 10 & 30 \\
\hline Cerebelo & D & - & 1559 & 4,73 & 33 & -55 & -35 \\
\hline Giro do Cíngulo Posterior & D & 31 & 1682 & 4,64 & 6 & -30 & 26 \\
\hline Giro do Cíngulo Posterior & D & 31 & 9577 & 4,64 & 7 & -30 & 26 \\
\hline Cerebelo & D & - & 973 & 4,59 & 28 & -62 & -35 \\
\hline Cerebelo & $\mathrm{E}$ & - & 1016 & 4,57 & -29 & -62 & -36 \\
\hline Giro Fusiforme & $\mathrm{E}$ & 37 & 3558 & 4,54 & -43 & -62 & -18 \\
\hline Giro Fusiforme & $\mathrm{E}$ & 37 & 6488 & 4,53 & -43 & -61 & -21 \\
\hline Giro do Cíngulo Anterior & $\mathrm{E}$ & 32 & 2624 & 4,53 & -3 & 12 & 28 \\
\hline Amígdala & $\mathrm{E}$ & & 436 & 4,52 & -31 & -15 & -9 \\
\hline
\end{tabular}


Cerebelo

Giro Fusiforme

Giro do Cíngulo Posterior

Giro Fusiforme

Giro Supramarginal

Claustrum

Giro Frontal Medial

Giro Frontal Medial

Giro Frontal Medial

Cerebelo

Giro Angular

Cerebelo

Pré-Cuneus

Giro do Cíngulo Anterior

Cerebelo

Giro Parahipocampal

Núcleo Caudado

Giro do Cíngulo Posterior

Giro Lingual

Giro do Cíngulo Posterior

Giro Frontal Inferior

Cuneus

Núcleo Caudado

Ínsula

Borda do Sulco Intraparietal

Cerebelo

Cerebelo

Tálamo

Putâmen

Cerebelo

Giro Temporal Médio

Putâmen

Cuneus

Cerebelo

Giro Fusiforme

Claustrum

Cerebelo

Giro Occipital Superior

Giro do Cíngulo Anterior

Cerebelo

Giro Pós Central

Giro Frontal Medial

Giro Frontal Medial

Giro Parahipocampal

Cerebelo

Giro Fusiforme

Giro Lingual

Tálamo

Cerebelo

Cerebelo

Cerebelo

Giro do Cíngulo Anterior

Cerebelo

Cerebelo

Cerebelo

Cerebelo

Cerebelo

Cerebelo

Cerebelo

Cuneus

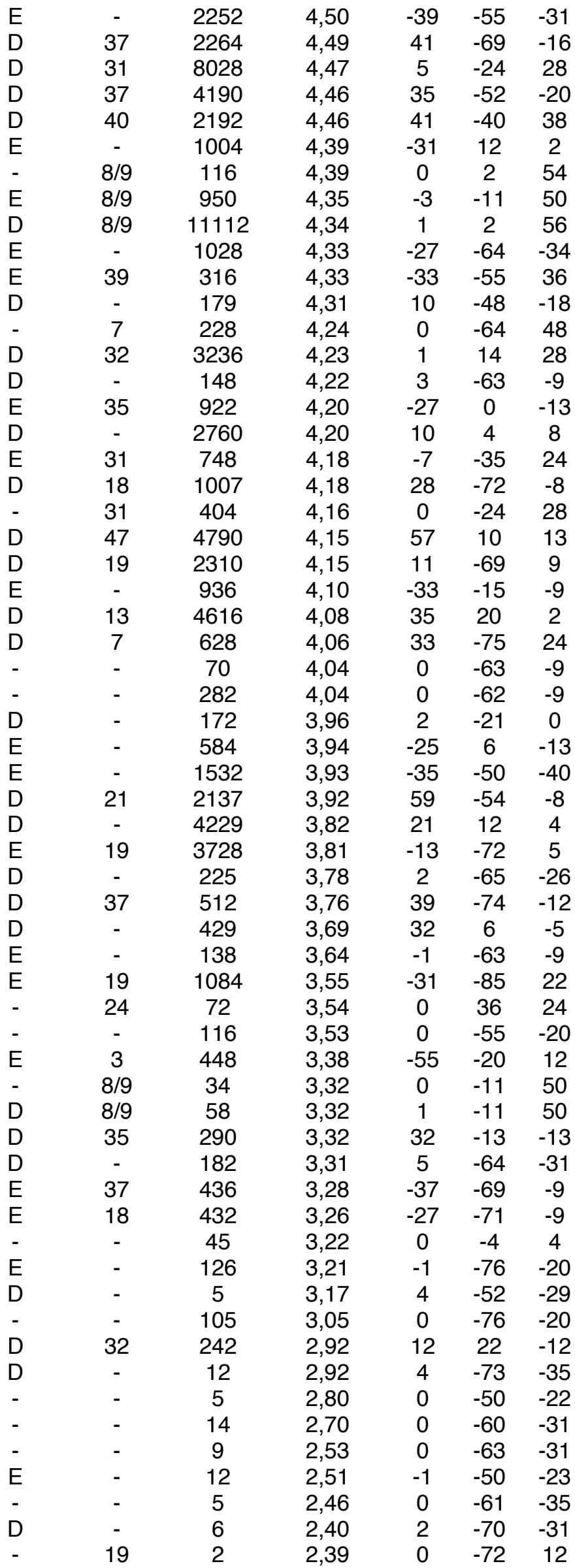


Cuneus

Cerebelo

$\begin{array}{cccc}- & 19 & 2 & 2,39 \\ \mathrm{E} & - & 8 & 2,34\end{array}$

$\begin{array}{llll}2,39 & 0 & -73 & 12\end{array}$

Cerebelo

E $\quad-\quad 16$

2,31

\begin{tabular}{lll}
-5 & -58 & -31 \\
-5 & -58 & -30 \\
\hline
\end{tabular}


APÊNDICE U12 - Análise de Conjunção da Atenção Automática e da Atenção

Voluntária

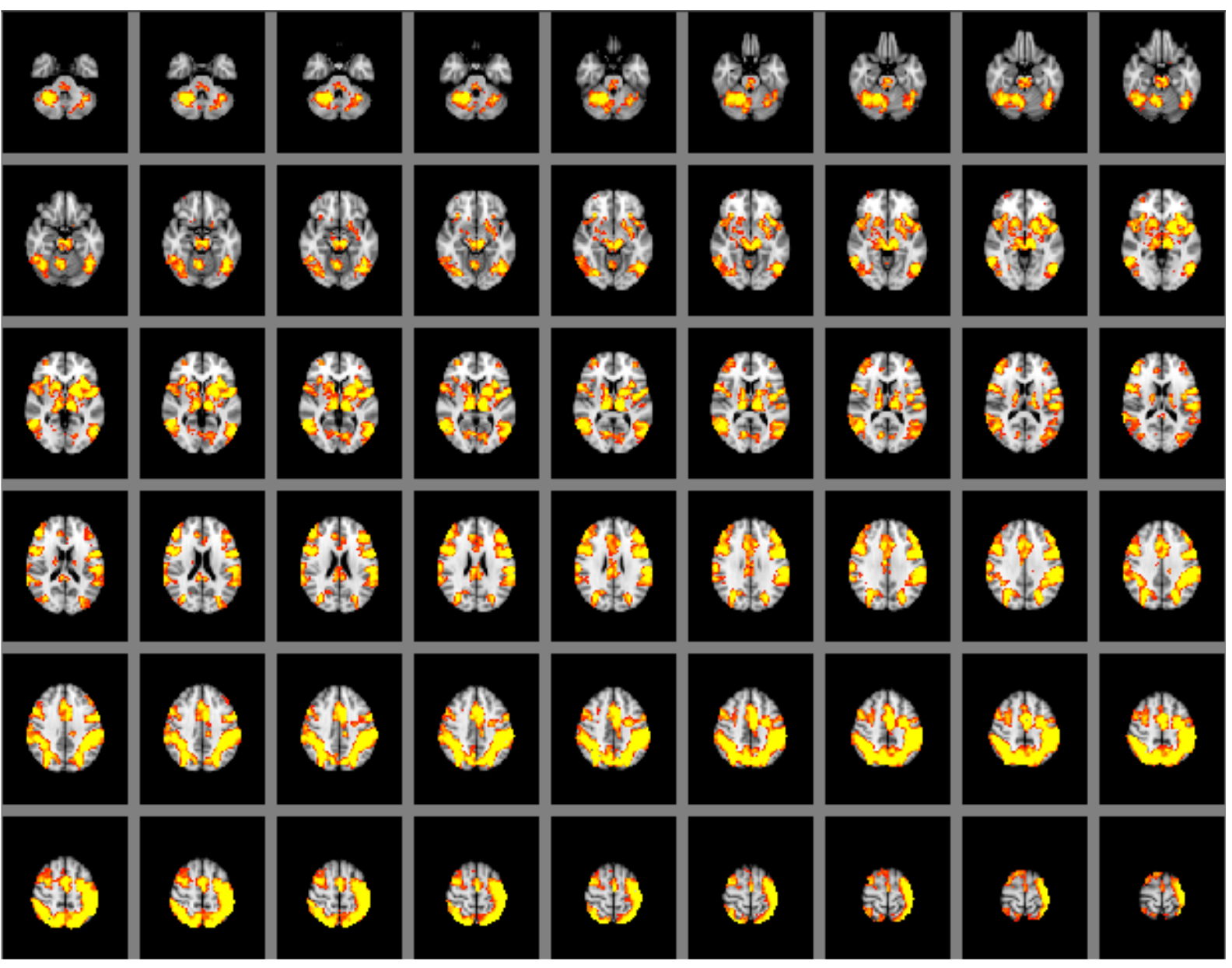

Figura 12. Mapa probabilístico de ativação de grupo, com a análise de conjunção, dos Experimentos de Atenção Automática e Atenção Voluntária $(\mathrm{N}=20)$. Observa-se a resposta BOLD nas Áreas Frontais: giro frontal médio, giro frontal medial, giro pré central bilaterais; giro frontal inferior direito. Áreas Parietais: borda do sulco intraparietal, giro pós central, lobo parietal superior, pré-cuneus, giro angular, giro supramarginal bilaterais; Áreas Temporais: giro temporal médio, giro temporal superior bilaterais. Áreas Occipitais: giro fusiforme, giro lingual bilaterais, cuneus direito. Outras Áreas: cerebelo, tálamo, mesencéfalo, giro parahipocampal, giro do cíngulo anterior e posterior, ínsula bilaterais (cluster $>2,3 ; p<0,05$; escala de ativação $Z=2,3$ a 6,6 ). 
Tabela 12. Regiões com ativação máxima no contraste dos experimentos de atenção voluntária versus atenção automática $(\mathrm{V}>\mathrm{A})$. BA - área de Brodmann; TAM tamanho do cluster com efeito BOLD em voxels; $Z$ - nível de significância estatística do estimado efeito BOLD do determinado cluster; $\mathrm{MNI}$ - coordenadas nos eixos X, Y e Z no espaço definido pelo Atlas de Montreal Neurological Institute (Mazziotta et al., 2001).

\begin{tabular}{|c|c|c|c|c|c|c|c|}
\hline \multirow[t]{2}{*}{ REGIÃO CEREBRAL } & \multirow[t]{2}{*}{ LADO } & \multirow[t]{2}{*}{ BA } & \multirow[t]{2}{*}{ TAM } & \multirow[t]{2}{*}{ Z } & \multicolumn{3}{|c|}{$\mathrm{MNI}$} \\
\hline & & & & & $\mathrm{X}$ & $\mathrm{Y}$ & Z \\
\hline Borda do Sulco Intraparietal & $\mathrm{E}$ & 7 & 18092 & 6,45 & -45 & -32 & 42 \\
\hline Borda do Sulco Intraparietal & E & 7 & 17140 & 6,34 & -47 & -32 & 42 \\
\hline Tálamo & E & - & 5974 & 5,93 & -13 & -20 & 9 \\
\hline Lobo Parietal Superior & D & 7 & 8828 & 5,81 & 29 & -60 & 54 \\
\hline Pré-cuneus & $\mathrm{D}$ & 7 & 16282 & 5,78 & 28 & -58 & 52 \\
\hline Lobo Parietal Superior & $\mathrm{E}$ & 7 & 9292 & 5,78 & -27 & -66 & 52 \\
\hline Borda do Sulco Intraparietal & $\mathrm{E}$ & 7 & 15450 & 5,67 & -33 & -46 & 42 \\
\hline Cerebelo & D & - & 42993 & 5,67 & 18 & -52 & -28 \\
\hline Cerebelo & D & - & 8863 & 5,67 & 19 & -52 & -28 \\
\hline Giro Pré-Central & $\mathrm{E}$ & 4 & 8164 & 5,62 & -57 & 8 & 31 \\
\hline Insula & E & 13 & 7802 & 5,45 & -37 & 18 & 0 \\
\hline Giro Pré-Central & $\mathrm{E}$ & 4 & 17100 & 5,3 & -59 & 4 & 31 \\
\hline Borda do Sulco Intraparietal & D & 7 & 15043 & 5,34 & 35 & -54 & 54 \\
\hline Borda do Sulco Intraparietal & D & 7 & 1677 & 5,33 & 26 & -60 & 54 \\
\hline Insula & $\mathrm{E}$ & 13 & 9290 & 5,31 & -35 & 20 & 0 \\
\hline Giro Pré-Central & $\bar{E}$ & 4 & 18056 & 5,26 & -31 & -4 & 60 \\
\hline Giro do Cíngulo Anterior & E & 32 & 10374 & 5,25 & -9 & 2 & 48 \\
\hline Pré-cuneus & E & 7 & 14668 & 5,15 & -25 & -62 & 50 \\
\hline Giro Temporal Médio & D & 21 & 9695 & 5,11 & 53 & -54 & 4 \\
\hline Tálamo & D & - & 5847 & 5,1 & 11 & -18 & 9 \\
\hline Giro Pós-Central & D & 3 & 9873 & 5 & 46 & -32 & 48 \\
\hline Giro Supramarginal & $\mathrm{E}$ & 40 & 3340 & 4,98 & -37 & -44 & 38 \\
\hline Giro Frontal Médio & $\bar{E}$ & 46 & 6648 & 4,91 & -5 & 4 & 52 \\
\hline Giro Temporal Superior & $\bar{E}$ & 22 & 6504 & 4,78 & -51 & 0 & 1 \\
\hline Putamen & E & - & 5508 & 4,78 & -21 & 8 & 1 \\
\hline Giro Frontal Médio & $\mathrm{E}$ & 46 & 4604 & 4,76 & -3 & 4 & 52 \\
\hline Cerebelo & $\mathrm{D}$ & - & 198 & 4,75 & 10 & -52 & -26 \\
\hline Cerebelo & D & - & 6518 & 4,72 & 19 & -57 & -23 \\
\hline Giro Frontal Médio & D & 46 & 24525 & 4,71 & 45 & 40 & 24 \\
\hline Giro Frontal Inferior & $\mathrm{D}$ & 47 & 9196 & 4,67 & 43 & 10 & 30 \\
\hline Giro Frontal Medial & - & 46 & 136 & 4,66 & 0 & -2 & 56 \\
\hline Giro Frontal Medial & D & 46 & 3522 & 4,66 & 1 & -2 & 56 \\
\hline Giro Fusiforme & $\mathrm{E}$ & 37 & 4658 & 4,57 & -45 & -65 & -12 \\
\hline Giro Fusiforme & $\bar{E}$ & 37 & 3174 & 4,54 & -43 & -62 & -18 \\
\hline Giro Temporal Superior & $\bar{D}$ & 22 & 7226 & 4,53 & 49 & -56 & 12 \\
\hline Giro Fusiforme & $\mathrm{E}$ & 37 & 2186 & 4,49 & -47 & -68 & -1 \\
\hline Giro Fusiforme & $\mathrm{E}$ & 37 & 9384 & 4,49 & -47 & -68 & 0 \\
\hline Giro Supramarginal & $\mathrm{D}$ & 40 & 1366 & 4,39 & 41 & -40 & 38 \\
\hline Giro Frontal Médio & - & 46 & 116 & 4,39 & 0 & 2 & 54 \\
\hline Cerebelo & E & - & 2744 & 4,38 & -43 & -62 & -21 \\
\hline Giro Frontal Medial & $\bar{E}$ & $8 / 9$ & 784 & 4,35 & -3 & -11 & 50 \\
\hline Giro Frontal Medial & $\bar{D}$ & $8 / 9$ & 5896 & 4,33 & 1 & 2 & 56 \\
\hline Giro Angular & $\mathrm{D}$ & 39 & 346 & 4,31 & 33 & -64 & 36 \\
\hline Giro Pré-Central & D & 3 & 4304 & 4,15 & 57 & 10 & 13 \\
\hline Giro Lingual & D & 18 & 955 & 4,1 & 29 & -74 & -9 \\
\hline Giro Frontal Medial & D & $8 / 9$ & 6930 & 4,08 & 1 & 18 & 46 \\
\hline Insula & D & 13 & 3868 & 4,08 & 35 & 20 & 2 \\
\hline Cerebelo & E & - & 3522 & 4,08 & -35 & -52 & -30 \\
\hline Giro Frontal Medial & - & $8 / 9$ & 306 & 4,06 & 0 & 0 & 50 \\
\hline
\end{tabular}


Cerebelo

Giro Fusiforme

Insula

Precuneus

Núcleo Caudado

Cerebelo

Giro Temporal Médio

Cerebelo

Giro do Cíngulo Posterior

Claustrum

Cuneus

Giro Occipital Médio

Giro Parahipocampal

Giro do Cíngulo Anterior

Giro do Cíngulo Posterior

Cerebelo

Putâmen

Giro Fusiforme

Giro Lingual

Caudado

Borda do Sulco Intraparietal

Mesencéfalo

Cerebelo

Cerebelo

Cerebelo

Giro Occipital Superior

Giro do Cíngulo Anterior

Giro Angular

Cerebelo

Cerebelo

Cerebelo

Cerebelo

Cerebelo

Putâmen

Giro Pós-Central

Giro Frontal Medial

Cerebelo

Giro Occipital Inferior

Giro Lingual

Cerebelo

Claustrum

Giro Parahipocampal

Cerebelo

Tálamo

Cerebelo

Cerebelo

Cerebelo

Cerebelo

Giro do Cíngulo Anterior

Cuneus

Cuneus

Cerebelo

\begin{tabular}{ccccccc} 
D & - & 385 & 4,05 & 33 & -55 & -35 \\
D & 37 & 3540 & 4,03 & 39 & -52 & -18 \\
D & 13 & 5697 & 4,01 & 35 & 20 & 0 \\
- & 7 & 196 & 3,99 & 0 & -62 & 52 \\
D & - & 2298 & 3,98 & 9 & 8 & 5 \\
D & - & 350 & 3,96 & 28 & -57 & -35 \\
D & 21 & 528 & 3,96 & 33 & -75 & 24 \\
D & - & 121 & 3,89 & 2 & -63 & -13 \\
D & 31 & 1500 & 3,87 & 13 & -66 & 12 \\
E & - & 752 & 3,86 & -27 & 16 & 4 \\
D & 19 & 1792 & 3,85 & 11 & -72 & 13 \\
D & 17 & 1950 & 3,76 & 41 & -66 & -9 \\
E & 35 & 140 & 3,74 & -15 & -29 & -5 \\
E & 32 & 1784 & 3,72 & -9 & 26 & 28 \\
E & 31 & 552 & 3,69 & -7 & -36 & 24 \\
D & - & 117 & 3,69 & 10 & -48 & -20 \\
D & - & 3476 & 3,68 & 17 & 14 & -2 \\
D & 37 & 1861 & 3,68 & 51 & -47 & -16 \\
D & 18 & 493 & 3,68 & 33 & -73 & -8 \\
E & - & 312 & 3,67 & -11 & 10 & 1 \\
E & 7 & 3516 & 3,65 & -25 & -77 & 31 \\
- & - & 53 & 3,62 & 0 & -26 & -4 \\
- & - & 236 & 3,6 & 0 & -60 & -12 \\
D & - & 272 & 3,56 & 31 & -50 & -40 \\
D & - & 115 & 3,55 & 29 & -63 & -31 \\
E & 19 & 636 & 3,54 & -31 & -85 & 22 \\
D & 32 & 1816 & 3,52 & 10 & 38 & 26 \\
E & 39 & 220 & 3,51 & -33 & -55 & 36 \\
E & - & 122 & 3,48 & -1 & -63 & -12 \\
- & - & 56 & 3,45 & 0 & -63 & -13 \\
- & - & 106 & 3,43 & 0 & -60 & -15 \\
E & - & 494 & 3,42 & -29 & -66 & -34 \\
E & - & 532 & 3,42 & -29 & -66 & -35 \\
E & - & 412 & 3,38 & -19 & 8 & -13 \\
E & 3 & 416 & 3,38 & -55 & -20 & 12 \\
- & $8 / 9$ & 34 & 3,32 & 0 & -11 & 50 \\
E & - & 356 & 3,29 & -27 & -66 & -35 \\
E & 19 & 352 & 3,28 & -37 & -69 & -9 \\
E & 18 & 414 & 3,26 & -27 & -71 & -9 \\
D & - & 74 & 3,13 & 4 & -69 & -20 \\
D & - & 126 & 3,13 & 30 & 20 & 0 \\
D & 35 & 102 & 3,07 & 14 & -33 & -2 \\
D & - & 28 & 2,98 & 14 & -54 & -35 \\
D & - & 94 & 2,91 & 10 & -6 & 16 \\
E & - & 268 & 2,72 & -37 & -52 & -40 \\
- & - & 12 & 2,55 & 0 & -65 & -26 \\
- & - & 5 & 2,5 & 0 & -50 & -21 \\
E & - & 12 & 2,47 & -1 & -50 & -23 \\
- & 32 & 8 & 2,43 & 0 & 36 & 24 \\
- & 19 & 2 & 2,39 & 0 & -72 & 12 \\
- & 19 & 2 & 2,39 & 0 & -73 & 12 \\
D & - & 4 & 2,39 & 2 & -70 & -31 \\
\hline & & & & & & \\
\hline
\end{tabular}

